UNIVERSIDADE DE SÃO PAULO

ESCOLA DE ENGENHARIA DE SÃO CARLOS

Liri Yoko Cruz Prieto Hojo

OPERAÇÃO E MODELAGEM HIDRODINÂMICA DE FILTROS LENTOS DOMICILIARES

VERSÃO CORRIGIDA

São Carlos

2021 
(Página em branco) 
Liri Yoko Cruz Prieto Hojo

\section{OPERAÇÃO E MODELAGEM HIDRODINÂMICA DE FILTROS LENTOS DOMICILIARES}

Tese apresentada à Escola de Engenharia de Engenharia de São Carlos, da Universidade de São Paulo, como parte dos requisitos para obtenção do título de Doutor em Ciências: Engenharia Hidráulica e Saneamento.

Orientadora: Profa. Dra. Lyda Patricia Sabogal Paz Coorientador: Prof. Dr. Sandro Rogério Lautenschlager

\section{VERSÃO CORRIGIDA}

São Carlos 


\section{AUTORIZO A REPRODUÇÃO E DIVULGAÇÃO TOTAL OU PARCIAL DESTE TRABALHO, POR QUALQUER MEIO CONVENCIONAL OU ELETRÔNICO, PARA FINS DE ESTUDO E PESQUISA, DESDE QUE CITADA A FONTE.}

Ficha catalográfica elaborada pela Biblioteca Prof. Dr. Sérgio Rodrigues Fontes da EESC/USP

\footnotetext{
H6780

Hojo, Liri Yoko Cruz Prieto

Operação e modelagem hidrodinâmica de filtros lentos domiciliares / Liri Yoko Cruz Prieto Hojo; orientadora Lyda Patricia Sabogal-Paz; Coorientador Sandro Rogério Lautenschlager. -- São Carlos, 2021.

Tese (Doutorado) - Programa de Pós-Graduação em Engenharia Hidráulica e Saneamento e Área de Concentração em Hidráulica e Saneamento -- Escola de Engenharia de São Carlos da Universidade de São Paulo, 2021.

1. Biofiltro. 2. Turbidez. 3. Dinâmica dos fluídos computacional. 4. Escoamento em meio poroso. 5. Modelagem matemática. I. Titulo.
} 


\section{FOLHA DE JULGAMENTO}

Candidata: Engenheira LIRI YOKO CRUZ PRIETO HOJO.

Título da tese: "Operação e modelagem hidrodinâmica de filtros lentos domiciliares".

Data da defesa: 11/06/2021.

\section{Comissão Julgadora}

Profa. Dra. Lyda Patricia Sabogal Paz

(Orientadora)

(Escola de Engenharia de São Carlos/EESC-USP)

Prof. Dr. Adriano Luiz Tonetti

(Universidade Estadual de Campinas/UNICAMP)

Prof. Dr. Rodrigo Braga Moruzzi

(Universidade Estadual Paulista "Júlio de Mesquita Filho"/UNESP-Rio Claro)

Prof. Dr. Ricardo Vicente de Paula Rezende

(Universidade Estadual de Maringá/UEM)

Prof. Dr. Alisson Carraro Borges

(Universidade Federal de Viçosa/UFV)

Coordenador do Programa de Pós-Graduação em Engenharia Hidráulica e Saneamento:

Prof. Dr. Eduardo Mario Mendiondo

Presidente da Comissão de Pós-Graduação:

Prof. Titular Murilo Araujo Romero
Resultado

Aprovada
Aprovada

Aprovida 
(Página em branco) 
Dedico aos meus pais Roseli e Sérgio Akira, aos meus irmãos Edmo, Gleison, Aionan, Ian e Yuri e ao meu companheiro André, com muita gratidão pelo apoio incondicional. 
(Página em branco) 


\section{AGRADECIMENTOS}

À Professora Dra. Lyda Patricia Sabogal Paz pela confiança depositada, disponibilidade de orientação e pelos exemplos de dedicação e entusiasmo no desenvolvimento da pesquisa.

Ao Professor Dr. Sandro Rogério Lautenschlager pelas ideias inovadoras e o incentivo.

À Maria Teresa Hoffman, Paulo Maciel, Bárbara Freitas e Ulisses Terin pela ajuda prestada no Laboratório (LATAR) e demais colegas da EESC.

À Universidade Estadual de Maringá, especialmente ao Departamento de Engenharia Civil na utilização dos Laboratórios de Mecânica dos Solos e de Saneamento Ambiental e especialmente ao COMCAP (Complexo de Centrais de Apoio à Pesquisa).

Ao Ivan Rocha, Claudinei Pereira, Oswaldo Teruo, Etel Regina, Claudia Benatti, Katia Hespanhol e José Wilson pela disponibilidade e cooperação nos experimentos realizados nos Laboratórios da UEM.

Ao Ricardo Rezende e à Regiani Almeida por compartilhar o valioso conhecimento.

Ao William de Lucca, Lucas Cariolando, Daniel Alves, Jessyca Guedes e Aline Furtado pelo apoio nas análises e a dedicação à pesquisa.

Ao meu companheiro de longa data, André Gorjon Neto, pelo companheirismo e incentivo nessa caminhada.

À toda minha família que me apoiou durante essa trajetória.

À empresa Amanco pela doação dos materiais utilizados na construção dos filtros.

Ao projeto temático internacional intitulado "Low cost technologies for safe drinking water in developing regions (SAFEWATER)" e ao Global Challenges Research Fund (GCRF) of Research Councils UK Collective Fund (Grant Ref: EP/P032427/1) que financiou a pesquisa. 
(Página em branco) 


\section{RESUMO}

HOJO, L. Y. C. P. Operação e modelagem hidrodinâmica de filtros lentos domiciliares.

2021. 183 p. Tese (Doutorado) - Escola de Engenharia de São Carlos, Universidade de São Paulo, São Carlos, 2021.

O acesso à água potável não é uma realidade para todas as comunidades, uma solução para atender essa demanda é a utilização do filtro lento domiciliar (FLD), um tratamento de água individual que pode ser aplicado em comunidades rurais sem acesso a água tratada. Há poucas pesquisas que avaliam como as mudanças geométricas e o tipo de operação (contínua ou intermitente) dos FLDs afetam o comportamento hidráulico e, consequentemente, o desempenho da filtração. Na primeira etapa da pesquisa foram construídos quatro FLDs em escala plena, sendo dois filtros operados em escoamento contínuo e dois em escoamento intermitente. Os filtros foram alimentados com água de estudo composta por 15\% de água superficial e $85 \%$ de água subterrânea. Analisaram-se temperatura, turbidez, cor aparente, condutividade elétrica, $\mathrm{pH}$, oxigênio dissolvido, nitrito, nitrato, absorbância, coliformes totais e Escherichia coli para verificar a eficiência do tratamento. Os FLDs atenderam aos limites estabelecidos na Portaria GM/MS n ${ }^{\circ}$ 888/2021 para turbidez, cor, nitrito e nitrato e os FLDs operados em escoamento contínuo apresentaram maior eficiência de tratamento. Na segunda etapa, estudaram-se as geometrias e os FLDs em escoamento contínuo e intermitente por meio da dinâmica dos fluídos computacional, com o uso do software ANSYS Student Fluent ${ }^{\circledR} 2020$ R2, a fim de avaliar a hidrodinâmica dos filtros. As simulações da hidrodinâmica dos quatro modelos matemáticos dos FLDs foram validadas por meio da distribuição do tempo de residência experimental, realizada previamente nos modelos físicos, e não apresentaram diferenças estatisticamente significativas. Os resultados mostraram que não foram constatadas zonas internas de recirculação, nem de curto circuito, porém constatou-se a existência de zonas mortas na base do filtro com volumes inferiores à 3\%, não sendo necessário realizar mudanças nas geometrias. A simulação computacional mostrou que os filtros contínuos apresentaram menor variação de velocidade e os filtros com menor diâmetro apresentaram redução das zonas mortas. Dentre os FLDs estudados, o que apresentou melhores resultados em termos de eficiência e da hidrodinâmica foi o filtro contínuo de menor diâmetro (C-FLD 1).

Palavras-chave: biofiltro; turbidez; dinâmica dos fluidos computacional; escoamento em meio poroso; modelagem matemática. 



\begin{abstract}
HOJO, L. Y. C. P. Operation and hydrodynamic modeling of household slow sand filters. 2021. 183 p. Doctor of Science Thesis. São Carlos School of Engineering, University of São Paulo, São Carlos, 2021.
\end{abstract}

Access to potable water is not a reality for all communities, a solution to meet this demand is the use of the household slow sand filter (HSSF), an individual water treatment that can be applied in rural communities without access to treated water. There is little research that assesses how geometric changes and the type of operation (continuous or intermittent) of HSSFs affect hydraulic behavior and, consequently, filtration performance. In the first stage of the research, four full-scale HSSFs were built, two filters operated in continuous flow and two in intermittent flow. The filters were fed with study water consisting of $15 \%$ surface water and $85 \%$ ground water. Temperature, turbidity, apparent color, electrical conductivity, $\mathrm{pH}$, dissolved oxygen, nitrite, nitrate, absorbance, total coliforms and Escherichia coli were analyzed to verify the efficiency of the treatment. The HSSFs met the limits established in Ordinance GM/MS n ${ }^{\circ}$ 888/2021 for turbidity, color, nitrite and nitrate and the HSSFs operated in continuous flow showed greater treatment efficiency. In the second stage, the geometries and HSSFs in continuous and intermittent flow were studied through computational fluid dynamics, using the ANSYS Student Fluent ${ }^{\circledR} 2020$ R2 software, in order to evaluate the hydrodynamics of the filters. The hydrodynamic simulations of the four mathematical models of the HSSFs were validated through the distribution of the experimental residence time, previously performed in the physical models, and did not show statistically significant differences. The results showed that internal recirculation zones were not found, nor short circuit, but it was found the existence of dead zones at the base of the filter with volumes below 3\%, not being necessary to make changes in the geometries. The computer simulation showed that the continuous filters had less speed variation and the filters with smaller diameter had a reduction in dead zones. Among the studied HSSFs, the one with the best results in terms of efficiency and hydrodynamics was the continuous filter with a smaller diameter (C-HSSF 1).

Keywords: biosand filter; turbidity; computational fluid dynamics; flow in porous media; mathematical modeling. 



\section{LISTA DE FIGURAS}

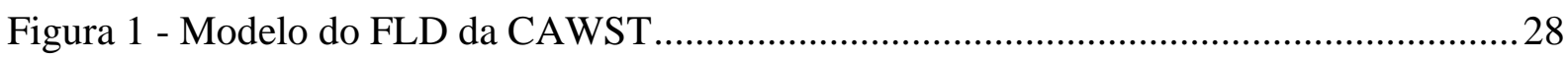

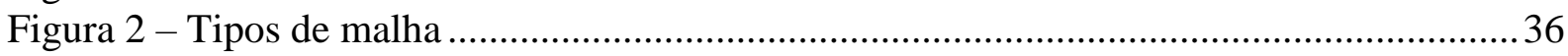

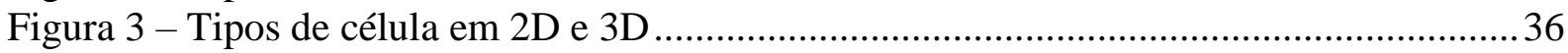

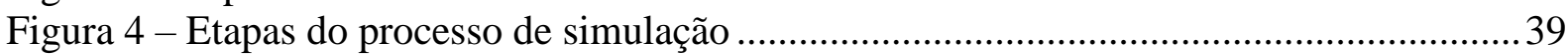

Figura 5 - Linhas de corrente em quatro configurações do filtro PEU/UEM: (A) centro, (B)

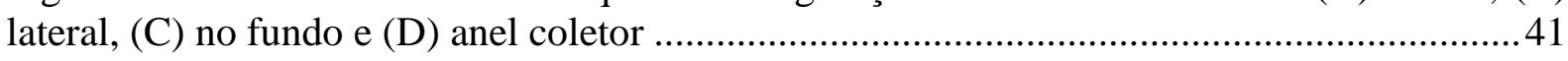

Figura 6 - Formas diferentes para se determinar a distribuição do tempo de residência......... 43

Figura 7 - Curvas típicas da concentração por tempo na entrada e na saída de um reator ...... 45

Figura 8 - Exemplos de comportamentos de curvas DTR em reatores de escoamento pistonado

Figura 9 - Resultado de três ensaios de traçador conduzidos em FLD construídos com material

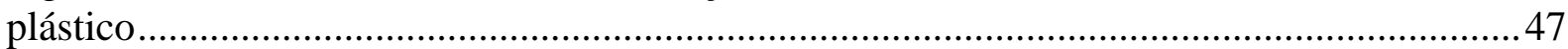

Figura 10 - Desenho do filtro lento domiciliar em escoamento contínuo...............................52

Figura 11 - Desenho do filtro lento domiciliar em escoamento intermitente ..........................53

Figura 12 - Local de instalação dos piezômetros no filtro em escoamento contínuo ...............54

Figura 13 - Local de instalação dos piezômetros no filtro em escoamento intermitente..........54

Figura 14 - Filtros construídos de acrílico em escoamento intermitente e contínuo ................57

Figura 15 - Disposição dos filtros lentos domiciliares no laboratório de hidráulica da UEM. 58

Figura 16 - Preparo dos materiais que compõem os filtros ................................................60

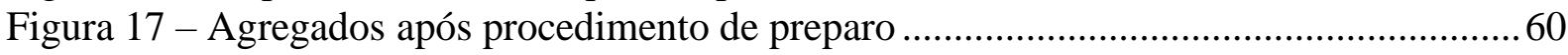

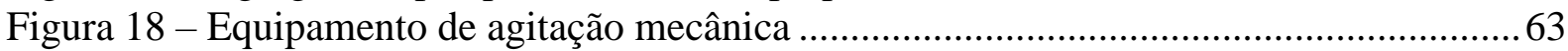

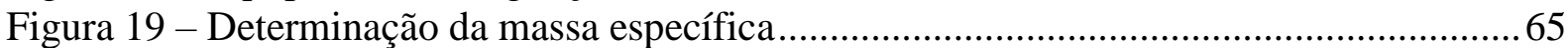

Figura 20 - Cilindro para determinação do índice de vazios ...................................................66

Figura 21 - Preparo do corpo de prova e experimento pronto para o ensaio de permeabilidade

Figura 22 - Ensaio de solubilidade realizado com os agregados ........................................69

Figura 23 - Local de coleta de água de poço no Campus da UEM e transporte dos galões .... 70

Figura 24 -Local de coleta de água do Rio Pirapó............................................................... 70

Figura 25 - Valores da turbidez média do rio Pirapó 10/2014 à 09/2016............................... 71

Figura 26 - Croqui do sistema de abastecimento com os filtros........................................ 73

Figura 27 - Sistema de abastecimento no laboratório ...................................................... 74

Figura 28 - Instalações empregadas no ensaio de distribuição de tempo de residência ..........77

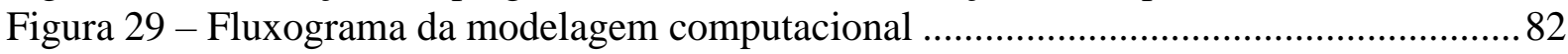

Figura 30 - Esquema dos C-FLDs indicando entrada, saída e parede do filtro. ..................... 83

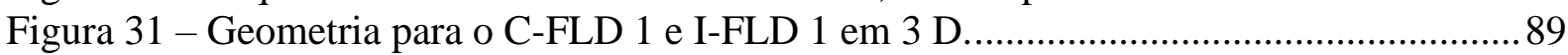

Figura 32 - Geometria para o C-FLD 2 e I-FLD 2 em 3 D................................................ 89

Figura 33 - Curva granulométrica do material filtrante - areia fina .................................... 95

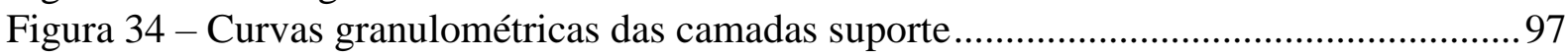

Figura 35 - Curvas DTR do C-FLD 1 (A) e do C-FLD 2 (B) .............................................. 102

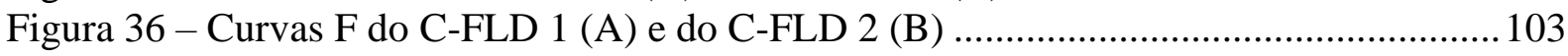

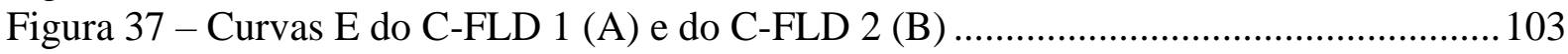

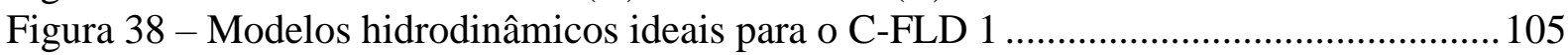

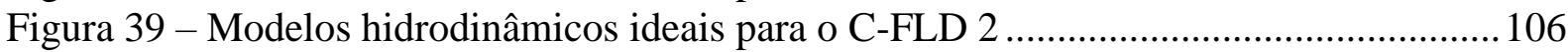

Figura 40 - Curvas DTR do I-FLD 1 (A) e do I-FLD 2 (B) .............................................. 107

Figura 41 - Curva da concentração de traçador por volume filtrado (A) e curva de porcentagem de traçador acumulado por volume filtrado (B) para o I-FLD 1 ....................................... 107 
Figura 42 - Curva da concentração de traçador por volume filtrado (A) e curva de porcentagem de traçador acumulado por volume filtrado (B) para o I-FLD 2 .......................................... 108

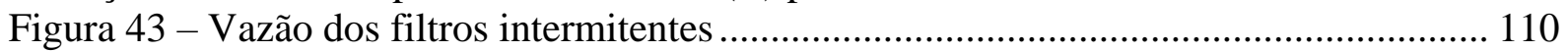

Figura 44 - Taxa de filtração dos filtros lentos domiciliares em regime intermitente (I-FLD 1 e

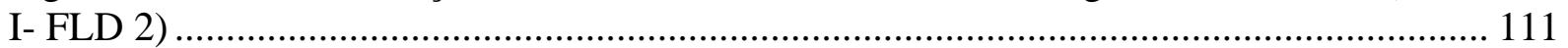

Figura 45 - Perda de carga unitária entre piezômetro 1 e 6 do C-FLD 1 ............................. 113

Figura 46 - Perda de carga unitária entre piezômetro 1 e 6 do C-FLD 2 .............................. 113

Figura 47 - Perda de carga unitária entre piezômetro 1 e 6 do I-FLD 1 ............................... 114

Figura 48 - Perda de carga unitária entre piezômetro 1 e 6 do I-FLD 2 .............................. 114

Figura 49 - Temperatura do ar, da água de estudo e do ar condicionado.............................. 116

Figura 50 - Monitoramento da concentração de oxigênio dissolvido e da temperatura nos C-

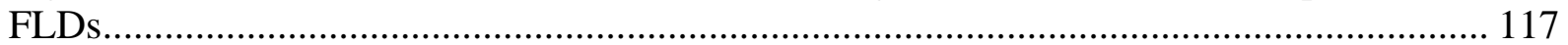

Figura 51 - Monitoramento da concentração de oxigênio dissolvido e da temperatura nos I-

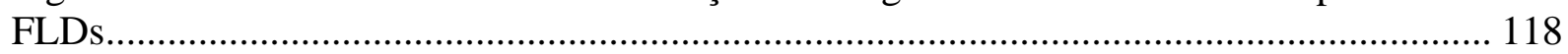

Figura 52 - Monitoramento da cor aparente da água de estudo e dos C-FLDs ...................... 121

Figura 53 - Monitoramento da turbidez da água de estudo e dos C-FLDs ......................... 121

Figura 54 - Monitoramento da cor aparente da água de estudo e dos I-FLDs ...................... 122

Figura 55 - Monitoramento da turbidez da água de estudo e dos I-FLDs ............................ 123

Figura 56 - Monitoramento da condutividade da água de estudo e dos C-FLDs .................. 127

Figura 57 - Monitoramento da condutividade da água de estudo e dos I-FLDs ................... 128

Figura 58 - Monitoramento da absorbância $(\lambda 254 \mathrm{~nm})$ da água de estudo, dos C-FLDs e dos I-

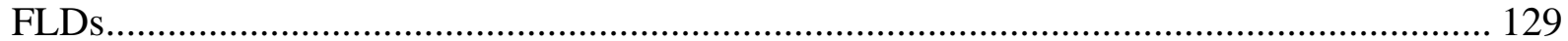

Figura 59 - Monitoramento do pH da água de estudo e dos C-FLDs .................................. 131

Figura 60 - Monitoramento do $\mathrm{pH}$ da água de estudo e dos I-FLDs.................................... 132

Figura 61 - Monitoramento de nitrato da água de estudo, dos C-FLDs e dos I-FLDs ........... 133

Figura 62 - Monitoramento de nitrito da água de estudo, dos C-FLDs e dos I-FLDs .......... 134

Figura 63 - Contagem de Escherichia coli na água de estudo e na água efluente dos filtros

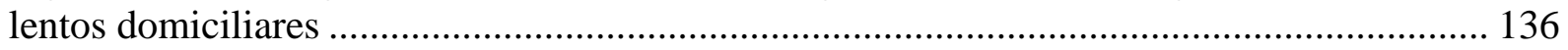

Figura 64 - Redução de Escherichia coli em $\log _{10}$ entre a entrada da água de estudo e a água

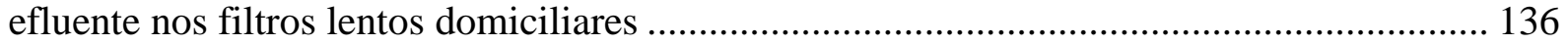

Figura 65 - Contagem de coliforme totais na água de estudo e na água efluente dos filtros lentos

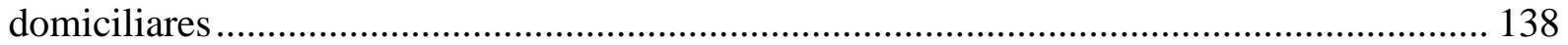

Figura 66 - Redução de coliformes totais em $\log _{10}$ entre a entrada da água de estudo e a água efluente nos filtros lentos domiciliares ................................................................................. 139

Figura 67-Velocidade em função do número de elementos da malha numérica obtida no teste de independência de malha do C-FLD1 e do C-FLD2. ..................................................... 146

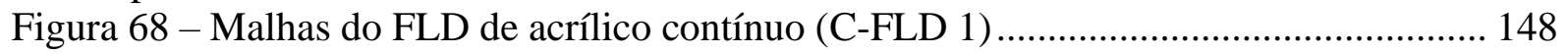

Figura 69 - Malhas do FLD de Defofo MPVC contínuo (C-FLD 2) .................................... 149

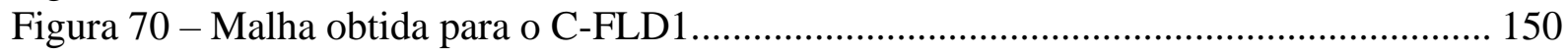

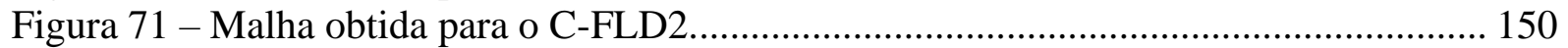

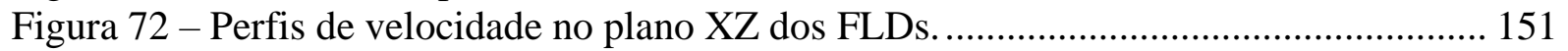

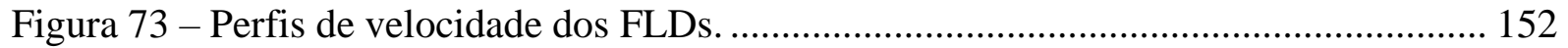

Figura 74 - Linhas de corrente dos C-FLDs e os detalhes observados. ................................ 153

Figura 75 - Linhas de corrente dos I-FLDs e os detalhes observados.................................. 154

Figura 76 - Curvas DTR experimentais e computacional dos C-FLDs. ................................ 155

Figura 77 - Escalar passivo no tempo para um plano XZ no C-FLD 1.............................. 157

Figura 78 - Escalar passivo no tempo para um plano XZ no C-FLD 2 ............................... 158

Figura 79 - Curvas DTR experimentais e computacional dos I-FLDs................................. 159

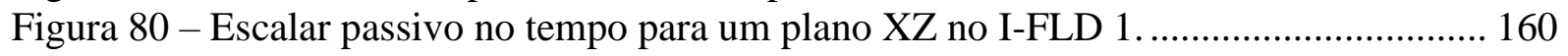

Figura 81 - Escalar passivo no tempo para um plano XZ no I-FLD 2 ............................... 161 
Figura 82-Zona morta no C-FLD1 (A - Linhas de corrente e plano de contorno da velocidade; $\mathrm{B}$ - Volume da zona morta) 162

Figura 83-Zona morta no C-FLD2 (A - Linhas de corrente e plano de contorno da velocidade; B - Volume da zona morta). 163

Figura 84 - Zona morta no I-FLD1 (A - Linhas de corrente e plano de contorno da velocidade; B - Volume da zona morta). 163 Figura 85 - Zona morta no I-FLD2 (A - Linhas de corrente e plano de contorno da velocidade; B - Volume da zona morta) 164

Figura 86 - Desvio padrão da curva computacional dos C-FLDs...................................... 165

Figura 87 - Desvio padrão da curva computacional dos I-FLDs. 166 


\section{LISTA DE TABELAS}

Tabela 1 - Resumo da exigência de nível de serviço de água para promover a saúde ............ 25

Tabela 2 - Materiais utilizados para construção dos filtros em escoamento contínuo ............. 55

Tabela 3 - Materiais utilizados para construção dos filtros em escoamento intermitente....... 56

Tabela 4 - Conjunto de peneiras utilizado na separação dos agregados ............................... 59

Tabela 5 - Peneiras e aberturas de malha utilizadas no ensaio granulométrico da areia fina . 61

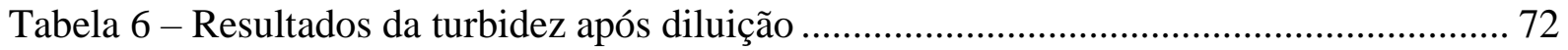

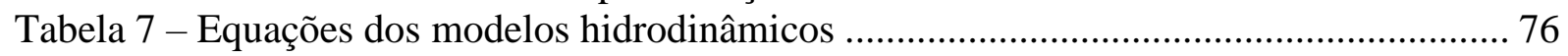

Tabela 8 - Parâmetros, amostra, métodos/equipamento e frequência .................................... 79

Tabela 9 - Ferramentas utilizadas no desenvolvimento do modelo e da simulação................. 82

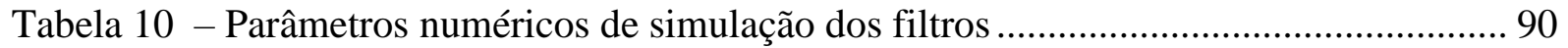

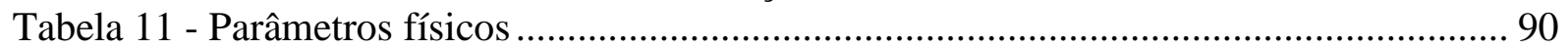

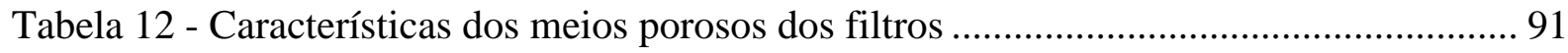

Tabela 13 - Parâmetros de simulação das DTRs................................................................... 91

Tabela 14 - Tamanhos efetivos e coeficiente de uniformidade da areia fina ......................... 96

Tabela 15 - Tamanhos efetivos e coeficiente de uniformidade dos materiais das camadas

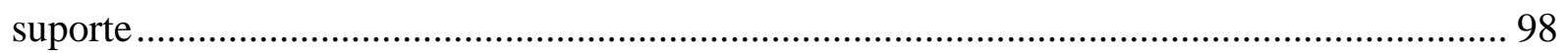

Tabela 16 - Temperatura de ensaio e massa específica dos materiais filtrantes .................... 98

Tabela 17 - Índice de vazios dos materiais....................................................................... 98

Tabela 18 - Coeficiente de permeabilidade dos materiais .................................................... 99

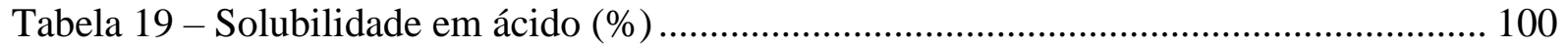

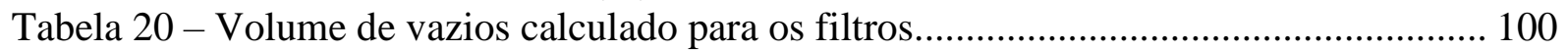

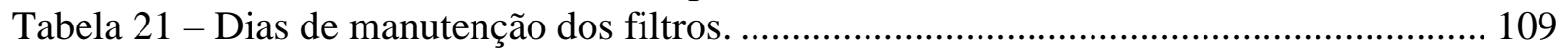

Tabela 22 - Comparação estatística do consumo de oxigênio dissolvido entre os filtros ${ }^{1} \ldots 119$

Tabela 23 - Comparação estatística para o oxigênio dissolvido nos filtros ${ }^{1}$......................... 120

Tabela 24 - Comparação estatística de cor entre AE e os filtros ${ }^{1}$........................................ 124

Tabela 25 - Comparação estatística de turbidez entre AE e os filtros ${ }^{1}$.................................. 125

Tabela 26 - Comparação estatística de absorbância entre AE e os filtros ${ }^{1}$............................ 130

Tabela 27 - Comparação estatística de pH entre AE e os filtros ${ }^{1}$.......................................... 132

Tabela 28 - Comparação estatística de Escherichia coli entre AE e os filtros ${ }^{1}$..................... 137

Tabela 29 - Comparação estatística de coliformes totais entre AE e os filtros ${ }^{1}$.................... 140

Tabela 30 - Desempenho dos filtros contínuos em relação aos parâmetros físico-químicos 142

Tabela 31 - Teste de correlação de Spearman para o primeiro conjunto de dados ............... 144

Tabela 32 - Teste de correlação de Spearman para o segundo conjunto de dados ................. 145

Tabela 33 - Teste de correlação de Spearman para o terceiro conjunto de dados .................. 145

Tabela 34 - Parâmetros para os ensaios de DTR computacional ......................................... 146

Tabela 35 - Características das malhas do C-FLD 1 ......................................................... 147

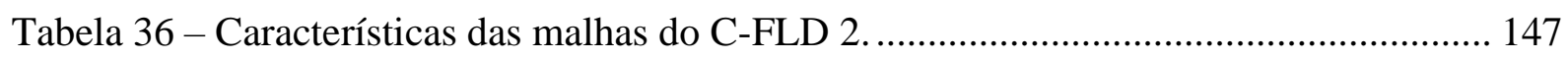

Tabela 37 - Velocidade dos FLDs modelos físicos (experimental) e simulados ................... 152 


\section{LISTA DE SIGLAS E SÍMBOLOS}

CAWST Centre for Affordable Water and Sanitation Technology

CFD Computacional Fluid Dynamics

C-FLD 1 Filtro lento domiciliar contínuo de acrílico

C-FLD 2 Filtro lento domiciliar contínuo de Defofo MPVC

COMCAP Complexo de Centrais de Apoio à Pesquisa

CU Coeficiente de Uniformidade

$\mathrm{D}_{10} \quad$ Diâmetro de abertura de peneira em que passam $10 \%$ dos grãos, em massa

$\mathrm{D}_{60} \quad$ Diâmetro de abertura de peneira em que passam $60 \%$ dos grãos, em massa

DN Diâmetro Nominal

DEC/UEM Departamento de Engenharia Civil/ Universidade Estadual de Maringá

DFC Dinâmica dos Fluidos Computacional

DTR Distribuição do tempo de residência

EESC Escola de Engenharia de São Carlos

FLD Filtro Lento Domiciliar

HSSF Household Slow Sand Filter

IDM Índice de Dispersão de Morrill

I-FLD 1 Filtro lento domiciliar intermitente de acrílico

I-FLD 2 Filtro lento domiciliar intermitente de Defofo MPVC

OMS Organização Mundial de Saúde

TDH Tempo de detenção hidráulico

UDS User-defined scalar

UEM Universidade Estadual de Maringá 
(Página em branco) 


\section{SUMÁRIO}

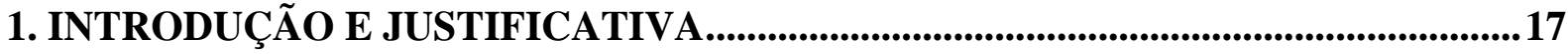

2. HIPÓTESES E OBJETIVOS ......................................................................................21

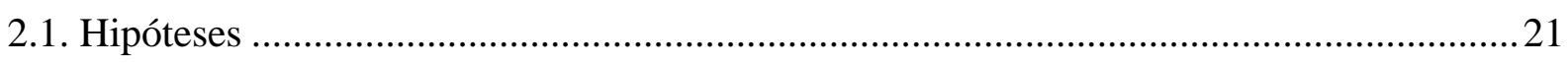

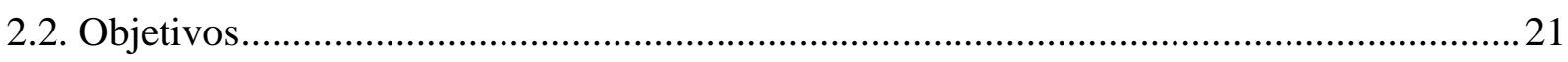

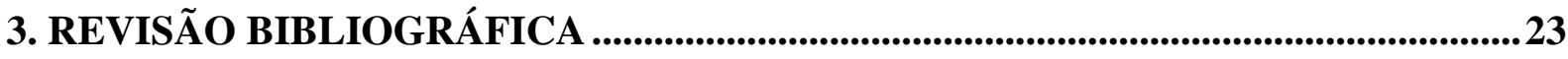

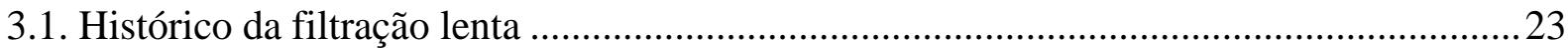

3.2. Consumo de água em situações de escassez................................................................... 24

3.3. Tecnologias de tratamento de água para comunidades rurais .........................................26

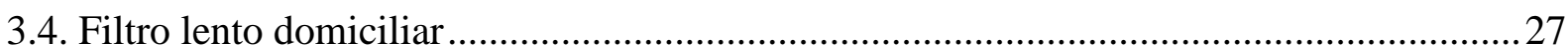

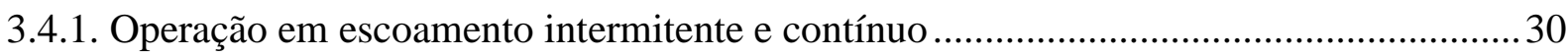

3.4.2. Experiências com o filtro lento domiciliar ............................................................. 32

3.5. Modelagem matemática e dinâmica dos fluidos computacional ....................................... 34

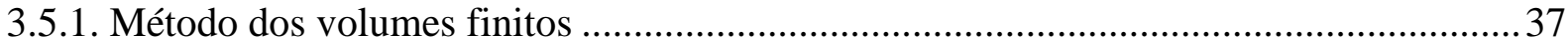

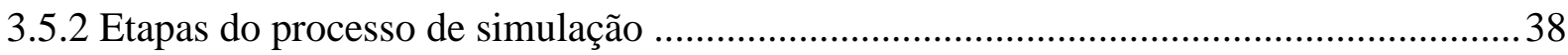

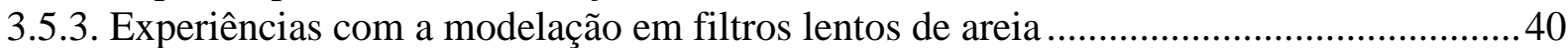

3.6. Distribuição de tempo de residência experimental ........................................................... 42

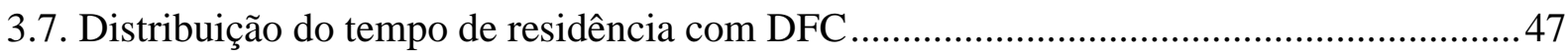

3.8. Verificação e validação dos modelos em DFC.............................................................. 49

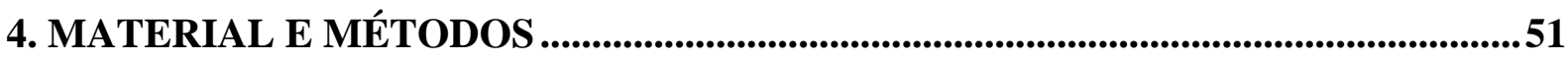

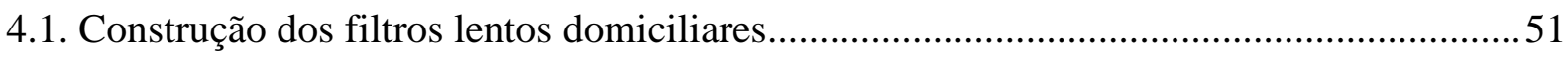

4.2. Caracterização dos materiais que compõem as camadas do filtro....................................58

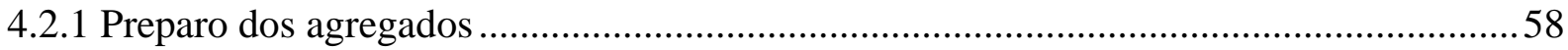

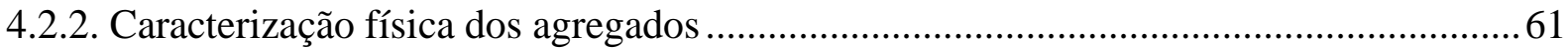

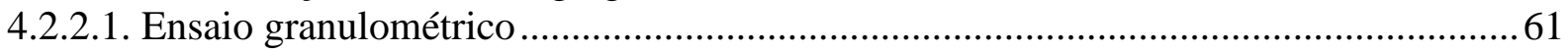

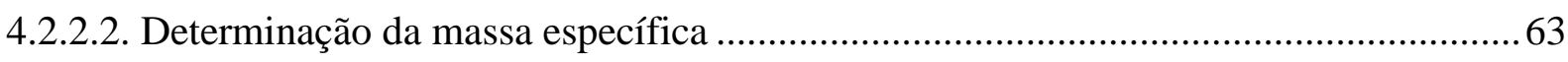

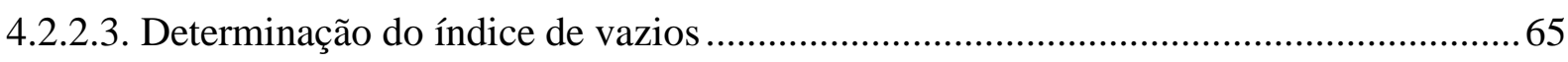

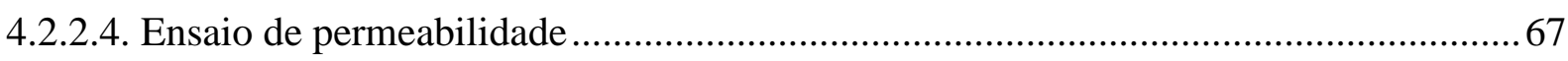

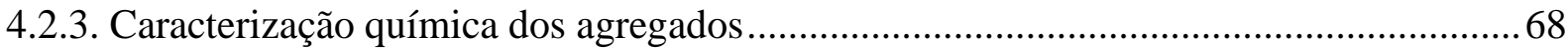

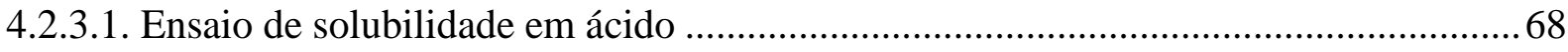

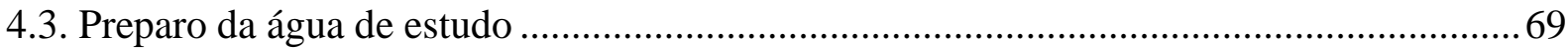

4.4. Sistema de abastecimento e operação dos filtros lentos domiciliares .............................. 72

4.5. Caracterização do escoamento - Ensaio de traçador experimental................................... 74

4.5.1. Determinação da distribuição do tempo de residência nos filtros contínuos ..................77

4.5.2. Determinação da distribuição do tempo de residência nos filtros intermitentes .............78 
4.6. Monitoramento dos parâmetros de qualidade da água, perda de carga e vazão dos filtros

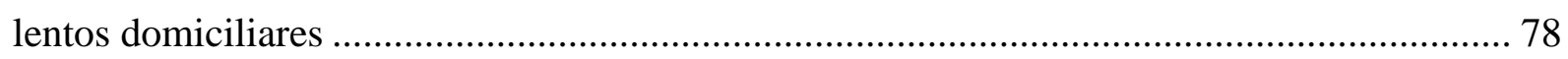

4.7. Validação das simulações numéricas em análises hidráulicas para FLDs ........................ 80

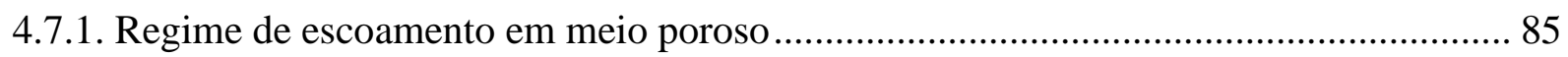

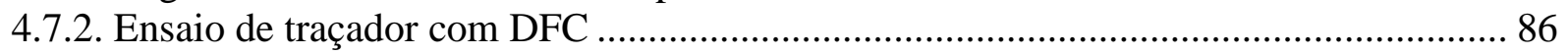

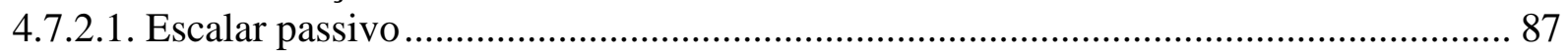

4.7.2.2. Discretização temporal e definição do passo de tempo .............................................. 87

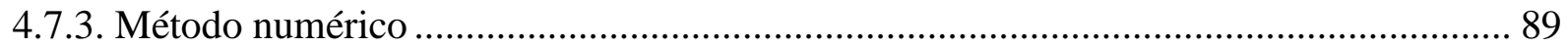

4.8. Estudo das anomalias no escoamento obtido com DFC e sua relação com a eficiência dos

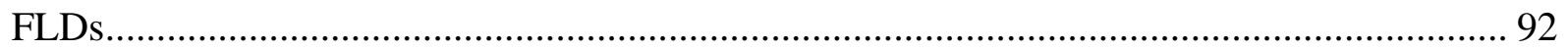

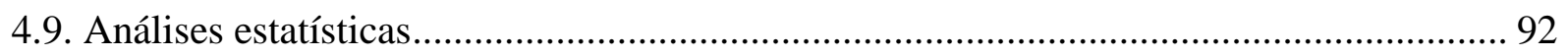

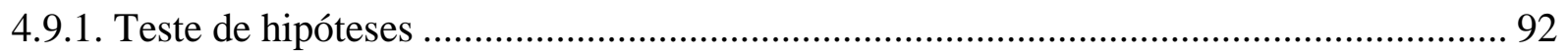

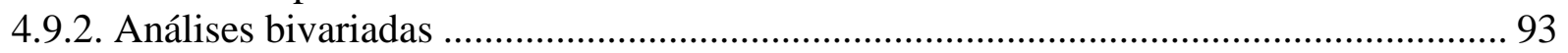

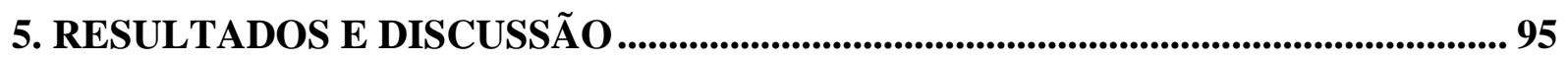

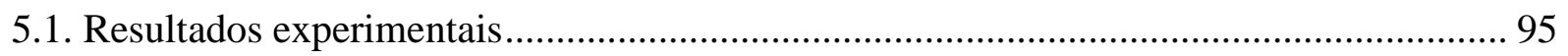

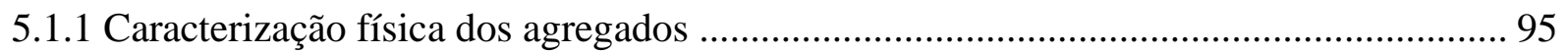

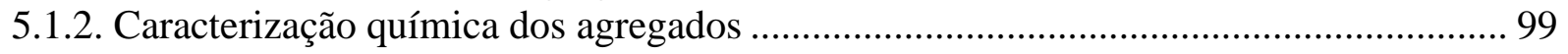

5.1.3. Volume de vazios nos filtros lentos domiciliares ...................................................... 100

5.1.4. Caracterização do escoamento - Ensaio de traçador experimental .............................. 101

5.1.4.1. Determinação da distribuição do tempo de residência nos filtros contínuos ............. 101

5.1.4.2. Determinação da distribuição do tempo de residência nos filtros intermitentes....... 106

5.1.5. Monitoramento dos parâmetros de qualidade da água dos filtros lentos domiciliares 109

5.1.5.1. Parâmetros físico e químicos ............................................................................... 115

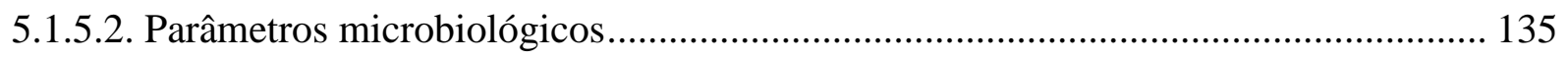

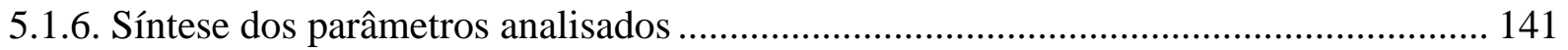

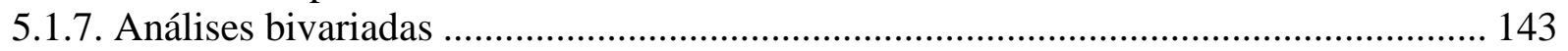

5.2. Validação das simulações numéricas em análises hidráulicas para FLDs...................... 146

5.2.1. Comparação entre a DTR experimental e a simulada com a DFC ............................. 154

5.3. Estudo das anomalias no escoamento obtido com DFC ............................................. 161

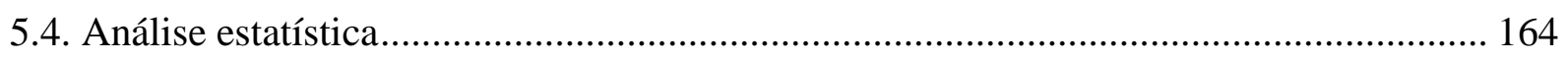

5.5. Análise da influência da hidrodinâmica na eficiência do filtro ..................................... 166

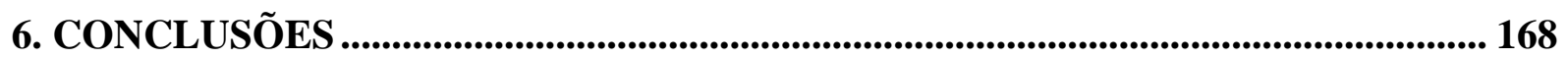

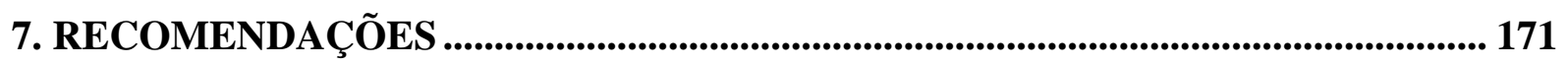

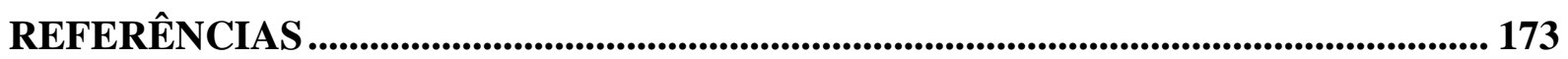




\section{INTRODUÇÃO E JUSTIFICATIVA}

Segundo a Organização Mundial de Saúde, estima-se que 2 bilhões de pessoas utilizam uma fonte de água inapropriada para o consumo, e.g. contaminada por fezes. Além disso, 2,9 milhões de pessoas em todo o mundo, anualmente, são afetadas por cólera e outras doenças de veiculação hídrica por não terem acesso a serviços de água potável gerenciados com segurança, 829.000 mortes ocorrem por doenças diarreicas todo ano sendo que 485.000 mortes ocorrem em países de baixa e média renda atribuída à água não potável (WHO, 2019).

A ingestão de água contaminada por material fecal, a ausência de coleta de esgoto sanitário e hábitos de higiene inadequados são as causas de cerca de 4 bilhões de doenças diarreicas por ano e destes, 1,8 milhões de casos são fatais (UNEP, 2016). Cabe destacar que o acesso a água segura foi estabelecido como direito humano fundamental em 2010 pela ONU (ONU, 2010). Tanto o acesso ao abastecimento de água quanto o esgotamento sanitário adequado são direitos fundamentais dos cidadãos, essencial assegurar condições dignas de moradia, manutenção da saúde e preservação do meio ambiente (IBGE, 2020).

Os resultados da Pesquisa Nacional de Saneamento Básico de 2017 mostram que o serviço de abastecimento de água por rede geral de distribuição já estava presente na maioria dos municípios de forma homogênea, com exceção da região norte do país que apresentou maior defasagem, a região Norte tem $98,4 \%$ dos municípios atendidos por rede de distribuição de água e em vinte e dois municípios de todo o país não foram identificados nenhuma empresa executora desse tipo de serviço (IBGE, 2020).

Dentre os municípios atendidos por serviços de rede de distribuição de água, apenas 88,3\% apresentavam estações de tratamento de água e/ou unidade de tratamento simplificado e a região Nordeste foi a que apresentou o menor percentual, 75,8\% (IBGE, 2020).

O serviço de esgotamento sanitário por rede coletora é mais heterogêneo quando comparado entre as grandes regiões do país, e as regiões Norte e Centro-Oeste são as mais afetadas, têm 16,2\% e 43,0\% dos municípios atendidos, respectivamente (IBGE, 2020).

Uma forma de baixo custo e eficiente para reduzir o número de pessoas sem acesso à água tratada, tanto nas áreas urbanas quanto rurais, ou em locais onde o tratamento é precário, são as denominadas tecnologias de tratamento no ponto de uso ou point-of-use (POU) e, entre elas, o Filtro Lento Domiciliar (FLD) ou Household Slow Sand Filter (HSSF) se destacam (Sobsey et al., 2008; WHO, 2016).

O próprio usuário pode construir um FLD com materiais de fácil acesso e operá-lo em alimentação intermitente ou contínua. O FLD foi uma adaptação do filtro lento convencional 
(Slow Sand Filter - SSF) projetado para operar em batelada, essa adaptação ao regime intermitente foi possível mantendo-se uma lâmina d’água no topo da camada filtrante. Tanto o FLD quanto o SSF precisam do desenvolvimento de uma camada biológica que auxilia no tratamento da água (CAWST, 2012; MACIEL E SABOGAL-PAZ, 2018).

O processo de tratamento da água por FLD pode ser considerado simples quando comparado com outros tipos como: i) o convencional, que utiliza coagulação, floculação, decantação, filtração e desinfecção; ii) o tratamento realizado por membranas filtrantes; e iii) o tratamento por oxidação avançada. Entretanto, do ponto de vista de simulação numérica o tratamento de água por FLD é um problema complexo, pois envolve vários processos físicoquímicos e biológicos como, por exemplo, o escoamento em meio poroso, formação da camada biológica e remoção de parâmetros-alvo.

A DFC tem sido utilizada com sucesso para projeto de reatores incluindo cenários complexos de leitos fluidizados trifásicos segundo Sivaguru, Begum e Anantharaman (2009) além disso, os experimentos em escala laboratorial têm um número limitado de pontos e intervalos de tempo amostrados e apresentam problemas experimentais e condições de operação não uniformes. Por outro lado, os modelos matemáticos e as simulações numéricas permitem uma previsão quantitativa do fenômeno de transporte de partículas com alta resolução no espaço e no tempo para o domínio de escoamento real, assim, a modelagem é uma alternativa econômica e rápida para gerar conhecimento do transporte de partículas que ocorre em um sistema de grande escala (HASSAN et al., 2013).

Dessa maneira quatro FLDs foram operados, sendo dois operados em escoamento contínuo e dois em escoamento intermitente para obtenção dos dados experimentais de desempenho dos filtros e, posteriormente, realizou-se a simulação numérica utilizando o software ANSYS Student Fluent ${ }^{\circledR} 2020$ R2. A dinâmica de fluidos computacional foi aplicada em cada um dos FLDs, para obter as curvas de distribuição do tempo de residência (DTR) e o volume ocupado pelas zonas mortas.

Nos FLDs construídos em escala plena foram avaliadas as curvas DTRs, as perdas de carga e os parâmetros qualitativos relacionadas à qualidade da água. A comparação dos resultados das curvas DTRs dos filtros em escala real com os ensaios computacionais das curvas DTRs permitiram a validação das curvas DTRs simuladas.

$\mathrm{Na}$ presente tese, estudaram-se quatro FLDs com o intuito de responder o seguinte questionamento: 
“Como as alterações geométricas e o tipo de operação contínuo e intermitente alteram a curva de distribuição do tempo de residência (DTR), a formação das zonas de mortas e a eficiência do tratamento?" 


\section{HIPÓTESES E OBJETIVOS}

\subsection{Hipóteses}

A presente pesquisa se fundamentou em duas hipóteses. A primeira relacionada com os tipos de escoamento e as taxas de filtração estudados e a segunda relacionada com a eficiência do tratamento e com a hidrodinâmica dos filtros.

- Hipótese 1: As taxas de filtração baixas, para filtros operados em um mesmo regime de escoamento, resultam em melhores eficiências de tratamento.

- Hipótese 2: A minimização de fenômenos hidráulicos adversos, como a variação da velocidade nas camadas dos filtros, aumenta a eficácia do filtro.

\subsection{Objetivos}

Analisar a influência das operações (escoamento contínuo e intermitente) e das formas geométricas na hidrodinâmica do projeto de filtros lentos domiciliares. Os objetivos específicos foram:

- Avaliar as eficiências de tratamento de água dos filtros lentos domiciliares com geometrias (diâmetros) diferentes e em escoamento contínuo e intermitente;

- Caracterizar o escoamento dos filtros com ensaios de traçador experimental nos FLDs para taxas de filtração diferentes;

- Validar as simulações numéricas com os ensaios experimentais de DTR;

- Estudar as possíveis anomalias no escoamento, relacionado com as alterações geométricas e as operações em escoamento contínuo ou intermitente, verificadas com DFC; e

- Avaliar a relação das eficiências dos filtros lentos domiciliares com a hidrodinâmica gerada por DFC. 


\section{REVISÃO BIBLIOGRÁFICA}

\subsection{Histórico da filtração lenta}

O primeiro exemplo de filtração como tecnologia de tratamento de água data de 1804, quando John Gibb projetou e construiu um filtro lento de areia experimental em Paisley, na Escócia, e vendeu o excedente de água tratada para o público. Ele e outros aprimoraram os detalhes práticos e, em 1829, o método foi adotado pela primeira vez para uma fonte pública, quando James Simpson construiu uma instalação para tratar a água fornecida pela Chelsea Water Company, em Londres (WHO, 1974).

Nas primeiras décadas do século XIX, a população de Londres dispunha de oito companhias de abastecimento de água, sendo que cinco delas forneciam água sem tratamento algum para a população, diretamente do poluído rio Tamisa. A Chelsea Water Works Co., por meio das observações e estudos de James Simpson, foi a primeira das companhias a oficialmente dar atenção a esta má condição, bem como construir e colocar em operação um filtro lento de areia em 14 de junho de 1829. O filtro lento de areia de Simpson era de larga escala e possuía um escoamento descendente através de camadas de areias fina e grossa, conchas, seixos e pedregulhos miúdo e graúdo. A superfície era disposta em sulcos, que lhe conferia uma aparência ondulada, essa camada de areia fina retinha as impurezas em seu topo que, portanto, precisava ser limpa esporadicamente por raspagem manual e escoamento reverso da água (BAKER, 1948).

Em 1852, o tratamento havia se estabelecido, e suas vantagens eram tão evidentes, que “Metropolis Water Act" ou a Lei da Água da Metrópole foi aprovada exigindo que toda a água derivada do rio Tamisa, próximo da Catedral de São Paulo em Londres, fosse filtrada antes de ser fornecida ao público (WHO, 1974).

Na época, a existência de bactérias patogênicas era desconhecida, e o filtro de areia lento era considerado um meio físico de eliminar a turbidez e os sólidos suspensos. O médico inglês John Snow, no entanto, em seus estudos sobre a transmissão da cólera chegou à conclusão de que a doença era transmitida pela água, e postulou a existência de materiais derivados de casos, ou doenças, anteriores que poderiam transmitir a infecção àqueles que a ingeriram. Este material era removido, com outros sólidos, por filtração, ou a contaminação poderia ser evitada se a captação de água estivesse localizada em um ponto à montante de qualquer descarga de esgoto. Como resultado, os primeiros exames regulares de suprimentos de água, incluindo análises químicas, foram iniciados em Londres, em 1858. Em 1885, após as descobertas de 
Pasteur, Koch, Escherich e outros durante as décadas de 1860 e 1870, eles foram estendidos para incluir o exame bacteriológico (WHO, 1974).

A prova mais convincente da eficácia da filtração de água foi fornecida em 1892 pela experiência adquirida em duas cidades vizinhas na Alemanha, Hamburgo e Altona, que extraíam a sua água bruta do rio Elba, a primeira distribuindo-a sem tratamento enquanto a última filtrava toda a água a ser distribuída. Quando o rio foi infectado por um campo de imigrantes, Hamburgo sofreu de uma epidemia de cólera que infectou um em cada trinta da sua população e causou mais de 7.500 mortes, enquanto Altona escapou quase ilesa. Epidemias subsequentes transmitidas pela água em muitas partes do mundo confirmaram essa experiência. Em todos os casos, a infecção tinha sido quase inteiramente confinada às pessoas que beberam água não filtrada (WHO, 1974).

Em 1885, os primeiros filtros mecânicos foram instalados nos EUA e, em 1899, os filtros automáticos de pressão foram patenteados pela primeira vez na Inglaterra. Desde então, várias modificações e melhorias foram introduzidas e alcançaram vários graus de popularidade, particularmente em países altamente industrializados. A maioria dessas melhorias estava relacionada com detalhes de construção - a redução da quantidade de areia necessária ou a introdução de operação e controle automáticos - e não à qualidade da água fornecida. Os filtros lentos de areia se expandiram para outras localidades como Paris, Suécia e Japão (WHO, 1974).

\subsection{Consumo de água em situações de escassez}

A quantidade de água fornecida e utilizada pelas famílias é um importante aspecto que influencia na higiene e consequentemente na saúde pública (HOWARD; BARTRAM, 2003). Esses autores publicaram um documento para a $W H O$ no qual é analisado o consumo de água para fins de saúde buscando um valor mínimo que seja aceitável para atender as necessidades de consumo que incluam hidratação, preparo de alimentos e higiene básica.

O volume de água usado pelas famílias em situação de escassez é determinado principalmente pela distância que precisam percorrer da sua casa até uma fonte de água e pelo tempo que demoram em percorrer esse caminho. Baseado na estimativa da necessidade de mulheres lactantes que realizam atividade física moderada em temperaturas acima da média, o valor mínimo é de 7,5 litros per capita por dia e necessita ter uma qualidade suficiente para que que apresente um risco tolerável. Essa estimativa de consumo também atende aos requisitos da maioria das pessoas em condições semelhantes (HOWARD; BARTRAM, 2003). 
No Tabela 1 apresenta-se um resumo do grau em que os diferentes níveis de serviço atendem aos requisitos para manter uma boa saúde.

Tabela 1 - Resumo da exigência de nível de serviço de água para promover a saúde

\begin{tabular}{|c|c|c|c|c|}
\hline $\begin{array}{l}\text { Nível de } \\
\text { serviço }\end{array}$ & $\begin{array}{l}\text { Distância/ } \\
\text { tempo }\end{array}$ & $\begin{array}{c}\text { Estimativa do } \\
\text { volume de água } \\
\text { coletada }\end{array}$ & Necessidades atendidas & $\begin{array}{c}\text { Nível de } \\
\text { preocupação } \\
\text { com a saúde }\end{array}$ \\
\hline $\begin{array}{l}\text { Nenhum } \\
\text { acesso }\end{array}$ & $\begin{array}{lr}\text { Mais de } & 1000 \\
\mathrm{~m} \text { ou } & 30 \\
\text { minutos } & \text { no } \\
\text { tempo total } & \text { de } \\
\text { coleta } & \end{array}$ & $\begin{array}{l}\text { Muito baixa } \\
\text { (frequentemente } \\
\text { abaixo de } 5 \\
\text { L.hab }{ }^{-1} \cdot \mathrm{d}^{-1} \text { ) }\end{array}$ & $\begin{array}{l}\text { Consumo - não pode ser } \\
\text { assegurado } \\
\text { Higiene - não é possível } \\
\text { (a menos que praticado } \\
\text { na fonte) }\end{array}$ & Muito alto \\
\hline $\begin{array}{l}\text { Acesso } \\
\text { básico }\end{array}$ & $\begin{array}{l}\text { Entre } 100 \mathrm{e} \\
1000 \mathrm{~m} \text { ou } 5 \text { a } \\
30 \text { minutos no } \\
\text { tempo total de } \\
\text { coleta }\end{array}$ & $\begin{array}{l}\text { Quantidade } \\
\text { média } \\
\text { improvável que } \\
\text { exceda } 20 \mathrm{~L} \cdot \text { hab }^{-} \\
{ }^{1} \cdot \mathrm{d}^{-1}\end{array}$ & $\begin{array}{l}\text { Consumo - deve ser } \\
\text { assegurado } \\
\text { Higiene }- \\
\text { mãos e lavagem das } \\
\text { básicos, alimentos } \\
\text { possível, } \\
\text { lavanderia/banhos } \\
\text { difíceis de assegurar a } \\
\text { menos realizado na fonte }\end{array}$ & Alto \\
\hline $\begin{array}{l}\text { Acesso } \\
\text { Intermedi } \\
\text { ário }\end{array}$ & $\begin{array}{l}\text { Água fornecida } \\
\text { através de uma } \\
\text { torneira (ou } \\
\text { dentro de } 100 \\
\text { m ou } 5 \text { minutos } \\
\text { no tempo total } \\
\text { de coleta) }\end{array}$ & $\begin{array}{l}\text { Quantidade } \\
\text { média de } 50 \\
\text { L.hab }{ }^{-1} \cdot \mathrm{d}^{-1}\end{array}$ & $\begin{array}{l}\text { Consumo - assegurado } \\
\text { Higiene - toda higiene } \\
\text { pessoal e preparo de } \\
\text { alimentos é assegurada; } \\
\text { Lavanderia e banho } \\
\text { também podem ser } \\
\text { assegurados }\end{array}$ & Baixo \\
\hline $\begin{array}{l}\text { Acesso } \\
\text { otimizado }\end{array}$ & $\begin{array}{l}\text { Água fornecida } \\
\text { através de } \\
\text { múltiplas } \\
\text { torneiras } \\
\text { continuamente }\end{array}$ & $\begin{array}{l}\text { Quantidade } \\
\text { média de } 100- \\
200 \mathrm{~L} \cdot \mathrm{hab}^{-1} \cdot \mathrm{d}^{-1}\end{array}$ & $\begin{array}{l}\text { Consumo - todas as } \\
\text { necessidades atendidas } \\
\text { Higiene - todas as } \\
\text { necessidades podem ser } \\
\text { atendidas }\end{array}$ & Muito baixo \\
\hline
\end{tabular}

Fonte: Adaptado de Howard e Bartram (2003).

Com base nos valores apresentados no Tabela 1, o estudo foi desenvolvido para atender famílias consideradas sem acesso a água, ou seja, que consomem 7,5 L.hab ${ }^{-1} \cdot \mathrm{d}^{-1}$. Assim o tratamento para uma vazão de $48 \mathrm{~L} \cdot \mathrm{d}^{-1}$ pode atender uma família com até 6 pessoas. 


\subsection{Tecnologias de tratamento de água para comunidades rurais}

O saneamento ambiental é definido como um conjunto de medidas que visam preservar ou modificar as condições do meio ambiente, de forma a prevenir patologias, melhorar a qualidade de vida da população e a produtividade do indivíduo e facilitar a atividade econômica. No Brasil, o Saneamento Básico é um direito constitucional e é definido pela Lei Federal $\mathrm{n}^{\mathrm{o}}$ 11.445/2007 (BRASIL, 2007) como sendo “o conjunto dos serviços, infraestrutura e instalações operacionais de abastecimento de água, esgotamento sanitário, limpeza urbana, drenagem urbana, manejos de resíduos sólidos e de águas pluviais" (Instituto Trata Brasil, 2013). A atualização do marco legal do saneamento básico definida pela Lei Federal no 14.026/2020 considera o saneamento básico como um conjunto de serviços públicos, infraestruturas e instalações operacionais de abastecimento de água potável; esgotamento sanitário; limpeza urbana e manejo de resíduos sólidos; e drenagem urbana e manejo das águas pluviais urbanas (BRASIL, 2020).

$\mathrm{O}$ tratamento de água tem a finalidade de adequar as características físico-químicas e biológicas da água bruta de acordo com os parâmetros de potabilidade. No Brasil quem estabelece os parâmetros de potabilidade é o Ministério da Saúde por meio da Portaria GM/MS nº 888/2021 (BRASIL, 2021).

As tecnologias de tratamento de água para abastecimento são classificadas como convencionais, aquelas que incluem a coagulação, floculação, decantação, filtração e desinfecção, e não convencionais, as que incluem a filtração direta ascendente e descendente; a dupla filtração; e a filtração lenta seguida de desinfecção, filtração por membranas e/ou oxidação por ozônio.

O tratamento convencional de água é feito em locais específicos, chamados de Estações de Tratamento de Água (ETA), onde a água bruta é submetida a diversas etapas de tratamento: pré-cloração, pré-alcalinização, coagulação, floculação, decantação, filtração, pósalcalinização, desinfecção e fluoretação, para posteriormente ser transportada e distribuída para as residências por meio da rede de distribuição.

Para residências que não possuam sistema de distribuição de água tratada, a Organização Mundial da Saúde recomenda o tratamento residencial de água no ponto de uso como uma intervenção para atender imediatamente (provisoriamente ou não) à necessidade de consumo humano, uma vez que é uma alternativa de custo baixo e implantação rápida na própria residência, sendo esse tipo de tratamento denominado POU (point of use) pois trata a água de 
um único dispositivo ou uma única saída, diferente do tratamento $P O E$ (point of entry) que trata toda a água que entra em uma casa (WHO, 2005).

Sobsey et. al. (2008) em sua pesquisa compararam cinco formas distintas de tratamentos alternativos no ponto de uso $(P O U)$ para pessoas que não têm acesso à água potável, que foram: utilização de cloro líquido, coagulação e cloração utilizando sulfato de alumínio e cloro, desinfecção utilizando luz solar em garrafas PETs (Polietileno tereftalato), filtros cerâmicos e FLDs para uso residencial. Sobsey et. al. (2008) concluíram que os filtros cerâmicos e os FLDs são capazes de superar os obstáculos de sustentabilidade do tratamento, uma vez que exigem uma compra única para construção dos filtros, sem a necessidade de adquirir produtos químicos para o tratamento de água, o que poderia comprometer as despesas de uma família, e produzem água em quantidade suficiente para o uso doméstico com pouco tempo e esforço, podendo ser utilizado em larga escala e de forma continua, ou seja, a sua utilização é de longo prazo. Portanto, justifica-se a pesquisa visando melhorar o desempenho e compreender o filtro lento domiciliar, pois ele foi o mais aceito pelas comunidades, conforme apresentado no estudo de Sobsey et. al. (2008).

\subsection{Filtro lento domiciliar}

O Filtro Lento Domiciliar (FLD) foi uma adaptação do filtro lento convencional (Slow Sand Filter - SSF), projetado para operar em batelada, essa adaptação ao regime intermitente é possível mantendo-se uma lâmina d’água no topo da camada filtrante. Tanto o FLD quanto o SSF permitem o desenvolvimento de uma camada biológica que auxilia no tratamento (CAWST, 2012; MACIEL E SABOGAL-PAZ, 2018; ANDREOLI E SABOGAL-PAZ, 2020).

As tecnologias de tratamento de água $P O U$ são adotadas para reduzir o número de pessoas sem acesso à água potável tanto nas áreas urbanas quanto rurais. O FLD foi desenvolvido em 1990 pelo Dr. Davis Manz na Universidade de Calgary, Canadá, e hoje essa tecnologia é distribuída em todo o mundo por algumas organizações sem fins lucrativos (KENNEDY et. al., 2012). O CAWST, Centre for Affordable Water and Sanitation, é um centro de tecnologia acessível de água e saneamento do Canadá, é uma organização sem fins lucrativos que fornece treinamento e consultoria para organizações que trabalham diretamente com as populações em países em desenvolvimento que não têm acesso a água potável e saneamento básico. Segundo estudos do CAWST, estima-se que mais de 300.000 FLDs em areia foram instalados em mais de 70 países até junho de 2011 (CAWST, 2012). Na Figura 1 ilustra-se o 
modelo do filtro CAWST (2012) com o reservatório, uma placa difusora metálica e o meio filtrante.

\section{Figura 1 - Modelo do FLD da CAWST}

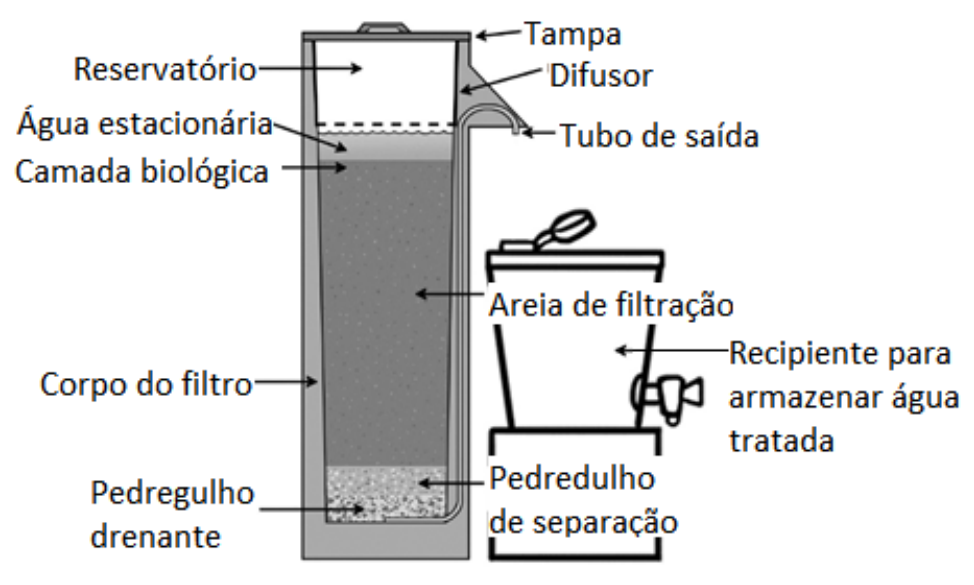

Fonte: Adaptado de CAWST (2012).

Segundo o modelo do filtro proposto pelo CAWST (2012), este deve ser constituído de um corpo de concreto; uma tampa na parte superior de modo a ficar justa e prevenir possíveis contaminações; um reservatório no topo do filtro com capacidade de 12 litros para despejar a água a ser tratada; um difusor que pode ser de material plástico ou metálico de modo que a água seja despejada de forma homogênea sem perturbar a areia e danificar a camada biológica formada na parte superior do leito.

Uma camada de separação composta por pedregulho miúdo que impede a saída da areia para o tubo de saída, caso contrário, poderia ocorrer a obstrução dessa tubulação, para a qual se recomenda uma espessura de $5 \mathrm{~cm}$; camada de drenagem composta por pedregulho graúdo que impede a saída do pedregulho miúdo, para a qual se recomenda que o diâmetro dos grãos seja maior do que o diâmetro interno do tubo de saída e que essa camada tenha $5 \mathrm{~cm}$ de espessura; tubo de saída no qual a água tratada escoa para o reservatório com capacidade para 12 litros; e o reservatório de armazenamento de água tratada para que a água seja mantida segura e livre de contaminação posterior (CAWST, 2012).

Segundo a CAWST (2012), a areia utilizada no filtro deve ter diâmetro menor que 0,7 mm para garantir a filtração lenta e a retenção de sólidos suspensos e microrganismos no topo da camada. O pedregulho da camada de separação deve ter diâmetro entre $0,7 \mathrm{~mm}$ e $6 \mathrm{~mm}$ e o pedregulho da camada de drenagem deve ter entre $6 \mathrm{~mm}$ e $12 \mathrm{~mm}$. Esta configuração permite uma taxa de filtração de $9,6 \mathrm{~m}^{3} \cdot \mathrm{m}^{2} \cdot \mathrm{d}^{-1}$ e uma vazão de $0,4 \mathrm{~L} \cdot \mathrm{min}^{-1}$ (CAWST, 2012). Para os 
filtros recomenda-se que a areia utilizada na filtração lenta tenha o tamanho efetivo das partículas $\left(D_{10}\right)$ entre 0,15 a 0,20 mm, o coeficiente de uniformidade $(C U)$ entre 1,5 e 2,5, o percentual passante na peneira \#150 seja menor ou igual a $4 \%$ e valores máximos de turbidez na água de alimentação de 50 UNT, caso a turbidez da água afluente seja superior, recomendase fazer uma sedimentação prévia (CAWST, 2009).

Todos os materiais podem ser obtidos, por exemplo, das margens do rio mais próximo das comunidades. Após a escolha do local para retirada do material, este deve ser selecionado utilizando peneiras para separação com aberturas de malhas conforme a recomendação dos diâmetros citada anteriormente. Após essa separação é preciso fazer a lavagem dos agregados em um balde para a retirada de contaminantes e matéria orgânica ainda presentes na areia e no pedregulho. Após essa etapa o material deve ser colocado para secar sobre uma lona plástica para posterior montagem dos filtros (CAWST, 2012).

Existem diversos modelos de FLD que podem ser construídos em concreto ou plástico com dispositivo de saída que permite que uma camada de água fique acima da camada superior de areia, evitando a secagem do topo do leito. Segundo Kennedy et. al. (2012) é necessário um processo de amadurecimento de 2 a 3 semanas para se formar a camada biológica, também conhecida como schmutzdecke. Esse período de amadurecimento difere do apresentado pelo manual da CAWST (2009), mas pode estar associado com as características da água a ser tratada e condições climáticas para o desenvolvimento da camada biológica.

O amadurecimento do FLD pode demorar dias, semanas ou meses dependendo da qualidade da água afluente. A camada biológica auxilia na remoção de microrganismos, sólidos e compostos orgânicos e inorgânicos devido à diminuição do tamanho dos poros na camada inicial de areia (KENNEDY et al., 2012; SABOGAL-PAZ et al 2020).

Após a formação da camada biológica, o FLD tem um aumento na perda de carga com consequente redução da taxa de filtração, a qual é compensada pelo aumento de nível no interior do filtro, portanto, pode-se manter a produção diária constante. Contudo, no decorrer do tempo, a produção diária inevitavelmente diminui, assim, o filtro precisa entrar em manutenção. A limpeza do FLD não requer raspagem do topo do meio granular, somente uma agitação manual do topo de areia fina gerando um vórtice de forma que os sólidos presos fiquem em suspensão e possam ser retirados manualmente. Após a limpeza, como a camada biológica foi alterada, alguns dias são necessários para que a camada biológica possa regenerar-se e ter a mesma eficiência de tratamento (KENNEDY et al., 2012).

Os FLDs têm limitações semelhantes aos tratamentos realizados por filtros lentos convencionais na remoção de sólidos e compostos orgânicos. O excesso de material suspenso 
na água afluente obstrui os vazios entre os grãos causando uma redução na passagem do filtro e um aumento nas atividades de limpeza (FREITAS; SABOGAL-PAZ, 2019).

Segundo Kennedy et. al. (2012), a água potável é um recurso escasso para aproximadamente 800 milhões de pessoas em todo o mundo e o número de pessoas sem acesso a água potável foi reduzido devido ao uso da tecnologia como o filtro lento domiciliar, um filtro lento de areia operado em escala domiciliar e que pode ser operado de modo intermitente ou contínuo.

\subsubsection{Operação em escoamento intermitente e contínuo}

A operação do FLD em escoamento intermitente é possível pois o nível de água na saída do filtro mantém o nível mínimo constante na entrada de água do filtro, conforme ilustrado na Figura 1, recomenda-se o uso diário e várias vezes ao longo do dia desde que respeite o período de pausa mínimo de 1 h e máximo de 48 h CAWST (2012).

Na pesquisa de Stauber et al. (2006) o FLD de escoamento intermitente foi alimentado com cerca de $40 \mathrm{~L} \cdot \mathrm{d}^{-1}$, esse volume é referente ao volume dos poros obtidos empiricamente até a saturação de todas as camadas. Os pesquisadores Young-Rojanschi, Madramootoo (2014a) definiram o volume de alimentação do FLD de escoamento intermitente com base no volume dos poros da camada de areia de 1,8L, porém o volume total de água no filtro durante o período de residência era de 2,5 L pois incluía o volume dos poros das camadas de areia e de drenagem e o volume do tubo de saída.

Após o despejo da água sobre a placa difusora, a carga hidráulica força a passagem da água através da paca difusora para o topo da camada filtrante. O nível da água diminui conforme a água escoa pelo meio filtrante e consequentemente a taxa de escoamento é reduzida com o passar do tempo (STAUBER et al., 2006; YOUNG-ROJANSCHI, MADRAMOOTOO, 2014a). Após determinado período o escoamento cessa, pois o nível de água da camada filtrante se iguala ao do tubo de saída, e assim se inicia o período de pausa, tempo em que ocorre os processos físico-químicos e microbiológicos de tratamento da água.

Uma camada de água estacionária de aproximadamente $5 \mathrm{~cm}$ de lâmina d'água deve permanecer sobre a camada biológica para permitir o desenvolvimento dos microrganismos e fornecer oxigênio dissolvido e nutrientes; a camada biológica propriamente dita que se desenvolve de 1 a $2 \mathrm{~cm}$ do topo da camada filtrante, é responsável pela remoção de contaminantes e patógenos; o meio filtrante composto por uma espessa camada de areia é 
responsável por filtrar demais partículas em suspensão e patógenos ainda restantes (CAWST, 2012).

Na camada biológica ocorrem diversas atividades metabólicas que reduzem o oxigênio dissolvido causando a morte e inativação de organismos aeróbios, oxidação e absorção de componentes inorgânicos. Também ocorre interações biológicas do tipo predação, competição e consumo por organismos saprófitos melhorando a eficiência do tratamento de água através do filtro (GALVIS, LATORRE, VISSCHER, 1998).

Se o período de pausa exceder o período máximo pode ocorrer a morte desses microrganismos, pois após consumirem todos os nutrientes e degradarem os patógenos, faltará alimento para esses microrganismos sobreviverem. Períodos longos também podem fazer com que a água estacionária evapore provocando a morte da camada biológica. Os patógenos podem ser reduzidos através dos mecanismos de aprisionamento mecânico das partículas de areia, predação, adsorção e morte natural (CAWST, 2012). A camada filtrante sem a presença da camada biológica é responsável por remover de 30 a $70 \%$ dos patógenos por meio do aprisionamento mecânico e por adsorção. A presença da camada biológica pode aumentar essa eficiência para até $99 \%$ (2 log), sendo essa camada considerada como principal no processo de tratamento. A camada biológica pode demorar até 30 dias para estar completamente formada, período este definido com período de amadurecimento (CAWST, 2009).

Fava et al. (2020) trabalharam com FLDs operados em escoamento contínuo e intermitente e obtiveram reduções de coliformes totais e de E. coli, reduções essas que aumentaram com o tempo de operação, indicando uma relação entre o amadurecimento do biofilme e a eficiência do filtro, além de constatarem a interferência negativa da eficiência após a manutenção dos FLDs.

Os FLDs operados em escoamento intermitente não requerem o uso de energia elétrica e o sistema é menos complexo do que o FLD operado em escoamento contínuo. Todavia, a variação da carga hidráulica causada em cada alimentação nos FLDs intermitentes pode alterar a composição da camada biológica e influenciar a eficiência do tratamento.

Uma solução seria os FLDs operados em escoamento contínuo por bombeamento direto (YOUNG-ROJANSCHI, MADRAMOOTOO, 2014b) ou por bombeamento seguido da ação da gravidade (MACIEL E SABOGAL-PAZ, 2018), porém a falta de energia elétrica pode tornar essa tecnologia de tratamento inexequível nas comunidades isoladas.

O FLD em escoamento contínuo (C-FLD) pode ser operado com uma taxa de filtração mais baixa, de até $9,6 \mathrm{~m}^{3} \cdot \mathrm{m}^{-2} \cdot \mathrm{d}^{-1}$ (MACIEL E SABOGAL-PAZ, 2018) e sua alimentação pode 
ser por gravidade ou por bombeamento direto, desde que haja um controle da taxa de filtração (SABOGAL-PAZ et al., 2020).

Pesquisas realizadas com os FLDs mostraram a facilidade na construção e na operação dos FLDs operados em escoamento intermitente e contínuo, porém os FLDs contínuos são mais complexos devido à necessidade de aquisição e instalação de uma bomba elétrica e de uma estrutura para suporte do reservatório elevado (YOUNG-ROJANSCHI, MADRAMOOTOO, 2014b; MACIEL E SABOGAL-PAZ, 2018; SABOGAL-PAZ et al 2020).

\subsubsection{Experiências com o filtro lento domiciliar}

O estudo desenvolvido por Elliott et al. (2008) utilizou um FLD de plástico operado em escoamento intermitente com capacidade de 60 litros, os filtros foram compostos por $5 \mathrm{~cm}$ de cascalho no meio suporte, seguido de $5 \mathrm{~cm}$ cascalho médio e $40 \mathrm{~cm}$ de areia, o tamanho efetivo $\left(\mathrm{D}_{10}\right)$ foi de 0,19 - 0,22 mm e o coeficiente de uniformidade foi de 3,5-4,0. Após a primeira carga de 20 L a vazão foi de 0,9 L.min ${ }^{-1}$. Foram utilizados volumes de alimentações diárias de $20 \mathrm{~L}$ e $40 \mathrm{~L}$ em um filtro que possuía um volume de poros de $18,3 \mathrm{~L}$. A escolha de $20 \mathrm{~L}$ foi baseada no volume máximo do reservatório acima da camada filtrante e na faixa inferior do consumo diário típico familiar nos países em desenvolvimento (SOBSEY, 2002 apud ELLIOT et al., 2008). A escolha de $40 \mathrm{~L}$ foi baseada no maior volume típico para usos domésticos por uma família em países em desenvolvimento. A pesquisa concluiu que o desempenho do filtro foi melhor quando o filtro era operado com um volume de água a ser tratada de $20 \mathrm{~L}$. Nesse caso o amadurecimento da camada biológica demorou aproximadamente 30 dias, observandose melhoras no desempenho do filtro na redução de $E$. coli, enterovirus e bacteriófagos (ELLIOT et al., 2008).

Young-Rojanschi, Madramootoo (2014a) realizaram o experimento em escala laboratorial seguindo o modelo da CAWST Versão 10, operado em escoamento intermitente, o modelo tinha $10 \mathrm{~cm}$ de diâmetro, $5 \mathrm{~cm}$ de altura da lâmina de água estacionária, precedida de um placa difusora e $17 \mathrm{~cm}$ da altura máxima de lâmina de água, após a água estacionária havia $55 \mathrm{~cm}$ de profundidade da camada filtrante, $5 \mathrm{~cm}$ de cascalho de separação com diâmetro menor que $6,4 \mathrm{~mm}$ e $5 \mathrm{~cm}$ de cascalho de drenagem com diâmetro menor que $12,7 \mathrm{~mm}$ e um tubo de saída na parte inferior do filtro. Compararam filtros lentos de areia operados de forma intermitente e contínua. Os autores trabalharam com cinco filtros operados de forma intermitente com um período de pausa de 24 horas e três de forma contínua. Constatou-se que 
a operação contínua dos filtros teve uma redução significativamente melhor de E. coli, bacteriófagos e turbidez.

Devido às limitações do FLD, foi desenvolvida uma pesquisa aplicando um prétratamento com filtro dinâmico de pedregulho (PFD) ao FLD denominando esse sistema de tratamento como filtração domiciliar de múltiplos estágios (FLDM) operados em escoamento contínuo (MEDEIROS et al., 2020).

Dois PFDs foram construídos, um com uma manta não tecido no topo da camada de pedregulho e outro sem a manta. Os PFDs foram operados à uma taxa de filtração de $3,21 \mathrm{~m}^{3}$. $\mathrm{m}^{-}$ ${ }^{2} \cdot \mathrm{d}^{-1}$ e os FLD à $1,52 \mathrm{~m}^{3} \cdot \mathrm{m}^{-2} \cdot \mathrm{d}^{-1}$ e a produção diária era de 25 litros. A remoção de cor verdadeira, carbono orgânico total e absorbância $(\lambda=254 \mathrm{~nm})$ foi de apenas $6,6 \%$, entretanto os FLDMs tiveram uma redução de turbidez acima de $60 \%$, redução de $E$. coli até $1,78 \log$, cistos de Giardia spp. e oocistos de Cryptosporidium spp. de até 3,15 log e 2,24 log, respectivamente. A manta não tecido foi uma barreira física importante para remoção dos sólidos, E. coli e protozoários. O FLDM não foi suficiente para produzir água potável se acordo com as recomendações da Organização Mundial de Saúde (MEDEIROS et al., 2020).

No estudo desenvolvido por Freitas e Sabogal-Paz (2019) foram operados dois FLDs, um em regime contínuo e outro em regime intermitente, usando uma manta não tecido sobre o topo do meio filtrante e um pré-tratamento com coagulante natural em pó extraído da Opuntia cochenillifera.

A melhor dosagem de coagulante foi de $30 \mathrm{mg} . \mathrm{L}^{1} \mathrm{em} \mathrm{pH}$ natural. A produção diária dos FLDs foi de 60 litros, sendo que o filtro intermitente era alimentado em batelada com volumes de 15 litros, à taxa máxima de filtração foi de $2,79 \mathrm{~m}^{3} \cdot \mathrm{m}^{-2} \cdot \mathrm{d}^{-1}$ e um período de pausa de 8 horas e três períodos de 4 horas, e para o filtro contínuo a taxa de filtração foi ajustada para 1,22 $\mathrm{m}^{3} \cdot \mathrm{m}^{-2} \cdot \mathrm{d}^{-1}$. O FLD em escoamento contínuo apresentou melhor desempenho na remoção de turbidez $(79,2 \% \pm 8,39 \%)$ e o filtro em escoamento intermitente apresentou maior eficiência na remoção de $E$. coli $(2,86 \log \pm 0,79 \log$ para o período de pausa de 12 h e 2,41 log $\pm 0,42 \log$ para o período de pausa de 4 h) (FREITAS; SABOGAL-PAZ, 2019).

O processo de amadurecimento da camada biológica não está totalmente compreendido, devido à essa lacuna, foi desenvolvido um estudo para acelerar o amadurecimento do FLD com adição de nutrientes, optou-se em utilizar a comida de peixe na água afluente (CALIXTO et al., 2020).

O filtro produziu $70 \mathrm{~L}$ por dia, foi operado em escoamento contínuo, com taxas máximas e mínimas de 1,92 e $0,964 \mathrm{~m}^{3} \cdot \mathrm{m}^{-2} \cdot \mathrm{d}^{-1}$. O FLD obteve um parcial nível de maturação em um curto período de tempo com redução dos parâmetros de turbidez e microbiológicos. A operação 
do filtro foi realizada em um curto período, de uma a duas semanas, e a instabilidade observada na qualidade da água filtrada indicou um desenvolvimento incompleto da camada biológica, que pode acarretar em riscos à saúde humana associados ao consumo de água sem o amadurecimento do FLD (CALIXTO et al., 2020).

Os FLDs requerem tempo para o crescimento da camada biológica (schmutzdecke) para ter o máximo desempenho e nesse período de amadurecimento microorganismos patogênicos podem passar pelo filtro. O estudo avaliou dois FLDs em duplicata, sendo dois em escoamento contínuo e dois intermitentes, seguidos de pós-tratamento com desinfecção por hipoclorito de sódio. A água afluente era composta com por uma mistura de água subterrânea com Escherichia coli, cistos de Giardia muris e oocistos de Cryptosporidium parvum. Semanalmente foi introduzida água do rio como agente de amadurecimento (ANDREOLI; SABOGAL-PAZ, 2020).

Os 4 FLDs foram operados durante 374 dias, com produção diária de 48 litros cada filtro, taxa de filtração dos filtros em escoamento contínuo foi de $0,91 \mathrm{~m}^{3} \cdot \mathrm{m}^{-2} \cdot \mathrm{d}^{-1}$ e taxa de filtração dos filtros intermitentes entre 0 e $8,64 \mathrm{~m}^{3} \cdot \mathrm{m}^{-2} \cdot \mathrm{d}^{-1}$. Os filtros intermitentes foram alimentados em batelada com volumes de 16 litros três vezes ao dia, sendo um período de pausa de 14 horas e outros dois de 5 horas. O FLD em escoamento contínuo apresentou melhor desempenho na redução do risco microbiológico. A água do rio reduziu o tempo de amadurecimento para 80 dias e a desinfecção da água melhorou a qualidade da água e inativou os protozoários (ANDREOLI; SABOGAL-PAZ, 2020).

\subsection{Modelagem matemática e dinâmica dos fluidos computacional}

Os modelos matemáticos, empregados na dinâmica de fluidos computacional (DFC), são obtidos por meio de balanços diferenciais ou integrais das propriedades conservadas, ou seja, empregam os princípios da conservação da massa, momentum e energia.

O modelo matemático permite a previsão de resultados a partir das condições de controle e de operação definidas pelo usuário para prever-se melhorias em um processo de filtração na produção de água potável (BOTARI e DI BERNARDO, 2012).

A dinâmica dos fluidos computacional (DFC) também conhecida como (CFD) é a área da computação científica que estuda métodos computacionais para simulação de fenômenos que envolvem fluidos em movimento com ou sem troca de calor. O uso da DFC permite que os resultados da simulação possam orientar o projetista na escolha do experimento ou comparar 
os resultados do modelo com os obtidos nos experimentos, confirmando ou não a validade desses novos modelos (FORTUNA, 2000).

Este método pode ser utilizado para elucidar problemas com diferentes geometrias e apresentar resultados de forma rápida e econômica se comparado a outros métodos, como a análise experimental (GONÇALVES, 2007).

O CFD é um método de análise de escoamento de fluidos, transferência de calor e de massa, reações químicas e outros fenômenos relacionados que resolve um conjunto de equações matemáticas apropriadas para descrever cada um dos processos relacionados à conservação de massa, momentum e energia dentro de um reator (GRESCH et al., 2009). Os modelos em duas dimensões (2D) ou em três dimensões (3D) são preferíveis para uma compreensão detalhada dos efeitos da hidrodinâmica comparados com apenas modelos numéricos sem visualização (YANG et al., 2011).

A DFC tem sido amplamente empregada para simular os diferentes sistemas hidráulicos e fenômenos biológicos que ocorrem dentro dos reatores e autores desenvolveram modelos numéricos para simular o comportamento do escoamento em reatores biológicos (SÁNCHEZ et al., 2018).

A modelagem de escoamentos no meio ambiente tem uma importância significativa para os pesquisadores com o objetivo de compreender os fenômenos naturais, como por exemplo, na análise de dispersão de poluente em rios (OLIVEIRA; MOREIRA, 2010). Outro exemplo é a correta previsão do transporte e destino de partículas coloidais em meios porosos saturados, que tem interesse prático para aplicações ambientais e que incluem o transporte desses coloides e dos poluentes que possam estar associados aos coloides em águas subterrâneas e na filtração natural de microrganismos para tratamento de água e efluente (HASSAN et. al.,2013).

Segundo Langergraber et al. (2009), os modelos matemáticos foram desenvolvidos e validados com testes experimentais, assim, eles podem ser utilizados para avaliar e melhorar critérios de projeto existentes. A DFC tornou-se uma ferramenta robusta no processo de design e de diagnóstico do reator fornecendo informações detalhadas dos reatores, como o campo de distribuição de velocidade, a distribuição da concentração e consumo de energia (ZHANG, PAN e REMPEL, 2007).

Na dinâmica de fluidos computacional as malhas empregadas podem ser classificadas em duas famílias, uma do tipo estruturada e outra do tipo não estruturada, conforme apresentado na Figura 2. A malha estruturada é utilizada para domínios com geometria complexa e exige procedimentos especiais para sua construção. Dependendo da complexidade do domínio, a malha deve ser gerada por sub-regiões. A malha não estruturada exige uma estrutura de dados 
mais elaborada se comparada com a malha estruturada, porém, a utilização de malha não estruturada possibilita a discretização de domínios complexos mais facilmente que a anterior (FORTUNA, 2000).

Figura 2 - Tipos de malha

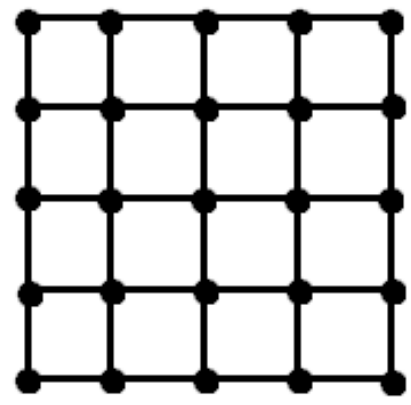

Estruturada

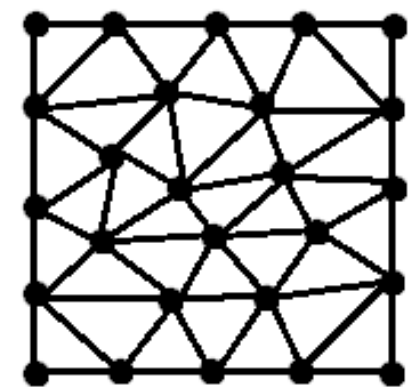

Não estruturada

Fonte: Autor

Nas malhas em 2D a célula ou o elemento finito pode ser do tipo triangular ou quadrilátero e nas malhas em 3D pode ser do tipo tetraédrico, hexaédrico, prisma, piramidal ou poliédrico, conforme apresentado na Figura 3.

Figura 3 - Tipos de célula em 2D e 3D

Célula em 2D

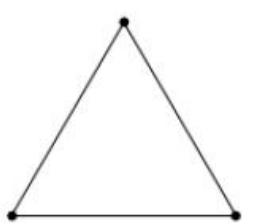

Triangular

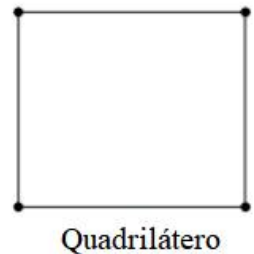

Célula em 3D
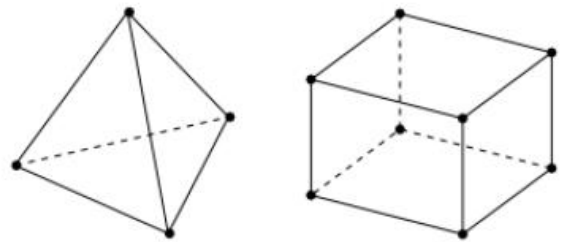

Hexaédrico

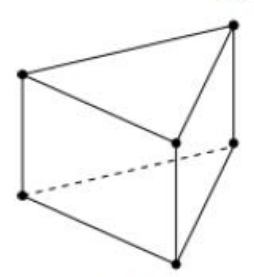

Prisma

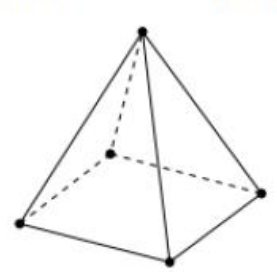

Piramidal

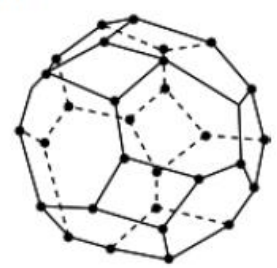

Poliédrico 
Fonte: Adaptado de ANSYS (2013)

\subsubsection{Método dos volumes finitos}

O método dos volumes finitos é um método de discretização utilizado para obter uma solução numérica a partir das equações diferenciais e da integração dessas equações em uma determinada região, denominada de volume de controle. Em cada volume discretizado nesse método, as leis de conservação são obedecidas, por exemplo, uma grandeza física como a massa permanece conservada a nível discreto. Essa característica do método dos volumes finitos é útil quando se modela sistemas para os quais o escoamento é importante, como por exemplo, na mecânica dos fluidos (SANTOS e GARCIA, 2015).

Segundo Fortuna (2000), a técnica de volumes finitos está relacionada ao conceito de fluxo entre regiões, ou volumes, adjacentes. O fluxo de uma grandeza, como massa ou energia, é quantidade dessa grandeza que atravessa em uma dada direção, sempre normal, à uma área por unidade de tempo. A quantidade de uma grandeza $\varphi$, que atravessa as fronteiras do volume de controle $v$ por unidade de tempo, é calculada pela integração sobre essas fronteiras, da diferença entre os fluxos que entram e os que saem de $v$. Os fluxos podem ser classificados em dois tipos:

- Fluxos convectivos: devido à velocidade do fluido. Exemplo: considerando $\varphi$, como a temperatura, um fluxo convectivo seria o fluxo de calor devido ao escoamento de água quente, por uma tubulação, para uma região onde a água estivesse mais fria. Os fluxos convectivos têm forma geral $\rho \varphi \boldsymbol{V}$, em que $\rho$ é a densidade, $\mathbf{V}$ é o vetor velocidade do fluido e $\varphi$ é a propriedade transportada. O fluxo convectivo em uma direção qualquer é dado por $\rho \varphi \boldsymbol{V}$. $\widehat{\boldsymbol{n}}$, em que $\widehat{\boldsymbol{n}}$ é o vetor unitário normal à área nessa direção.

- Fluxos difusivos: originados pela não uniformidade da distribuição espacial de $\varphi$. Exemplo: considerando $\varphi$, como a temperatura, surge um fluxo de calor na direção $\mathrm{x}$ quando há um gradiente de temperatura presente. O fluxo de calor na direção $\mathrm{x}$, dado por $-k \frac{\partial \varphi}{\partial x}$, em que k é o coeficiente de condutividade térmica do meio, o fluxo aparece no sentido da temperatura mais alta para a mais baixa. Os fluxos difusivos geralmente têm a forma $-\Gamma \nabla \varphi$, em que $\Gamma$ é o coeficiente de difusão e $\varphi$ a propriedade sendo difundida. Em coordenadas cartesianas tridimensionais, o operador $\nabla$ (nabla) é dado pela Equação 1:

$$
\nabla=\widehat{x} \frac{\partial}{\partial x}+\widehat{\boldsymbol{y}} \frac{\partial}{\partial y}+\hat{\boldsymbol{z}} \frac{\partial}{\partial z}
$$


em que $\widehat{\boldsymbol{x}}, \widehat{\boldsymbol{y}}$ e $\hat{\boldsymbol{z}}$ são vetores unitários nas direções $\mathrm{x}, \mathrm{y}$ e z, respectivamente. Se $\widehat{\boldsymbol{n}}$ for o vetor unitário ao longo de uma direção qualquer, então o fluxo nessa direção é dado pela expressão $\Gamma \nabla \varphi . \widehat{\boldsymbol{n}}$, em que $\widehat{\boldsymbol{n}}$ é o vetor unitário normal à área nessa direção. Mesmo que a velocidade do fluido seja nula, os fluxos difusivos podem existir.

O resultado dessa integração com a produção resultante $\varphi$ no volume, ou seja, a diferença entre a geração e o consumo de $\varphi$ em $v$, é proporcional à variação temporal de $\varphi$ dentro do volume (FORTUNA, 2000).

\subsubsection{Etapas do processo de simulação}

O desenvolvimento dos processos de simulação utilizando a ferramenta da dinâmica dos fluidos computacional é composta por etapas que precisam ser realizadas sequencialmente para se obter os resultados, essas etapas podem ser caracterizadas como:

1- Problemática: definição dos objetivos da simulação e identificação dos domínios a serem criados;

2- Pré-processamento: elaboração da geometria, geração da malha, determinação das propriedades físicas dos fluidos, escolha dos modelos matemáticos e configuração dos parâmetros do solver;

3- Processamento: Cálculo da solução matemática;

4- Pós-processamento: análise dos resultados e a visualização em $2 \mathrm{D}$ ou 3D, como a criação de planos e vetores

O fluxograma apresentado na Figura 4 ilustra as etapas do processo de simulação e as atividades a serem desenvolvidas em cada etapa. 
Figura 4 - Etapas do processo de simulação

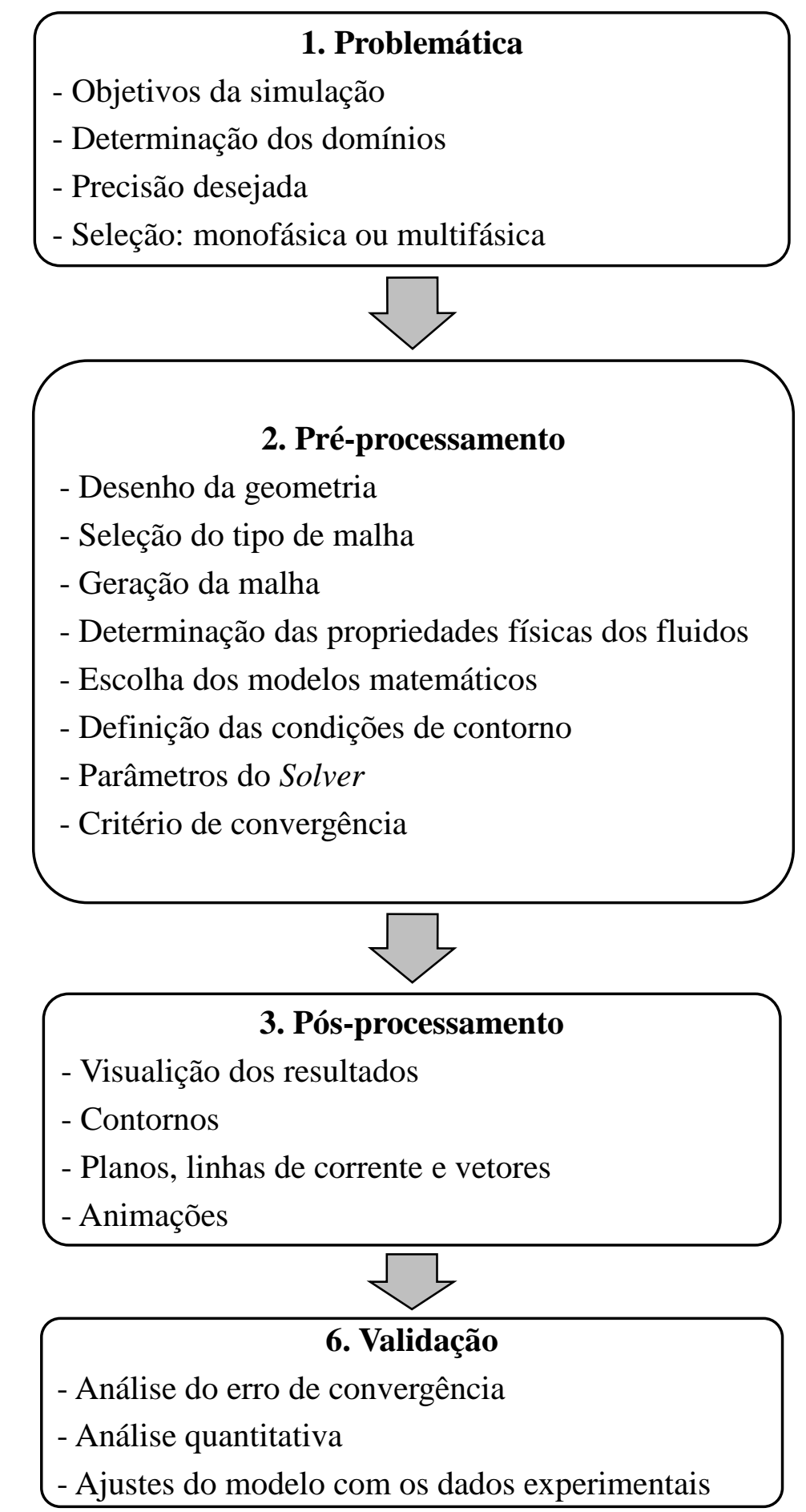

Fonte: Autor

Após o desenho da geometria (domínios), a etapa da geração da malha é a parte inicial da aplicação do método de volumes finitos, pois o domínio contínuo é transformado em domínio discreto, devido à criação dos vários elementos que compõem a malha (LEMOS, 2011). 
A precisão da solução gerada depende do número de elementos que compõem a malha, a qual pode ser refinada para obter uma melhor precisão, porém, esse refinamento da malha, depende da capacidade e do custo computacional disponível.

A definição das condições de contorno é de extrema importância, pois é quando se determina a entrada, saída e as paredes do sistema. A entrada apresenta as características do fluido que entra no sistema, como o sentido do fluxo e a velocidade; a saída apresenta a característica como a pressão externa; e as paredes são as regiões limítrofes do escoamento, nas quais se pode definir o escorregamento do fluido na parede ou não. Por fim, os resultados da simulação numérica podem ser avaliados por meio de linhas de correntes, planos, contornos, animações e gráficos gerados.

\subsubsection{Experiências com a modelação em filtros lentos de areia}

Langenbach et al. (2010) desenvolveram um experimento que consistiu em duas colunas de filtro de 18,5 cm de diâmetro ( $\mathrm{S} 1$ e S4) contendo uma camada de areia de $50 \mathrm{~cm}$, suportado por $10 \mathrm{~cm}$ de cascalho e com um nível mínimo de água sobrenadante de $30 \mathrm{~cm}$. O filtro $\mathrm{S} 1$ tinha o coeficiente $\mathrm{D}_{10}$ de $0,25 \mathrm{~mm}$ e o coeficiente de uniformidade de 1,56, o filtro S4 tinha coeficiente $\mathrm{D}_{10}$ de $0,82 \mathrm{~mm}$ e o coeficiente de uniformidade de 1,51 .

Os filtros lentos de areia foram continuamente alimentados com um efluente oriundo do clarificador secundário de uma estação de tratamento de efluente localizada em Langenreichenbach (Saxônia, Alemanhã). No estudo, foi utilizada a ferramenta de simulação AQUASIM para desenvolver um modelo de remoção de Escherichia coli em filtros lentos de areia, o processo mais importante foi a retenção de bactérias na camada biológica que foi descrita por uma equação cinética de primeira ordem (LANGENBACH et al., 2010).

Jenkings, Tiwari e Darby (2011) analisaram a remoção de bactérias, vírus e turbidez em um filtro lento domiciliar com escoamento intermitente utilizando experimentos e a modelagem linear mista. O projeto experimental e a modelagem possibilitaram avaliar os principais efeitos do tamanho da areia, $D_{10}$ de $0,17 \mathrm{~mm}$ e de 0,52 $\mathrm{mm}$ e das cargas hidráulicas de 10, 20 e $30 \mathrm{~cm}$ na remoção de coliforme fecais, vírus do bacteriófago e turbidez, sob dois modos de operação intermitente, um longo e outro curto. Os filtros foram construídos com tubo de PVC para irrigação de 12 polegadas, com uma placa difusora onde se despejava a água a ser tratada, uma lâmina d'água de $2,5 \mathrm{~cm}$, camada de areia de $60 \mathrm{~cm}$, camada de pedregulho de $5 \mathrm{~cm}$ e camada de rocha de $5 \mathrm{~cm}$, constataram que os filtros com areia fina apresentaram melhor eficiência de remoção. 
Embora existam pesquisas sobre hidrodinâmica dos FLDs, pouco se discute sobre a influência do sistema de saída na hidrodinâmica dos filtros (BERBERT et al., 2016). O estudo de Berbert et al. (2016) consistiu em analisar a influência do sistema de saída dos FLDs na hidrodinâmica dos filtros, foram simulados três modelos diferentes operados em escoamento intermitente: o modelo PEU/UEM (BERBERT et al., 2016), o CAWST versão 10 (CAWST, 2012) e o HydrAid (KIKKAWA, 2008). O modelo PEU/UEM tinha área superficial de 3,10 x $10^{-2} \mathrm{~m}^{2}$, velocidade de entrada de $3,68 \times 10^{-6} \mathrm{~m} \cdot \mathrm{s}^{-1}$, taxa de filtração de $3,18 \times 10^{-1} \mathrm{~m}^{3} \cdot \mathrm{m}^{-2} \cdot \mathrm{d}^{-1} \mathrm{e}$ alturas da camada de areia, areia grossa e pedregulho de $60 \mathrm{~cm}, 5 \mathrm{~cm}$ e $5 \mathrm{~cm}$, respectivamente. O modelo CAWST versão 10 tinha área superficial de $6,0 \times 10^{-2} \mathrm{~m}^{2}$, alturas da camada de areia, areia grossa e pedregulho de $54,5 \mathrm{~cm}, 5 \mathrm{~cm}$ e $5 \mathrm{~cm}$. O modelo HydrAid tinha área superficial de $1,13 \times 10^{-1} \mathrm{~m}^{2}$, alturas da camada de areia, areia grossa e pedregulho de $43 \mathrm{~cm}, 5 \mathrm{~cm}$ e $6 \mathrm{~cm}$. Os três tipos de filtros foram simulados considerando os valores de porosidade da areia de 0,40 , da areia grossa de 0,60 e do pedregulho de 0,70, e, considerando os valores de permeabilidade da areia de $9,0 \times 10^{-5} \mathrm{~mm}^{2}$, da areia grossa de $1,0 \times 10^{-2} \mathrm{~mm}^{2}$ e do pedregulho de $0,1 \mathrm{~mm}^{2}$.

Os filtros dos modelos CAWST e HydrAid foram simulados com a geometria original que possui sistema de saída na lateral e simulados uma configuração de saída com anel coletor no interior. No modelo PEU/UEM foram simulados quatro tipos de saídas localizadas: no centro em escoamento ascendente, na lateral, na parte inferior e um anel coletor no interior, apresentado na Figura 5. O estudo concluiu que o filtro PEU/UEM que possui saída em forma de anel coletor com a interface para baixo contribui para melhorar as linhas de corrente criando uma melhor distribuição da velocidade nas três direções, diminuindo zonas mortas e aumentando o tempo de detenção hidráulico (BERBERT et al., 2016).

Figura 5 - Linhas de corrente em quatro configurações do filtro PEU/UEM: (A) centro, (B) lateral, (C) no fundo e (D) anel coletor

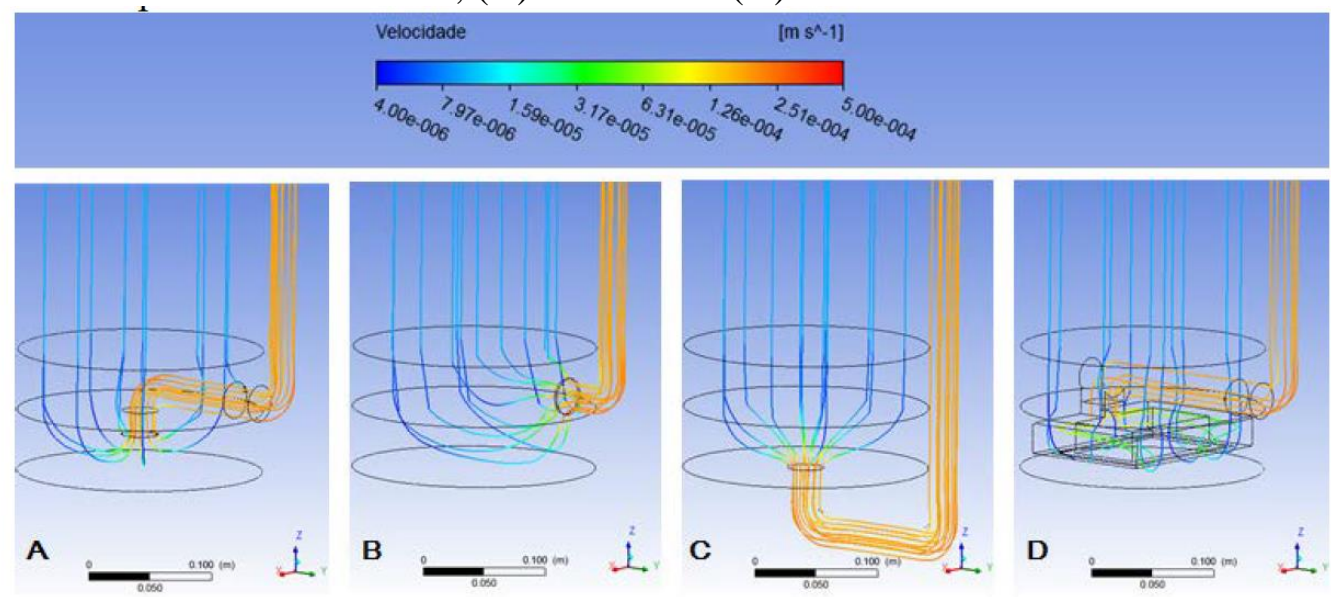

Fonte: Berbert et al. (2016) 
Segundo Langergraber et al. (2009), uma vez que os modelos matemáticos foram desenvolvidos e validados com testes experimentais, podem ser utilizados para avaliar e melhorar critérios de projeto existentes. A DFC é um importante instrumento que proporciona uma distribuição detalhada do escoamento em três dimensões (KLUSENER et al., 2007).

As curvas da distribuição do tempo de residência experimentais são utilizadas para avaliar os parâmetros cinéticos, o transporte em reatores e identificar anomalias do escoamento como zonas mortas, curto-circuito e caminhos preferenciais que ocorrem nos reatores, tanto em escala de bancada, piloto ou real (LEVENSPIEL, 1999). No estudo, os modelos matemáticos dos FLDs foram validados a partir da análise das curvas DTRs obtidas dos experimentos em escala plena com as curvas DTRs obtidas por DFC.

\subsection{Distribuição de tempo de residência experimental}

Sabe-se que o estudo do comportamento hidrodinâmico de reatores contribui para compreender o funcionamento desses sistemas e permite obter equações de desempenho e do modelo mais satisfatório. A distribuição do tempo de residência pode ser obtida tanto experimentalmente com ensaios em laboratório quanto pela utilização da ferramenta da dinâmica de fluidos computacional.

No reator, os elementos de fluido podem percorrer caminhos diferentes e consequentemente, gastar tempos diferentes para atingirem a saída do recipiente/reator. A função que descreve a distribuição desses tempos para a corrente que deixa o recipiente é chamada de curva de distribuição do tempo de residência (DTR) do fluido. Sendo um parâmetro utilizado na caracterização do desempenho dos reatores. A DTR é obtida através da técnica experimental de estímulo-resposta, com injeção de traçadores. De acordo com Levenspiel (1999), esta técnica permite avaliar quantitativamente os parâmetros cinéticos e o transporte em reatores. As curvas de DTR podem ainda auxiliar na identificação e quantificação de anomalias do escoamento como zonas mortas, curto-circuito e caminhos preferenciais que ocorrem nos reatores, tanto em escala de bancada, piloto ou plena/real.

Os reatores reais têm uma tendência de se desviar da idealidade de uma forma geral, mas para a caracterização hidrodinâmica de reatores consideram-se para modelação os escoamentos ideais que podem ocorrer no reator com escoamento pistonado (Plug Flow Reactor - PRF) e no reator com escoamento de mistura completa (Continuous Stirred Tank Reactor CSTR). Estes são considerados por apresentarem desempenhos diferentes, além de que, na 
maioria das vezes, o processo escolhido adapta-se bem a um destes dois modelos com um simples tratamento dos dados (LEVENSPIEL, 1999).

No reator com escoamento pistonado o fluido passa pelo reator sem ocorrer a mistura da massa do fluido anterior com o posterior e sem ultrapassagem, ou seja, é como se o fluido se movesse "em fila", e cada elemento de fluido saísse do reator de forma sequencial sem ocorrer mistura no eixo longitudinal. No reator de mistura completa, considera-se uma mistura uniforme, ou seja, todo fluido que entra no tanque é uniformemente e instantaneamente misturado resultando na mesma concentração e composição em todos os pontos dentro do reator e na saída (LEVENSPIEL, 1999).

Segundo Fogler (2009), a distribuição de tempo de residência para caracterizar reatores não ideais, ou seja, quando os reatores de tanque não são perfeitamente misturados ou quando os reatores tubulares não exibem o comportamento de escoamento pistonado, é utilizada com dois objetivos: diagnosticar problemas de reatores em operação e prever concentrações do efluente em reatores quando diferentes reações ocorrerem.

A distribuição do tempo de residência pode ser determinada experimentalmente injetando um traçador, substância química inerte, no interior do reator e medindo a concentração do traçador da corrente efluente em função do tempo. O traçador utilizado deve ser do tipo não reagente, de fácil detecção, deve ter propriedades físicas semelhantes à da mistura reagente e ser solúvel na mistura. Os métodos mais utilizados são o da injeção com perturbação em pulso e perturbação em degrau (LEVENSPIEL, 1999).

Levenspiel (1999) aborda outros tipos de estímulo-resposta com traçador. Na Figura 6 os modelos de alimentação tipo pulso, alimentação tipo degrau, alimentação periódica e alimentação aleatória são apresentados respectivamente.

Figura 6 - Formas diferentes para se determinar a distribuição do tempo de residência
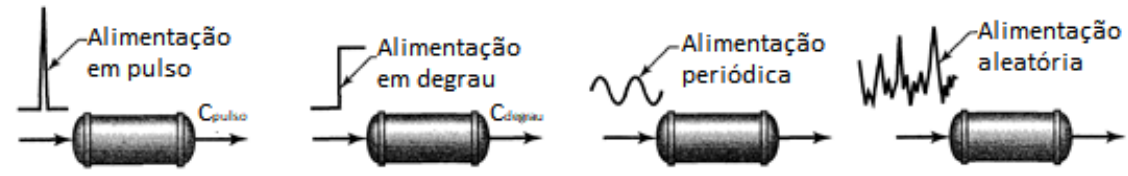

Fonte: Adaptado de Levenspiel (1999)

Segundo Fogler (2009), a perturbação em pulso consiste em injetar na corrente de alimentação uma quantidade de traçador uma única vez em um espaço de tempo tão curto quanto possível e medir a sua concentração efluente. É preciso escolher um incremento de tempo $(\Delta \mathrm{t})$ suficientemente pequeno, para que a concentração do traçador $\mathrm{C}(\mathrm{t})$, que sai entre os 
tempos $\mathrm{t}$ e $\mathrm{t}+\Delta \mathrm{t}$, seja a mesma. Assim a quantidade de traçador $(\Delta \mathrm{N})$ que sai do reator entre os tempos $\mathrm{t}$ e $\mathrm{t}+\Delta \mathrm{t}$ pode ser expressa pela Equação 2, em que $\vartheta$ é a vazão volumétrica do efluente:

$$
\Delta N=C(t) \vartheta \Delta t
$$

Segundo Fogler (2009), a perturbação em degrau consiste em introduzir na corrente de alimentação uma concentração de traçador a uma taxa constante até que a concentração no efluente seja indistinguível daquela na alimentação, assim que atingir a concentração do traçador o teste pode ser interrompido. Como a concentração na entrada é constante com o tempo, $\mathrm{C}_{0}$, a concentração de saída relaciona-se com a de entrada pela integral da convolução, expressa pela Equação 3, na qual E(t) é chamada de função de distribuição de tempo de residência que é a função que descreve de forma quantitativa, quanto tempo os elementos de fluido permaneceram no reator entre os tempos $\mathrm{t} e \mathrm{t}+\mathrm{dt}$ :

$$
C_{\text {saída }}(t)=\int_{0}^{t} C_{\text {entrada }}\left(t-t^{\prime}\right) E\left(t^{\prime}\right) d t
$$

A curva $E(t)$ pode ser determinada diretamente por uma perturbação tipo pulso e a distribuição cumulativa $\mathrm{F}(\mathrm{t})$ pode ser determinada a partir de uma perturbação em degrau. $\mathrm{O}$ ensaio de injeção tipo degrau apresenta vantagens e desvantagens: é mais fácil de ser executado que o teste tipo pulso e tem a vantagem de que a quantidade total de traçador na alimentação não precisa ser conhecida, como no caso do tipo pulso. As desvantagens são a dificuldade de manter a concentração constante de traçador na alimentação, a obtenção da curva DTR, que requer diferenciação de dados e que pode ocasionar grandes erros; e a grande quantidade de traçador necessária para realização do teste, que pode torna-lo inviável se o traçador escolhido tiver custo elevado (FOGLER, 2009).

As curvas típicas de concentração-tempo na entrada e na saída de um reator para a injeção tipo pulso e tipo degrau são apresentadas na Figura 7, assim como o esquema que ilustra o local de injeção do traçador e o local de detecção na saída. 
Figura 7 - Curvas típicas da concentração por tempo na entrada e na saída de um reator

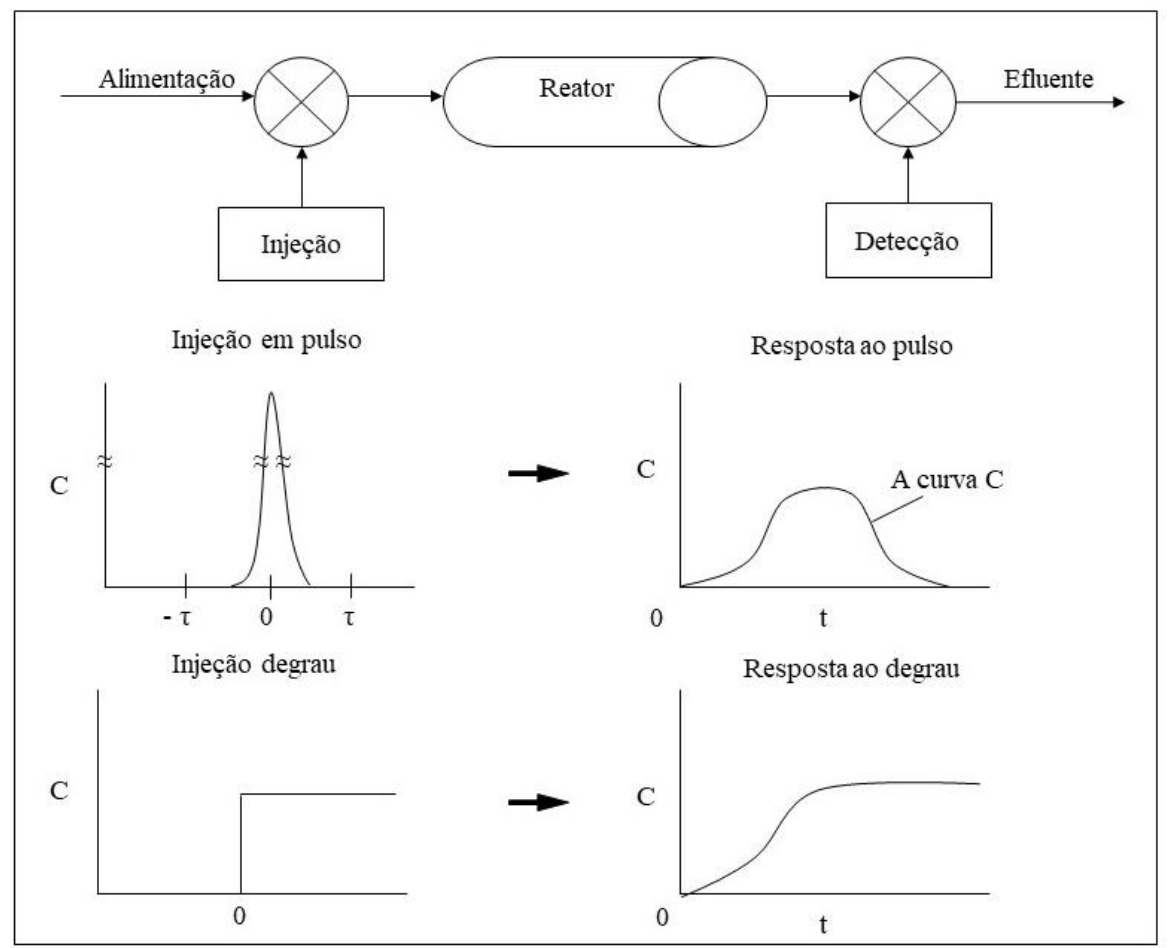

Fonte: Adaptado de Fogler (2009)

Segundo Levenspiel (1999), outro modo de interpretar as curvas DTR é por meio da análise visual do comportamento da curva. As anomalias de escoamento podem ser observadas facilmente e o seu resultado pode fornecer informações de extrema relevância para a análise do sistema. Por exemplo, o escoamento próximo à idealidade pistonada deve apresentar uma curva simétrica com o eixo central no tempo médio com valor esperado, curvas adiantadas são indicativo de zonas de estagnação, múltiplos picos em tempos regulares indicam a presença de zonas internas de recirculação, dois picos indicam a presença de dois caminhos distintos e curvas atrasadas podem indicar erros na medição de vazão, erro no volume disponível ou uso de traçador não inerte, conforme ilustrado na Figura 8. 
Figura 8 - Exemplos de comportamentos de curvas DTR em reatores de escoamento pistonado
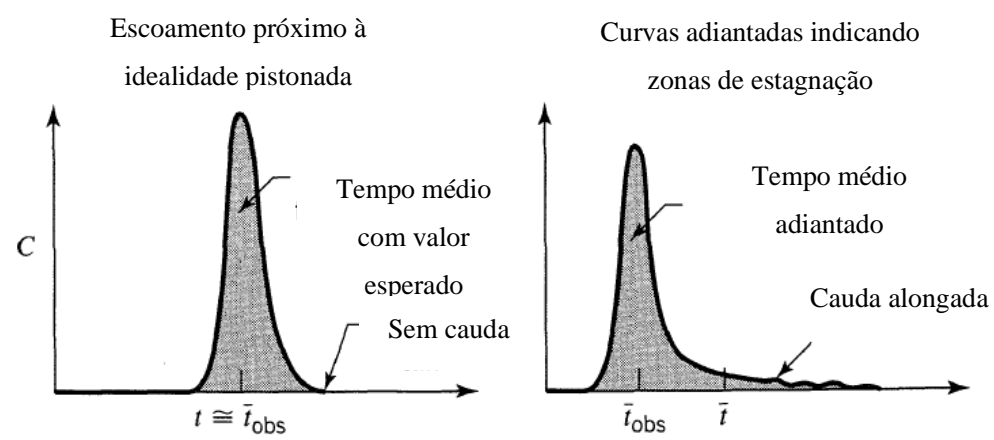

Múltiplos picos em intervalos de tempo regulares indicando zonas internas de recirculação

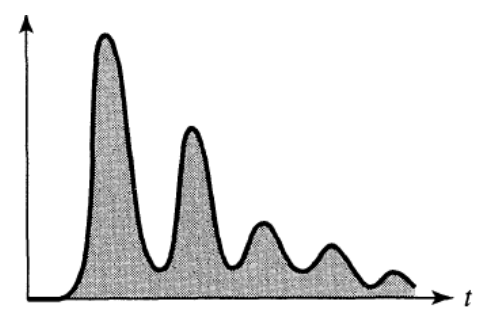

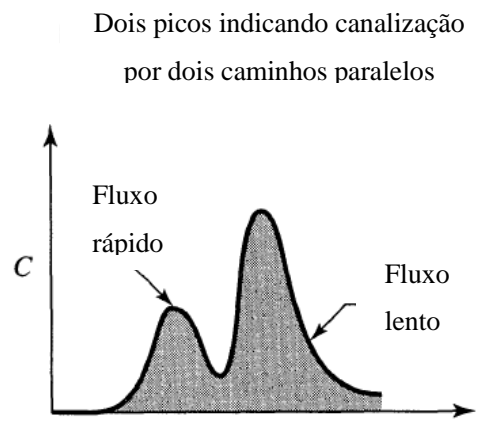

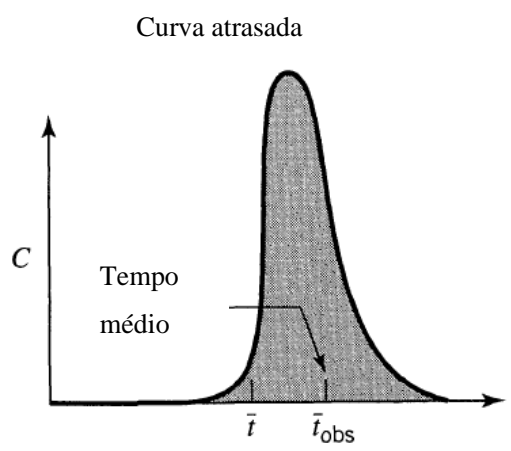

Curvas atrasadas não esperadas, as possíveis explicações são:

- Erro na medição da vazão;

- Erro no volume disponível;

- Uso de traçador não inerte.

Fonte: Adaptado de Levenspiel (1999)

A interpretação prática dos ensaios com traçadores pode ser realizada por meio do índice de dispersão de Morrill (IDM). Esse índice foi desenvolvido em estudos em tanques de sedimentação por Morrill em 1932, que sugeriu a razão dos valores do 90 percentil e do 10 percentil da curva cumulativa do traçador para medir o índice de dispersão e o inverso do índice de dispersão para determinar a média da eficiência volumétrica conforme as Equações 4 e 5, respectivamente (METCALF e EDDY, 2016).

$$
I D M=\frac{P_{90}}{P_{10}}
$$

\section{Em que:}

IDM: Índice de Dispersão de Morrill

$\mathrm{P}_{90}$ : valor do 90 percentil do gráfico log-probabilidade

$\mathrm{P}_{10}$ : valor do 10 percentil do gráfico log-probabilidade

$$
\text { Eficiência volumétrica, } \%=\frac{1}{I D M} \times 100
$$


Valores do IDM próximo de 1,0 indicam um reator de fluxo pistonado ideal (PFR), mas valores de IDM de 2,0 ou menores já caracterizam um reator de fluxo pistonado eficiente pela U. S. EPA. Valores próximo de 22 indicam reatores de mistura completa (CSTR) (METCALF e EDDY, 2016).

Ensaios de traçador em filtros lentos domiciliares de escoamento intermitente foram realizados no estudo de Elliott et al. (2008), que consistiu em fazer as duas primeiras alimentações com traçador (200 mg. $\mathrm{L}^{-1}$ de $\left.\mathrm{NaCl}\right)$ e outras duas alimentações com água deionizada, como ilustrado na Figura 9. Foi constatada uma rápida ascensão das medidas de condutividade seguida de um decaimento dos valores medidos logo após o volume de poros esperado. Os resultados evidenciaram um escoamento do tipo pistonado e um mínimo efeito de dispersão. O índice de dispersão de Morrill (IDM) calculado foi de 1,3, o que indica um escoamento próximo de um reator pistonado ideal.

Figura 9 - Resultado de três ensaios de traçador conduzidos em FLD construídos com material plástico

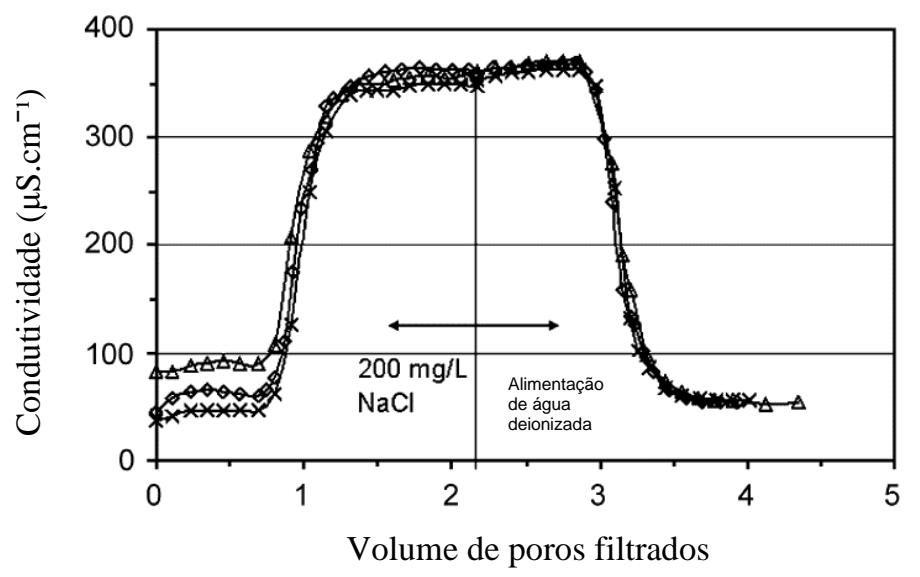

Fonte: Elliot et al. (2008)

Nos estudos de Andreoli e Sabogal-Paz (2020), Bradley et al. (2011), Elliott et al. (2008), Maciel e Sabogal-Paz (2018), Lynn et al. (2013), Sabogal-Paz et al. (2020) e Terin e Sabogal-Paz (2019) foi avaliado o comportamento hidráulico do I-FLD e classificado como reator de fluxo pistonado. O C-FLD também foi classificado como um reator de fluxo pistonado por Maciel e Sabogal-Paz (2018), Sabogal-Paz et al. (2020), Terin and Sabogal-Paz (2019), Young-Rojanschi e Madramootoo (2014b).

\subsection{Distribuição do tempo de residência com DFC}

A DTR de um reator por ser calculada a partir da velocidade de campo obtida previamente usando duas técnicas diferentes: o método do rastreamento da partícula 
(STROPKY et al., 2007), também conhecido como método de Lagrange ou pela equação de transporte de um escalar passivo (TALVY et al., 2011).

O transporte de um escalar passivo ou conservativo se dá quando a presença dessa propriedade não altera significativamente as propriedades físicas das demais equações de transporte, e.g. viscosidade e densidade. Por isso o seu transporte é dito como passivo, ou seja, não interfere no campo de velocidade, pressão e temperatura quando for o caso. Na ausência de reações químicas, o processo se restringe apenas a advecção-difusão de um campo escalar dentro do fluido em movimento (ANSYS, 2013).

Quanto a aplicação da técnica DTR em filtros, Qi et al. (2013) realizaram ensaios de traçador com CFD em um filtro de areia em escoamento ascendente com comprimento de 2,0 m e largura 1,0 m e vazão de 25,2 L.h ${ }^{-1}$ e determinou o tempo de detenção hidráulico - TDH para caracterizar o escoamento em filtros com duas configurações sendo: o primeiro sem camada suporte, sem lâmina de água sobre a camada filtrante e com tubo coletor em toda a extensão na porção superior da camada filtrante, e o segundo, com camada suporte, com lâmina de água sobre a camada filtrante e com tubo coletor em parte da porção superior da camada filtrante.

A simulação com CFD desenvolvida por Qi et al. (2013), indicou que as linhas de corrente de água apresentaram direção e sentido para cima, inclinadas, e a velocidade no meio do filtro foi a mais alta, cerca de cinco vezes maior que a mínima. A comparação dos resultados experimentais com a simulação CFD conclui que o filtro que tinha a camada suporte, a lâmina de água e tubo coletor parcial eliminou os caminhos preferenciais e as zonas de estagnação em comparação ao filtro que não tinham essas características. Nos filtros com caminhos de escoamento preferenciais foi comprovado que o TDH obtido com CFD foi menor que o TDH calculado.

A validação das simulações numéricas realizada com a dinâmica dos fluidos computacional normalmente é obtida com a comparação entre o ensaio de traçador simulado e o ensaio de traçador realizado no experimento físico, construído em escala plena (BRANNOCK, WANG, LESLIE, 2010; FURMAN E STEGOWSKI, 2011; GHARIBIAN, HAZRATI, ROSTAMIZADEH, 2020; KLUSENER et al., 2007; QI et al., 2013; ZHANG, PAN, REMPEL, 2007). 


\subsection{Verificação e validação dos modelos em DFC}

Furman e Stegowski (2011) sugeriram as seguintes etapas de verificação dos resultados de CFD:

1) escolha apropriada do modelo de CFD, do ponto de vista físico do problema;

2) obter o campo de velocidade e a simulação da DTR com CFD;

3) avaliar a convergência dos resultados da DTR experimental e DTR previstas com CFD; e

4) inspecionar os campos de velocidade analisando os perfis de velocidade.

Furman, Stegowski (2011) aplicaram a teoria da DTR para caracterizar o fluxo em um misturador de jato de laboratório, no qual foram testados três modelos de turbulência em escala plena. Os modelos de CFD previram padrões de fluxo um pouco diferente dos experimentos em escala plena e ficou evidente que a DTR experimental por ser usada para identificar previsões inaceitáveis. A comparação da DTR experimental com a simulada por CFD é essencial para garantir a acurácia aceitável.

Experimentos com traçadores radioativos em fase gasosa e líquida foram realizados em reatores de coluna com fluxo horizontal de bolhas em um processo de oxidação do etilbenzeno. Esses experimentos validaram as previsões de modelagem de CFD, que serviram de base para avaliar possíveis medidas para reduzir a diminuição de oxigênio determinadas pelas configurações do projeto e condições operacionais (KLUSENER et al., 2007).

Brannock, Wang, Leslie (2010) utilizaram os resultados experimentas da DTR para validar a hidrodinâmica do modelo de CFD de biorreatores de membrana, utilizado para o tratamento aeróbico de águas residuárias. O modelo de CFD considerou a aeração, a reologia do lodo e a geometria, esse modelo foi aplicado a dois biorreatores de membrana em escala real. As DTRs obtidas por simulação foram correspondentes as DTRs experimentais.

Gharibian, Hazrati, Rostamizadeh (2020) também validaram a simulação de CFD com a técnica experimental da DTR aplicada na eletrooxidação contínua do azul de metileno no filtro prensa, um reator eletroquímico. As simulações de CFD da hidrodinâmica e do transporte de massa no reator foram validadas pela técnica DTR e pela degradação eletroquímica experimental do azul de metileno.

O estudo de Campos, Smith e Graham (2006a e 2006b) desenvolveu um modelo de simulação determinístico do processo de slow sand filtration (SSF), utilizado no tratamento de água potável, incorporando os processos físico-químicos e biológicos em uma estrutura clássica de filtração. A calibração e a verificação do modelo foram realizadas com base nos dados operacionais de unidades SSF em escala piloto. 
$\mathrm{Na}$ tese foi explorada a validação das curvas DTRs por meio dos ensaios de traçador realizados nos modelos físico, tema pouco estudado em simulações de filtros lentos domiciliares. 


\section{MATERIAL E MÉTODOS}

A estrutura da metodologia consistiu em abordar tópicos específicos que detalham:

1) a construção dos filtros: os materiais que compõem as camadas filtrantes e as camadas suportes;

2) a caracterização física dos agregados utilizados: realizada por meio dos ensaios granulométrico, da determinação da massa específica, dos índices de vazios e do ensaio de permeabilidade;

3) a caracterização química: com ensaio de solubilidade em ácido;

4) preparo da água de alimentação dos filtros;

5) sistema de abastecimento e operação dos filtros;

6) caracterização do escoamento: ensaio de traçador nos filtros em escala plena e ensaio de traçador com DFC;

7) monitoramento dos parâmetros de qualidade da água;

8) validação das simulações numéricas;

9) análises estatísticas.

\subsection{Construção dos filtros lentos domiciliares}

Quatro filtros foram construídos, sendo dois de material acrílico cristal com diâmetro interno de $190 \mathrm{~mm}$ e dois de material Defofo MPVC com diâmetro interno de $250 \mathrm{~mm}$. Os tubos de acrílico foram adquiridos pelo Departamento de Engenharia Civil da Universidade Estadual de Maringá (UEM) e os tubos Defofo MPVC foram doados pela Amanco para a Escola de Engenharia de São Carlos (EESC/USP) para o desenvolvimento da pesquisa. O material Defofo MPVC é fabricado em policloreto de vinila modificado e destinado para aplicação em sistemas de adução e distribuição de água à temperatura ambiente, redes de abastecimento condominial e setor agrícola.

O C-FLD 1 era o filtro de escoamento contínuo, com diâmetro de $190 \mathrm{~mm}$ e em material acrílico, o C-FLD 2 era o filtro de escoamento contínuo, com diâmetro de $250 \mathrm{~mm}$ e construído em Defofo MPVC. O I-FLD 1 era operado em escoamento intermitente, com diâmetro de 190 mm e com corpo em acrílico e, finalmente, o I-FLD 2 era operado em escoamento intermitente, com diâmetro de 250 mm e construído em Defofo MPVC.

Os materiais utilizados na construção dos filtros como os tubos de saída e as conexões com DN $25 \mathrm{~mm}$ foram facilmente encontrados em lojas de materiais de construção e de materiais hidráulicos. Os filtros de acrílico foram montados no laboratório de hidráulica na 
UEM e os filtros Defofo MPVC foram montados na EESC/USP, todos os quatro foram operados na UEM.

Os filtros contínuos tinham altura total de $0,90 \mathrm{~m}$ e os filtros intermitentes de $0,95 \mathrm{~m}$ desconsiderando a altura do recipiente de 20 litros que era utilizado como reservatório superior individual. Os filtros contínuos e intermitentes eram compostos por quatro camadas, uma camada filtrante composta por areia fina com espessura de $0,50 \mathrm{~m}$, uma camada de areia grossa de 0,05 m, uma camada de pedregulho miúdo de 0,05 $\mathrm{m}$ e uma camada de pedregulho graúdo de $0,075 \mathrm{~m}$. O tubo de coleta da água tratada era localizado a 2,0 cm do fundo, no centro do tampão (CAP).

As entradas de água nos quatro filtros eram controladas por boias para regular o nível de água máximo. Nos filtros contínuos, além da boia instalada no filtro, a vazão foi regulada na saída por um registro do tipo agulha. Nos filtros intermitentes apenas a boia instalada no fundo do recipiente de 20 L era responsável por regular a vazão, havia uma torneira de esfera na saída desse filtro mantida constantemente em posição aberta e sua vazão variava conforme a altura da lâmina de água. Nos FLDs foram instalados uma mangueira de silicone antes das torneiras e das válvulas de agulha para que a pressão fosse igual a pressão atmosférica e, desta forma, impedir o efeito sifão. Nas Figuras 10 e 11 ilustram-se os filtros contínuos e intermitentes com as respectivas espessuras das camadas e distâncias para instalação das peças e tubos para construção dos filtros.

Figura 10 - Desenho do filtro lento domiciliar em escoamento contínuo

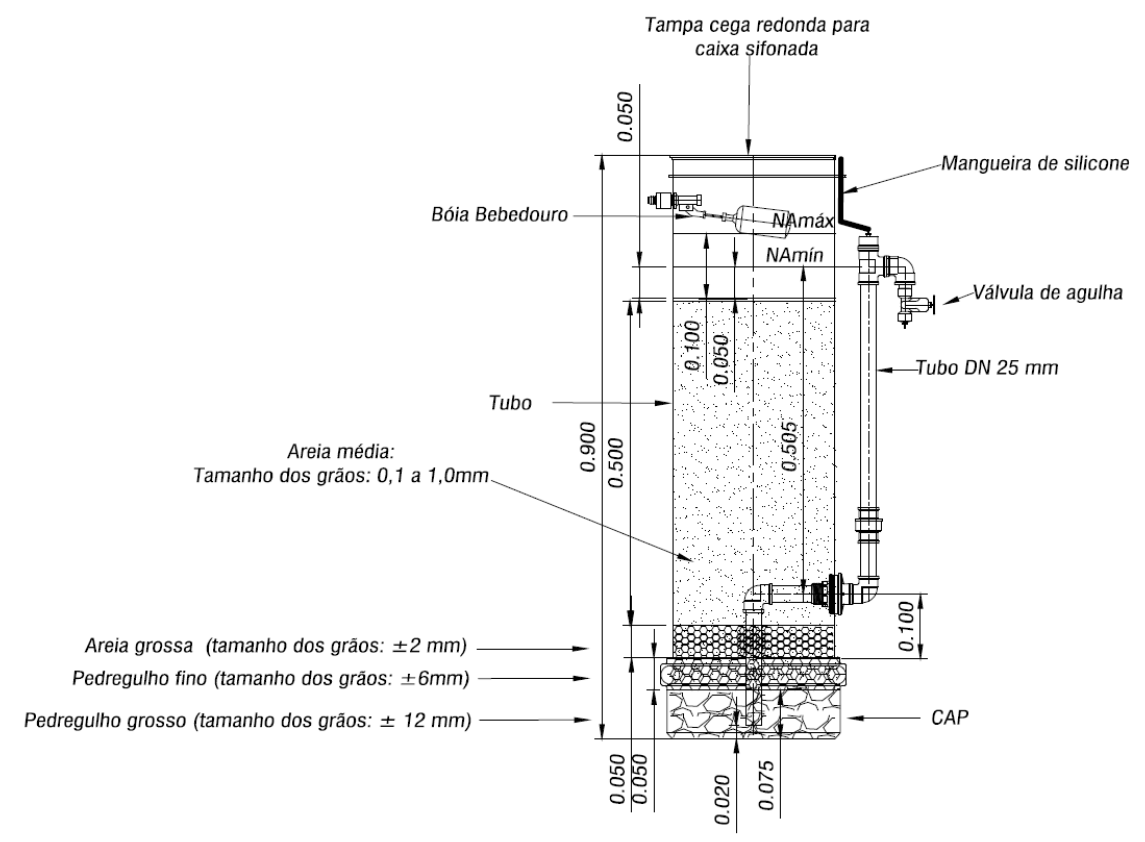

Nota: Unidades em metros

Fonte: Desenhos cedidos pela prof ${ }^{a}$ Lyda P. Sabogal Paz 
Figura 11 - Desenho do filtro lento domiciliar em escoamento intermitente

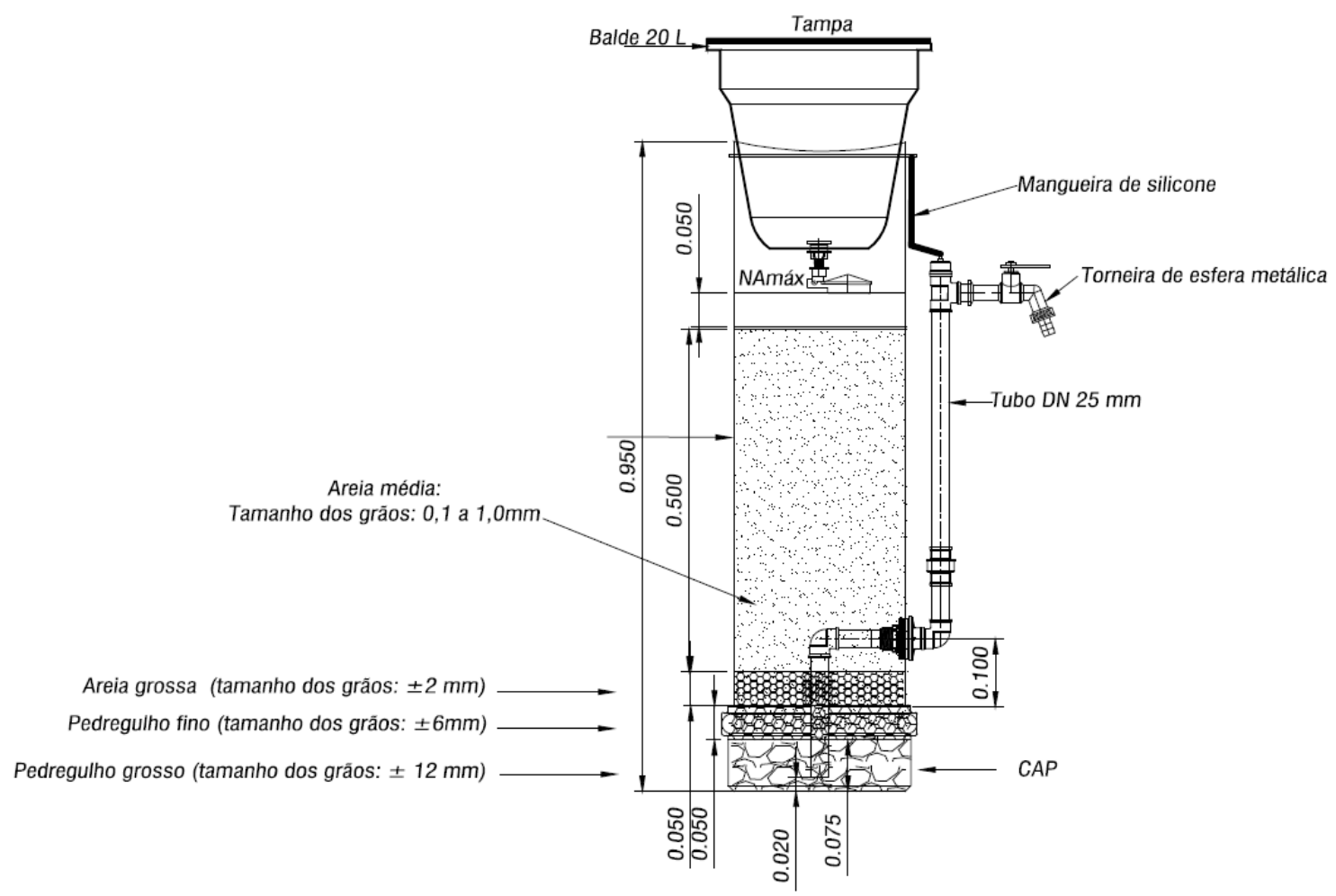

Nota: Unidades em metros

Fonte: Desenhos cedidos pela prof ${ }^{\mathrm{a}}$ Lyda P. Sabogal Paz (modificado)

Os piezômetros foram construídos com a instalação de espigões ao longo do corpo do filtro conectados às mangueiras de silicone e fixadas no topo de cada filtro. Os piezômetros foram instalados nas mesmas alturas nos filtros operando em escoamento contínuo e intermitente.

A instalação dos piezômetros nos filtros foi definida para duas vistas laterais, denominadas lado A e lado B. No filtro de material Defofo em um dos lados, denominado o lado A, foram instalados piezômetros para leitura da perda de carga com espaçamento horizontal e vertical. No lado oposto, denominado lado B, foram instalados piezômetros com espaçamento apenas na vertical para coleta de amostras. No filtro de material acrílico foram instalados apenas os piezômetros com espaçamento vertical, conforme lado B, devido a fragilidade do material, mas que foi utilizado tanto para leitura da perda de carga quanto para coleta de amostras. Nas Figuras 12 e 13 ilustra-se os locais de instalação dos piezômetros no filtro contínuo e intermitente, respectivamente, indicado por setas. 
Figura 12 - Local de instalação dos piezômetros no filtro em escoamento contínuo

Local dos piezômetros

- Lado A (filtro contínuo)

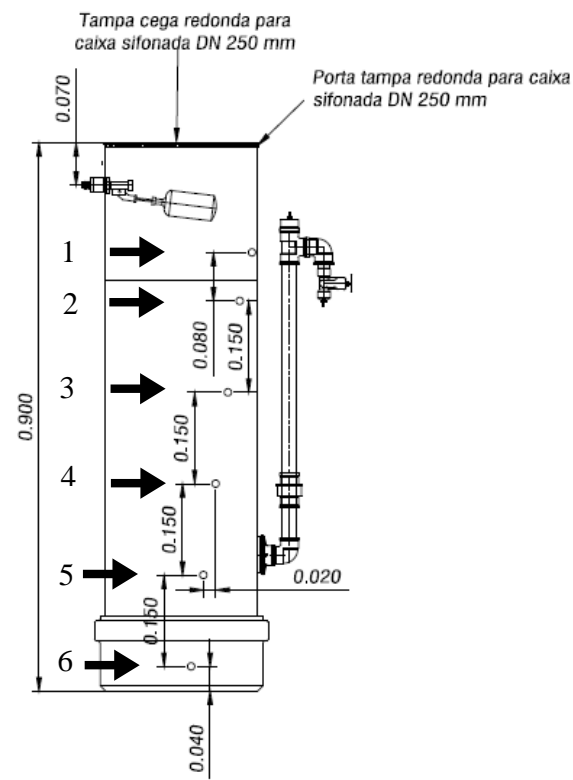

Local dos pontos de tomada Lado B (filtro contínuo)

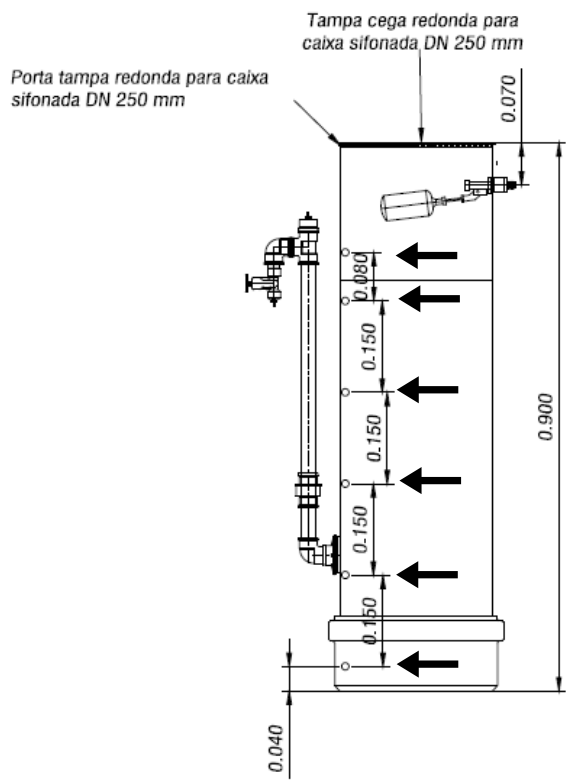

Nota: Unidades em metros

Fonte: Desenhos cedidos pela prof ${ }^{a}$ Lyda P. Sabogal Paz (modificado)

Figura 13 - Local de instalação dos piezômetros no filtro em escoamento intermitente

Local dos piezômetros Lado A ( filtro intermitente)

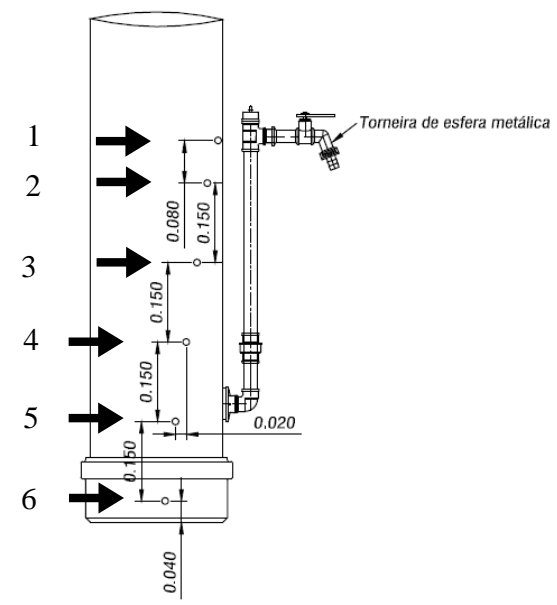

Local dos pontos de tomada Lado B (filtro intermitente)

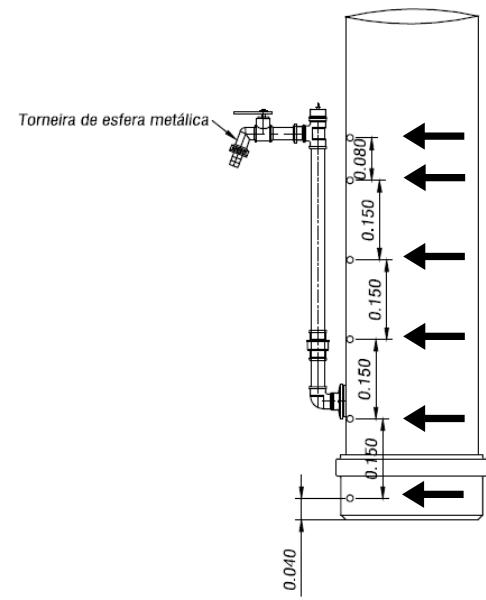

Nota: Unidades em metros

Fonte: Desenhos cedidos pela prof ${ }^{a}$ Lyda P. Sabogal Paz (modificado) 
Os piezômetros enumerados como $\mathrm{n}^{\mathrm{o}} 1$ e $\mathrm{n}^{\mathrm{o}} 2$ foram instalados na camada de água e no topo da camada de areia, respectivamente, com o objetivo de coletar amostras de água para analisar a concentração de oxigênio dissolvido e, assim, verificar o efeito do crescimento da camada biológica devido ao consumo de oxigênio dissolvido. O terceiro, quarto e quinto piezômetros foram instalados ao longo da camada de areia fina e o sexto piezômetro na camada de pedregulho graúdo. O monitoramento da perda de carga foi realizado com leitura direta em escala estabelecida em papel milimetrado, que foi colocado no próprio corpo dos filtros para os C-FLD2 e I-FLD2 e em um painel no caso dos filtros de acrílico, os C-FLD1 e I-FLD1.

Após a construção dos filtros e a espera do período de secagem das junções soldáveis, foi realizado o teste de estanqueidade para verificar e corrigir possíveis vazamentos antes de fazer o preenchimento das camadas dos leitos dos filtros. Após essa etapa, os filtros foram preenchidos com água e os respectivos materiais das camadas suporte e filtrante foram despejados de forma cuidadosa para que todos os vazios fossem preenchidos por água, ou seja, foram colocados o pedregulho graúdo, o pedregulho miúdo, a areia grossa e a areia fina nessa sequência e com as respectivas as espessuras de cada camada. Foi utilizada uma trena para auxiliar na medição das espessuras.

Os materiais utilizados para a construção dos filtros contínuos e intermitente são apresentados nas Tabelas 2 e 3 , respectivamente.

Tabela 2 - Materiais utilizados para construção dos filtros em escoamento contínuo

\begin{tabular}{|c|c|c|}
\hline Item & Quantidade & Unidade \\
\hline Tubo de acrílico cristal DN 200 mm (90 cm altura) & 1 & Unidade \\
\hline Tubo de Defofo MPVC DN $250 \mathrm{~mm}(90 \mathrm{~cm}$ altura $)$ & 1 & Unidade \\
\hline CAP de DN $200 \mathrm{~mm}$ & 1 & Unidade \\
\hline CAP de DN $250 \mathrm{~mm}$ & 1 & Unidade \\
\hline Espigões de latão DN 1/4" & 14 & Unidade \\
\hline Tampa da caixa sifonada DN $250 \mathrm{~mm}$ & 2 & Unidade \\
\hline Tubo de DN $25 \mathrm{~mm}$ & 180 & $\mathrm{~cm}$ \\
\hline Flange rosqueável com redução 1 '’x 3/4", & 2 & Unidade \\
\hline Joelho $90^{\circ}$ DN $25 \mathrm{~mm}$ & 2 & Unidade \\
\hline Joelho $90^{\circ}$ redução saída rosqueável de 3/4" $\times 1 / 2{ }^{\prime}$ ' & 2 & Unidade \\
\hline União soldável DN 25 mm & 2 & Unidade \\
\hline Tê soldável com saída com redução lateral rosqueável 1' 'x 3/4"' & 2 & Unidade \\
\hline CAP de DN $25 \mathrm{~mm}$ & 2 & Unidade \\
\hline Niple de DN 25 & 2 & Unidade \\
\hline Niple de DN 3/4,' & 2 & Unidade \\
\hline Joelho de $90^{\circ}$ com redução saída rosqueável de 1 " $\mathrm{x} 3 / 4$ " & 2 & Unidade \\
\hline Espigão de Latão de DN 1/8', & 2 & Unidade \\
\hline
\end{tabular}




\begin{tabular}{lll}
\hline Válvula de $1 / 2 "$ ' tipo agulha & 2 & Unidade \\
\hline Torneira bóia & 2 & Unidade \\
\hline
\end{tabular}

Fonte: Autor

Tabela 3 - Materiais utilizados para construção dos filtros em escoamento intermitente

\begin{tabular}{|c|c|c|}
\hline Item & Quantidade & Unidade \\
\hline Tubo de acrílico cristal DN $200 \mathrm{~mm}$ (95 cm altura) & 1 & Unidade \\
\hline Tubo de Defofo MPVC DN $250 \mathrm{~mm}$ (95 cm altura) & 1 & Unidade \\
\hline CAP de DN $200 \mathrm{~mm}$ & 1 & Unidade \\
\hline CAP de DN $250 \mathrm{~mm}$ & 1 & Unidade \\
\hline Espigões de latão DN 1/4” & 14 & Unidade \\
\hline Tubo de DN $25 \mathrm{~mm}$ & 180 & $\mathrm{~cm}$ \\
\hline Flange rosqueável com redução 1 ' 'x 3/4" & 2 & Unidade \\
\hline Joelho $90^{\circ} \mathrm{DN} 25 \mathrm{~mm}$ & 2 & Unidade \\
\hline União soldável DN 25 mm & 2 & Unidade \\
\hline Tê soldável com saída com redução lateral rosqueável 1 ' $x$ 3/4" & 2 & Unidade \\
\hline CAP de DN $25 \mathrm{~mm}$ & 2 & Unidade \\
\hline Niple de DN 25 & 2 & Unidade \\
\hline Joelho de $90^{\circ}$ com redução saída rosqueável de 1 ' $\mathrm{x} 3 / 4$ ' & 2 & Unidade \\
\hline Registro de esfera metálica 1" & 2 & Unidade \\
\hline Bóia de filtro & 2 & Unidade \\
\hline Balde de plástico de 20 litros com tampa & 2 & Unidade \\
\hline
\end{tabular}

Fonte: Autor

Na Figura 14 apresentam-se os filtros de acrílico construídos no laboratório de hidráulica da UEM. 
Figura 14 - Filtros construídos de acrílico em escoamento intermitente e contínuo

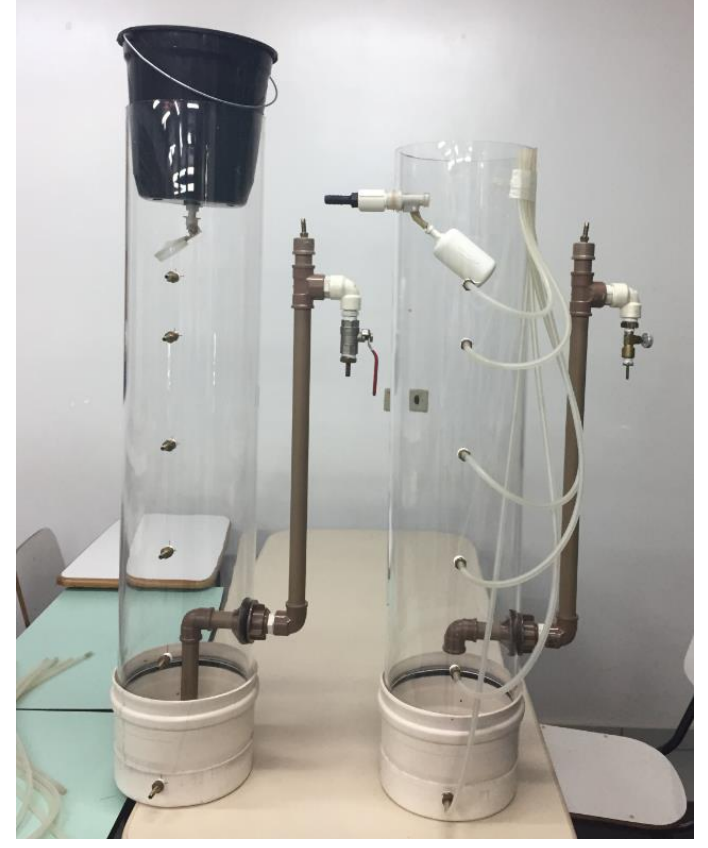

Fonte: Autor

Na Figura 15 apresentam-se os quatro FLDs construídos. Os filtros contínuos são os da esquerda e os intermitentes são os da direita na imagem. Os filtros foram nomeados da seguinte forma: C-FLD 1 - filtro lento domiciliar contínuo de acrílico (área da seção transversal = 0,028 $\mathrm{m}^{2}$ ), C-FLD 2 - filtro lento domiciliar contínuo de Defofo (área da seção transversal = 0,049 $\mathrm{m}^{2}$ ), I-FLD 1 - filtro lento domiciliar intermitente de acrílico (área da seção transversal = 0,028 $\mathrm{m}^{2}$ ) e I-FLD 2 - filtro lento domiciliar intermitente de Defofo (área da seção transversal = 0,049 $\mathrm{m}^{2}$ ). Os filtros em acrílico foram cobertos com material de EVA (Acetato de Vinil-etileno) de cor azul para impedir a incidência de radiação solar, o que poderia provocar o crescimento de algas dentro do filtro. 
Figura 15 - Disposição dos filtros lentos domiciliares no laboratório de hidráulica da UEM

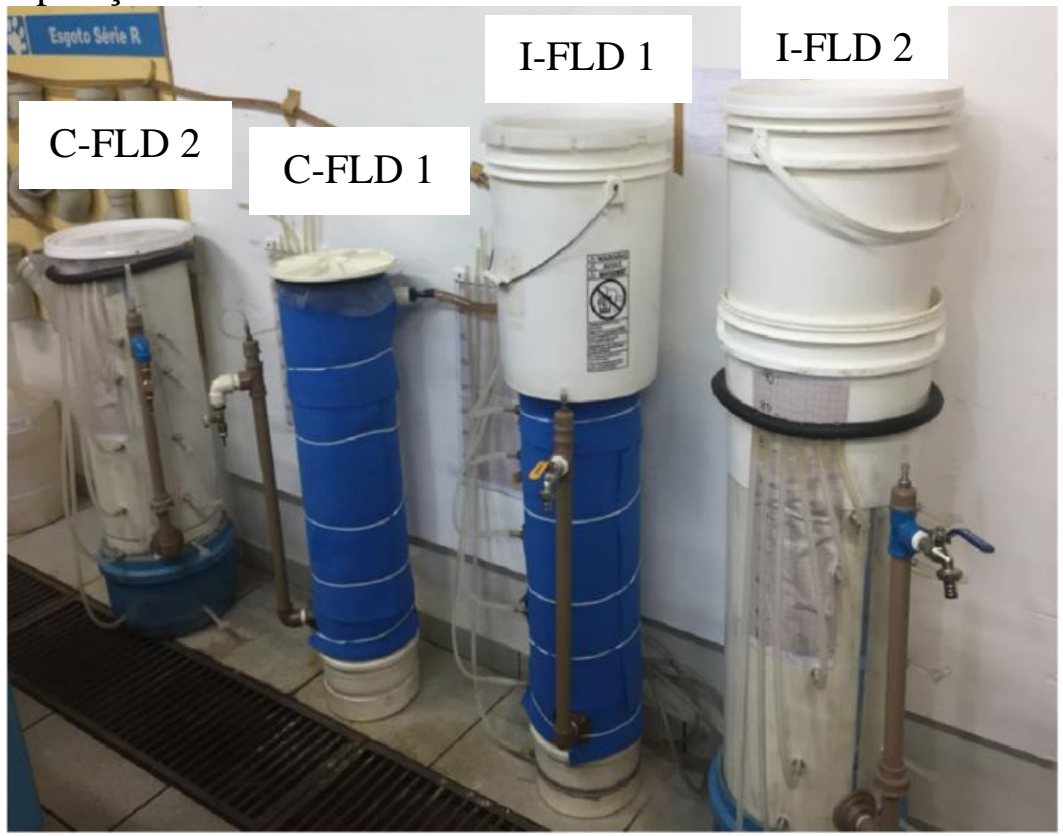

Fonte: Autor

Os FLDs foram mantidos no Laboratório de Hidráulica da UEM, local fechado, coberto e mantidos na temperatura ambiente, o laboratório era equipado com aparelho de ar condicionado que era utilizado duas vezes na semana (terça-feira e quinta-feira) à temperatura de $21 \pm 5{ }^{\circ} \mathrm{C}$.

A taxa de filtração média e o desvio padrão dos filtros foram de $1,69 \pm 0,01 \mathrm{~m}^{3} \cdot \mathrm{m}^{2} \cdot \mathrm{d}^{-1}$

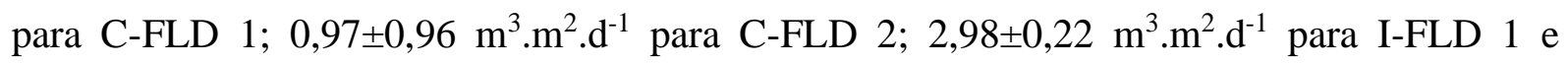
$3,29 \pm 0,65 \mathrm{~m}^{3} \cdot \mathrm{m}^{2} \cdot \mathrm{d}^{-1}$ para I-FLD 2, os filtros tiveram uma produção diária de 48 litros cada.

\subsection{Caracterização dos materiais que compõem as camadas do filtro}

\subsubsection{Preparo dos agregados}

Os FLDs eram compostos por quatro camadas, uma camada filtrante constituída de areia fina e outras três camadas suporte constituídas de areia grossa, pedregulho miúdo e pedregulho graúdo. Os materiais foram comprados em um estabelecimento comercial na cidade de São Carlos - SP e transportados de São Carlos/SP para Maringá/PR, onde foi realizado o preparo desses materiais para a posterior montagem dos filtros.

O preparo dos materiais consistiu em realizar três procedimentos: lavagem, secagem e peneiramento. Os agregados foram lavados manualmente em pequenas porções em um balde 
de 20 L utilizando água potável. Os materiais foram lavados até que a água estivesse visualmente límpida e transparente.

Após esse procedimento, os materiais foram colocados sobre uma lona plástica e expostos ao Sol para a secagem, até atingirem a umidade higroscópica. Depois de secos, os materiais foram peneirados e armazenados em sacos plásticos para a futura montagem dos filtros. As peneiras utilizadas foram adquiridas em loja de produtos agropecuários e que podem ser facilmente encontradas em qualquer localidade, inclusive em comunidades isoladas. Foram utilizadas peneiras de café, de feijão e de arroz e tela de galinheiro. O preparo dos materiais foi realizado no laboratório de materiais de construção e mecânica dos solos, no Bloco P02 da UEM.

Na Figura 16 são apresentados os procedimentos realizados no preparo dos agregados antes da montagem dos filtros, indicando a visualização da primeira água de lavagem e da última água de lavagem, já com o aspecto límpido e translúcido, a secagem com exposição ao Sol e o peneiramento para separação da granulometria recomendada.

Na Tabela 4 mostra-se o conjunto de peneiras utilizado para a separação de cada tipo de agregado, areia fina, areia grossa, pedregulho miúdo e pedregulho graúdo.

Tabela 4 - Conjunto de peneiras utilizado na separação dos agregados

\begin{tabular}{|c|c|c|c|c|}
\hline $\begin{array}{l}\text { Tipo de } \\
\text { camada }\end{array}$ & $\begin{array}{l}\text { Tipo de } \\
\text { agregado }\end{array}$ & $\begin{array}{l}\text { Tipo de } \\
\text { peneira }\end{array}$ & $\begin{array}{l}\text { Tamanho da } \\
\text { abertura (mm) }\end{array}$ & Material de descarte \\
\hline $\begin{array}{l}\text { Camada } \\
\text { filtrante }\end{array}$ & Areia fina & Fubá & 1,18 & $\begin{array}{l}\text { Agregados de tamanho } \\
\text { superior à malha da peneira }\end{array}$ \\
\hline \multirow{6}{*}{$\begin{array}{l}\text { Camada } \\
\text { suporte }\end{array}$} & \multirow[t]{2}{*}{ Areia grossa } & Arroz & 2,08 & $\begin{array}{l}\text { Agregados de tamanho } \\
\text { superior à malha da peneira }\end{array}$ \\
\hline & & Fubá & 1,18 & $\begin{array}{l}\text { Agregados de tamanho } \\
\text { inferior à malha da peneira }\end{array}$ \\
\hline & \multirow[t]{2}{*}{$\begin{array}{l}\text { Pedregulho } \\
\text { miúdo }\end{array}$} & Café & 5,50 & $\begin{array}{l}\text { Agregados de tamanho } \\
\text { superior à malha da peneira }\end{array}$ \\
\hline & & Feijão & 3,70 & $\begin{array}{l}\text { Agregados de tamanho } \\
\text { inferior à malha da peneira }\end{array}$ \\
\hline & \multirow[t]{2}{*}{$\begin{array}{l}\text { Pedregulho } \\
\text { Graúdo }\end{array}$} & $\begin{array}{l}\text { Tela de } \\
\text { galinheiro }\end{array}$ & 50,0 & $\begin{array}{l}\text { Agregados de tamanho } \\
\text { superior à malha da peneira }\end{array}$ \\
\hline & & Café & 5,50 & $\begin{array}{l}\text { Agregados de tamanho } \\
\text { inferior à malha da peneira }\end{array}$ \\
\hline
\end{tabular}

Fonte: Autor 
Figura 16 - Preparo dos materiais que compõem os filtros

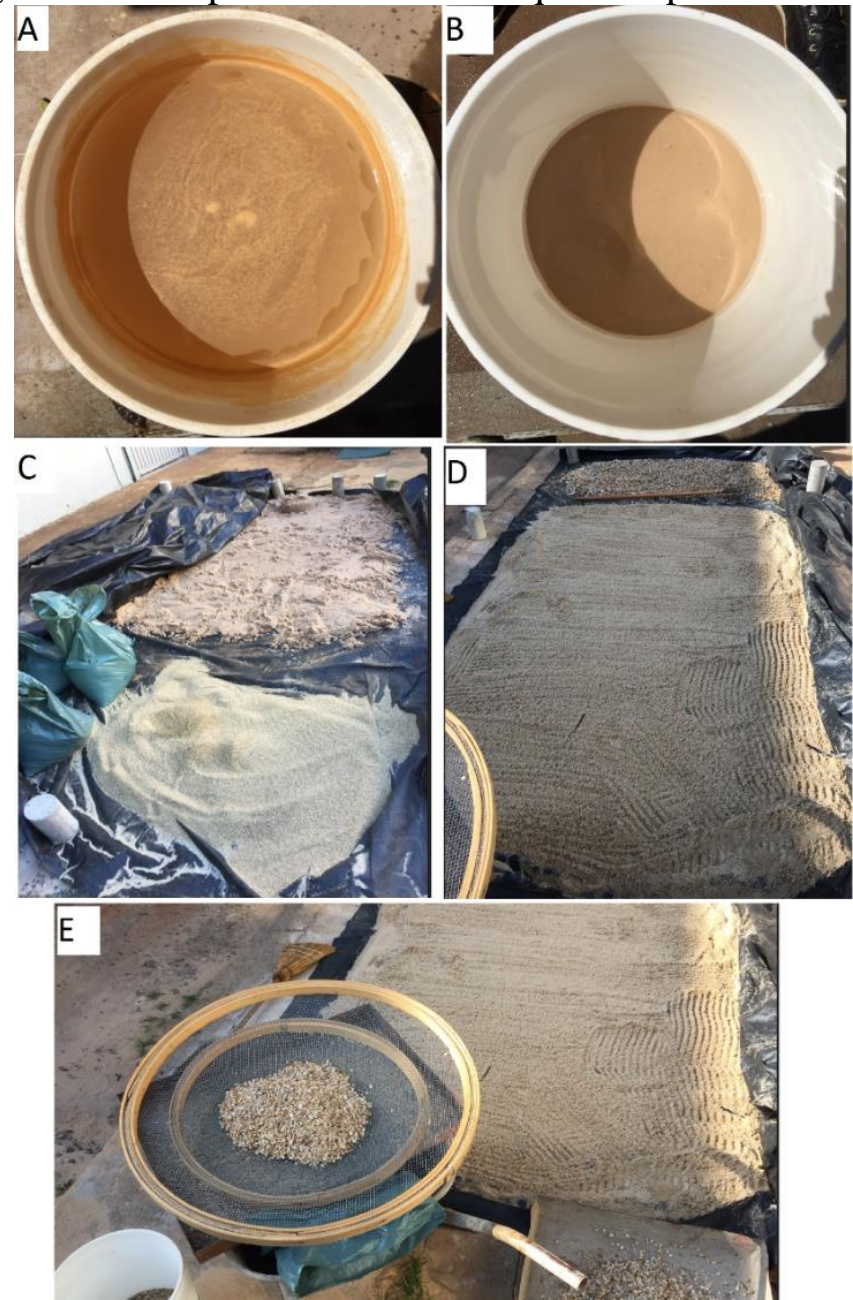

Legenda: A- Aspecto da primeira água de lavagem da areia fina; B - Aspecto límpido e transparente da água da última lavagem; C e D - Secagem com exposição ao Sol; E - Peneiramento do pedregulho miúdo com peneira de café e de feijão.

Fonte: Autor

Na Figura 17 apresentam-se os agregados após o procedimento de preparo e prontos para utilização na montagem dos filtros lentos domiciliares.

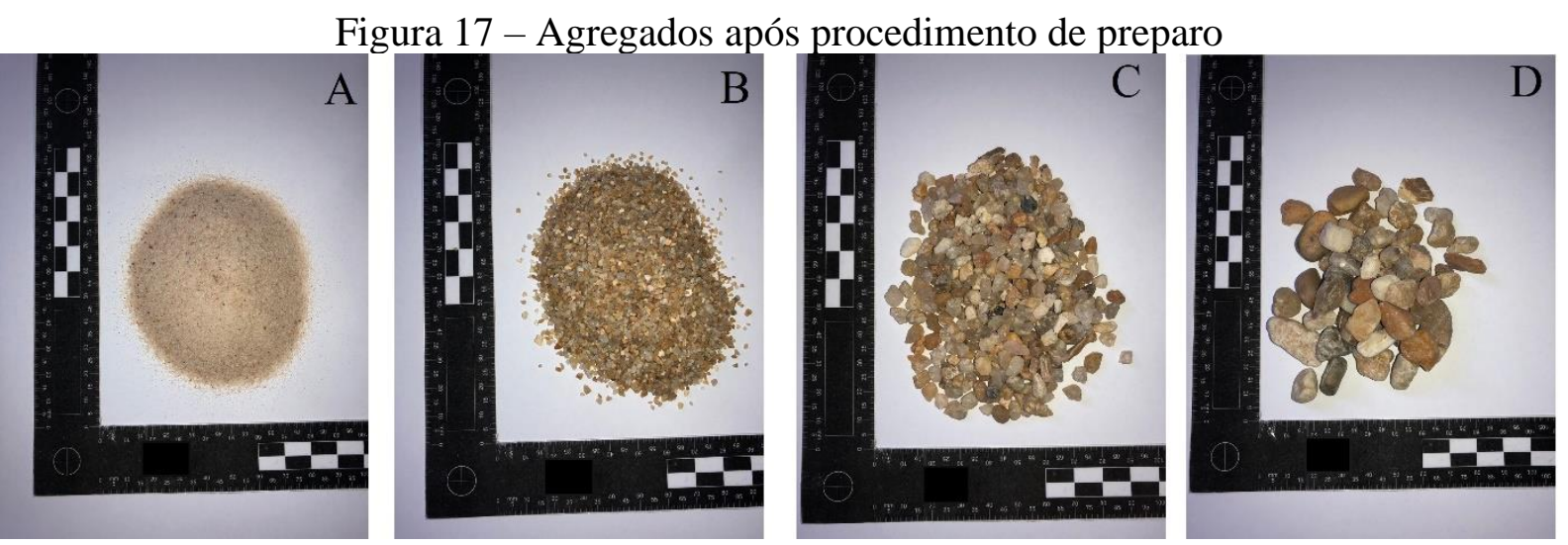

Legenda: A- Areia fina; B - Areia grossa; C - Pedregulho miúdo; D - Pedregulho graúdo.

Fonte: Autor 


\subsubsection{Caracterização física dos agregados}

Os ensaios de análise granulométrica, determinação da massa específica, determinação do índice de vazios e ensaio de permeabilidade realizados com os agregados que compõem os filtros lentos domiciliares são apresentados a seguir.

\subsubsection{Ensaio granulométrico}

A areia fina utilizada como material filtrante foi caracterizada de acordo com a ABNT NBR 11799/2016 "Material filtrante - Areia, antracito e pedregulho - especificação". A areia foi seca em estufa a $105 \pm 3{ }^{\circ} \mathrm{C}$ por 3 horas, os ensaios foram realizados em duplicata com porções de $500 \mathrm{~g}$, o conjunto de peneiras foi colocado em agitador mecânico por 15 min. a uma frequência de $5 \mathrm{~Hz}$, a massa de material retirada de cada peneira foi pesada em uma balança para elaboração da curva granulométrica, conforme recomendado pela ABNT NBR $11799 / 2016$.

A ABNT NBR 11799/2016 sugere para um ensaio inicial de areia, que sejam utilizadas peneiras com aberturas de 1,$00 ; 0,85 ; 0,71 ; 0,50$ e $0,425 \mathrm{~mm}$. O conjunto de peneiras utilizadas e as respectivas malhas são apresentados na Tabela 5 .

Tabela 5 - Peneiras e aberturas de malha utilizadas no ensaio granulométrico da areia fina

\begin{tabular}{cc}
\hline \#ASTM & Abertura de malha $(\mathrm{mm})$ \\
\hline 18 & 1 \\
\hline 20 & 0,85 \\
\hline 25 & 0,71 \\
\hline 30 & 0,6 \\
\hline 35 & 0,5 \\
\hline 40 & 0,425 \\
\hline 50 & 0,3 \\
\hline 60 & 0,25 \\
\hline 80 & 0,18 \\
\hline 200 & 0,15 \\
\hline
\end{tabular}

Fonte: Autor 
A partir da curva granulométrica, foram determinados os diâmetros $\mathrm{D}_{10}$ e $\mathrm{D}_{60}$ que correspondem a $10 \%$ e $60 \%$ da porcentagem acumulada de material passante, respectivamente. $\mathrm{O}$ tamanho efetivo é igual ao $\mathrm{D}_{10}$. O coeficiente de uniformidade $(\mathrm{CU})$ foi calculado pela Equação 6.

$$
C U=\frac{D_{60}}{D_{10}}
$$

Sendo:

CU: coeficiente de uniformidade;

$\mathrm{D}_{10}$ : diâmetro correspondente à $10 \%$ da porcentagem acumulada que passa nas peneiras [mm]; $\mathrm{D}_{60}$ : diâmetro correspondente à $60 \%$ da porcentagem acumulada que passa nas peneiras [mm].

Segundo a ABNT NBR 6502/1995 "Rochas e solos" o grau de uniformidade das partículas é proporcional à inclinação da curva granulométrica, logo, quanto maior é a inclinação mais bem graduado é o material, assim, o coeficiente de uniformidade menor que 5 $(\mathrm{CU}<5)$ indica material relativamente uniforme, maior que 5 e menor ou igual a $15(5<\mathrm{CU} \leq$ 15) indica uniformidade média e $\mathrm{CU}$ maior que 15 ( $\mathrm{CU}>15)$ indica desuniformidade.

Ressalta-se que o termo coeficiente de uniformidade (CU) é definido por Libânio (2010) como coeficiente de desuniformidade $\left(\mathrm{Cd}=D_{60} / D_{10}\right)$ pois é um adimensional que indica o quão desuniforme é o meio filtrante.

Os ensaios granulométricos também foram realizados para a areia grossa, pedregulho miúdo e pedregulho graúdo conforme a ABNT NM 248/2001 “Agregados - Determinação da composição granulométrica". No ensaio granulométrico da areia grossa foi utilizada uma série de peneiras com as aberturas de malha de 6,30; 4,76;2,38; 1,18;0,60;0,30 e 0,15 mm.

Nos ensaios granulométricos do pedregulho miúdo e do pedregulho graúdo foi utilizada uma série de peneiras com as aberturas de malha de 32,$0 ; 25,0 ; 19,0 ; 12,5 ; 9,5 ; 6,3 ; 4,76 ; 2,38$; 1,$18 ; 0,60 ; 0,30$ e $0,15 \mathrm{~mm}$. As amostras foram previamente secas em estufa e depois esfriadas à temperatura ambiente. A massa mínima da amostra utilizada para o ensaio depende da dimensão máxima nominal do agregado. Assim, foram realizados ensaios em duplicata e utilizados amostras de $500 \mathrm{~g}$ de areia grossa, $500 \mathrm{~g}$ de pedregulho miúdo e $2,5 \mathrm{~kg}$ pedregulho graúdo.

Na Figura 18 ilustra-se o equipamento de agitação mecânica utilizado para realização dos ensaios granulométricos para a areia fina, areia grossa, pedregulho miúdo e pedregulho graúdo. 
Figura 18 - Equipamento de agitação mecânica

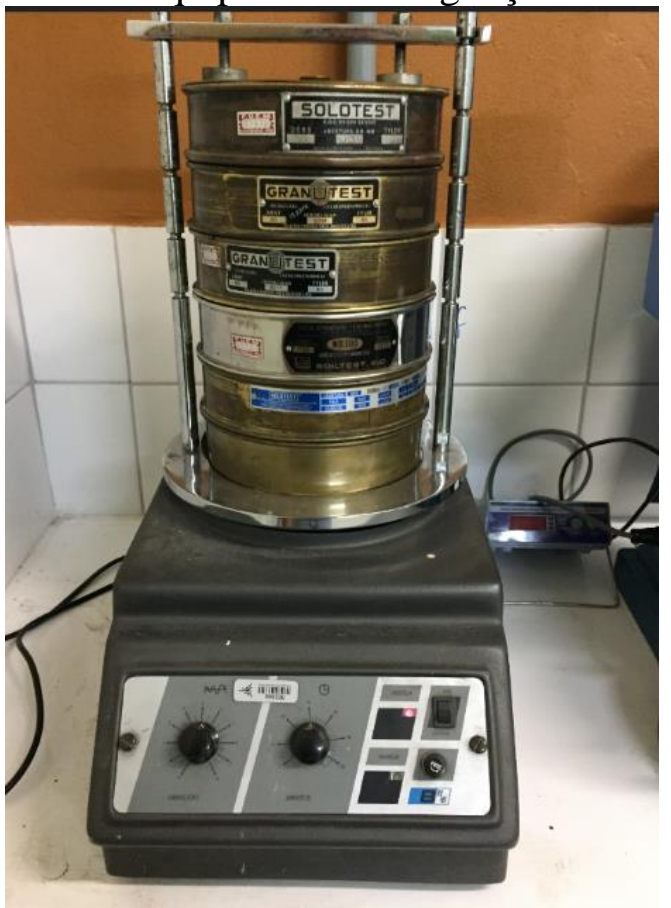

Fonte: Autor

\subsubsection{Determinação da massa específica}

Os ensaios para determinação da massa específica foram realizados conforme a ABNT NBR 6458/2016 “Grãos de pedregulho retidos na peneira de abertura 4,8 mm - Determinação da massa específica, da massa específica aparente e da absorção de água”. Os ensaios foram realizados em duplicata para as areias fina e grossa e para os pedregulhos miúdo e graúdo. $\mathrm{Na}$ Figura 19 apresenta-se a realização do ensaio.

As areias fina e grossa são materiais que passam na peneira de abertura $4,8 \mathrm{~mm}$, portanto foi utilizado o Anexo B da ABNT NBR 6458/2016, que consiste em utilizar o picnômetro para determinação da massa específica. Como o pedregulho miúdo tem uma parcela de material passante na peneira de abertura $4,8 \mathrm{~mm}$, foram aplicados os métodos descritos na ABNT NBR 6458/2016 para material passante e não passante na peneira $4,8 \mathrm{~mm}$.

Em cada um dos ensaios realizados com areia fina, areia grossa e a parcela passante na peneira de abertura 4,8 $\mathrm{mm}$ do pedregulho miúdo foram utilizados $60 \mathrm{~g}$ da amostra para o cálculo da massa específica empregada a Equação 7.

$$
\rho_{s}=\frac{M_{1} \times 100 /(100+w)}{\left[M_{1} \times 100 /(100+w)\right]+M_{3}-M_{2}} \times \rho_{w(T)}
$$


Sendo:

$\rho_{\mathrm{s}}$ : massa específica dos grãos em $\left[\mathrm{g} \cdot \mathrm{cm}^{-3}\right]$;

$\mathrm{M}_{1}$ : massa da amostra úmida $[\mathrm{g}]$;

M2: massa do picnômetro + amostra + água, à temperatura $\mathrm{T}$ de ensaio [g];

M3: massa do picnômetro preenchido com água até a marca de referência, à temperatura $\mathrm{T}$ de ensaio $[\mathrm{g}]$;

w: umidade inicial da amostra [\%];

$\rho_{\mathrm{w}(\mathrm{T})}$ : massa específica da água, à temperatura $\mathrm{T}$ de ensaio $\left[\mathrm{g} \cdot \mathrm{cm}^{-3}\right]$.

No ensaio do pedregulho graúdo foram utilizados $600 \mathrm{~g}$ de amostra e no ensaio com a parcela retida na peneira de abertura $4,8 \mathrm{~mm}$ do pedregulho miúdo foram utilizados $200 \mathrm{~g}$ de amostras. A massa específica foi determinada pela Equação 8.

$$
\rho_{s}=\frac{M_{S}}{M_{S}-M_{i}} \times \rho_{w}
$$

Sendo:

$\rho_{\mathrm{s}}$ : massa específica dos grãos $\left[\mathrm{g} \cdot \mathrm{cm}^{-3}\right]$;

Ms: massa da amostra seca [g];

$\mathrm{M}_{\mathrm{i}}$ : massa da amostra totalmente imersa em água destilada [g];

$\rho_{\mathrm{w}}$ : massa específica da água, à temperatura $\mathrm{T}$ de ensaio $\left[\mathrm{g} \cdot \mathrm{cm}^{-3}\right]$.

A massa específica da amostra contendo as frações passada e retida na peneira de 4,8 mm foi determinada pela Equação 9.

$$
\rho_{s}=\frac{\rho_{s p} \times \rho_{s r}}{\rho_{s p} \times M_{2}+\rho_{s r} \times M_{1}} \times 100
$$

Sendo:

$\rho_{\mathrm{s}}$ : massa específica dos grãos contendo frações passada e retida na peneira de $4,8 \mathrm{~mm}$ $\left[\mathrm{g} . \mathrm{cm}^{-3}\right]$;

$\rho_{\mathrm{sp}}$ : massa específica dos grãos que passam pela peneira de $4,8 \mathrm{~mm}\left[\mathrm{~g} \cdot \mathrm{cm}^{-3}\right]$;

$\rho_{\text {sr: }}$ massa específica dos grãos retidas na peneira de $4,8 \mathrm{~mm}\left[\mathrm{~g} \cdot \mathrm{cm}^{-3}\right]$;

$\mathrm{M}_{1}$ : porcentagem em massa, da fração da amostra que passa na peneira de 4,8 mm [\%];

$\mathrm{M}_{2}$ : porcentagem em massa, da fração da amostra retida na peneira de 4,8 mm [\%]. 
Figura 19 - Determinação da massa específica
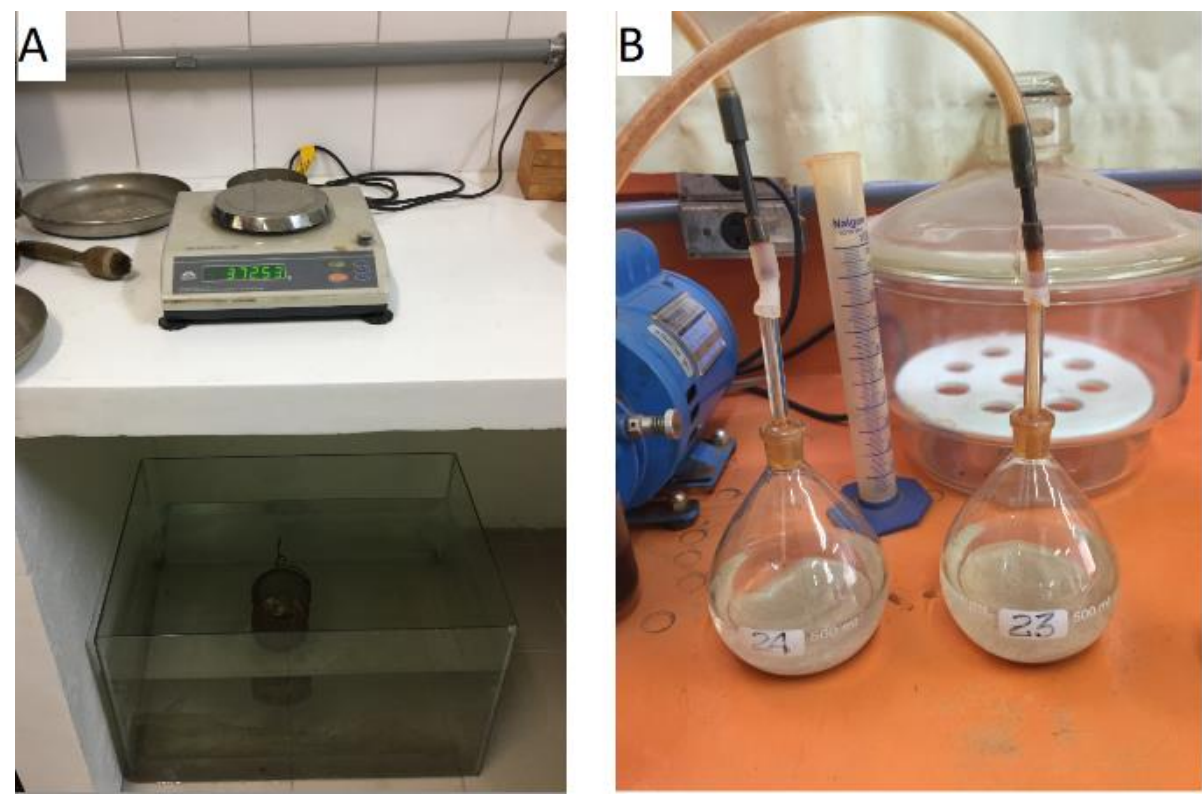

Legenda: A - Massa da amostra totalmente imersa em água destilada; B - Picnômetro com amostra e água.

Fonte: Autor

O teor de umidade dos materiais foi determinado com ensaios realizados em triplicata e o resultado foi calculado pela Equação 10.

$$
w=\frac{M_{1}-M_{2}}{M_{2}-M_{3}} \times 100
$$

Sendo:

w: umidade da amostra [\%];

$\mathrm{M}_{1}$ : massa da amostra úmida mais cápsula $[\mathrm{g}]$;

$\mathrm{M}_{2}$ : massa da amostra seca mais cápsula, secagem em estufa 105 a $110^{\circ} \mathrm{C}$ por 24 horas [g];

$\mathrm{M}_{3}$ : massa da cápsula [g].

\subsubsection{Determinação do índice de vazios}

O índice de vazios foi determinado conforme a ABNT NBR NM 45/2006 “Agregados - Determinação da massa unitária e do volume de vazios”. Foram realizados ensaios em triplicata das amostras de areia fina, areia grossa, pedregulho miúdo pedregulho graúdo e utilizadas as Equações 11 e 12.

$$
E_{v}=\frac{100\left[\left(d_{1} \times \rho_{w}\right)-\rho_{a p}\right]}{d_{1} \times \rho_{w}}
$$

Sendo:

$\mathrm{E}_{\mathrm{v}}$ : índice de volume de vazios [\%]; 
$\mathrm{d}_{1}$ : massa específica relativa do agregado seco $\left[\mathrm{g} \cdot \mathrm{cm}^{-3} \cdot \mathrm{g}^{-1} \cdot \mathrm{cm}^{3}\right]$;

$\rho_{\mathrm{w}}$ : massa específica da água $\left[\mathrm{g} . \mathrm{cm}^{-3}\right]$;

$\rho_{\mathrm{ap}}$ : massa unitária média do agregado $\left[\mathrm{g} \cdot \mathrm{cm}^{-3}\right]$.

$$
\rho_{a p}=\frac{m_{a r}-m_{r}}{V}
$$

Sendo:

$\rho_{\text {ap: }}$ massa unitária do agregado $\left[\mathrm{g} . \mathrm{cm}^{-3}\right]$;

$\mathrm{m}_{\mathrm{ar}}$ : massa do recipiente mais o agregado $[\mathrm{g}]$;

$\mathrm{m}_{\mathrm{r}}$ : massa do recipiente vazio $[\mathrm{g}]$;

$\mathrm{V}$ : volume do recipiente $\left[\mathrm{cm}^{3}\right]$.

Na Figura 20 apresenta-se o cilindro utilizado para determinação do índice de vazios das amostras. A altura média do cilindro a partir de três medições com paquímetro foi de 16,913 $\mathrm{cm}$, o diâmetro médio a partir de três medições foi de $15,022 \mathrm{~cm}$, o que corresponde ao volume interno de $2.997,47 \mathrm{~cm}^{3}$ e a massa de $3.179,76 \mathrm{~g}$, pesada em balança analítica.

Figura 20 - Cilindro para determinação do índice de vazios

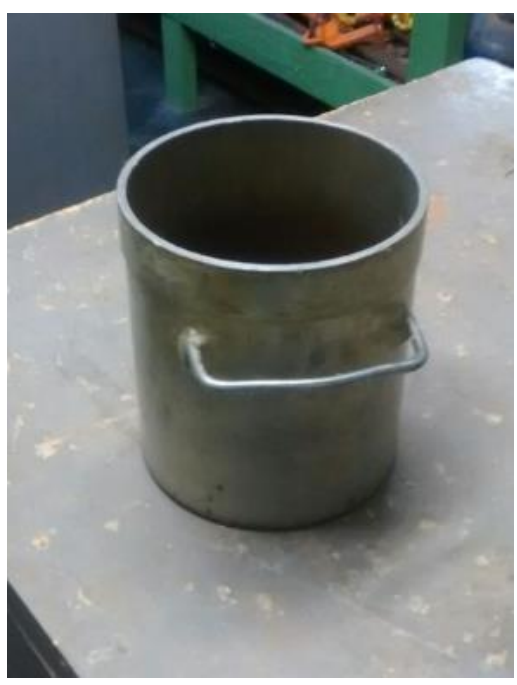

Fonte: Autor

O volume de vazios nos filtros contínuo e intermitente foram determinados a partir da geometria dos filtros e dos resultados obtidos do índice de vazios para cada material, sendo possível calcular o volume de vazios para cada uma das camadas de areia fina, areia grossa, pedregulho miúdo e pedregulho graúdo, o volume de vazios existente na tubulação de saída e o volume de água da camada de água estacionária, que ficava acima da camada filtrante. 


\subsubsection{Ensaio de permeabilidade}

O ensaio de permeabilidade foi realizado conforme a ABNT NBR 13292/1995 "Solo Determinação do coeficiente de permeabilidade de solos granulares à carga constante". Os ensaios foram realizados em triplicata para as amostras de areia fina, areia grossa, pedregulho miúdo e pedregulho graúdo.

Nos ensaios com as amostras de areia fina e areia grossa foi utilizado um permeâmetro cilíndrico de metal com diâmetro interno médio de $10 \mathrm{~cm}$ com um pequeno orifício lateral para a saída da água. Nos ensaios com pedregulho miúdo e graúdo foi utilizado um tubo de acrílico de $50 \mathrm{~cm}$ de comprimento com diâmetro interno médio de $8 \mathrm{~cm}$, no qual a saída da água ocorre por todo o fundo do tubo que foi colocado sobre malha de ferro com abertura inferior ao tamanho dos grãos para permitir a saída água sem comprometer o escoamento de água.

O coeficiente de permeabilidade foi determinado aplicando-se a Lei de Darcy e a correção da viscosidade de água para $20^{\circ} \mathrm{C}$ conforme as Equações 13 e 14.

$$
Q=k \times A \times \frac{\Delta H}{L}
$$

Sendo:

Q: vazão $\left[\mathrm{cm}^{3} \cdot \mathrm{s}^{-1}\right]$;

$\mathrm{k}$ : coeficiente de permeabilidade $\left[\mathrm{cm} \cdot \mathrm{s}^{-1}\right]$;

A: área transversal do corpo de prova, perpendicular às linhas de fluxo $\left[\mathrm{cm}^{2}\right]$;

$\Delta \mathrm{H}$ : perda de carga total de Bernoulli, correspondente à perda de carga existente entre a entrada e saída das linhas de fluxo no corpo de prova [cm];

L: comprimento do corpo de prova na direção das linhas de fluxo [cm].

$$
k_{20^{\circ} \mathrm{C}}=k \times \frac{V_{T}}{V_{20^{\circ} \mathrm{C}}}
$$

Sendo:

$\mathrm{k}_{20}{ }^{\circ} \mathrm{C}$ : coeficiente de permeabilidade à $20^{\circ} \mathrm{C}\left[\mathrm{cm} \cdot \mathrm{s}^{-1}\right]$;

$\mathrm{k}$ : coeficiente de permeabilidade $\left[\mathrm{cm} . \mathrm{s}^{-1}\right]$;

$\mathrm{V}_{\mathrm{T}} / \mathrm{V}_{20^{\circ} \mathrm{C}}$ : relação de viscosidade da água, Tabela 2 da ABNT NBR 13292/1995.

Na Figura 21 apresenta-se a preparação do corpo de prova e um ensaio de permeabilidade com permeâmetro de carga constante. 
Figura 21 - Preparo do corpo de prova e experimento pronto para o ensaio de permeabilidade

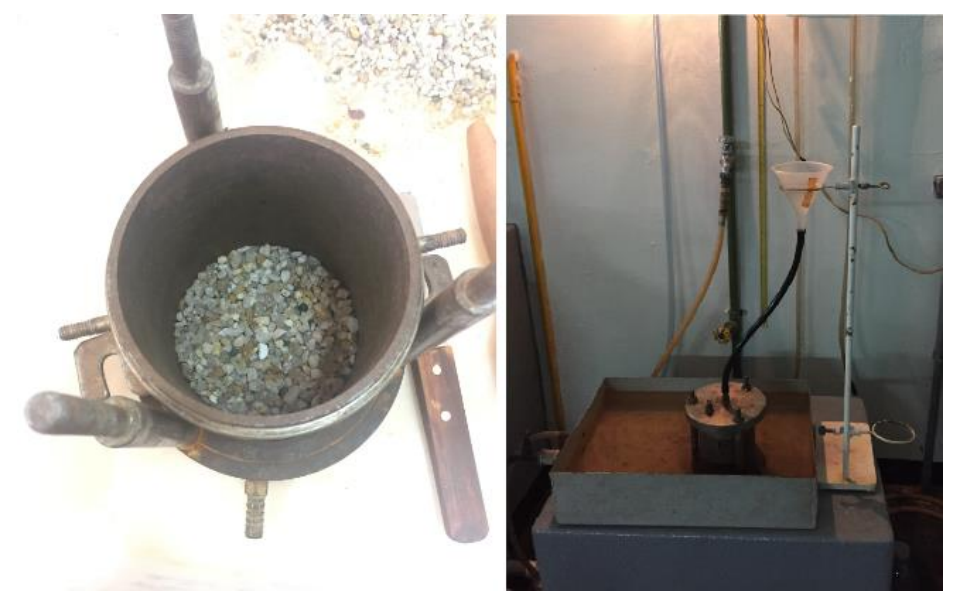

Fonte: Autor

Os ensaios de caracterização física de granulometria, massa específica, índice de vazios e permeabilidade foram realizados no laboratório de materiais de construção e mecânica dos solos da UEM.

\subsubsection{Caracterização química dos agregados}

\subsubsection{Ensaio de solubilidade em ácido}

$\mathrm{Na}$ caracterização química dos agregados foram realizados os ensaios de solubilidade conforme estabelecido na ABNT NBR 11799 "Material filtrante - Areia, antracito e pedregulho - Especificação" (ABNT, 2016). O ensaio foi realizado em duplicata com as amostras de areia fina, areia grossa, pedregulho miúdo e pedregulho graúdo.

A execução do ensaio consiste em utilizar $100 \mathrm{~g}$ de amostra, secar em estufa à $105 \pm 3$ ${ }^{\circ} \mathrm{C}$ durante uma hora, pesar $\left(\mathrm{m}_{1}\right)$, transferir a amostra seca para um béquer de dois litros e adicionar um litro de ácido clorídrico $(\mathrm{HCl})$ previamente diluído a 1:1 com água destilada. Deixar o material em repouso e em contato com ácido por trinta minutos, à temperatura ambiente, depois lavar completamente por decantação com água destilada, secar em estufa à $105 \pm 3{ }^{\circ} \mathrm{C}$ durante uma hora e pesar $\left(\mathrm{m}_{2}\right)$. A solubilidade foi calculada conforme a Equação 15 .

$$
S=\frac{m_{1}-m_{2}}{m_{1}} \times 100
$$

Sendo:

S: solubilidade [\%];

$\mathrm{m}_{1}$ : massa seca em estufa previamente $[\mathrm{g}]$;

$\mathrm{m}_{2}$ : massa seca em estufa após contato com ácido clorídrico [g]; 
Na Figura 22 apresenta-se o ensaio de solubilidade realizado com as amostras de areia fina e grossa e pedregulho miúdo e graúdo. Visualmente não ocorreu formação de bolhas nem desprendimento de sólidos, que seria um indicativo de solubilidade do material.

Figura 22 - Ensaio de solubilidade realizado com os agregados

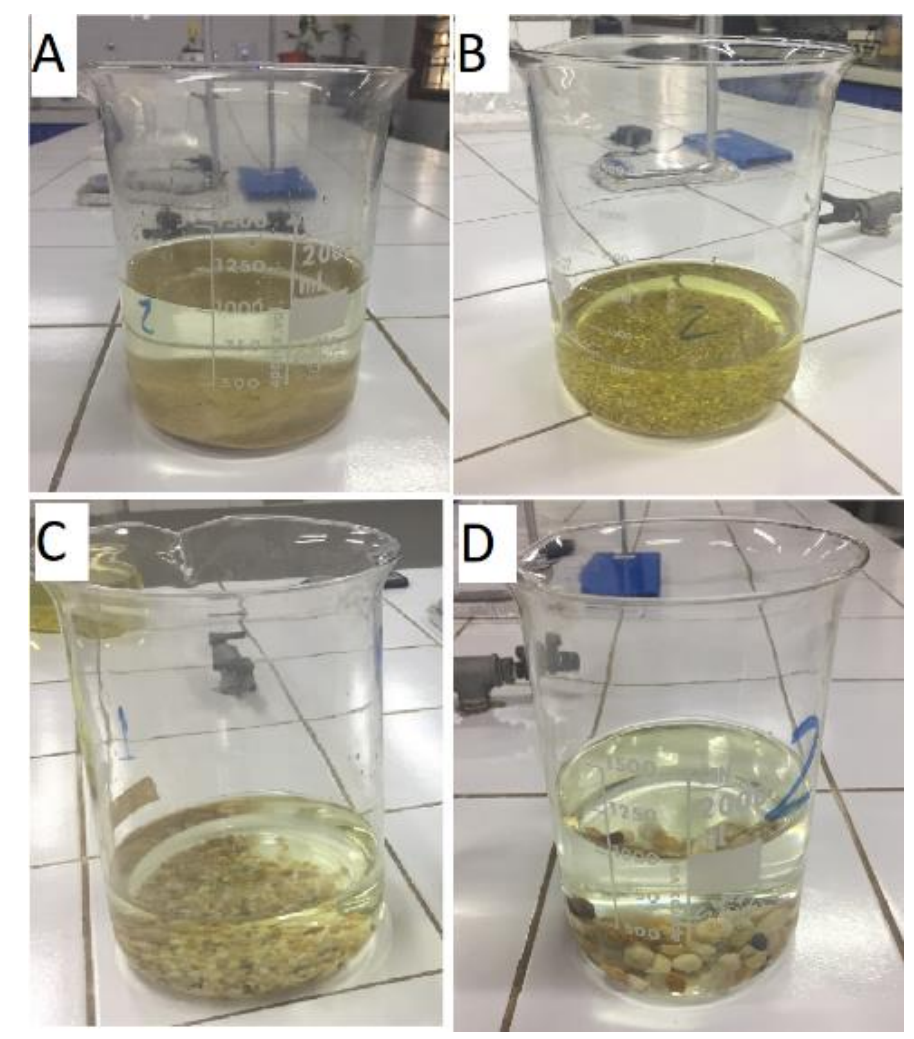

Legenda: A - ensaio com areia fina; B - ensaio com areia grossa; C - ensaio com pedregulho miúdo; D - ensaio com pedregulho graúdo.

Fonte: Autor

\subsection{Preparo da água de estudo}

A água de estudo foi preparada diariamente em um reservatório inferior (bombona de 200 litros), no qual foram preparados 196 litros de água de estudo que foi utilizada nos quatro filtros, ou seja, um volume de $48{\mathrm{~L} . \mathrm{d}^{-1}}^{-1}$ para cada filtro. A água de estudo era composta por $15 \%$ de água superficial proveniente do rio Pirapó e $85 \%$ de água subterrânea oriunda do poço instalado no Campus da UEM. Nas Figuras 23 e 24 são apresentadas os locais de coleta de água do poço e do rio, respectivamente. 
Figura 23 - Local de coleta de água de poço no Campus da UEM e transporte dos galões
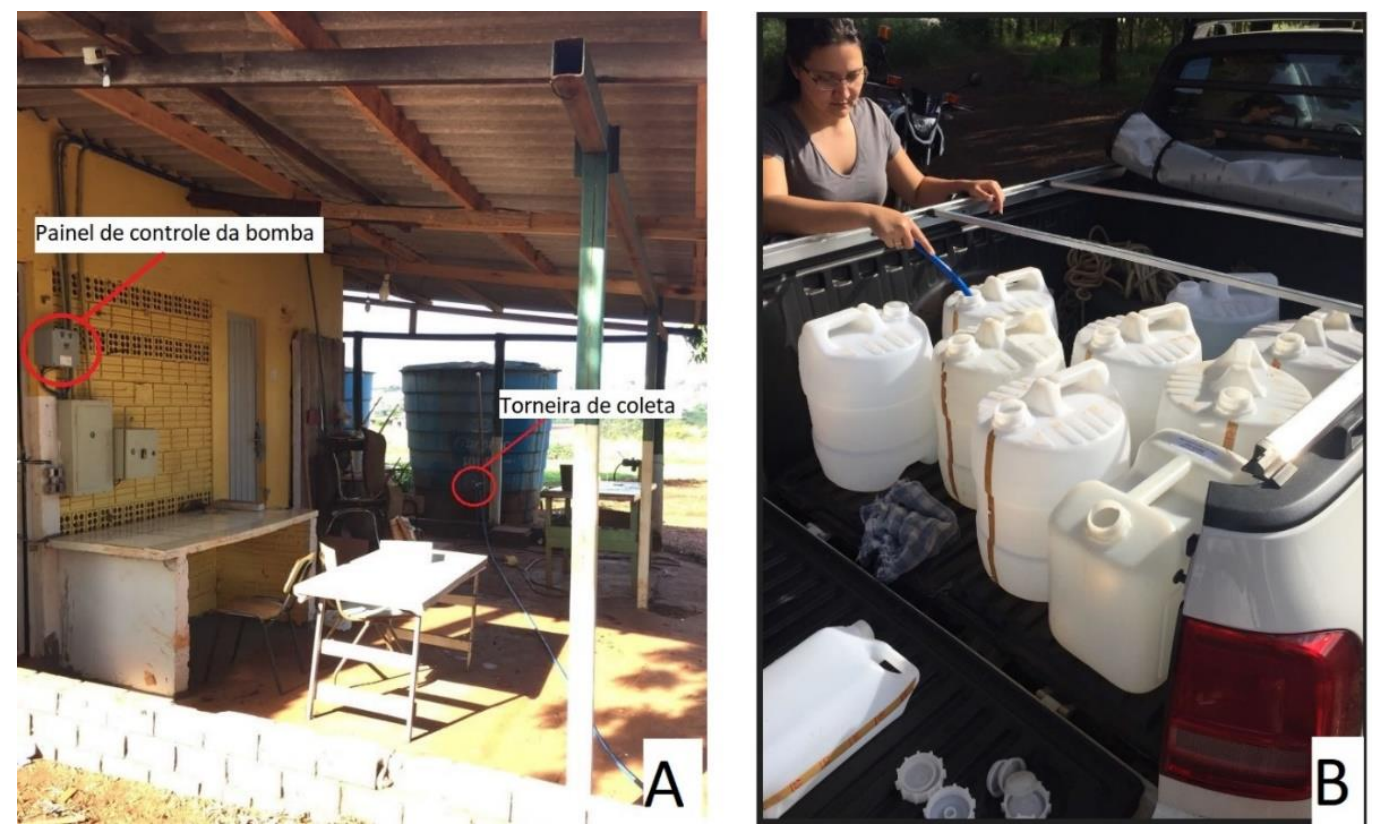

Legenda: A - local de coleta de água de poço; B - transporte dos galões;

Fonte: Autor

Figura 24 -Local de coleta de água do Rio Pirapó

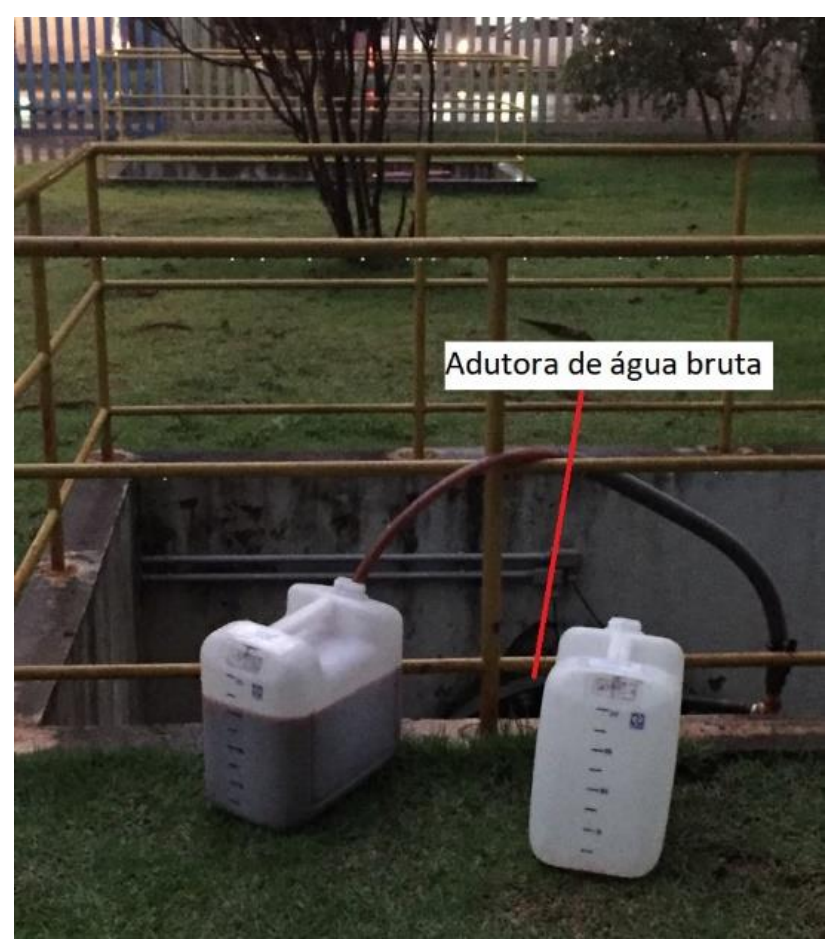

Fonte: Autor

O rio Pirapó é o manancial que abastece a cidade de Maringá-PR. Com base nos valores da turbidez média monitorada pela Sanepar no período de outubro de 2014 a setembro de 2016, 
a turbidez média foi de 155,01 UNT, a mínima obtida nesse período foi de 11,60 UNT e a máxima de 2.984,67 UNT, esta última referente ao dia 10 de fevereiro de 2016. Segundo a CAWST (2009) a tecnologia de filtração lenta domiciliar deve ser aplicada para valores máximos de turbidez de 50 UNT, caso seja superior, recomenda-se realizar um pré tratamento para reduzir a turbidez. Na Figura 25 apresenta-se os valores da turbidez média de outubro de 2014 a setembro de 2016.

Figura 25 - Valores da turbidez média do rio Pirapó 10/2014 à 09/2016

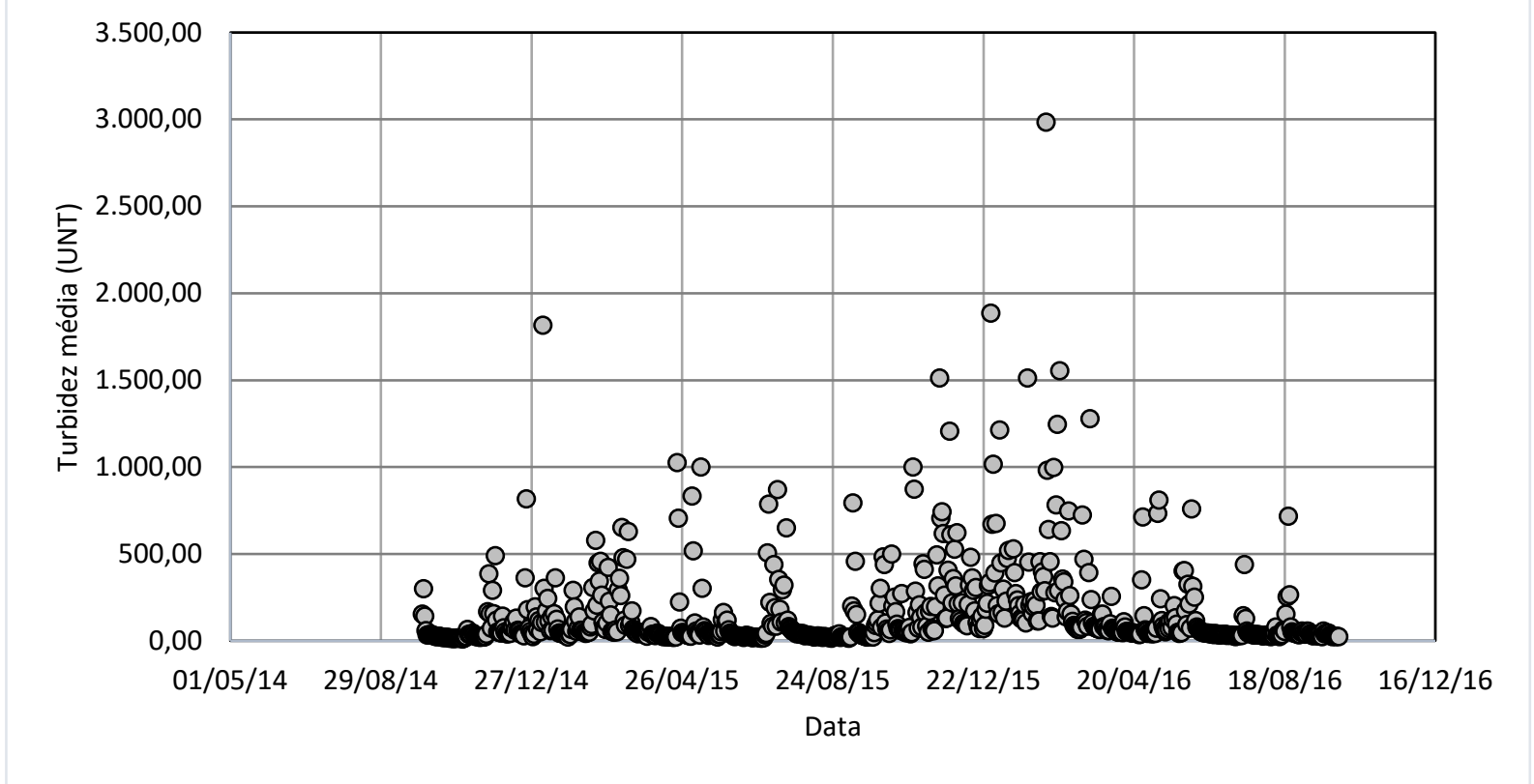

Fonte: Dados cedidos pela Sanepar (2017)

Como a turbidez média da água do rio Pirapó é superior ao limite estabelecido por essa tecnologia, foram testados pré-tratamento com filtração em manta não tecida, mas não se obteve sucesso. Isto porque no mês de março de 2018, quando foram realizados testes iniciais e os prétratamentos, a água do rio estava com uma turbidez superior a 1.000 UNT. A solução encontrada foi trabalhar com uma água de estudo diluindo a água do rio Pirapó com água de poço sem cloro. No dia 08 de março de 2018 foi coletada a água do rio Pirapó com uma turbidez de 150 UNT e foram realizadas diluições de 10, 20 e 30\% com água de poço com uma turbidez de 0,5 UNT e a partir desses resultados optou-se em trabalhar com uma água de alimentação composta por $15 \%$ de água de rio e $85 \%$ de água de poço, conforme mostra a Tabela 6. 
Tabela 6 - Resultados da turbidez após diluição

\begin{tabular}{ll}
\hline Amostra & Turbidez (UNT) \\
\hline $10 \%$ de água de rio e $90 \%$ de água de poço & 9,9 \\
\hline $20 \%$ de água de rio e $80 \%$ de água de poço & 20,1 \\
\hline $30 \%$ de água de rio e $70 \%$ de água de poço & 29,4 \\
\hline
\end{tabular}

Fonte: Autor

Assim, a água bruta utilizada foi coletada direto da adutora na estação de tratamento de água da Sanepar duas vezes por semana em galões de $20 \mathrm{~L}$ e ficava armazenada para ser utilizada durante três dias, e a água de poço era coletada diariamente do aquífero Caiuá em galões de $20 \mathrm{~L}$. O poço artesiano estava localizado no centro de treinamento em irrigação na UEM. A Sanepar autorizou a coleta após solicitação formalizada pelo Ofício $n^{0}$ 025/2017 DEC/UEM na data de 31/05/2017.

\subsection{Sistema de abastecimento e operação dos filtros lentos domiciliares}

O sistema de abastecimento dos filtros era composto por um reservatório inferior, constituído de uma bombona de 200 litros, e um reservatório superior, que era composto por uma caixa de água de 100 litros que foi instalada sobre um suporte metálico a um nível superior, o que permitiu a alimentação dos filtros contínuos por gravidade, reduzindo o consumo de energia elétrica e mantendo estabilidade hidrodinâmica, uma vez que o sistema de bombeamento direto que poderia causar oscilações de vazão e instabilidade hidrodinâmica. $\mathrm{O}$ transporte da água de estudo do reservatório inferior para o reservatório superior foi realizado com o auxílio de uma bomba submersa.

O preparo da água de estudo foi realizado manualmente ao final de cada dia para que a mesma pudesse ser utilizada no dia seguinte. Às 7 horas do dia seguinte a bomba submersa era ligada para recirculação e homogeneização da água de estudo e em seguida era coletada uma amostra de $500 \mathrm{ml}$ da água de estudo. Eram elevados 96 litros de água de estudo às 7 horas para o reservatório superior que alimentava os filtros contínuos C-FLD 1 e C-FLD 2. O filtro intermitente I-FLD 1 foi alimentado manualmente com água de estudo do reservatório inferior às 7:00, 9:30, 12:00, 14:30 e 17:00 horas com volumes de 10, 10, 8, 10 e 10 litros respectivamente, totalizando $48 \mathrm{~L}^{\mathrm{d}} \mathrm{d}^{-1}$. O filtro intermitente I-FLD 2 foi alimentado manualmente com água de estudo do reservatório inferior às 7:00, 12:00 e 17:00 horas com

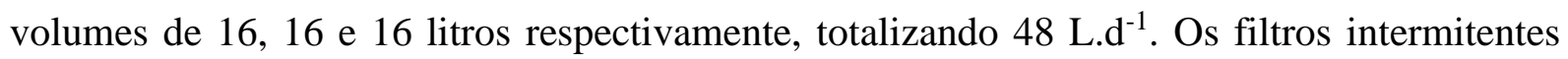


foram operados de segunda-feira à sexta-feira com as alimentações nos horários descritos anteriormente, ficando sem operar no sábado e no domingo, totalizando um período de pausa de 62 horas.

Os volumes de alimentação foram determinados com base no volume de vazios obtidos, sendo de 9,7 litros para o I-FLD1 e de 16 litros para o I-FLD 2, como o valor do I-FLD 1 não era um número inteiro, optou-se realizar as alimentações com 10 e 8 litros pensando na viabilidade da alimentação pelo usuário de forma que o volume de alimentação fosse próximo dos 9,7 litros. Os horários de alimentação foram determinados considerando a rotina diurna da família, das 7 até as 17 horas, e intervalos regulares de alimentação nesse período, no caso, o IFLD 1 foi alimentado a cada 2 horas e 30 minutos e o I-FLD 2 foi alimentado a cada 5 horas, desconsiderando o período de pausa entre o final de um dia e o próximo dia, de segunda-feira à sexta-feira, e o período de pausa dos finais de semana.

Nos filtros contínuos foram coletadas amostras de $500 \mathrm{ml}$ de água tratada às 7:00 horas e nos filtros intermitentes foram coletadas amostras de água tratada após cada alimentação, que ocorreu da seguinte forma, às 7 horas coletaram-se $500 \mathrm{ml}$ de água tratada e nas demais alimentações coletaram-se $100 \mathrm{ml}$ de água tratada.

Nas Figuras 26 e 27 mostram-se o croqui do sistema de abastecimento com os filtros lentos domiciliares e as instalações no laboratório do sistema de abastecimento com reservatório inferior e reservatório superior para alimentação dos filtros, respectivamente.

Figura 26 - Croqui do sistema de abastecimento com os filtros.

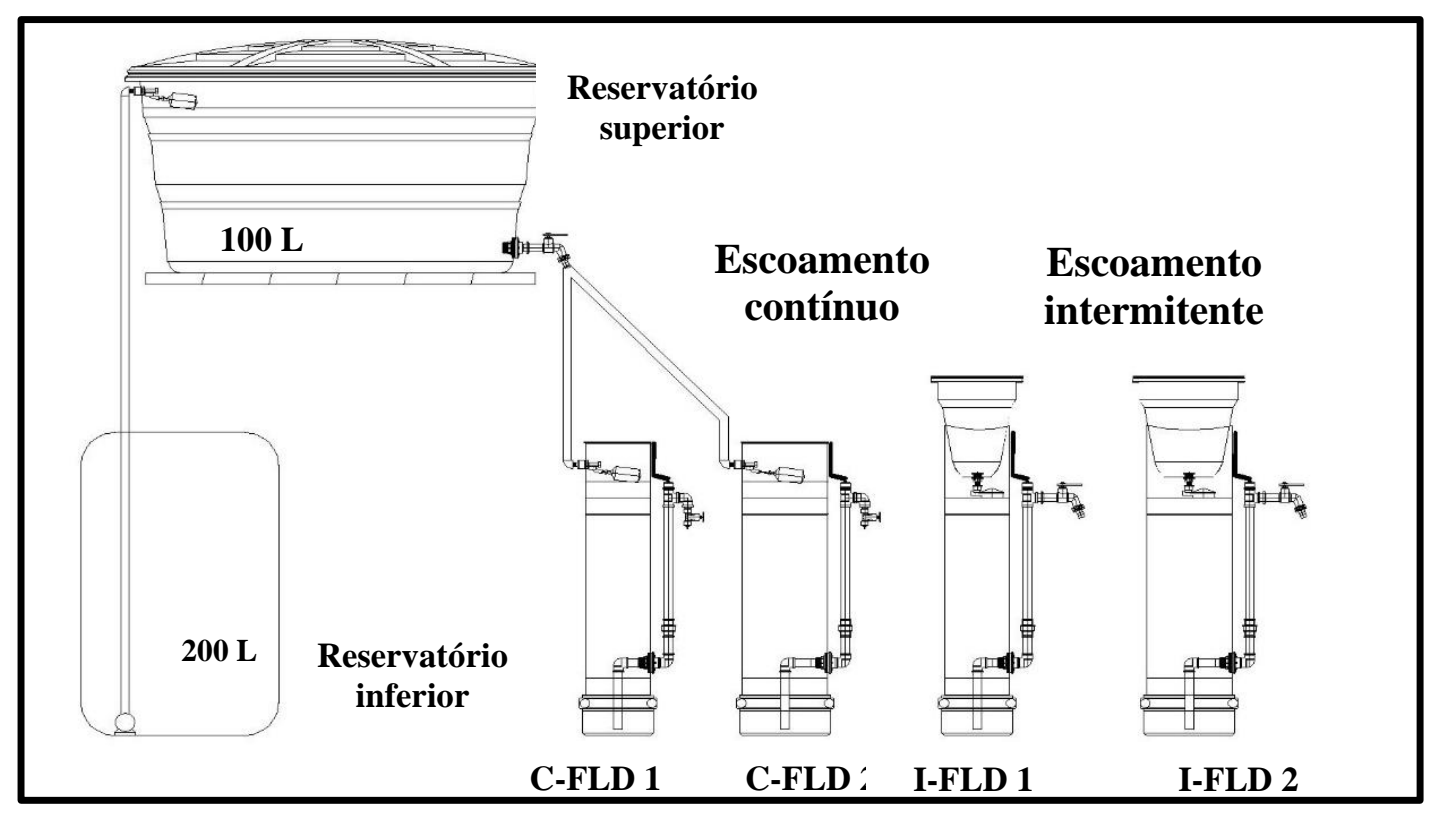

Fonte: Autor 
Figura 27 - Sistema de abastecimento no laboratório

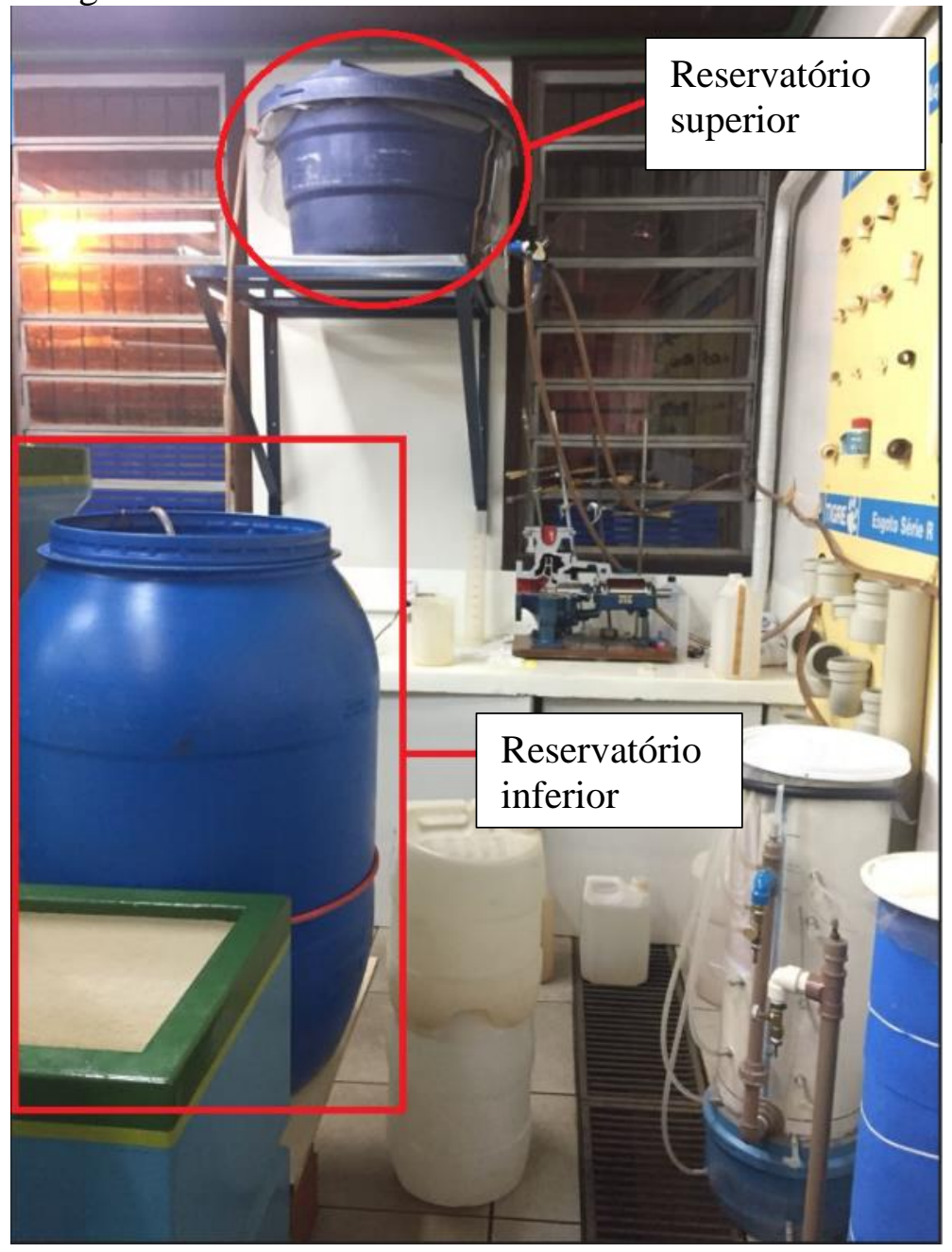

Fonte: Autor

\subsection{Caracterização do escoamento - Ensaio de traçador experimental}

Um método simples e direto de se encontrar a distribuição de tempo de residência pode ser utilizando um traçador físico, não reativo, empregando a técnica de estímulo e resposta. Vários tipos de experimentos podem ser usados com estímulos do tipo pulso e/ou degrau.

No estudo, a perturbação escolhida para os C-FLDs e os I-FLDs foi do tipo degrau, segundo reportado por Maciel e Sabogal-Paz (2018), Terin e Sabogal-Paz (2019) e SabogalPaz et al. (2020).

Os ensaios em cada um dos filtros foram realizados em triplicata, o traçador utilizado foi o cloreto de sódio $(\mathrm{NaCl})$ com teor de $99 \%$ o qual foi utilizado para preparar uma solução de $100 \mathrm{mg} . \mathrm{L}^{-1}$ de sal. A variação da condutividade elétrica da água filtrada foi medida na torneira de saída, em tempo real, com uma sonda de condutividade da marca Venier Software \& Technology, dos Estados Unidos da América (EUA). 
A calibração da sonda permitiu correlacionar a variação da condutividade com a concentração do traçador. A sonda foi conectada a um computador com o software Logger Lite (Venier Software \& Technology, EUA) que permitiu coletar e armazenar os dados das medições da concentração do traçador no tempo. Os dados de condutividade foram medidos a cada $60 \mathrm{~s}$.

O processamento dos dados foi realizado com auxílio do software Excel 2013 (Microsoft®, EUA) e do software OriginPro 8 (OriginLab, EUA). A curva de concentração versus tempo foi normalizada para a obtenção da curva $\mathrm{F}$ e, a partir dela, foi calculada uma curva E e demais parâmetros de interesse. A limpeza dos filtros, após cada ensaio, foi realizada pela introdução de água da rede de distribuição até eliminar totalmente o traçador.

A construção da curva de distribuição de tempo de residência foi elaborada após o tratamento dos dados que foram medidos pela sonda de condutividade elétrica. Essa curva permitiu determinar o tempo de detenção hidráulica de cada filtro e verificar se os filtros apresentaram um comportamento do escoamento do tipo pistonado (Plug Flow Reactor - PRF) ou do tipo mistura completa (Continuous Stirred Tank Reactor-CSTR).

Nos ensaios do tipo degrau é preciso normalizar os dados obtidos de concentração para construir a curva F, ou seja, a distribuição cumulativa F(t) conforme Equação 16 (FOGLER, 2009). A diferenciação da curva F gera a curva de distribuição do tempo de residência (DTR), ou curva E conforme Equação 17 (FOGLER, 2009). Com essa curva é possível determinar o tempo médio de detenção hidráulica pela Equação 18 e o volume do reator para um sistema fechado considerando a vazão volumétrica $(v)$ e o tempo $\tau=t_{m}$ conforme a Equação 19 (FOGLER, 2009).

$$
\begin{gathered}
F(t)=\left[\frac{C_{\text {saída }}}{\mathrm{C}_{0}}\right]_{\text {degrau }}=\int_{0}^{t} E\left(t^{\prime}\right) \cdot d t^{\prime} \\
E(t)=\frac{d}{d t} \cdot\left[\frac{C(t)}{\mathrm{C}_{0}}\right]_{\text {degrau }} \\
\tau=\int_{0}^{\infty} t \cdot E(t) \cdot d t \\
V=v \cdot t_{m}
\end{gathered}
$$

A partir da curva E é possível realizar a modelagem hidrodinâmica com base nos modelos de escoamento mistura completa e escoamento pistonado. Esses modelos dependem 
de algumas variáveis adimensionais que são apresentadas pelas Equações 20 e 21 (FOGLER, 2009) e pelas Equações 22 e 23, em que $\overline{\theta_{h}}$ é o tempo médio de residência (Levenspiel, 2000).

Tempo de residência adimensional:

$$
\theta=\frac{t}{\tau}
$$

DTR em função do tempo de residência adimensional:

$$
E(\theta)=\tau \cdot E(t)
$$

Variância na curva DTR:

$$
\sigma^{2}=\int_{0}^{\infty}\left(t-t_{m}\right)^{2} \cdot E(t) \cdot d t
$$

Variância adimensional na curva DTR:

$$
\sigma_{\theta}^{2}=\frac{\sigma^{2}}{\left(\overline{\theta_{h}}\right)^{2}}
$$

Com as variáveis obtidas a partir do tratamento dos dados do ensaio é possível classificar os modelos hidrodinâmicos dos reatores: em N-CSTR em série, dispersão longitudinal de pequena intensidade e dispersão longitudinal de grande intensidade, conforme as equações dispostas na Tabela 7.

Tabela 7 - Equações dos modelos hidrodinâmicos

\begin{tabular}{ccc}
\hline Modelo & Parâmetro & Equação \\
\hline N-CSTR em série & $N=\frac{1}{\sigma_{\theta}^{2}}=\frac{\left(\overline{\theta_{h}}\right)^{2}}{\sigma^{2}}$ & $E_{\theta}=\frac{N(N \cdot \theta)^{N-1}}{(N-1) !} \exp (-N \theta)$ \\
\hline $\begin{array}{c}\text { Dispersão } \\
\text { longitudinal de } \\
\text { pequena intensidade }\end{array}$ & $\frac{D}{\mu L}=\frac{\sigma_{\theta}^{2}}{2}$ & $E_{\theta}=\frac{1}{2 \sqrt{\pi\left(\frac{D}{\mu L}\right)}} \exp \left[-\frac{(1-\theta)^{2}}{4\left(\frac{D}{\mu L}\right)}\right]$ \\
\hline $\begin{array}{c}\text { Dispersão } \\
\text { longitudinal de } \\
\text { grande intensidade }\end{array}$ & $\sigma_{\theta}^{2}=2\left(\frac{D}{\mu L}\right)+8\left(\frac{D}{\mu L}\right)^{2}$ & $E_{\theta}=\frac{1}{2 \sqrt{\pi\left(\frac{D}{\mu L}\right)}} \exp \left[-\frac{(1-\theta)^{2}}{4 \cdot \theta \cdot\left(\frac{D}{\mu L}\right)}\right]$
\end{tabular}

Obs.: $D$ - coeficiente de dispersão axial para escoamento de fluido $\left[\mathrm{m}^{2} . \mathrm{s}^{-1}\right] ; \mu$ - viscosidade do fluido $\left[\mathrm{kg} \cdot \mathrm{m}^{-1} . \mathrm{s}^{-1}\right] ; L$ - comprimento do reator $[\mathrm{m}]$.

Fonte: Levenspiel (2000) 
Os procedimentos executados nos ensaios de DTR para os filtros foram semelhantes aos propostos por Elliott et al. (2008), Terin e Sabogal-Paz (2019) e Maciel e Sabogal-Paz (2018).

\subsubsection{Determinação da distribuição do tempo de residência nos filtros contínuos}

Nos ensaios de DTR nos filtros contínuos foi utilizado um reservatório elevado com capacidade para armazenar 20 litros de solução que permitiu o escoamento por gravidade. A taxa de aplicação superficial foi controlada pelo registro de saída e a alimentação por gravidade foi regulada devido à bóia instalada nos filtros.

A vazão de operação de ambos os filtros foi de $48 \mathrm{~L} \cdot \mathrm{d}^{-1}$, porém como os filtros de acrílico e de Defofo têm diâmetros diferentes as taxas de aplicação superficial também foram diferentes. Na Figura 28 apresenta-se a estrutura montada para alimentação dos filtros contínuos com solução salina (Figura 28 A), o suporte para a sonda de condutividade realizar as medições, o aparato para conectar a sonda ao computador e a formação da camada de água estacionária que poderia prejudicar o ensaio devido a dispersão, caso fosse utilizado o estímulo tipo pulso, Figura $28 \mathrm{~B}$.

Figura 28 - Instalações empregadas no ensaio de distribuição de tempo de residência
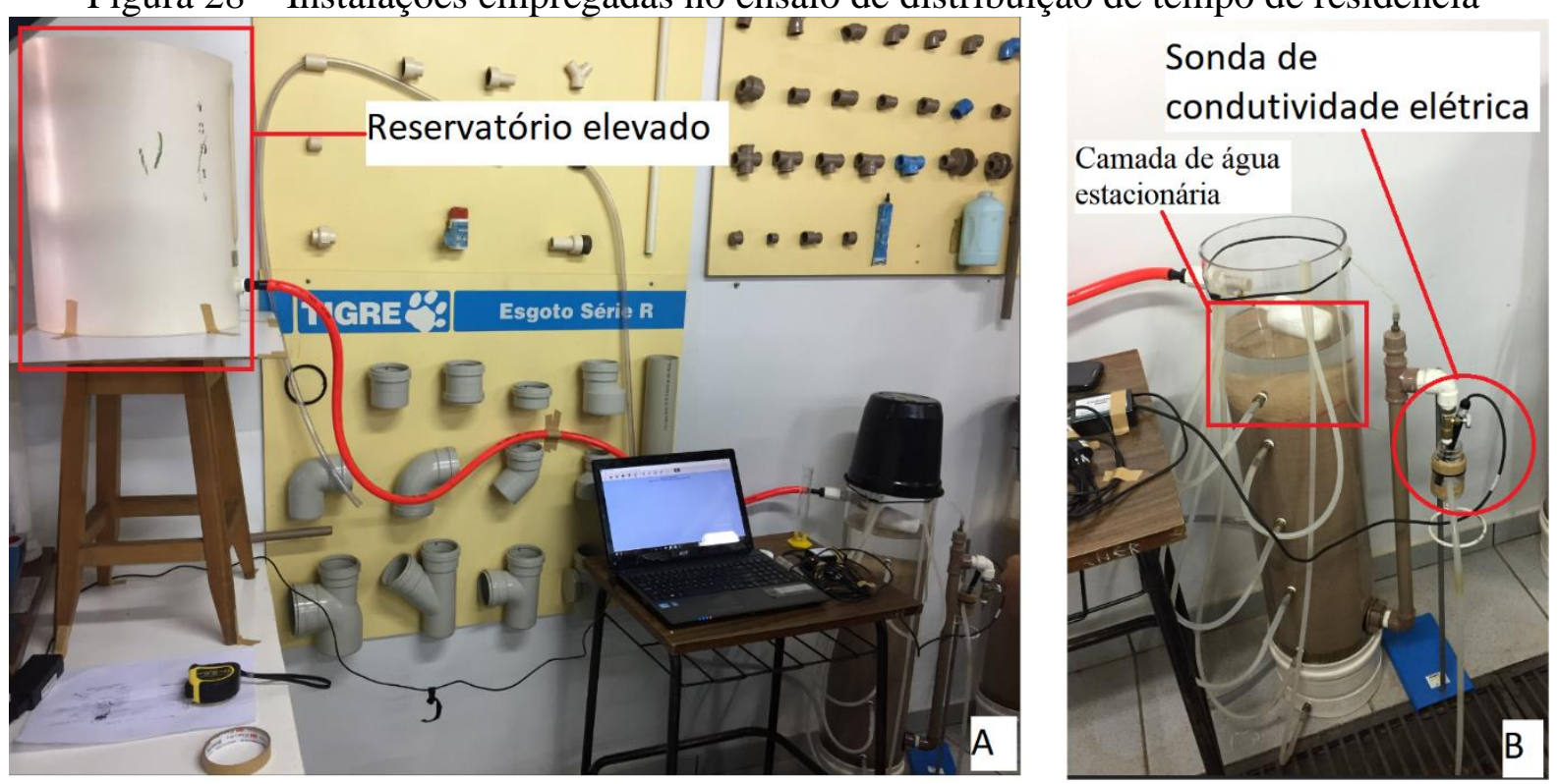

Fonte: Autor

Nos C-FLDs, os ensaios com traçador foram realizados com a mesma taxa de filtração usada durante a operação dos filtros. A DTR foi determinada e a curva da concentração versus tempo (C vs t) foi elaborada. O padrão de escoamento foi ajustado em três modelos matemáticos 
hidrodinâmicos: modelo de reatores de tanque agitado (N-CSTRs) e os modelos de dispersão (baixa e alta dispersão), conforme relatado por Levenspiel (1999).

\subsubsection{Determinação da distribuição do tempo de residência nos filtros intermitentes}

O ensaio com a injeção do traçador tipo degrau foi realizado conforme ensaio realizado por Elliott et al. (2008). Nos ensaios com traçador dos I-FLDs, a perturbação foi realizada com a primeira alimentação com solução de sal de 100 mg.L-1 e, em seguida, alimentações com água de torneira até que a concentração do traçador fosse próxima de zero.

A taxa de filtração reduziu para zero quando a carga hidráulica atingiu o mínimo nível (NA mínimo da Figura 10 e 11), momento em que um novo carregamento foi realizado. O volume de cada alimentação correspondeu ao volume de vazios do filtro. Nos ensaios do IFLD1 e do I-FLD2 foram utilizadas: quatro alimentações de 10 litros e quatro de 15 litros, respectivamente. As curvas de concentração de traçador versus volume (C vs v) obtidas resultaram em um degrau positivo seguido de um degrau negativo (concentração aumentada e diminuída).

Posteriormente, o Índice de Dispersão de Morrill (IDM) segundo Tchobanoglous, Burton e Stensel (2003) e o Índice de Dispersão de Morril Modificado (IDMM) proposto por Lynn et al. (2013) foram calculados. O IDM é a razão entre o tempo em que $90 \%$ e $10 \%$ do traçador saem o filtro, respectivamente. $O$ índice varia de 1,0 (reatores ideais de escoamento pistonado - PFR) a 22 (reatores ideais de mistura completa- CSTR) Tchobanoglous, Burton e Stensel (2003). O IDMM é uma adaptação do IDM pois considera o volume acumulado de água filtrada ao invés do tempo (Lynn et al., 2013).

O tempo de detenção hidráulico teórico foi calculado considerando a razão entre o volume de água armazenada pelo C-FLD1 e C-FLD2 e a vazão diária de 48 L para ambos.

As taxas de filtração máximas foram determinadas pela razão entre a vazão e a área, sendo a vazão obtida pela razão do volume pelo tempo, e, a vazão foi monitorada diariamente na primeira alimentação do dia quando a altura da lâmina de água era máxima.

\subsection{Monitoramento dos parâmetros de qualidade da água, perda de carga e vazão dos filtros lentos domiciliares}

Os parâmetros de temperatura, $\mathrm{pH}$, condutividade elétrica, cor aparente, turbidez, oxigênio dissolvido, Escherichia coli, coliformes totais, nitrito, nitrato e absorbância foram analisados durante o experimento, tanto para as amostras de água bruta diluída quanto de água 
filtrada para analisar o desempenho dos filtros. Os parâmetros citados foram determinados conforme estabelecido em Standard Methods for the Examination of Water and Wastwater (APHA, AWWA, WEF, 2017). Os parâmetros foram analisados conforme o método e/ou equipamentos e a frequência de análise descritos na Tabela 8.

Tabela 8 - Parâmetros, amostra, métodos/equipamento e frequência

Parâmetro Unidade Método/Equipamento $\quad$ Frequência

\begin{tabular}{|c|c|c|c|}
\hline Temperatura & ${ }^{\circ} \mathrm{C}$ & Termômetro de mercúrio & Cinco dias por semana \\
\hline $\mathrm{pH}$ & - & $\begin{array}{l}\text { Método 4500- } \mathrm{H}^{+} \text {B (Método } \\
\text { eletrométrico) } \\
\text { pHmetro Digimed DM-20 }\end{array}$ & Cinco dias por semana \\
\hline $\begin{array}{l}\text { Condutividade } \\
\text { elétrica }\end{array}$ & $\mu \mathrm{S} . \mathrm{cm}^{-2}$ & $\begin{array}{l}\text { Método } 2510 \text { B } \text { (Método } \\
\text { laboratorial) } \\
\text { Condutivímetro Digimed DM- } \\
32\end{array}$ & Cinco dias por semana \\
\hline Turbidez & UNT & $\begin{array}{l}\text { Método } 2130 \text { B (Método } \\
\text { nefelométrico) } \\
\text { Turbidímetro Hach } 2100 Q\end{array}$ & Cinco dias por semana \\
\hline Cor aparente & $\mathrm{uC}$ & $\begin{array}{l}\text { Método } 2120 \text { D (Fotometria } \\
\text { método tristimulus) } \\
\text { Colorímetro para cor } \\
\text { PoliControl Aquacolor }\end{array}$ & Cinco dias por semana \\
\hline $\begin{array}{l}\text { Oxigênio } \\
\text { dissolvido }\end{array}$ & $\mathrm{mg} \cdot \mathrm{L}^{-1}$ & $\begin{array}{l}\text { Oxímetro Digimed DM-4PP } \\
\text { Método 4500-O C (Método de } \\
\text { Winkler modificado pela azida } \\
\text { sódica) }\end{array}$ & Uma vez por semana \\
\hline Escherichia coli & UFC. $100 \mathrm{ml}^{-1}$ & Método 9222 B (Método da & Duas vezes por semana \\
\hline $\begin{array}{l}\text { Coliformes } \\
\text { totais }\end{array}$ & UFC. $100 \mathrm{ml}^{-1}$ & $\begin{array}{l}\text { Plate) } \\
\text { Plomat }\end{array}$ & \\
\hline Nitrito & mg.L NO${ }^{-}-\mathrm{N}$ & $\begin{array}{l}\text { Método } 4500-\mathrm{NO}_{2}^{-} \mathrm{B} \\
\text { Espectrofotômetro } \\
\text { DR2800 }\end{array}$ & Uma vez por semana \\
\hline Nitrato & mg.L NO${ }_{3}^{-}-\mathrm{N}$ & $\begin{array}{l}\text { Método } 4500-\mathrm{NO}_{3}^{-} \mathrm{E} \\
\text { Espectrofotômetro } \\
\text { DR2800 }\end{array}$ & Uma vez por semana \\
\hline $\begin{array}{l}\text { Absorbância - } \\
\lambda 254 \mathrm{~nm}\left(\mathrm{~cm}^{-1}\right)\end{array}$ & - & $\begin{array}{l}\text { Espectrofotômetro PerkinElmer } \\
\text { Lambda } 1050 \text { UV/VIS/NIR }\end{array}$ & Uma vez por semana \\
\hline
\end{tabular}

Fonte: Autor

As leituras dos piezômetros instalados nos filtros contínuos e intermitentes foram realizadas para avaliar o comportamento da perda de carga ao longo dos dias de operação como 
consequência dos mecanismos do filtro, como por exemplo, a retenção de impurezas e o desenvolvimento da camada biológica que podem causar variação da perda de carga.

A partir das leituras dos piezômetros, foi determinado a perda de carga unitária entre o piezômetro 1 e o piezômetro 6 , ou seja, a razão entre a perda de carga $(\Delta \mathrm{h})$ e o comprimento da tubulação (L) entre os piezômetros 1 e 6.

A vazão dos filtros intermitentes foi medida diariamente de segunda à sexta-feira após o abastecimento das 7 horas com auxílio de uma proveta graduada e um cronômetro. As análises foram realizadas no Laboratório de Hidráulica e Saneamento da Engenharia Civil da UEM e no Complexo de Centrais de Apoio à Pesquisa (COMCAP) da UEM.

\subsection{Validação das simulações numéricas em análises hidráulicas para FLDs}

Neste trabalho, as simulações dos FLDs resolveram as equações de conservação de massa e de conservação de momentum empregando o código comercial ANSYS Fluent (versão 2020 R2), baseado no método dos volumes finitos, onde as equações diferenciais são integradas em cada volume de controle da malha gerando um conjunto de equações algébricas discretas. O sistema linear resultante foi então resolvido numericamente de forma iterativa até que se atingisse a solução com precisão desejada.

As equações tridimensionais de conservação da massa e quantidade de movimento são dadas pelas Equações 24 e 25, que vigoram nos domínios fluidos.

Todos os domínios (Equação da continuidade)

$$
\nabla \cdot(\rho u)=0
$$

Domínio fluido (Equação de Navier-Stokes) (Navier, 1823; Stokes, 1845)

$$
\nabla \cdot(\rho u u)=-\nabla \mathrm{p}+\nabla \cdot\left(\mu\left(\nabla \mathrm{u}+\nabla u^{T}\right)-\frac{2}{3} \delta \nabla \cdot \mathrm{u}\right)
$$

onde $u \in \mathbb{R}^{3}$ é o vetor velocidade; $\rho$ é a densidade do fluido (água); p é a pressão estática; $\mu$ é a viscosidade e $\delta$ é o delta de Kronecker.

A equação de conservação de massa indica que a massa que entra em um determinado volume de controle deve ser a mesma que sai juntamente com a massa acumulada no sistema. A equação de conservação de momentum, aplicando-se a segunda Lei de Newton em 
um determinado volume de controle (VC) indica que o momento acumulado no volume de controle é a diferença entre o momento de entrada e de saída no VC mais a resultante das forças que atuam no sistema.

As equações diferenciais apresentadas, descrevem as propriedades do fluido dentro de um domínio que deve ser circundado por um contorno. Desta forma, deve-se estabelecer as condições de contorno especificando o comportamento da solução das equações para todo o tempo. As condições de contorno de entrada e saída são: vetor velocidade, pressão, temperatura e concentração de soluto.

Na simulação, inicialmente, desenhou-se as geometrias dos FLDs, depois se elaborou as malhas com refinos diferentes (divisões do domínio em volumes de controle) e aplicaram-se as condições de contorno de cada simulação, o que gerou um modelo para cada filtro. Os resultados obtidos das malhas refinadas permitiram aplicar o teste de independência da malha, no qual foram comparadas as velocidades da água no filtro simulado e no experimento real. Os resultados geraram os perfis de velocidade e as linhas de corrente do escoamento no interior dos filtros. Finalizando, realizou-se a verificação e a validação dos modelos matemáticos adotados a partir dos resultados numéricos e dos resultados obtidos nos ensaios de traçador experimental.

Inicialmente, a geometria de cada FLD foi criada utilizando o AutoCAD 2010® da Autodesk $®$ e, na sequência, a malha foi gerada no subcomponente do software Ansys 2020 R2 Meshing (Ansys $®)$. Depois, as condições de controle foram definidas para executar a simulação no software ANSYS 2020 R2 Fluent (Ansys®) e a visualização dos resultados no ANSYS 2020 R2 CFD Post-processing (Ansys®).

Os modelos foram simulados em um computador com processador Intel ${ }^{\circledR}$ Core ${ }^{\text {TM }}$ i77500U CPU @ $2.70 \mathrm{GHz} 2.90 \mathrm{GHz}$, sistema operacional de 64bits, memória instalada (RAM) de 8 GB, HD 1 TB, operando na plataforma Windows 10 da Microsoft $®$. Na Figura 29 apresenta-se as etapas da modelagem computacional. 
Figura 29 - Fluxograma da modelagem computacional

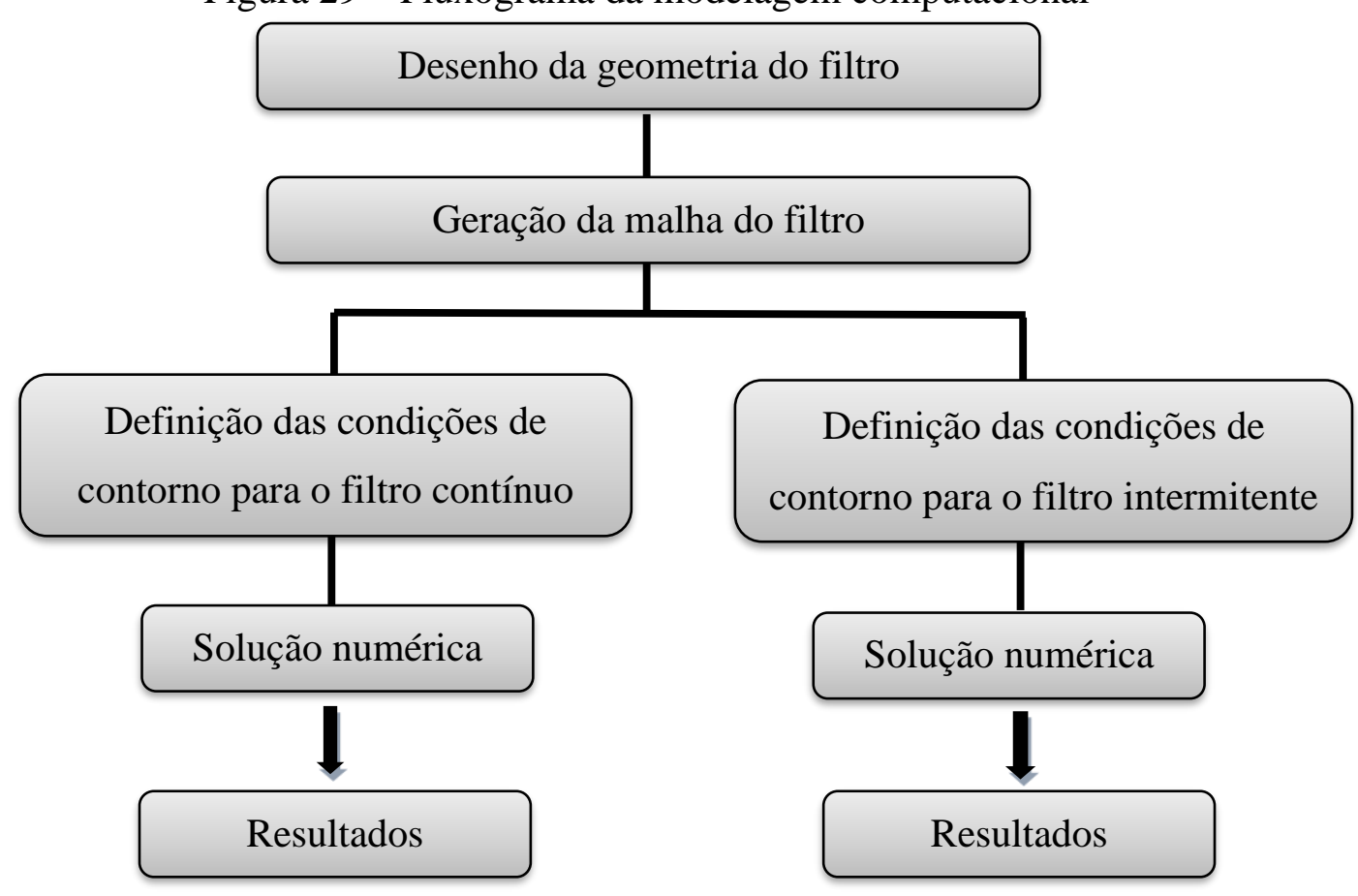

Fonte: Autor

Na Tabela 9 são apresentadas as ferramentas utilizadas no desenvolvimento de cada atividade para elaborar o modelo físico e realizar as simulações disponibilizadas no Workbench (Ansys $\left.{ }^{\circledR}\right)$.

Tabela 9 - Ferramentas utilizadas no desenvolvimento do modelo e da simulação

\begin{tabular}{lcc}
\hline \multicolumn{1}{c}{ Etapa } & Atividade & Ferramenta \\
\hline Pré-processamento & Geometria & AutoCAD 2015 \\
\hline Pré-processamento & Geração de malhas & ANSYS Meshing \\
\hline Pré-processamento & Definição do modelo físico & ANSYS Fluent \\
\hline Pré-processamento & Definição dos parâmetros do & \multirow{2}{*}{ ANSYS Fluent } \\
\hline Processamento & Solução de equações & ANSYS Fluent \\
\hline Pós-processamento & Visualização dos resultados & ANSYS CFD-Post \\
\hline
\end{tabular}

Fonte: Autor

$\mathrm{Na}$ tese foram realizadas duas simulações para cada FLD: a primeira do escoamento, sendo realizada em regime permanente; e a segunda da DTR, sendo realizada em regime transiente (escalar passivo). 
Nos quatro FLDs, para facilitar a simulação numérica, adotou-se os seguintes critérios: i) fluxo monofásico em três dimensões; ii) fluido newtoniano em estado estacionário; iii) escoamento isotérmico, escoamento laminar, escoamento incompressível e escoamento em meio poroso nas camadas filtrante e drenantes; e iv) Porosidade e permeabilidade homogêneas e específicas para cada uma das camadas filtrante e drenantes; conforme reportado por Berbert et al. (2016), porém com dados próprios obtidos nos ensaios em laboratório mencionados nos itens 4.3.2.

As condições de contorno utilizadas para o regime permanente, Navier-Stokes, foram: i) Inlet: velocidade prescrita; ii) Outlet: pressão prescrita; iii) Condição da parede: sem deslizamento. As condições de contorno para o regime transiente, escalar passivo, foram: i) Inlet: concentração prescrita de 100; ii) Outlet: gradiente nulo; iii) Condição da parede: impermeável (gradiente normal nulo). A condição de parede dos filtros foi adotada como sendo sem deslizamento, ou seja, a camada de fluido que adere à superfície tem velocidade nula pois a parede era fixa, na qual rege a teoria da camada limite. Na Figura 30 são indicadas a entrada, a saída e a parede do filtro.

Figura 30 - Esquema dos C-FLDs indicando entrada, saída e parede do filtro.

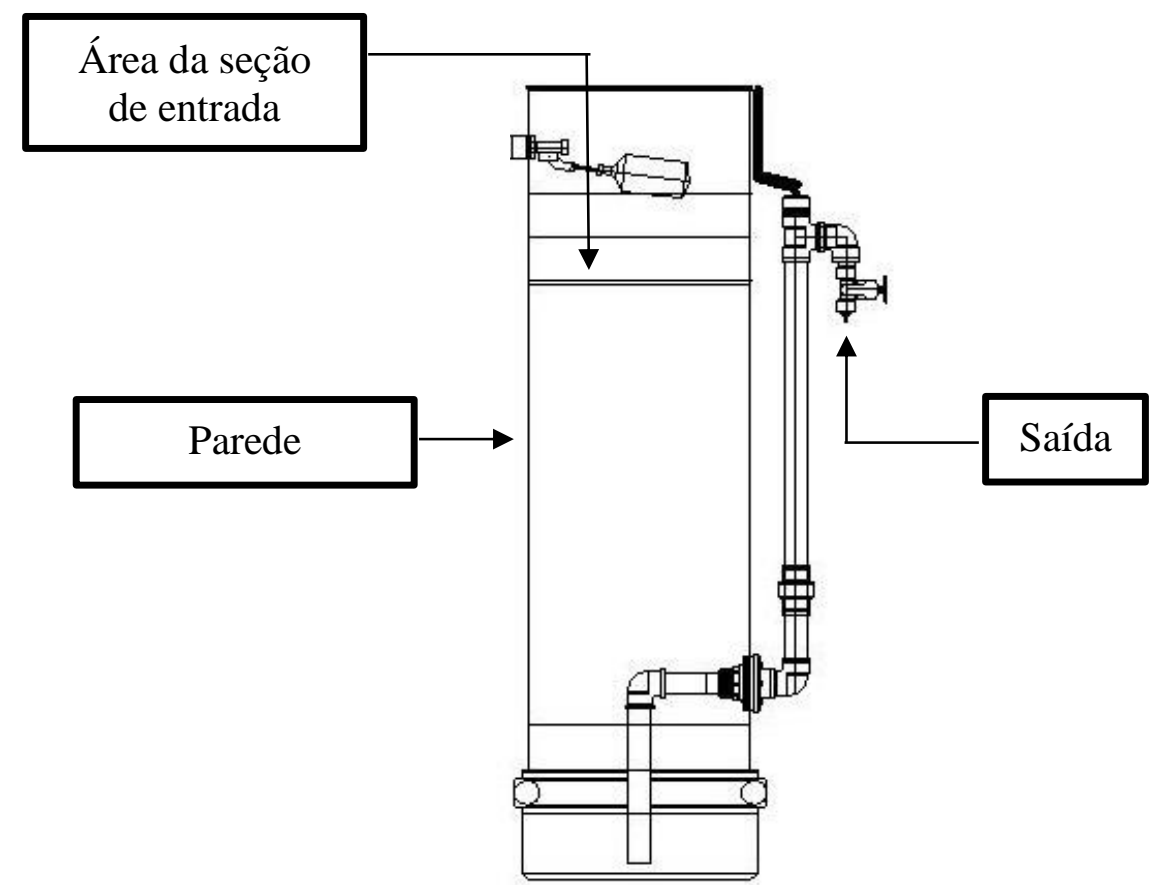

Fonte: Autor 
Os parâmetros físicos utilizados no estudo, ou seja, a espessura das camadas, granulometria, massa específica, o índice de vazios e a permeabilidade foram os mesmos para os quatro filtros.

As espessuras das camadas de água (topo da areia fina), areia fina, areia grossa, pedregulho fino e pedregulho grosso, sequencialmente, foram de $10 \mathrm{~cm}, 50 \mathrm{~cm}, 5 \mathrm{~cm}, 5 \mathrm{~cm} \mathrm{e}$ $7,5 \mathrm{~cm}$.

A velocidade do fluido na entrada dos C-FLDs foi calculada pela razão entre a vazão de alimentação de 48 L.d ${ }^{-1}$ e a área da seção de entrada, conforme a Equação 26.

$$
V=\frac{Q}{A}
$$

$\mathrm{V}$ : Velocidade $\left(\mathrm{m} . \mathrm{s}^{-1}\right)$

Q: vazão $\left(\mathrm{m}^{3} \cdot \mathrm{s}^{-1}\right)$

A: Área $\left(\mathrm{m}^{2}\right)$

A área da seção de entrada, ou seja, área superficial do filtro foi calculada pela equação $\pi . r^{2}$, sendo $r$ o raio do filtro.

A velocidade do fluido na entrada para os I-FLDs foi calculada considerando a velocidade média obtida a partir dos ensaios para obtenção da curva DTR experimental, ou seja, a vazão foi determinada segundo as Equações 26 e 27.

$$
Q=\frac{\text { Volume }}{\Delta t}
$$

Q: vazão $\left(\mathrm{m}^{3} \cdot \mathrm{s}^{-1}\right)$

Volume $\left(\mathrm{m}^{3}\right)$

$\Delta t:$ tempo (s)

O domínio físico estudado é o local onde ocorre as soluções numéricas, no caso dos FLDs, é delimitado pelas paredes do filtro e o seu interior, composto pelas camadas de água e pelas camadas filtrante e suporte. É necessário conhecer as propriedades físicas dos materiais constituintes do domínio físico como: viscosidade, massa específica, pressão, porosidade e condutividade hidráulica.

Considerando a hipótese de que os modelos matemáticos empregados nas simulações numéricas aproximam-se dos valores observados nos experimentos reais para a DTR nos FLDs, 
deve-se empregar no modelo o escoamento em meios porosos que incorpora a resistência de fluxo em uma região definida como "poroso".

\subsubsection{Regime de escoamento em meio poroso}

Os modelos de escoamento em meio poroso podem ser aplicados para problemas monofásicos e multifásicos, incluindo fluxo através de leito empacotado, membranas, placas perfuradas e distribuidores de fluxos.

Na utilização desses modelos, é preciso definir uma região “cell zone” na qual será aplicado o modelo de escoamento em meio poroso definindo-se a perda de pressão no fluxo através da passagem, ou seja, o modelo incorpora uma resistência de fluxo determinada de forma empírica em uma região definida como "meio poroso".

Os modelos de meio poroso para escoamentos monofásicos e escoamentos multifásicos usam a formulação de velocidade superficial em meio poroso como padrão. O ANSYS Fluent calcula a fase superficial ou velocidades de mistura com base na taxa de fluxo volumétrico em uma região porosa.

Nas camadas filtrantes e suporte dos FLDs foi adicionado o termo fonte de momento $\left(S_{i}\right)$ às equações de fluxo de fluido. A equação para meios porosos homogêneos simples, em que o termo fonte de momento é composto de duas partes: viscosa (i.e. Lei de Darcy em meios porosos, o primeiro termo no lado direito da Equação 28), e perda inercial (i.e. o segundo termo do lado direito da Equação 28).

Domínio Poroso (Darcy, 1857; Forchheimer, 1901a, 1901b)

$$
S_{i}=-\left(\frac{\mu}{\alpha} \boldsymbol{u}_{i}+C_{2} \frac{1}{2} \rho|\boldsymbol{u}| \boldsymbol{u}_{i}\right)
$$

Em que, $\boldsymbol{u} \in \mathbb{R}^{3}$ é o vetor velocidade; $\rho$ é a densidade do fluido (água); $\mathrm{p}$ é a pressão; $\mu$ é a viscosidade; onde, $S_{i}$ é o termo fonte para $i$ em $(x, y$ ou $z)$ na equação de momento, $\alpha$ é a permeabilidade do meio poroso, $|u|$ é a magnitude da velocidade, e $D$ e $C$ são as matrizes diagonais com $1 / \alpha$ e $C_{2}$, respectivamente.

Os parâmetros de resistência viscosa da Equação de Ergun e de resistência inercial utilizados para meios porosos foram calculados pelas Equações 29 e 30. 


$$
\alpha=\frac{D_{p}^{2}}{150} \cdot \frac{\varepsilon^{3}}{(1-\varepsilon)^{2}}
$$

1/ $\alpha$ : Resistência viscosa $\left(\mathrm{m}^{-2}\right)$

$\mathrm{D}_{\mathrm{p}}$ : Diâmetro médio da partícula $(\mathrm{m})$

$\varepsilon:$ Índice de vazios $\left(\mathrm{kg} \cdot \mathrm{m}^{-3} \cdot \mathrm{kg}^{-1} \cdot \mathrm{m}^{3}\right)$

$$
C_{2}=\frac{3,5}{D_{p}} \cdot \frac{(1-\varepsilon)}{\varepsilon^{3}}
$$

$\mathrm{C}_{2}$ : Resistência inercial $\left(\mathrm{m}^{-1}\right)$

$\mathrm{D}_{\mathrm{p}}$ : Diâmetro médio da partícula $(\mathrm{m})$

$\varepsilon$ : Índice de vazios $\left(\mathrm{kg} \cdot \mathrm{m}^{-3} \cdot \mathrm{kg}^{-1} \cdot \mathrm{m}^{3}\right)$

Nos fluxos laminares através de meios porosos, a queda de pressão é tipicamente proporcional à velocidade e a constante $C_{2}$ pode ser considerada zero. Ignorando a aceleração convectiva e a difusão, o modelo do meio se reduz à Lei de Darcy (Darcy, 1857), conforme Equação 31:

$$
\nabla p=-\frac{\mu}{\alpha} u
$$

As perdas inerciais em meio poroso, em altas velocidades, podem ser corrigidas pela constante $C_{2}$ da equação 32. Essa constante pode ser vista como um coeficiente de perda de resistência inercial por unidade de comprimento ao longo da direção do fluxo, permitindo assim que a queda de pressão seja especificada como uma função.

Caso, o termo de permeabilidade possa ser eliminado, pode-se usar apenas o termo de perda inercial, produzindo a seguinte forma simplificada da equação do meio poroso, Equação 32:

$$
\nabla p=-\sum_{j=1}^{3} C_{2_{i j}}\left(\frac{1}{2} \rho v_{j}|v|\right)
$$

O modelo efetivamente utilizado foi o composto pelas equações 28,29 e 30 .

\subsubsection{Ensaio de traçador com DFC}

A determinação da distribuição do tempo de residência com DFC utilizou a equação do escalar passivo para um regime transiente como solução para o uso de uma concentração de traçador no modelo. 


\subsubsection{Escalar passivo}

O transporte de um escalar passivo ou conservativo, se dá quando não ocorre o decaimento da substância por reações químicas, ou seja, refere-se à convecção-difusão de um campo escalar dentro do fluido em movimento. Utiliza-se a Equação 33, a seguir, para calcular o escalar passivo e assim solucionar o ensaio de traçador no modelo, (ANSYS, 2013):

$$
\frac{\partial C}{\partial t}+\nabla \cdot(\mathrm{UC})=\nabla \cdot\left(\mathrm{D}_{\text {disp }} \nabla \mathrm{C}\right)
$$

Onde: $\rho$ é a densidade do fluido em $\mathrm{kg} \cdot \mathrm{m}^{-3}$; C é a concentração de traçador em $\mathrm{mg} . \mathrm{L}^{-1}$; U o vetor velocidade em $\mathrm{m} \cdot \mathrm{s}^{-1}$; e $\mathrm{D}_{\text {disp }}$ é o coeficiente de dispersão dado em $\mathrm{m}^{2} \cdot \mathrm{s}^{-1}$.

Nessa equação, o primeiro termo corresponde à concentração de soluto no solvente pelo tempo, o segundo termo corresponde ao termo advectivo de concentração pelo campo de velocidade e o terceiro termo corresponde ao termo difusivo de concentração.

O software ANSYS Fluent pode resolver a equação de transporte para um escalar passivo definido pelo usuário como User-defined scalar (UDS) da mesma forma como resolve a equação de transporte para um escalar como de fração mássica. (ANSYS, 2013). Para simulações transientes, as equações governantes foram discretizadas no espaço e no tempo.

No ensaio de traçador com CFD foram utilizados o coeficiente de difusão a $25^{\circ} \mathrm{C}$ do $\mathrm{NaCl}$ correspondente a $1,612 \times 10^{-9} \mathrm{~m}^{2} \cdot \mathrm{s}^{-1}$ com difusividade de $1,609 \times 10^{-6} \mathrm{~kg} \cdot \mathrm{m}^{-1} \cdot \mathrm{s}^{-1}$, segundo estabelecido em Robinson e Stoke (1965). Nos ensaios dos C-FLDs e nos I-FLDs foi utilizado o valor do escalar adimensional de 100 para se referir a solução de sal 100 mg. $\mathrm{L}^{-1}$ e de 0 para as demais alimentações com água da torneira. A concentração de saída do escalar passivo foi obtida pela integral da área da seção de saída.

\subsubsection{Discretização temporal e definição do passo de tempo}

Segundo Fortuna (2000), a partir dos valores iniciais das grandezas no tempo inicial $t_{0}$, problemas transientes exigem o cálculo da solução da equação diferencial parcial em intervalos sucessivos de tempo $\Delta$ t até o instante final $\mathrm{t}_{f}$, conforme Equação 34:

$$
\mathrm{t}_{0}+\Delta \mathrm{t}, \mathrm{t}_{0}+2 \Delta \mathrm{t}, \mathrm{t}_{0}+3 \Delta \mathrm{t}, \ldots, \mathrm{t}_{f}-\Delta \mathrm{t}, \mathrm{t}_{f}
$$

Para simulações transientes, as equações governantes devem ser discretizadas no espaço e no tempo. A discretização espacial para as equações dependentes do tempo é idêntica ao estado estacionário. A discretização temporal envolve a integração de todos os termos nas equações diferenciais ao longo de um período de tempo $\Delta \mathrm{t}$. A integração dos termos transientes ocorre conforme as Equações 35, 36 ou 37 (ANSYS, 2013). 
Expressão genérica para a evolução temporal de uma variável $\varphi$ é:

$$
\frac{\partial \varphi}{\partial t}=F(\varphi)
$$

Em que a função F incorpora qualquer discretização espacial. Se a derivada de tempo é discretizada usando diferenças progressivas, a discretização temporal de primeira ordem é dada por:

$$
\frac{\varphi^{n+1}-\varphi^{n}}{\Delta t}=F(\varphi)
$$

e a discretização de segunda ordem é dada por:

$$
\frac{3 \varphi^{n+1}-4 \varphi^{n}+\varphi^{n-1}}{2 \Delta t}=F(\varphi)
$$

Em que: $\varphi$ é quantidade escalar; $n+1$ é o valor no próximo nível, $t+\Delta t ; n$ é o valor no tempo atual $(t) ; n-1$ é o valor no tempo anterior $(t-\Delta t)$.

A resolução no tempo é essencial para o sucesso da simulação, ou seja, resolver a partir da definição do passo de tempo. Como o modelo está operando nos limites da malha, deve-se selecionar um passo de tempo que garanta um Número de Courant (Co), menor que 1, conforme a Equação 38.

$$
\text { Co }=\frac{U . \Delta t}{\Delta}<1
$$

em que o parâmetro U é a velocidade local, $\Delta t$ é o passo de tempo e $\Delta$ é o tamanho local dos volumes finitos da malha (ANSYS, 2013).

O Número de Courant é um parâmetro local do domínio fluido que representa a razão entre tempo físico característico para a informação propagar a velocidade U de um nó da malha para o próximo, e o passo de tempo discreto empregado na simulação. O uso de passos de tempo maiores $(\mathrm{Co}>1)$ implica, localmente, em violação da física de transporte da propriedade em análise, o que quase sempre resulta em oscilações numéricas e/ou divergência da solução numérica.

Depois da construção das malhas com refinos diferentes (variação no número de elementos finitos), realizou-se um teste de independência de malha. Nesse teste foi analisado a velocidade obtida para cada malha, a fim de se determinar a partir de qual malha a velocidade não variava significativamente. Então, foi possível obter o mínimo volume do elemento finito a partir das malhas geradas no CFD, adotando o Número de Courant (Co) de 0.9, conforme as Equações 38 e 39. 


$$
\Delta=\sqrt[3]{\min (\Delta \mathrm{V})}
$$

Em que: mín $(\Delta V)$ é o mínimo volume do elemento finito da malha

\subsubsection{Método numérico}

Duas geometrias foram criadas correspondentes a cada diâmetro de filtro $(190 \mathrm{~mm}$ e $250 \mathrm{~mm}$ ), não sendo necessária a construção de quatro geometrias (uma por filtro), uma vez que a característica do escoamento (contínuo ou intermitente) depende somente das condições de contorno inseridas na simulação. As geometrias elaboradas para o C-FLD 1 e I-FLD 1 foram as mesmas, conforme apresentado na Figura 31 e as geometrias do C-FLD 2 e I-FLD 2 também foram as mesmas, conforme apresentado na Figura 32.

Figura 31 - Geometria para o C-FLD 1 e IFLD 1 em 3 D.

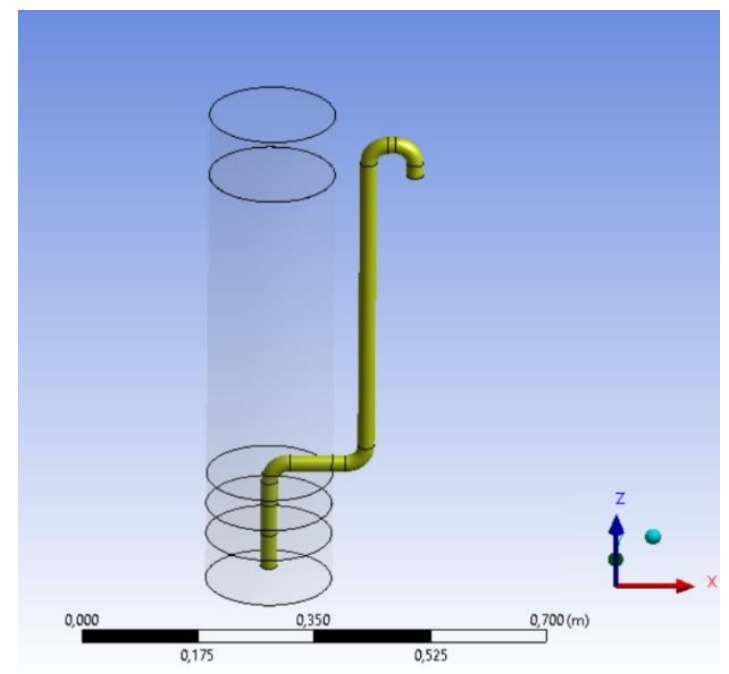

Fonte: Autor
Figura 32 - Geometria para o C-FLD 2 e IFLD 2 em 3 D.

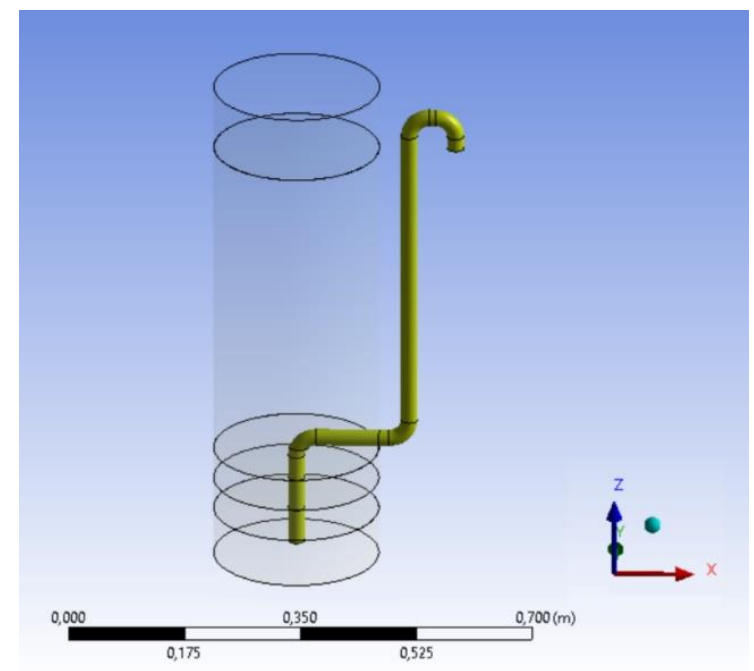

Fonte: Autor

Na Tabela 10 são apresentados os parâmetros numéricos empregados na simulação dos filtros. A pressão de referência adotada foi de $1 \mathrm{~atm}$. e a pressão estática relativa foi de $0 \mathrm{~atm}$, considerando que o experimento foi realizado próximo ao nível do mar e o escoamento era livre.

No I-FLD1 foi utilizado um volume de $30 \mathrm{~L}$ em um tempo de $430 \mathrm{~min}$ e no I-FLD2 foi aplicado 60 L em 360 min, obtidos nos ensaios de traçador experimentais. A pressão relativa 
na saída de 0 atm. foi utilizada, pois o escoamento dependia apenas da variação do nível de água que antecedia a camada de areia fina, ou seja, o escoamento era livre.

Tabela 10 - Parâmetros numéricos de simulação dos filtros

\begin{tabular}{lcccc}
\hline Parâmetros & C-FLD1 & C-FLD2 & I-FLD1 & I-FLD2 \\
\hline $\begin{array}{l}\text { Pressão de referência } \\
\text { [atm.] }\end{array}$ & 1 & 1 & 1 & 1 \\
\hline $\begin{array}{l}\text { Pressão estática relativa } \\
\text { [atm.] }\end{array}$ & 0 & 0 & 0 & 0 \\
\hline $\begin{array}{l}\text { Área da seção da entrada } \\
\text { [m }{ }^{2} \text { ] }\end{array}$ & 0,0283 & 0,0491 & 0,0283 & 0,0491 \\
\hline $\begin{array}{l}\text { Velocidade do fluido na } \\
\text { entrada [m.s }{ }^{-1} \text { ] }\end{array}$ & $1,96 \times 10^{-5}$ & $1,13 \times 10^{-5}$ & $4,10 \times 10^{-5}$ & $5,66 \times 10^{-5}$ \\
\hline $\begin{array}{l}\text { Pressão relativa de saída } \\
\text { [atm.] }\end{array}$ & 0 & 0 & 0 & 0 \\
\hline
\end{tabular}

Notas: C-FLD1 - filtro continuo com diâmetro de $190 \mathrm{~mm}$; C-FLD2: filtro continuo com diâmetro de $250 \mathrm{~mm}$; I-FLD1: filtro intermitente com diâmetro de 190 mm; e I-FLD2: filtro intermitente com diâmetro de $250 \mathrm{~mm}$.

Fonte: Autor

Os parâmetros físicos de espessura da camada e permeabilidade são apresentados na Tabela 11.

Tabela 11 - Parâmetros físicos

\begin{tabular}{|c|c|c|}
\hline Materiais & Espessura camada $(\mathrm{cm})$ & Permeabilidade $\left(\mathrm{cm} . \mathrm{s}^{-1}\right)$ \\
\hline Camada de água & 10 & --- \\
\hline Areia fina & 50 & $1,97 \times 10^{-2}$ \\
\hline Areia grossa & 5 & $1,06 \times 10^{-1}$ \\
\hline Pedregulho miúdo & 5 & 4,75 \\
\hline Pedregulho graúdo & 7,5 & 8,28 \\
\hline
\end{tabular}

Fonte: Autor

Os valores calculados de resistência viscosa $(1 / \alpha)$ e resistência inercial $\left(\mathrm{C}_{2}\right)$ foram obtidos com base nos valores de diâmetro médio da partícula $\left(D_{p}\right)$ e no índice de vazios $(\varepsilon)$ obtidos em ensaio de laboratório, conforme apresentado na Tabela 12. 
Tabela 12 - Características dos meios porosos dos filtros

\begin{tabular}{llllll}
\hline Materiais filtrantes & $\mathrm{D}_{\mathrm{p}}(\mathrm{m})$ & $\varepsilon()$ & $\alpha\left(\mathrm{m}^{2}\right)$ & $1 / \alpha\left(\mathrm{m}^{-2}\right)$ & $\mathrm{C}_{2}\left(\mathrm{~m}^{-1}\right)$ \\
\hline Areia fina & $2,70 \times 10^{-4}$ & 0,40 & $8,64 \times 10^{-11}$ & $1,16 \times 10^{10}$ & $1,21 \times 10^{5}$ \\
\hline Areia grossa & $1,30 \times 10^{-3}$ & 0,46 & $3,76 \times 10^{-9}$ & $2,66 \times 10^{8}$ & $1,49 \times 10^{4}$ \\
\hline Pedregulho fino & $4,00 \times 10^{-3}$ & 0,43 & $2,61 \times 10^{-8}$ & $3,83 \times 10^{7}$ & $6,27 \times 10^{3}$ \\
\hline Pedregulho grosso & $1,04 \times 10^{-2}$ & 0,39 & $1,15 \times 10^{-7}$ & $8,70 \times 10^{6}$ & $3,46 \times 10^{3}$
\end{tabular}

Notas: $1 / \alpha$ : resistência viscosa, $\mathrm{C}_{2}$ : resistência inercial, $\mathrm{D}_{\mathrm{p}}$ : diâmetro médio da partícula, $\varepsilon$ : índice de vazios

Fonte: Autor

Nas simulações realizadas em regime permanente dos FLDS foram utilizados os seguintes métodos de solução: i) Esquema de acoplamento pressão-velocidade: SIMPLE (Semi-Implicit Method for Pressure Linked Equations); ii) discretização espacial de gradiente “células baseadas nos mínimos quadrados"; iii) discretização espacial de pressão "segunda ordem"; e iv) discretização espacial de momentum "upwind de segunda ordem". O tempo computacional para cada uma das simulações foi de aproximadamente 2 horas e foram utilizadas 400 iterações. Os resultados dos resíduos da conservação da massa das simulações foram menores que $1 \times 10^{-5}$.

Nas simulações realizadas em regime transiente, ou seja, nas simulações da DTR foram utilizados os seguintes métodos de solução: i) Formulação transiente de "primeira ordem implícita", ii) esquema de acoplamento SIMPLE. Os parâmetros de simulação são listados na Tabela 13.

Tabela 13 - Parâmetros de simulação das DTRs.

\begin{tabular}{lccccccc}
\hline Parâmetros & C-FLD1 & C-FLD2 & \multicolumn{2}{c}{ I-FLD1 } & \multicolumn{2}{c}{ I-FLD2 } \\
\hline Valor do escalar passivo & 100 & 100 & 100 & 0 & 100 & 0 \\
\hline Passo de tempo (s) & 23 & 56 & 600 & & 600 & \\
\hline Número de passos de tempo & 1566 & 1072 & 13 & 30 & 12 & 24 \\
\hline Número máximo de iterações & 15 & 15 & 15 & & 15 & \\
\hline Tempo computacional total(h) & 5 & 8 & 4 & & 4 & \\
\hline
\end{tabular}

Fonte: Autor 


\subsection{Estudo das anomalias no escoamento obtido com DFC e sua relação com a eficiência dos FLDs}

As zonas de estagnação, também conhecidas como zonas mortas foram definidas com base na comparação entre os espaços percorridos pelas linhas de corrente e o plano de contorno da variação da velocidade, desta forma pode-se determinar as velocidades mínima e máxima do escoamento na zona morta, considerando os espaços onde não existia linha de corrente. Depois de definido esse critério e delimitado a zona morta, pode-se obter o seu volume no ANSYS CFD-Post e calcular a porcentagem que que a zona morta representa em relação ao somatório dos volumes das camadas filtrante e drenantes.

A análise das linhas de corrente apresentada por cada filtro, de acordo com a sua geometria e com o tipo de alimentação, permitiu avaliar se a hidrodinâmica do filtro influencia a sua eficiência na remoção/alteração dos parâmetros de qualidade da água monitorados.

\subsection{Análises estatísticas}

Os testes estatísticos foram realizados com o software PAST 4.03 (PAlaeontological STatistics) de acesso gratuito.

\subsubsection{Teste de hipóteses}

A priori os conjuntos de dados foram avaliados quanto a sua normalidade pelo teste de Shapiro-Wilk, isso permitiu classificar cada conjunto de dados como: dados com distribuição normal (teste de Shapiro-Wilk p >0,05) no qual se aplica testes paramétricos ou dados com distribuição não normal (teste de Shapiro-Wilk $\mathrm{p}<0,05$ ) no qual se aplica testes não paramétricos. Em seguida, os conjuntos de dados em pares foram analisados em relação a sua dependência, podendo ser pareados/dependentes (p.e. comparação da turbidez na entrada e na saída do C-FLD1) ou não pareados/independentes (p.e. comparação da turbidez entre o C-FLD1 e o C-FLD2).

Os conjuntos com distribuição não normal não pareados foram comparados por meio do teste de Mann-Whitney e os pareados foram comparados pelo teste de Wilcoxon, ambos com intervalo de confiança de $95 \%$. Os testes descritos para os dados com distribuição normal ou não normal foram considerados com diferença significativa entre as médias (testes paramétricos) ou entre as medianas (testes não paramétricos) quando o p-valor era menor que 0,05 .

Na comparação de três ou mais grupos se utilizou o teste não paramétrico de KruskalWallis (limite de confiança de 95\%) seguido do teste de Mann-Whitney pairwise. 


\subsubsection{Análises bivariadas}

A análise bivariada é o estudo das correlações entre os parâmetros do monitoramento qualitativo do tratamento da água para cada um dos FLDs. Os parâmetros que foram considerados no estudo foram: temperatura, oxigênio dissolvido, cor aparente, turbidez, condutividade elétrica, absorbância, $\mathrm{pH}$, nitrato, nitrito, coliformes totais e Escherichia coli.

Nas análises bivariadas foram avaliados três conjuntos de dados para cada um dos FLDs. O primeiro conjunto era referente aos dados monitorados diariamente como cor, turbidez, $\mathrm{pH}$, condutividade, temperatura e perda de carga unitária. O segundo conjunto era dos dados de temperatura, oxigênio dissolvido (O. D.) do piezômetro 1 e O. D. do piezômetro 2. Por fim, o terceiro conjunto era dos dados de turbidez, perda de carga unitária, coliformes totais e E. coli.

Os resultados da correlação de Spearman foram avaliados pelo coeficiente de correlação de Spearman $\left(\mathrm{r}_{\mathrm{s}}\right)$ que pode variar de -1 (correlação inversa) até +1 (correlação direta). A correlação de Spearman deve ser aplicada quando ao menos um dos parâmetros analisados é não paramétrico e não exige que a relação entre os parâmetros seja linear, ao contrário dos critérios para se aplicar a correlação de Pearson também denominado como correlação linear. 


\section{RESULTADOS E DISCUSSÃO}

\subsection{Resultados experimentais}

\subsubsection{Caracterização física dos agregados}

Na Figura 33 apresenta-se o resultado da curva granulométrica da areia fina. Observase que a porcentagem de finos foi de $2 \%$ e está em conformidade com o manual CAWST (2009) que recomenda um valor máximo de $4 \%$ para o material passante na peneira \#150 (0,104 mm).

Figura 33 - Curva granulométrica do material filtrante - areia fina

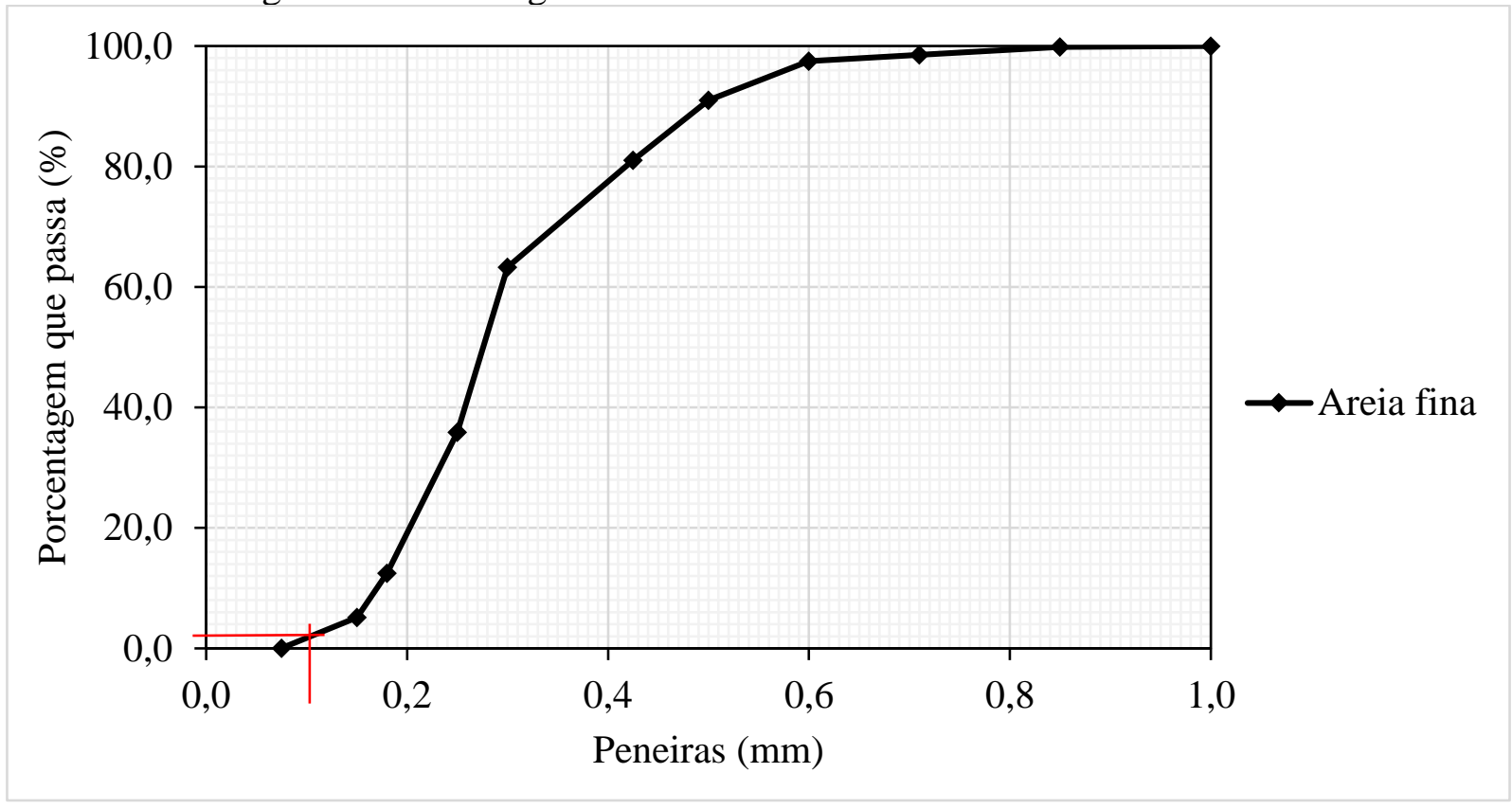

Obs.: As linhas em vermelho indicam a porcentagem de finos.

Fonte: Autor

$\mathrm{Na}$ Tabela 14 apresentam-se os tamanhos efetivos e o coeficiente de uniformidade comparados com o manual da CAWST (2009). Os resultados indicam que a areia fina se enquadra nas recomendações da CAWST (2009). O coeficiente de uniformidade menor que 5,0 indica um material relativamente uniforme segundo a classificação da ABNT NBR 6502 (ABNT, 1995). O manual da CAWST (2009) não aborda recomendações para os materiais que compõem as camadas suporte, apenas para a camada filtrante. 
Tabela 14 - Tamanhos efetivos e coeficiente de uniformidade da areia fina Coeficiente Resultado obtido Recomendação do manual

CAWST (2009)

\begin{tabular}{ccc}
\hline $\begin{array}{c}\text { porcentagem passante na } \\
\text { peneira \#150 }\end{array}$ & $2 \%$ & $4 \%$ \\
\hline $\mathrm{D}_{10}$ & $0,17 \mathrm{~mm}$ & $0,15-0,20 \mathrm{~mm}$ \\
\hline $\mathrm{D}_{60}$ & $0,29 \mathrm{~mm}$ & $0,225-0,5 \mathrm{~mm}$ \\
\hline $\mathrm{CU}$ & 1,73 & $1,5-2,5 \mathrm{~mm}$ \\
\hline
\end{tabular}

Fonte: Autor

As curvas granulométricas dos ensaios da areia grossa, pedregulho miúdo e pedregulho graúdo são mostradas na Figura 34, e, os valores obtidos de $\mathrm{D}_{10}$ e $\mathrm{D}_{60}$ são apresentados na Tabela 15. Os resultados dos coeficientes de uniformidade dos materiais da camada suporte foram menores que 5,0, o que indica que são materiais muito uniformes, segundo a ABNT NBR $6502 / 1995$. 
Figura 34 - Curvas granulométricas das camadas suporte
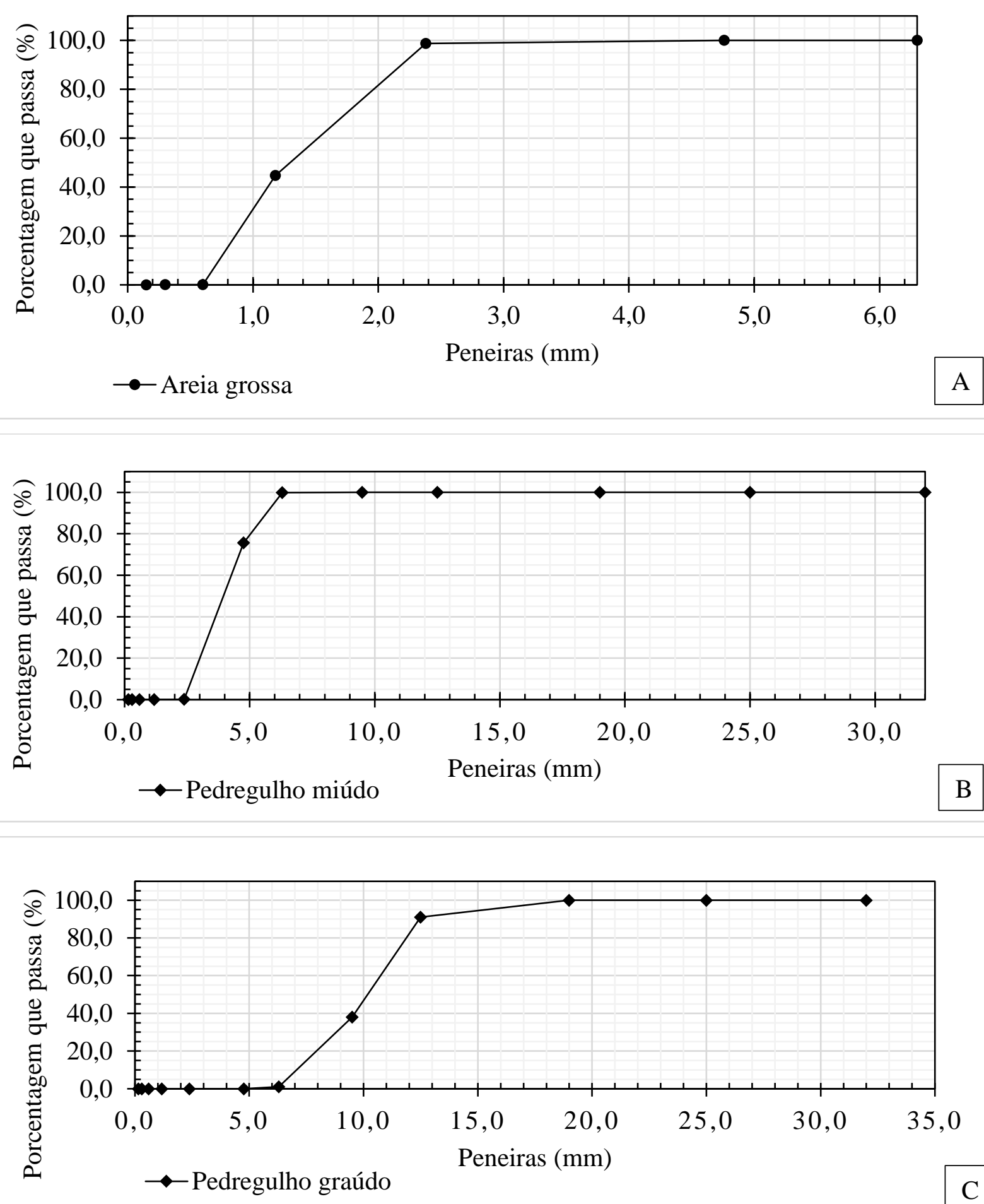

Legenda: A - curva granulométrica da areia grossa; B - curva granulométrica do pedregulho miúdo; C - curva granulométrica do pedregulho graúdo.

Fonte: Autor 
Tabela 15 - Tamanhos efetivos e coeficiente de uniformidade dos materiais das camadas suporte

\begin{tabular}{cccc}
\hline Coeficiente & Areia grossa & Pedregulho miúdo & Pedregulho graúdo \\
\hline $\mathrm{D}_{10}$ & $0,67 \mathrm{~mm}$ & $2,60 \mathrm{~mm}$ & $7,10 \mathrm{~mm}$ \\
\hline $\mathrm{D}_{60}$ & $1,52 \mathrm{~mm}$ & $4,60 \mathrm{~mm}$ & $10,70 \mathrm{~mm}$ \\
\hline $\mathrm{CU}$ & 2,26 & 1,77 & 1,51 \\
\hline
\end{tabular}

Fonte: Autor

Os resultados obtidos nos ensaios para determinação da massa específica são apresentados na Tabela 16 junto com as informações da temperatura dos ensaios. As areias utilizadas na filtração têm massa específica superior a $2,5{\mathrm{~g} . \mathrm{cm}^{-3}}^{\text {e }}$ se enquadram na recomendação da ABNT NBR 1799 (ABNT, 2016).

Tabela 16 - Temperatura de ensaio e massa específica dos materiais filtrantes

\begin{tabular}{lcc}
\hline Material & Temperatura do ensaio $\left({ }^{\circ} \mathrm{C}\right)$ & Massa específica $\left(\mathrm{g} . \mathrm{cm}^{-3}\right)$ \\
\hline Areia fina & 28,4 & 2,66 \\
\hline Areia grossa & 25,4 & 2,64 \\
\hline Pedregulho miúdo & 24,9 & 2,63 \\
\hline Pedregulho graúdo & 24,0 & 2,64 \\
\hline
\end{tabular}

Fonte: Autor

Os resultados obtidos nos ensaios para determinação do índice de vazios são apresentados na Tabela 17.

Tabela 17 - Índice de vazios dos materiais

\begin{tabular}{lc}
\hline Material & Índice de vazios $(\%)$ \\
\hline Areia fina & 40,40 \\
\hline Areia grossa & 45,53 \\
\hline Pedregulho miúdo & 43,38 \\
\hline Pedregulho graúdo & 38,56 \\
\hline
\end{tabular}

Fonte: Autor 
Os resultados obtidos nos ensaios para determinação do coeficiente de permeabilidade são apresentados na Tabela 18. A areia fina teve um coeficiente de permeabilidade menor, seguido da areia grossa, pedregulho miúdo e pedregulho graúdo.

\begin{tabular}{lc}
\multicolumn{3}{l}{ Tabela $18-$ Coeficiente de permeabilidade dos materiais } \\
\hline Material & $\mathrm{k}_{20^{\circ} \mathrm{C}}\left(\mathrm{cm} \cdot \mathrm{s}^{-1}\right)$ \\
\hline Areia fina & $1,97 \times 10^{-2}$ \\
\hline Areia grossa & $1,06 \times 10^{-1}$ \\
\hline Pedregulho miúdo & 4,75 \\
\hline Pedregulho graúdo & 8,28 \\
\hline
\end{tabular}

Fonte: Autor

A areia fina utilizada apresentou diâmetro $D_{10}$, coeficiente de uniformidade e índice de vazios semelhantes à areia utilizadas em FLDs, como por exemplo: o meio filtrante dos FLDs de Jenkins et al. (2011) que apresentou índice de vazios de 45\%; de Maciel (2018) que possuía $\mathrm{D}_{10}$ de 0,13 mm, CU de 1,46 e índice de vazios de 45\%; de Terin e Sabogal- Paz (2019) que apresentou $\mathrm{D}_{10}$ de 0,153 mm, CU de 1,68 e índice de vazios de 45\%; de Andreoli e SabogalPaz (2020) que possuía $\mathrm{D}_{10}$ de 0,19 mm, CU de 2,08 e índice de vazios de 37\%; Fava et al. (2020) com $\mathrm{D}_{10}$ de $0,17 \mathrm{~mm}, \mathrm{CU}$ de 2,27 e índice de vazios de 37\%; e Berbert et al. (2016) que apresentou índice de vazios e permeabilidade para de $40 \%$ e $9,0 \times 10^{-5} \mathrm{~mm}^{2}$ para o meio filtrante, de $60 \%$ e $1,0 \times 10^{-2} \mathrm{~mm}^{2}$ para a areia grossa e de $70 \%$ e $0,1 \mathrm{~mm}^{2}$ para o pedregulho.

\subsubsection{Caracterização química dos agregados}

Na Tabela 19 apresentam-se os resultados do ensaio de solubilidade em ácido para os quatro materiais e o critério da ABNT NBR 11799 (ABNT, 2016). Os resultados obtidos mostram que a areia fina e os materiais das camadas suporte adquiridos estão em conformidade com a solubilidade máxima. 
Tabela 19 - Solubilidade em ácido (\%)

Material

Solubilidade em ácido (\%)

Solubilidade máxima (\%) - ABNT

NBR $11799 / 2016$

\begin{tabular}{lll}
\hline Areia fina & 0,11 & 5 \\
\hline Areia grossa & 0,21 & 5 \\
\hline Pedregulho miúdo & 0,08 & 5 \\
\hline Pedregulho graúdo & 0,01 & 5 \\
\hline
\end{tabular}

Fonte: Autor

Os resultados obtidos com os ensaios de caracterização física e química da areia fina e das camadas suporte apresentaram-se em conformidade com as recomendações exigidas tanto pelo manual da CAWST (2009) quanto pela ABNT NBR 11799/2016. A partir desses resultados, o trabalho prosseguiu com a montagem dos filtros, a determinação da curva DTR e a operação dos filtros, para análise de desempenho quanto a remoção de sólidos e microorganismos.

\subsubsection{Volume de vazios nos filtros lentos domiciliares}

Na Tabela 20 apresentam os volumes de vazios discriminados de cada contribuição para os filtros de acrílico e de Defofo MPVC para determinar qual o volume total de água que comporta cada filtro.

Tabela 20 - Volume de vazios calculado para os filtros

\begin{tabular}{lcccccc}
\hline \multirow{2}{*}{$\begin{array}{l}\text { Partes do } \\
\text { filtro }\end{array}$} & $\begin{array}{c}\text { Índice } \\
\text { de } \\
\text { vazios } \\
(\%)\end{array}$ & $\begin{array}{c}\text { Altura } \\
(\mathrm{m})\end{array}$ & C-FLD 1 & I-FLD 1 & C-FLD 2 & I-FLD 2 \\
\cline { 7 - 7 } & $\begin{array}{l}\text { Areia fina } \\
40,40\end{array}$ & 0,50 & 5,73 & 5,73 & 9,92 & 9,92 \\
\hline $\begin{array}{l}\text { Areia } \\
\text { grossa }\end{array}$ & 45,53 & 0,05 & 0,65 & 0,65 & 1,12 & 1,12 \\
\hline $\begin{array}{l}\text { Pedregulho } \\
\text { fino }\end{array}$ & 43,38 & 0,05 & 0,61 & 0,61 & 1,06 & 1,06 \\
\hline $\begin{array}{l}\text { Pedregulho } \\
\text { grosso }\end{array}$ & 38,56 & 0,075 & 0,82 & 0,82 & 1,42 & 1,42 \\
\hline $\begin{array}{l}\text { Água } \\
\text { estacionária }\end{array}$ & - & 0,05 & 1,42 & 1,42 & 1,42 & 1,42 \\
\hline $\begin{array}{l}\text { Água } \\
\text { estacionária } \\
\text { até a bóia }\end{array}$ & - & - & 1,42 & 0,00 & 1,42 & 0,00 \\
\hline $\begin{array}{l}\text { Tubo DN } \\
25 m m\end{array}$ & - & 1,000 & 0,49 & 0,49 & 0,49 & 0,49 \\
\hline & $\begin{array}{c}\text { Volume de vazios } \\
\text { total (L): }\end{array}$ & 11,13 & 9,72 & 16,85 & 15,43 \\
\hline
\end{tabular}

Fonte: Autor 
Nos quatro filtros, a espessura das camadas e o comprimento da tubulação de saída são iguais, o que difere na geometria dos desenhos são o diâmetro e a altura da lâmina de água estacionária. Isso resultou em um volume de vazios diferentes para cada um dos filtros. Os filtros de acrílico apresentaram um volume de vazios aproximado de 11,1 litros e 9,7 litros para os C-FLD 1 e I-FLD 1, respectivamente. Nos filtros de Defofo MPVC os valores foram de 16,9 litros e 15,4 litros para os C-FLD 2 e I-FLD 2, respectivamente.

Nos FLDs de Maciel (2018) o volume de vazios do modelo intermitente, adotado como o volume de cada alimentação, foi de 16 litros e diariamente eram tratados 32 litros de água. Nos FLDs de escoamento intermitente de Freitas e Sabogal-Paz (2019) e Terin e Sabogal-Paz (2019) eram produzidos 60 L.d ${ }^{-1}$ e a alimentação dos filtros era programada em quatro alimentações de 15 litros cada, volume referente ao volume de vazios de todo o modelo. No estudo de Andreoli e Sabogal-Paz (2020) os filtros de escoamento intermitente eram alimentados três vezes ao dia com 16 litros de água, produzindo diariamente 48 litros de água tratada, e o somatório do volume de vazios do modelo era de 16,24 litros. No estudo de Fava et al. (2020) os FLD produziam diariamente 48 litros, os filtros de escoamento intermitente eram alimentados três vezes ao dia com 16 litros de água. Segundo Elliot et al. (2008) a utilização de um volume de alimentação igual ou menor do que o volume de vazios é recomendada para uma redução de microrganismos.

Nos FLDs de Maciel (2018) a taxa de filtração dos filtros operados continuamente possuíam taxa filtração de $0,68 \mathrm{~m}^{3} \cdot \mathrm{m}^{-2} \cdot \mathrm{d}^{-1}$, que é a taxa correspondente ao volume filtrado diário de 32 litros. Nos FLDs de Freitas e Sabogal-Paz (2019) e Terin e Sabogal-Paz (2019) eram

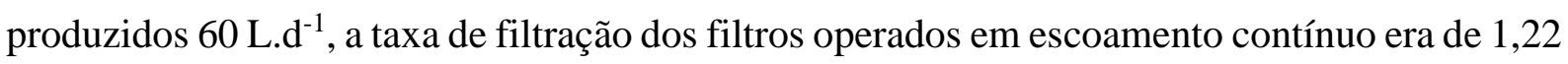
$\mathrm{m}^{3} \cdot \mathrm{m}^{-2} \cdot \mathrm{d}^{-1}$. As taxa de filtração estudadas por Andreoli e Sabogal-Paz (2020) para os filtros em escoamento contínuo foram de 0,88 e $0,87 \mathrm{~m}^{3} \cdot \mathrm{m}^{-2} \cdot \mathrm{d}^{-1}$ para uma produção diária de 48 litros. Fava et al. (2020) estudaram FLDs em escoamento contínuo operados a uma taxa de $0,90 \mathrm{~m}^{3} \cdot \mathrm{m}^{-}$ ${ }^{2} \cdot \mathrm{d}^{-1}$.

\subsubsection{Caracterização do escoamento - Ensaio de traçador experimental}

\subsubsection{Determinação da distribuição do tempo de residência nos filtros contínuos}

As taxas de filtração dos filtros contínuos de acrílico (C- FLD 1) e de Defofo MPVC (C-FLD 2) foram de $1,69 \mathrm{~m}^{3} \cdot \mathrm{m}^{-2} \cdot \mathrm{d}^{-1}$ e $0,97 \mathrm{~m}^{3} \cdot \mathrm{m}^{-2} \cdot \mathrm{d}^{-1}$, respectivamente. Os resultados experimentais mostraram que os tempos médios de residência do C-FLD 1 foi de $293 \pm 6$ min. (4 h $53 \mathrm{~min}$ ) e do C-FLD 2 foi de 506 min. $462 \pm 79$ min. ( 8 h 26 min.). Esses valores estão 
próximos do tempo de residência teórico ou tempo de detenção hidráulico teórico de $300 \pm 8$ min e $450 \pm 13$ min para o C-FLD 1 e C- FLD 2, respectivamente.

Em filtros lentos domiciliares operados à taxa de filtração de $0,38 \pm 0,13 \mathrm{~m}^{3} \cdot \mathrm{m}^{-2} \cdot \mathrm{d}^{-1}$ Sabogal-Paz, et al. (2020) obtiveram a DTR de $857 \pm 21 \mathrm{~min}$. Para a taxa de $0,68 \mathrm{~m}^{3} . \mathrm{m}^{-2} \cdot \mathrm{d}^{-1}$ Maciel e Sabogal-Paz (2018) obtiveram DTRs de 991 min e de 876 min para os FLDs, segundo os autores a diferença ocorreu devido a maior espessura da lâmina de água formada acima da camada filtrante. Na taxa de $0,91 \mathrm{~m}^{3} \cdot \mathrm{m}^{-2} \cdot \mathrm{d}^{-1}$ Andreoli e Sabogal-Paz (2020), a DTR dos FLDs foram de $578 \pm 4,4$ min e $578 \pm 9,3$ min. E para uma taxa mais elevada, de $1,22 \mathrm{~m}^{3} \cdot \mathrm{m}^{-2} \cdot \mathrm{d}^{-1}$ Freitas e Sabogal-Paz (2019) encontrou o tempo médio de residência de $350 \pm 22$ min e Terin e Sabogal-Paz (2019) de $417 \mathrm{~min}$.

Desta forma, as DTRs do C-FLD 1 e do C-FLD 2 são condizentes com os resultados obtidos pelos pesquisadores supracitados. O resultado da DTR do C-FLD 1 foi próximo porém inferior ao obtido por Terin e Sabogal-Paz (2019) e o resultado do C-FLD 2 foi próximo porém inferior ao constatado por Andreoli e Sabogal-Paz (2020), conforme esperado, uma vez que a taxa de filtração tem um relação inversamente proporcional a DTR, logo, como às taxas de filtração eram superiores às taxas encontradas pelos pesquisadores, as DTRs obtidas foram próximas porém menores do que as encontradas por Terin e Sabogal-Paz (2019) e Andreoli e Sabogal-Paz (2020).

Na Figura 35 apresenta-se os resultados obtidos nos ensaios realizados em triplicata para o C-FLD 1 (Figura 35 A) e o C-FLD 2 (Figura 35 B).

Figura 35 - Curvas DTR do C-FLD 1 (A) e do C-FLD 2 (B)
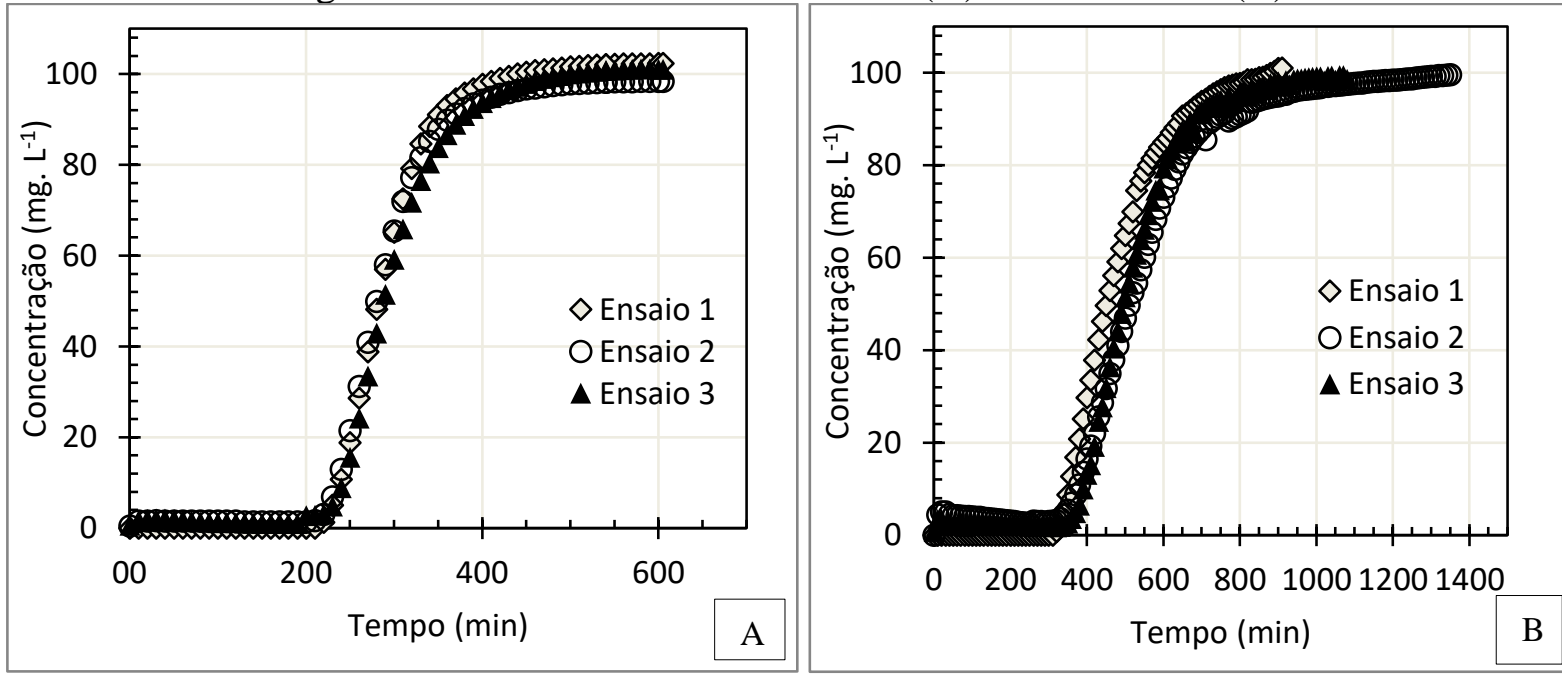

Fonte: Autor 
A normalização das curvas de concentração de traçador por tempo gerou as Curvas $\mathrm{F}$ para o C-FLD 1 e C-FLD 2, apresentadas nas Figuras 36A e 36B, respectivamente.

Figura 36 - Curvas F do C-FLD 1 (A) e do C-FLD 2 (B)
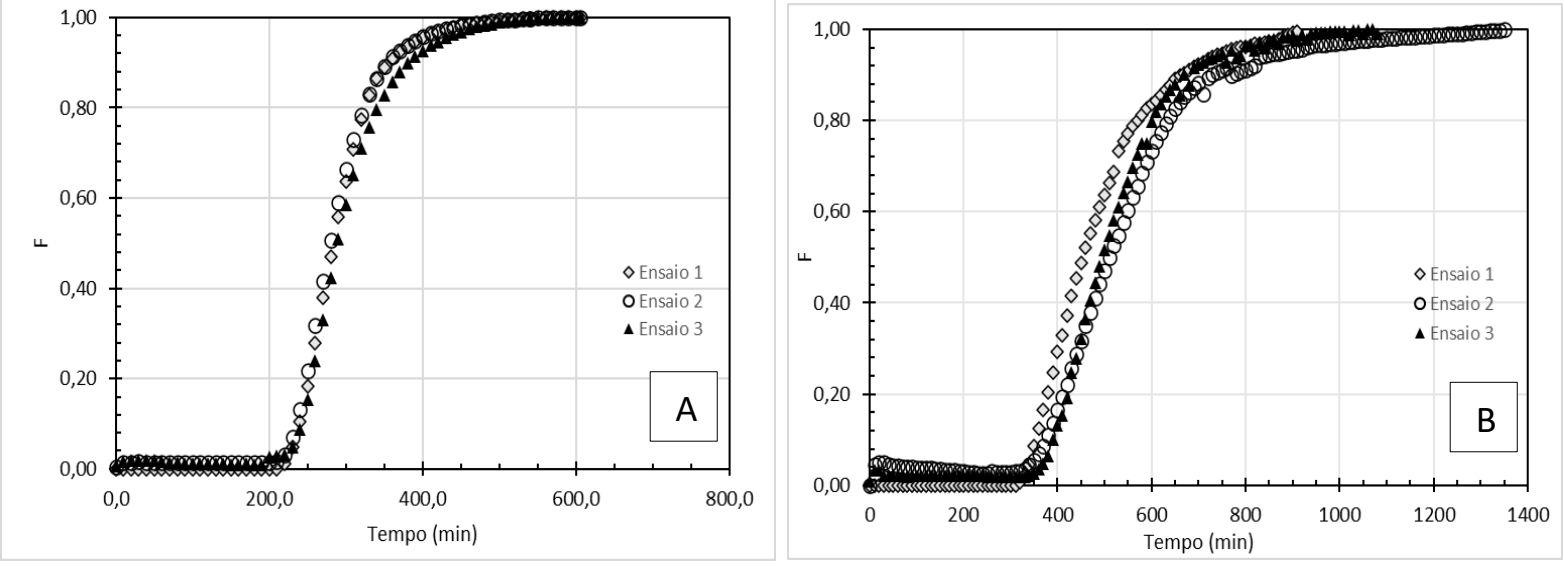

Fonte: Autor

A diferenciação das curvas $\mathrm{F}$ tem como resultados a geração das curvas $\mathrm{E}$ para o C-FLD 1 e o C-FLD 2, conforme apresentadas nas Figura 37A e 37B, respectivamente.

Figura 37 - Curvas E do C-FLD 1 (A) e do C-FLD 2 (B)
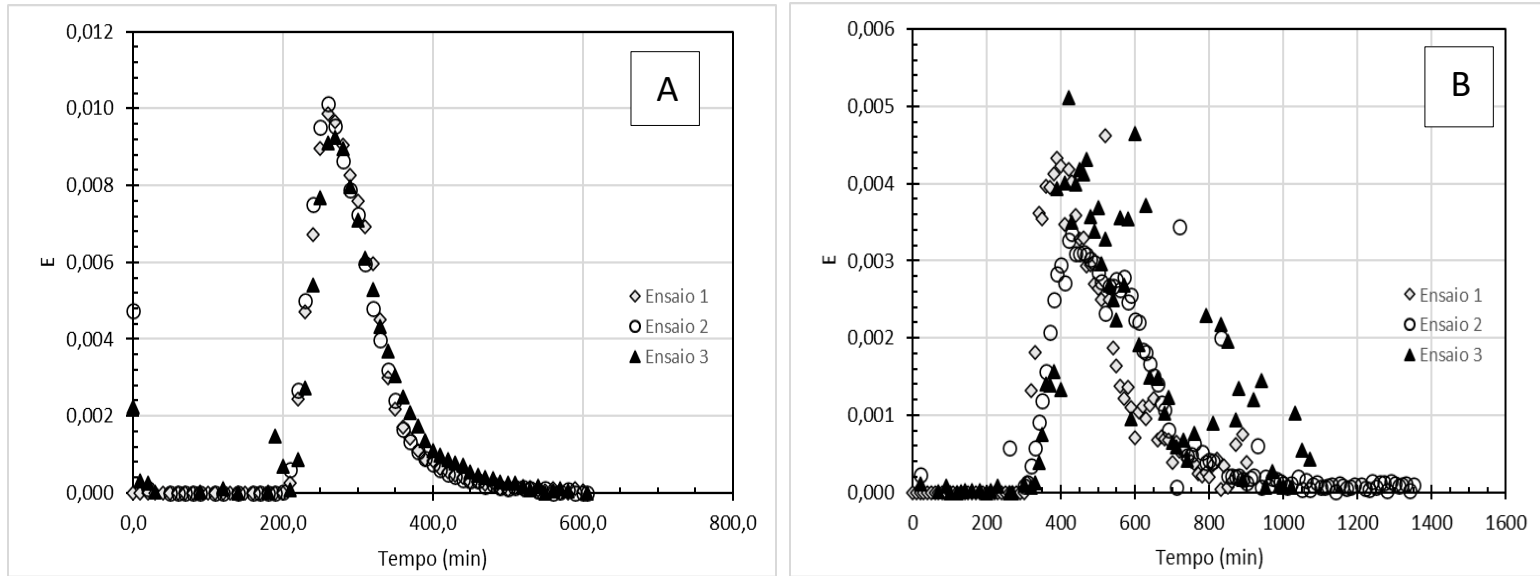

Fonte: Autor

Os resultados dos ensaios de traçador realizados em triplicata nos C-FLD 1 e C-FLD 2 apresentaram uma média da variância adimensional na curva DTR de 0,048 $( \pm 0,012)$ e 0,106 $( \pm 0,029)$, respectivamente, ou seja, o C-FLD 2 apresentou uma variação adimensional maior dos resultados do que os ensaios realizados no C-FLD 1. Esta ocorrência pode estar relacionada com erro do próprio experimento e/ou com a configuração do filtro, uma vez que o C-FLD 1 
possui diâmetro interno de $190 \mathrm{~mm}$ e o C-FLD 2 possui diâmetro interno $250 \mathrm{~mm}$, essa diferença dos diâmetros influencia no volume de água estacionária que fica acima da camada filtrante e pode contribuir para que a difusão do traçador, cloreto de sódio, seja maior nos filtros C-FLD 2.

Os ensaios de traçador realizados nos filtros contínuos permitem caracterizar o modelo do escoamento com base nos extremos de idealidade pistonada (pequena ou grande dispersão) ou de mistura completa (modelo de $\mathrm{n}$ reatores de mistura completa, $\mathrm{N}-\mathrm{CSTR}$ ). As curvas $\mathrm{E}_{\theta} \mathrm{em}$ função de $\theta$ foram geradas a partir das curvas E, o que permitiu determinar a qual o escoamento se assemelha. Nas Figuras 38 e 39 apresentam os modelos gerados para o C-FLD 1 e C-FLD 2, respectivamente, e os parâmetros obtidos de cada modelo.

Os três modelos apresentaram diferenças estatisticamente significativas entre si (teste de Kruskal Wallis ao nível de significância de 5\%) e o modelo N-CSTR apresentou diferença significativa (teste de Mann-Whitney pairwise) em relação ao modelo pistonado de pequena dispersão e ao modelo pistonado de grande dispersão.

Nos três ensaios realizados no C-FLD 1 (área da seção transversal $=0,028 \mathrm{~m}^{2}$ ), o modelo que apresentou o melhor ajuste, segundo a correlação de Pearson, foi o de N-CSTR com correlação média de $0,93( \pm 0,027)$. Esse modelo indicou um número de reatores de mistura completa em série de 28; 19 e 17, que equivale a uma média de 21,65 $( \pm 5,97)$.

Na Figura 39 os modelos N-CSTRs mostram que os picos de saída do traçador se aproximam da localização temporal dos picos dos ensaios experimentais. Em contrapartida, os modelos de dispersão mostraram-se próximos dos valores de pico, porém, sempre com atraso. 
Figura 38 - Modelos hidrodinâmicos ideais para o C-FLD 1
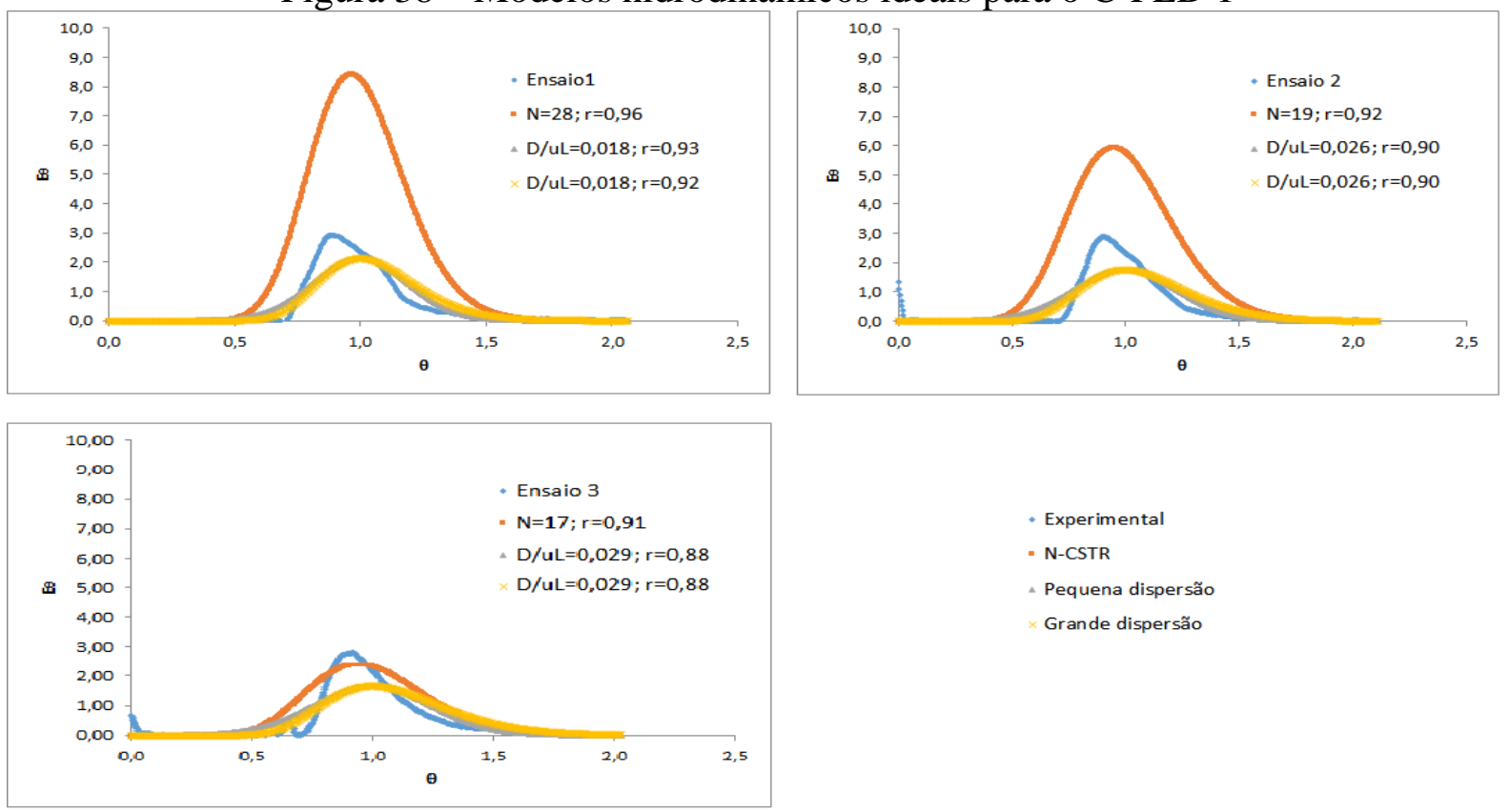

Fonte: Autor

Os três modelos obtidos para o C-FLD 2 também apresentaram diferenças estatisticamente significativas entre si (teste de Kruskal Wallis ao nível de significância de 5\%) e o modelo N-CSTR apresentou diferença significativa (teste de Mann-Whitney pairwise) em relação ao modelo pistonado de pequena dispersão e ao modelo pistonado de grande dispersão.

O ensaio 1 realizado no C-FLD 2 indicou que o modelo que apresentou o melhor ajuste, segundo a correlação de Pearson, foi o N-CSTR com correlação média de 0,88. Já os ensaios em triplicata indicaram que o modelo que apresentou o melhor ajuste, segundo a correlação de Pearson, foi o pistonado de grande dispersão com correlação média de $0,86( \pm 0,043)$.

Na Figura 39 os modelos de dispersão mostraram que a localização temporal de ascensão e decaimento da curva foram próximas dos ensaios experimentais. Por outro lado, os modelos $\mathrm{N}$-CSTRs conseguiram as melhores aproximações da magnitude de pico.

Os modelos indicaram um número de reatores de mistura completa em série de 10; 7 e 12, respectivamente, que equivale a uma média de 9,67 $( \pm 2,05)$. Os resultados experimentais mostram que o filtro teve um comportamento próximo ao apresentado nas curvas obtidas para o modelo N-CSTR. 
Figura 39 - Modelos hidrodinâmicos ideais para o C-FLD 2
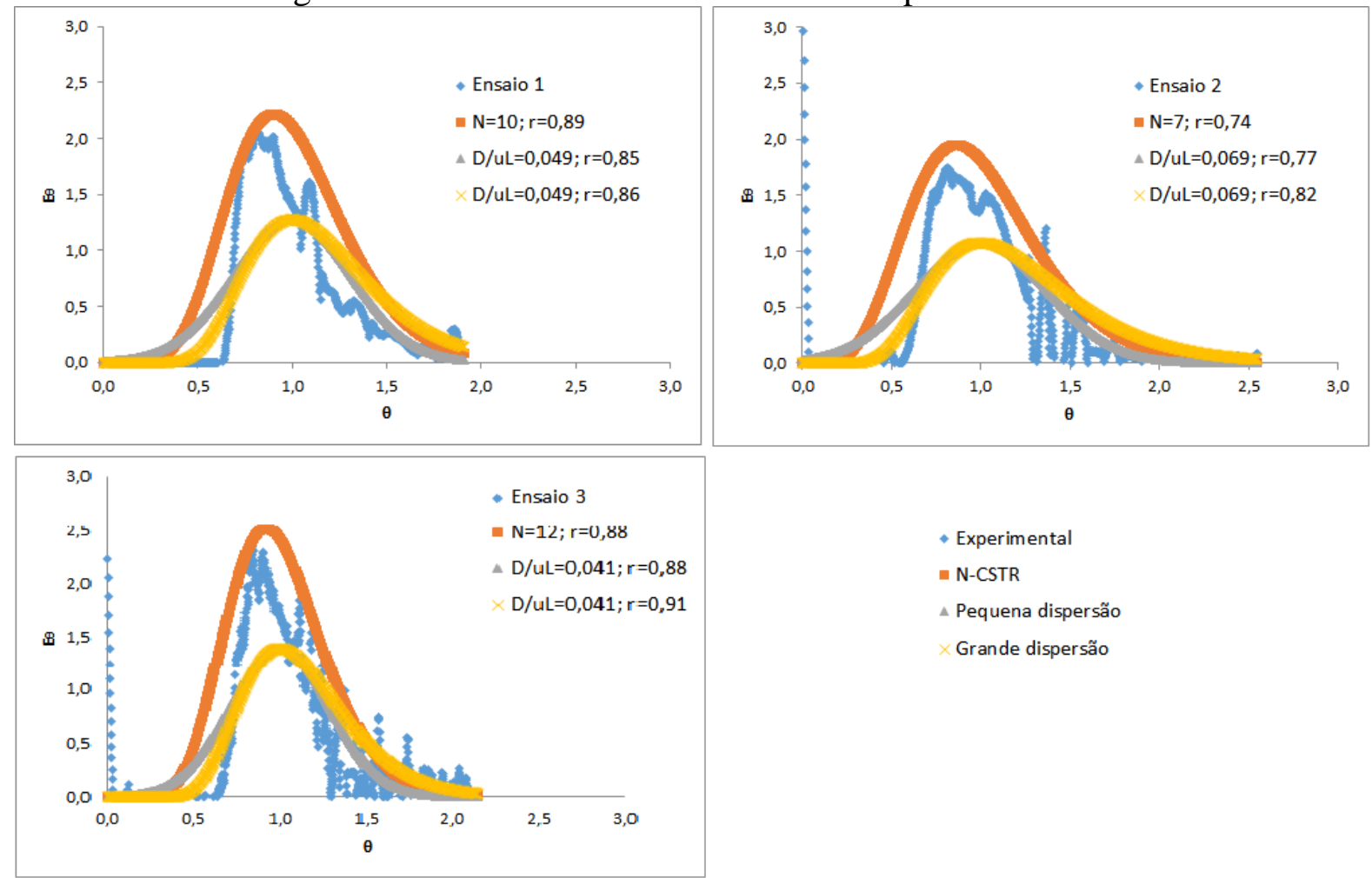

- Experimental

- N-CSTR

$\triangle$ Pequena dispersão

Grande dispersão

Fonte: Autor

O maior número de reatores em série indica um reator de fluxo pistonado (Levenspiel, 1999). Os C-FLDs estudados por Sabogal-Paz et al. (2020) apresentaram N = 17 (seção transversal do filtro de $0,0075 \mathrm{~m}^{2}$ ), os testados por Andreoli e Sabogal-Paz (2020) obtiveram N $=8$ e $\mathrm{N}=13$ (área de seção transversal do filtro de $0,049 \mathrm{~m}^{2}$ ), os testados por Terin e SabogalPaz (2019) tiveram $\mathrm{N}=6$ (área de seção transversal do filtro de 0,049 $\mathrm{m}^{2}$ ). Apesar do C-FLD 1 e do C-FLD 2 se ajustarem a modelos diferentes, os resultados de ambos remetem à um reator de fluxo pistonado.

\subsubsection{Determinação da distribuição do tempo de residência nos filtros intermitentes}

As taxas de filtração do I-FLD 1 e do I-FLD 2 variaram entre 0 e $4,66 \mathrm{~m}^{3} \cdot \mathrm{m}^{-2} \cdot \mathrm{d}^{-1} \mathrm{e}$ entre 0 e $5,28 \mathrm{~m}^{3} \cdot \mathrm{m}^{-2} \cdot \mathrm{d}^{-1}$, respectivamente.

As curvas de distribuição do tempo de residência (DTR) experimentais para os filtros intermitentes de acrílico (I-FLD 1) e de Defofo MPVC (I-FLD 2) que apresentam a concentração de traçador pelo tempo são mostradas na Figura 40A e 40B, respectivamente.

As curvas DTRs e de fração do traçador experimentais em função do volume filtrado do filtro intermitente de acrílico são apresentadas na Figura 41. 
Figura 40 - Curvas DTR do I-FLD 1 (A) e do I-FLD 2 (B)
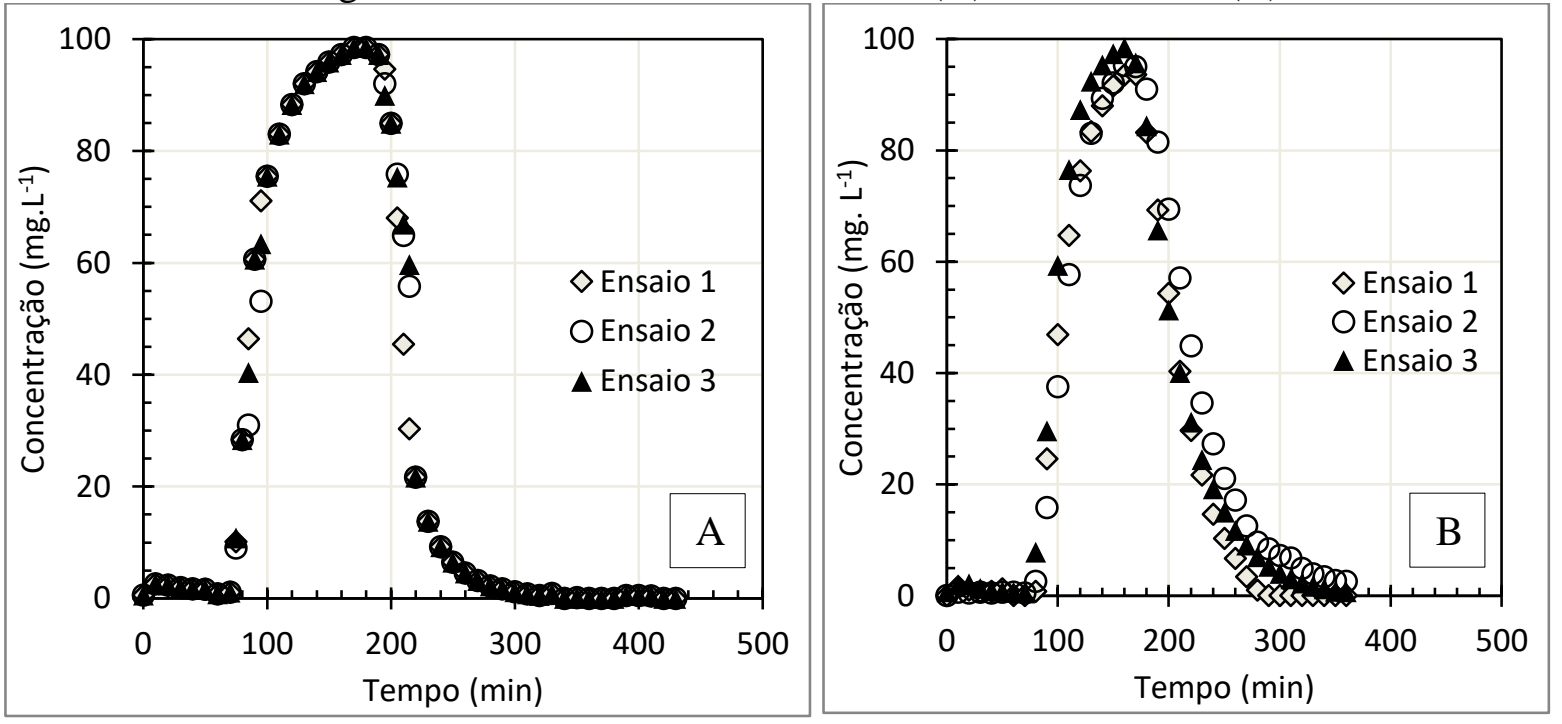

Fonte: Autor

Figura 41 - Curva da concentração de traçador por volume filtrado (A) e curva de porcentagem de traçador acumulado por volume filtrado (B) para o I-FLD 1

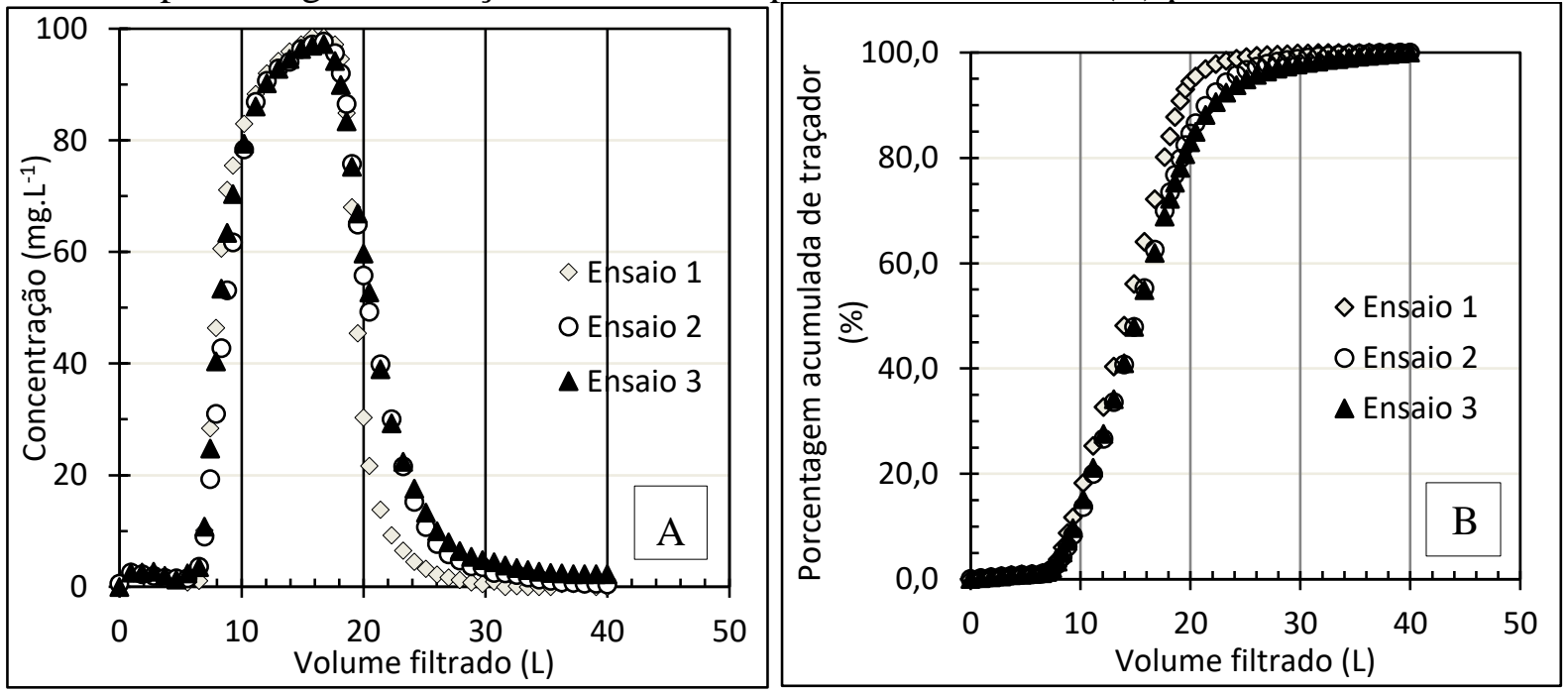

Fonte: Autor

As curvas DTRs e de fração do traçador experimentais em função do volume filtrado do filtro intermitente de I-FLD 2 são apresentadas na Figura 42. 
Figura 42 - Curva da concentração de traçador por volume filtrado (A) e curva de porcentagem de traçador acumulado por volume filtrado (B) para o I-FLD 2

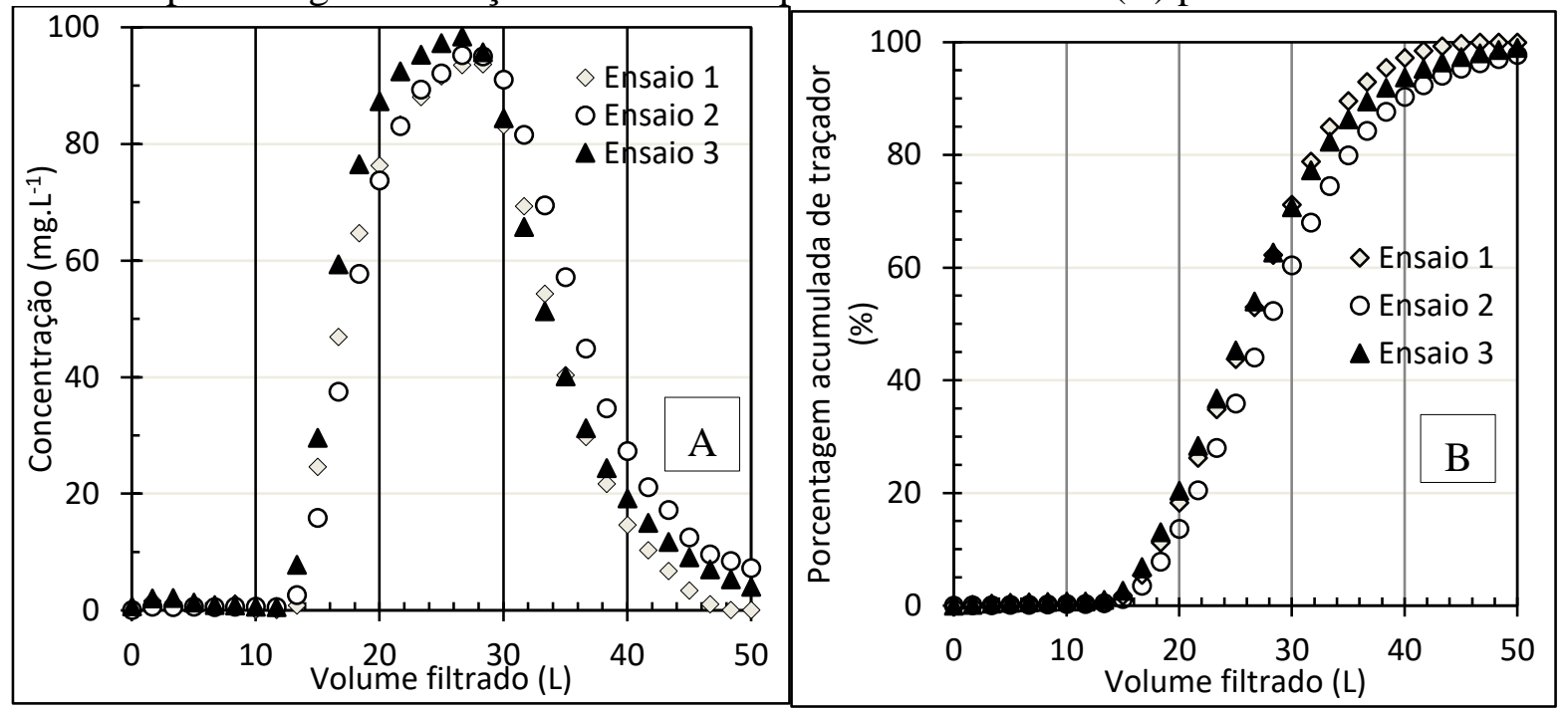

Fonte: Autor

Os resultados do IDM (Índice de Dispersão de Morrill) para o I-FLD 1 e o I-FLD 2 foram de 2,22 $\pm 0,137$ e 2,04 $\pm 0,082$, respectivamente. Esse índice considera que IDM próximo de 1 é um reator de fluxo pistonado (Tchobanoglous, Burton e Stensel, 2003). Bradley et al. (2011), Elliot et al. (2008), Sabogal-Paz et al. (2020) e Yong-Rojanschi e Madramootoo (2015) obtiveram valores de IDM para os FLDs de 1,4; 1,3; 1,54 e 1,8, respectivamente. Segundo a adaptação do IDM ao mIDM proposto por Lynn et al. (2013) que considera o volume acumulado de água filtrada (ao invés do tempo), obtiveram valores de mIDM de 2,92. Andreoli e Sabogal-Paz (2020) obtiveram valores para os I-FLDs de IDM de 2,19 e 2,21 e valores m IDM de 2,47 e 2,56, respectivamente, e Sabogal-Paz et al. (2020) reportaram valores de mIDM de 0,95 . No presente estudo os resultados do mIDM para o I-FLD 1 foi de 2,22 $\pm 0,132$ e para o I-FLD 2 foi de 2,04 \pm 0,082, o que está próximo dos valores obtidos por Andreoli e SabogalPaz (2020).

Os resultados obtidos nos I-FLDs corroboram com os comportamentos descritos por Andreoli e Sabogal-Paz (2020), Bradley et al. (2011), Elliott et al. (2008), Maciel e SabogalPaz (2018), Terin e Sabogal-Paz (2019) e Young-Rojanschi, Madramootoo (2014b), que caracterizaram o I-FLD como um reator de fluxo pistonado.

No final do primeiro, segundo e terceiro volume de alimentação as porcentagens acumuladas de traçador na saída do I-FLD 1 foram de aproximadamente 38; 98\% e 100\%. O IFLD 2 teve quatro alimentações e as porcentagens de alimentações foram de 2; 67; 97 e 100\%. Young-Rojanschi, Madramootoo (2014a) obtiveram 49\% do traçador acumulado no final da 
segunda alimentação, $96 \%$ no final da terceira e os $4 \%$ restantes na quarta alimentação. Nos estudos desenvolvidos por Elliott et al. (2008) e Young-Rojanschi, Madramootoo (2014b) foram utilizados quatro vezes o volume de poros para se executar o ensaio. No I-FLD 2 também foram utilizados quatro vezes o volume de vazios e no I-FLD 1 apenas três. Esse volume menor, pode ter uma relação direta com o volume total de poros, que é menor quando comparado com o I-FLD 2, isso pode ocasionar uma menor dispersão no meio filtrante e um tempo de resposta mais rápido.

Os valores máximos de concentração de traçador obtidos na saída do I-FLD 1 e do IFLD 2 dos ensaios experimentais foram de $98,5 \mathrm{mg}$. $\mathrm{L}^{-1}$ no tempo de $170 \mathrm{~min}$. e de $98,4 \mathrm{mg}$. $\mathrm{L}^{-}$ ${ }^{1}$ no tempo de 160 min., respectivamente.

Os resultados obtidos experimentalmente dos ensaios DTRs do I-FLD 1 e I-FLD 2 mostram que a máxima concentração de $100 \mathrm{mg}$. $\mathrm{L}^{-1}$ não foi alcançada, assim como ocorreu nos ensaios desenvolvidos por Terin e Sabogal-Paz (2019) em que a diferença obtida entre a concentração do traçador de entrada e saída foi de $27 \%$ e pode ser atribuída à diluição que ocorreu no traçador na camada de água superior.

\subsubsection{Monitoramento dos parâmetros de qualidade da água dos filtros lentos domiciliares}

A operação dos FLDs teve início no dia 19/03/2019 e término no dia 20/09/2019, totalizando 186 dias. Os parâmetros de qualidade da água tratada foram comparados com os valores de potabilidade exigidos pelo Ministério da Saúde por meio da Portaria GM/MS no 888/2021 (BRASIL, 2021) e com WHO (WHO, 2011).

Durante o período de operação, o C-FLD 1 foi limpo três vezes, o C-FLD 2 foi limpo uma vez, o I-FLD 1 foi limpo onze vezes e o I-FLD 2 foi limpo três vezes, na Tabela 21 apresentam-se os dias em que foram realizadas as manutenções.

Tabela 21 - Dias de manutenção dos filtros.

\begin{tabular}{ll}
\hline Filtros & Dia de operação \\
\hline C-FLD 1 & $51 ; 94 ; 141$ \\
\hline C-FLD 2 & 101 \\
\hline I-FLD 1 & $9 ; 16 ; 19 ; 24 ; 37 ; 66 ; 93 ; 110 ; 124 ; 141 ; 145$ \\
\hline I-FLD 2 & $19 ; 102 ; 149$ \\
\hline
\end{tabular}

Fonte: Autor 
Na Figura 43 apresentam-se os resultados de vazão dos filtros intermitentes. O I-FLD 1 teve a vazão máxima de $1,53 \mathrm{ml} . \mathrm{s}^{-1}$ ou $1,32 \times 10^{-1} \mathrm{~m}^{3} \cdot \mathrm{d}^{-1}$ e a mínima de $0,13 \mathrm{ml} . \mathrm{s}^{-1}$ ou $1,12 \mathrm{x}$ $10^{-2} \mathrm{~m}^{3} \cdot \mathrm{d}^{-1}$ e no I-FLD 2 foi de $3,0 \mathrm{ml} . \mathrm{s}^{-1}$ ou $2,59 \times 10^{-1} \mathrm{~m}^{3} \cdot \mathrm{d}^{-1}$ e $0,1 \mathrm{ml} . \mathrm{s}^{-1}$ ou $8,64 \times 10^{-3} \mathrm{~m}^{3} \cdot \mathrm{d}^{-1}$, respectivamente. As maiores vazões foram no I-FLD 2 devido ao maior volume de água a ser tratada, volume este, que foi determinado pelo índice de vazios. O declínio da vazão ao longo dos dias, em ambos os filtros, ocorreu conforme esperado, devido ao acúmulo de partículas e à maturação da camada biológica. Kennedy et. al. (2012) também constataram uma diminuição da vazão ao longo dos dias de operação.

Os filtros com diâmetro menor tiveram uma diminuição mais rápida da vazão e foi preciso realizar o procedimento de limpeza com mais frequência quando comparados com os filtros de maior diâmetro do mesmo tipo de escoamento, isso ocorreu, pois o volume de água a ser tratada era a mesma nos filtros e como o volume de vazios era menor, acarretou na redução da capacidade dos filtros de reter partículas quando comparados com os filtros com diâmetro maior.

Figura 43 - Vazão dos filtros intermitentes

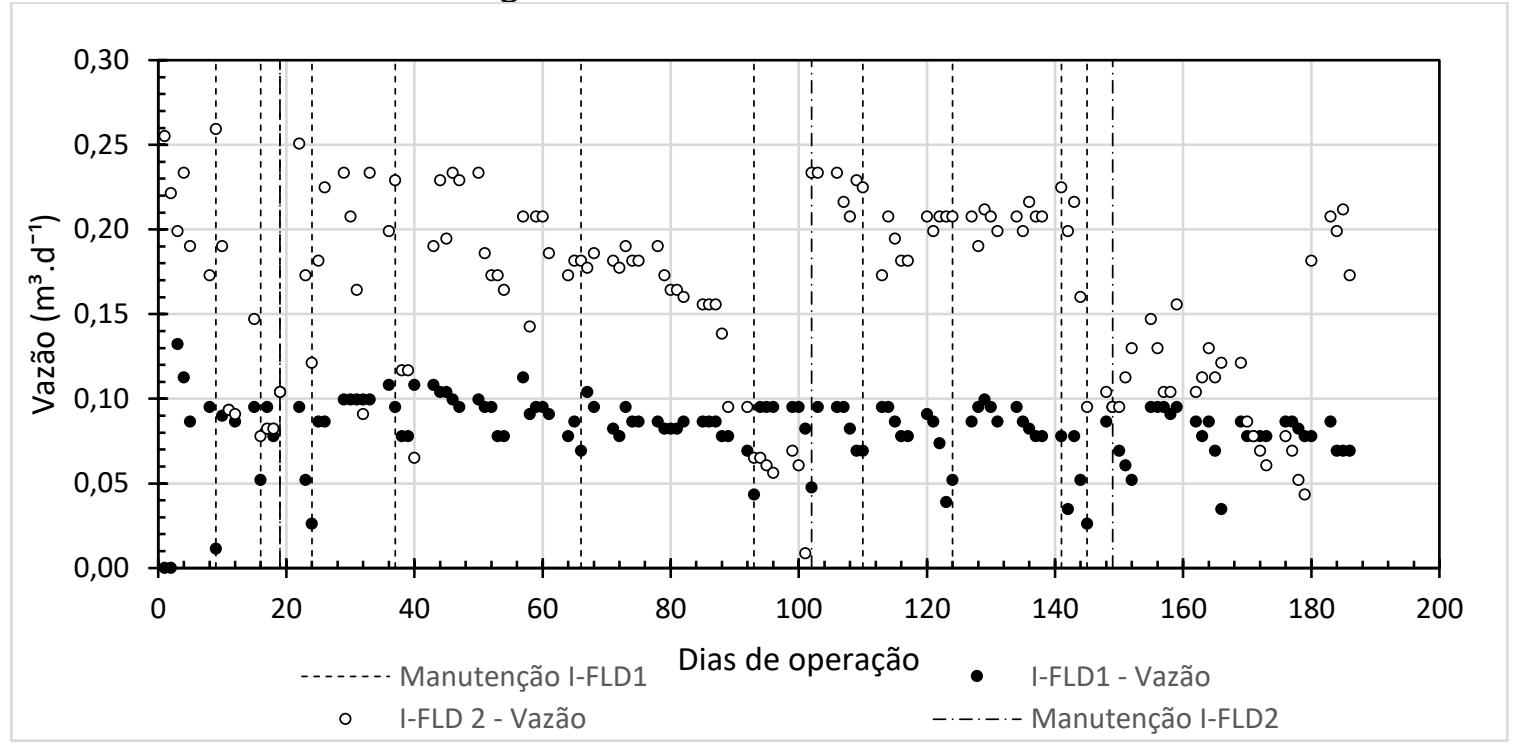

Fonte: Autor

Na Figura 44 apresentam-se os resultados das taxas de filtração dos filtros operados em regime intermitente. As taxas máximas de filtração foram de $4,66 \mathrm{~m}^{3} \cdot \mathrm{m}^{-2} \cdot \mathrm{d}^{-1} \mathrm{e}$ de $5,28 \mathrm{~m}^{3} \cdot \mathrm{m}^{-}$ ${ }^{2} \cdot \mathrm{d}^{-1}$ para o I-FLD 1 e o I-FLD 2, respectivamente, o que atendeu o limite de $9,6 \mathrm{~m}^{3} \cdot \mathrm{m}^{-2} \cdot \mathrm{d}^{-1}$ (CAWST, 2012). Com o avanço dos dias de operação, as impurezas eram retidas nos poros do meio filtrante e a camada biológica era desenvolvida, o que gerava um aumento da perda de 
carga e consequentemente uma redução na taxa de filtração, ficando próxima de zero, sempre após uma redução considerável da taxa de filtração foi necessário realizar a limpeza dos filtros para continuar a sua produção diária de 48 litros.

O decaimento da taxa de filtração durante à carreira de filtração está associado à melhoria da eficiência na redução de microrganismos (STAUBER et al., 2006; ELLIOTT et al., 2008) e no item 5.1.7 de análises bivariadas é apresentada a correlação obtida entre perda de carga e os microorganismos para os FLDs.

Figura 44 - Taxa de filtração dos filtros lentos domiciliares em regime intermitente (I-FLD 1 e I- FLD 2)

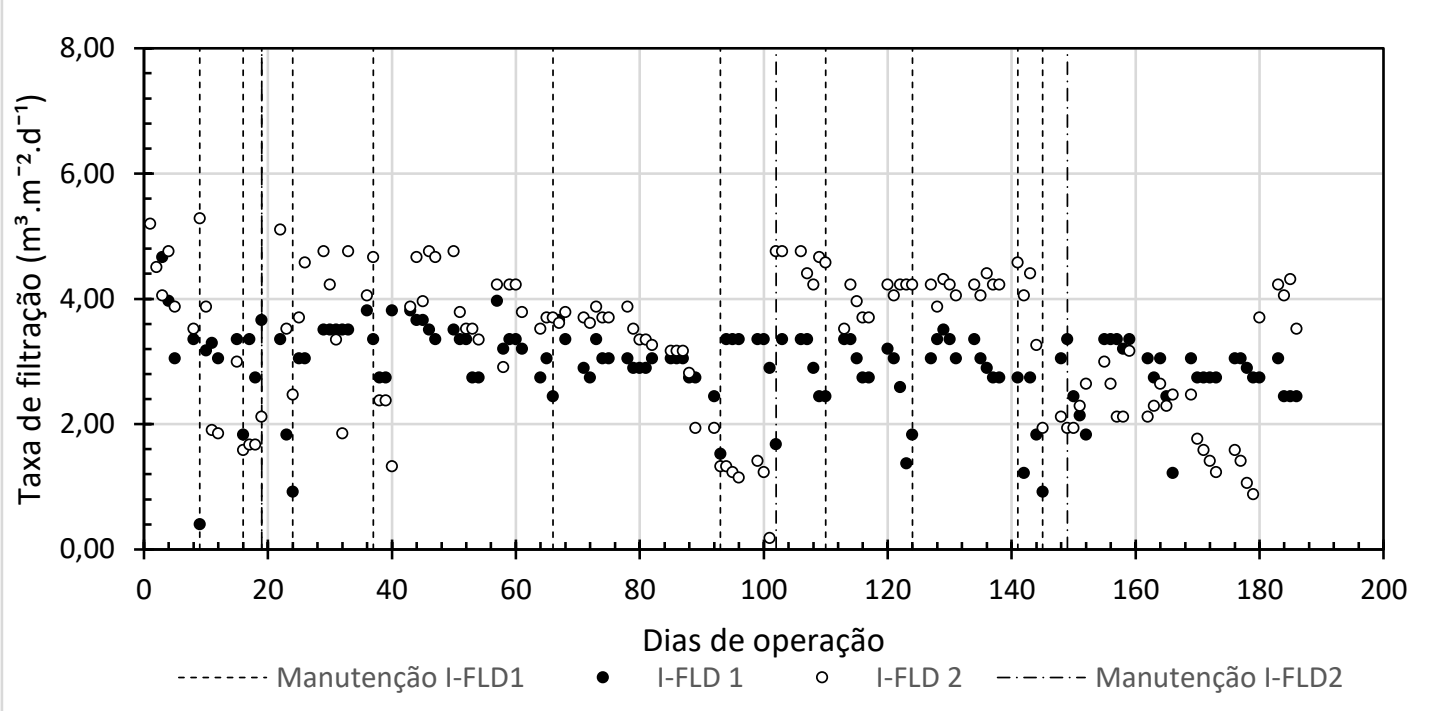

Fonte: Autor

As taxas de filtração de Maciel e Sabogal-Paz (2018) para os filtros operados em escoamento intermitente ficaram entre 9,0 e $0,8 \mathrm{~m}^{3} \cdot \mathrm{m}^{-2} \cdot \mathrm{d}^{-1}$ (início e fim da carreira de filtração) e entre 4,6 e $0,9 \mathrm{~m}^{3} \cdot \mathrm{m}^{-2} \cdot \mathrm{d}^{-1}$ (início e fim da carreira de filtração). No FLD de escoamento intermitente de Terin e Sabogal-Paz (2019) a máxima taxa de filtração foi de $2,95 \mathrm{~m}^{3} \cdot \mathrm{m}^{-2} \cdot \mathrm{d}^{-1}$, no de Freitas e Sabogal-Paz (2019) a taxa máxima foi de $2,79 \mathrm{~m}^{3} \cdot \mathrm{m}^{-2} \cdot \mathrm{d}^{-1}$. Andreoli e SabogalPaz (2020) obtiveram as taxas de filtração máximas para os filtros intermitentes de 6,93 e de $6,59 \mathrm{~m}^{3} \cdot \mathrm{m}^{-2} \cdot \mathrm{d}^{-1}$ e Fava et al. (2020) tiveram os valores máximos de 11,9 e $9,0 \mathrm{~m}^{3} \cdot \mathrm{m}^{-2} \cdot \mathrm{d}^{-1}$.

A redução da taxa de filtração e o consequente aumento da perda de carga mostram o avanço da carreira de filtração que é decorrente da retenção de impurezas na camada filtrante e da formação da camada biológica o que gera melhor eficiência na redução de microorganismos. As melhores eficiências para redução de E. coli para o I-FLD 1 e o I-FLD 2 ocorreram quando a taxa de filtração foi de $1,22 \mathrm{~m}^{3} \cdot \mathrm{m}^{-2} \cdot \mathrm{d}^{-1}$ e $4,05 \mathrm{~m}^{3} \cdot \mathrm{m}^{-2} \cdot \mathrm{d}^{-1}$, respectivamente. Nos dois filtros 
operados em escoamento intermitentes de Maciel e Sabogal-Paz (2018), as melhores eficiência de redução de $E$. coli foram quando a taxa de filtração máxima estava em $1 \mathrm{~m}^{3} \cdot \mathrm{m}^{-2} \cdot \mathrm{d}^{-1} \mathrm{e} 3 \mathrm{~m}^{3} \cdot \mathrm{m}^{-}$ ${ }^{2} \cdot \mathrm{d}^{-1}$, já no estudo de Elliott et al. (2008) a melhor eficiência foi atingida quando a taxa de filtração máxima foi de $2,4 \mathrm{~m}^{3} \cdot \mathrm{m}^{-2} \cdot \mathrm{d}^{-1}$.

Os FLDs contínuos foram operados com a taxa de filtração constante e esse parâmetro não pode ser utilizado como indicativo de perda de carga, logo, a leitura diária dos piezômetros instalados ao longo do corpo do filtro permitiu o registro e análise diária da perda carga tanto nos FLDs contínuos quanto nos intermitentes.

As perdas de cargas unitárias dos filtros contínuos são apresentadas nas Figuras 45 e 46. Para obtenção desses resultados utilizou-se a perda de carga entre o primeiro e o último piezômetro $(\Delta \mathrm{h})$ e o comprimento $(\mathrm{L})$ dessas duas tomadas de pressão para se obter a razão $\Delta \mathrm{h} / \mathrm{L}$.

No filtro C-FLD 1 as carreiras de filtração duraram, 51, 43 e 47 dias (média $47 \pm 3$ dias), já no C-FLD 2 a primeira carreira de filtração durou 101 dias até que fosse necessária sua limpeza. Vale ressaltar que a água de alimentação tinha qualidade diferente a cada dia e mesmo assim as carreiras de filtração do C-FLD 2 mostraram-se próximas.

Nos primeiros 20 dias de operação a turbidez da AE atingiu o máximo de 100 UNT e depois ficou próxima de 5 UNT, isso afetou consideravelmente a periodicidade de limpeza esperada para no C-FLD 2, logo, essa melhor qualidade da água de alimentação após os 20 dias fez com que não fosse necessário realizar uma limpeza logo no início da operação, como ocorreu no C-FLD 1. Como o C-FLD 2 tem um diâmetro maior, pode-se relacionar que a maior quantidade de poros fez com que o C-FLD 2 apresentasse maior resiliência para essa variação da qualidade da água de estudo e consequentemente reduzisse a necessidade de limpeza. No início da segunda carreira de filtração do C-FLD 2, a perda de carga foi menor quando comparada com o início da primeira carreira, essa diferença de comportamento está associada a turbidez da $\mathrm{AE}$ que foi elevada nos primeiros dias e depois se manteve baixa, conforme reportado anteriormente.

Maciel (2018) obteve carreiras de filtração em filtros contínuos que duraram 84 e 85 dias e filtros com duração de carreiras médias de 60 e 33 dias.

Nos experimentos de Elliott et al. (2008) e de Nair e Ahammed (2014) a duração das carreiras de filtração, em filtros operados em escoamento intermitente, foram de 50 dias e de 86 dias, respectivamente. Maciel (2018) obteve carreiras de filtração em filtros intermitentes que duraram em média de 24, 28 e 18 dias. 
Figura 45 - Perda de carga unitária entre piezômetro 1 e 6 do C-FLD 1

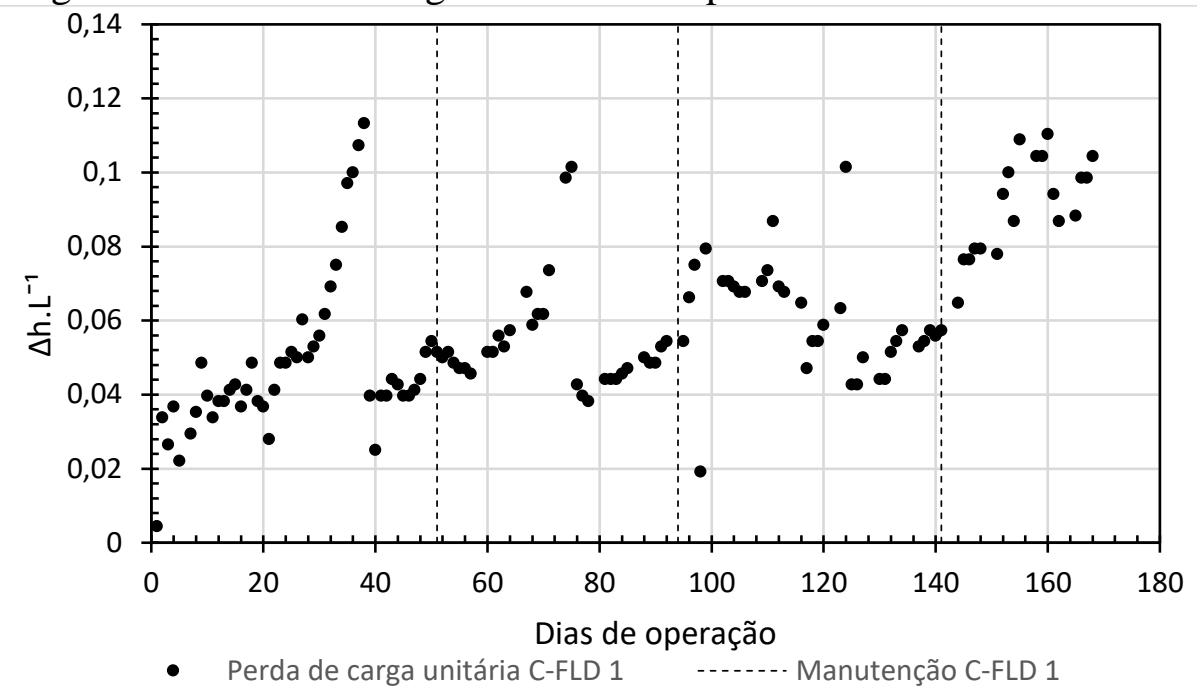

Fonte: Autor

Figura 46 - Perda de carga unitária entre piezômetro 1 e 6 do C-FLD 2

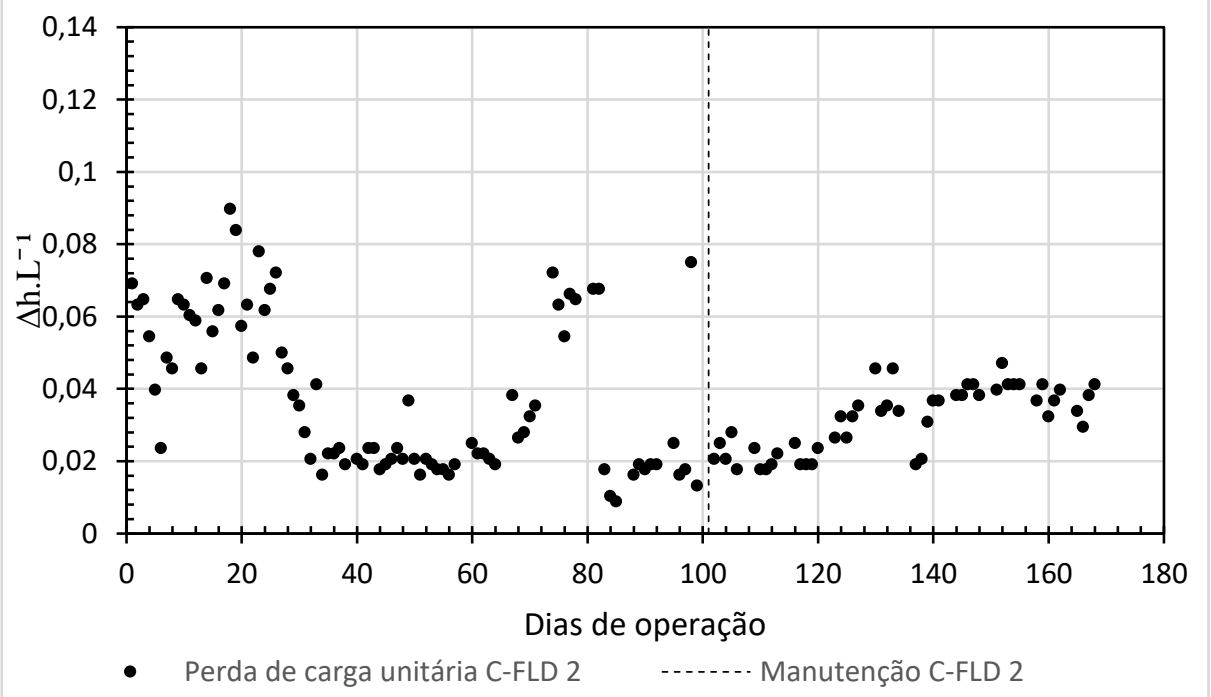

Fonte: Autor

As perdas de cargas unitárias dos filtros intermitentes são apresentadas nas Figuras 47 e 48. Nos filtros intermitentes, o número de limpezas no filtro com maior diâmetro (I-FLD 2) foi menor, assim como analisado nos filtros contínuos.

No filtro I-FLD 1 as carreiras de filtração duraram 9, 7, 3, 5, 13, 29, 27, 17, 14, 17 e 4 dias (média $13 \pm 8$ dias) e no I-FLD 2 duraram 19, 83 e 47 dias (média $50 \pm 26$ dias). No I-FLD 2 o comportamento das duas primeiras carreiras de filtração foram diferentes das demais, a primeira carreira foi a mais curta e isso pode ser uma consequência da qualidade da AE nos primeiros 20 dias que teve a turbidez elevada, depois a turbidez baixa da AE nos demais dias 
causou alterações nas perdas de cargas da segunda carreira de filtração, até que o filtro atingisse a sua estabilização, e esse comportamento da segunda carreira foi semelhante para a carreira subsequente.

Figura 47 - Perda de carga unitária entre piezômetro 1 e 6 do I-FLD 1

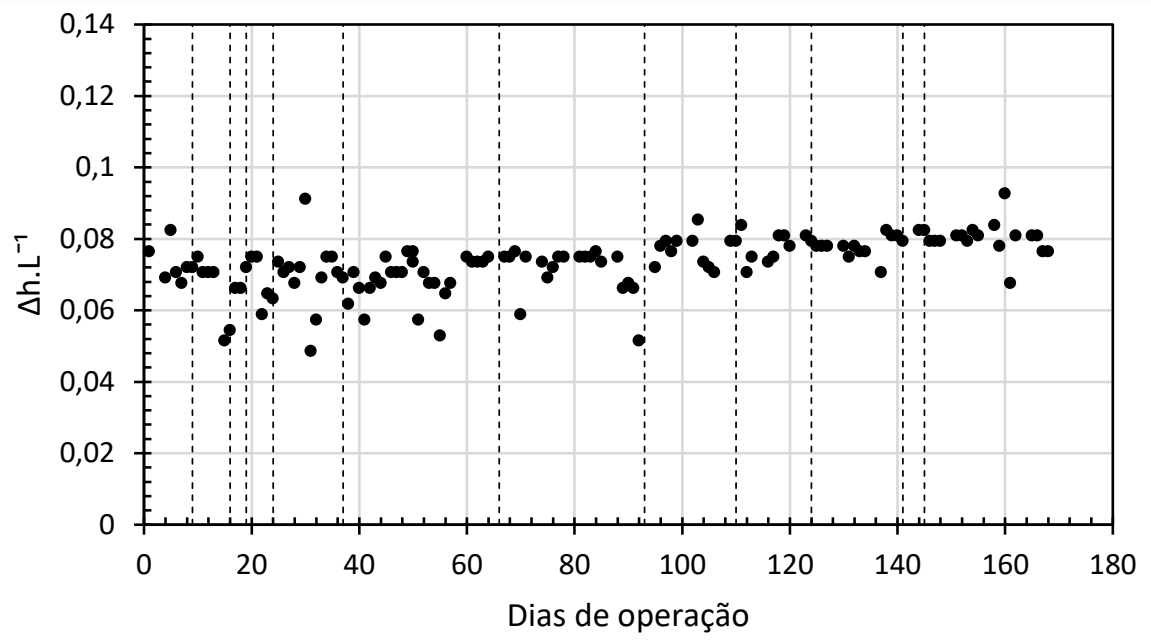

- Perda de carga unitário I-FLD 1 -..-...- Manutenção I-FLD 1

Fonte: Autor

Figura 48 - Perda de carga unitária entre piezômetro 1 e 6 do I-FLD 2

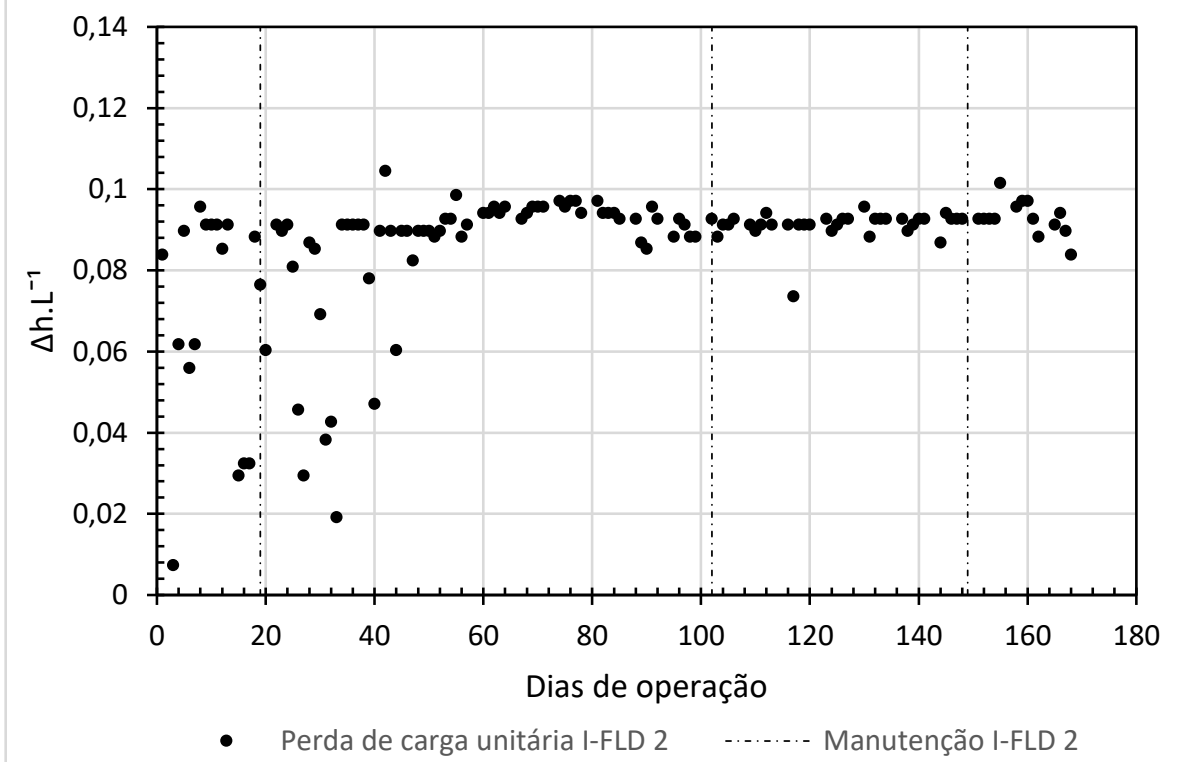

Fonte: Autor

A perda de carga total no C-FLD 1 e no C-FLD 2 variou de 0,3 a 7,7 $\mathrm{cm}$ e de 0,6 a 6,1 cm, respectivamente. Assim como Maciel (2018), que obteve comportamento ascendente da perda de carga ao longo da carreira de filtração e a variação nos FLDs contínuos foi de 2,6 a $10,5 \mathrm{~cm}$. 
No I-FLD 1 e no I-FLD 2 a variação da perda de carga total foi de 3,3 a 6,3 cm e de 0,5 a 7,1 cm, respectivamente. Apesar dessa variação ser semelhante nos FLDs contínuo e intermitentes, o comportamento ao longo da operação foi diferente, ou seja, o aumento da perda de carga unitária nos filtros contínuo é gradativo e nítido até ser realizada a limpeza/manutenção, fato que não foi observado nos filtros intermitentes.

Essa diferença de comportamento da perda de carga mostra que o tipo de alimentação influencia diretamente a resposta da perda de carga, ou seja, como os filtros de operação contínuos tem a sua vazão constantemente ajustada, a perda de carga variou de forma gradativa, já nos filtros intermitentes em que houve variação na vazão de alimentação, a perda de carga teve oscilações.

Os resultados do monitoramento da perda de carga nos FLDs contínuo e intermitentes corroboram com os resultados obtido por Maciel (2018) que constatou poucas alterações nas leituras dos últimos piezômetros dos FLDs contínuos, diferente do que foi observado nos FLDs intermitentes que tiveram um aumento de perda de carga apresentada no último piezômetro ao longo das carreiras de filtração.

\subsubsection{Parâmetros físico e químicos}

\subsection{Temperatura e oxigênio dissolvido}

Como os filtros foram instalados em uma sala e protegidos de intempéries, foram monitoradas a temperatura do ar e a temperatura da água de estudo que estava na bombona às 7 horas, antes da alimentação dos filtros. As temperaturas variaram em função das condições climáticas conforme apresentado na Figura 49, a temperatura da água sempre foi igual ou superior que a temperatura do ar. A temperatura média do ar foi de $21,2 \pm 2,2{ }^{\circ} \mathrm{C}$ e a temperatura média da água de estudo foi de $22,4 \pm 2,0{ }^{\circ} \mathrm{C}$. 
Figura 49 - Temperatura do ar, da água de estudo e do ar condicionado

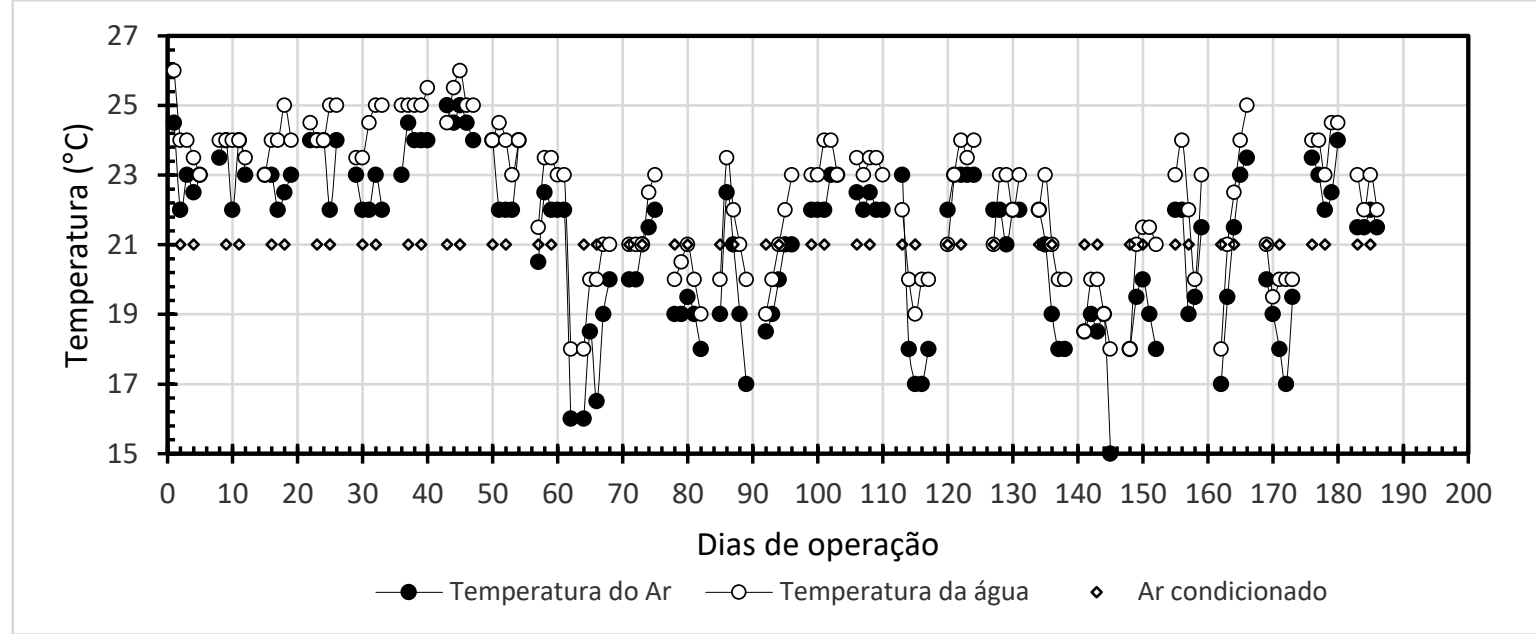

Fonte: Autor

Young-Rojanschi, Madramootoo (2014a) e Young-Rojanschi, Madramootoo (2014b) analisaram o efeito da localização dos filtros no laboratório com temperatura de $20^{\circ} \mathrm{C}$ e concluíram que as diferentes localizações não foram estatisticamente significativas para os parâmetros analisados de E. coli, turbidez, pH e nitrato. As três regiões de localização estavam em uma mesma área do laboratório, sem gradiente de temperatura significativo, e assim nenhum efeito foi detectado.

A variação da temperatura teve efeito direto na concentração de O. D., ou seja, os níveis de saturação de O. D. são mais elevados em temperaturas mais baixas. Como a água de alimentação ficava no mesmo local dos filtros durante à noite, essa água atingia a temperatura ambiente ficando na mesma temperatura da água dos filtros. Esse equilíbrio de temperatura beneficia a operação dos filtros, pois a variação da temperatura da água poderia impactar na maturação e na estabilidade da camada microbiana, assim como constataram Elliott et al. (2008).

Os organismos patogênicos nos recursos hídricos apresentaram variação sazonal, no estudo desenvolvido em Amsterdam, esses organismos apresentaram maiores concentrações em temperaturas mais baixas e menores concentrações em temperaturas mais altas, enquanto a eficiência de remoção nos filtros foi menor nas temperaturas mais baixas e maior em temperaturas mais elevadas (SCHIJVEN et al., 2013).

Nas Figuras 50 e 51 apresentam-se os resultados de oxigênio dissolvido para os filtros contínuos e intermitentes, respectivamente. 
Figura 50 - Monitoramento da concentração de oxigênio dissolvido e da temperatura nos C-

FLDs
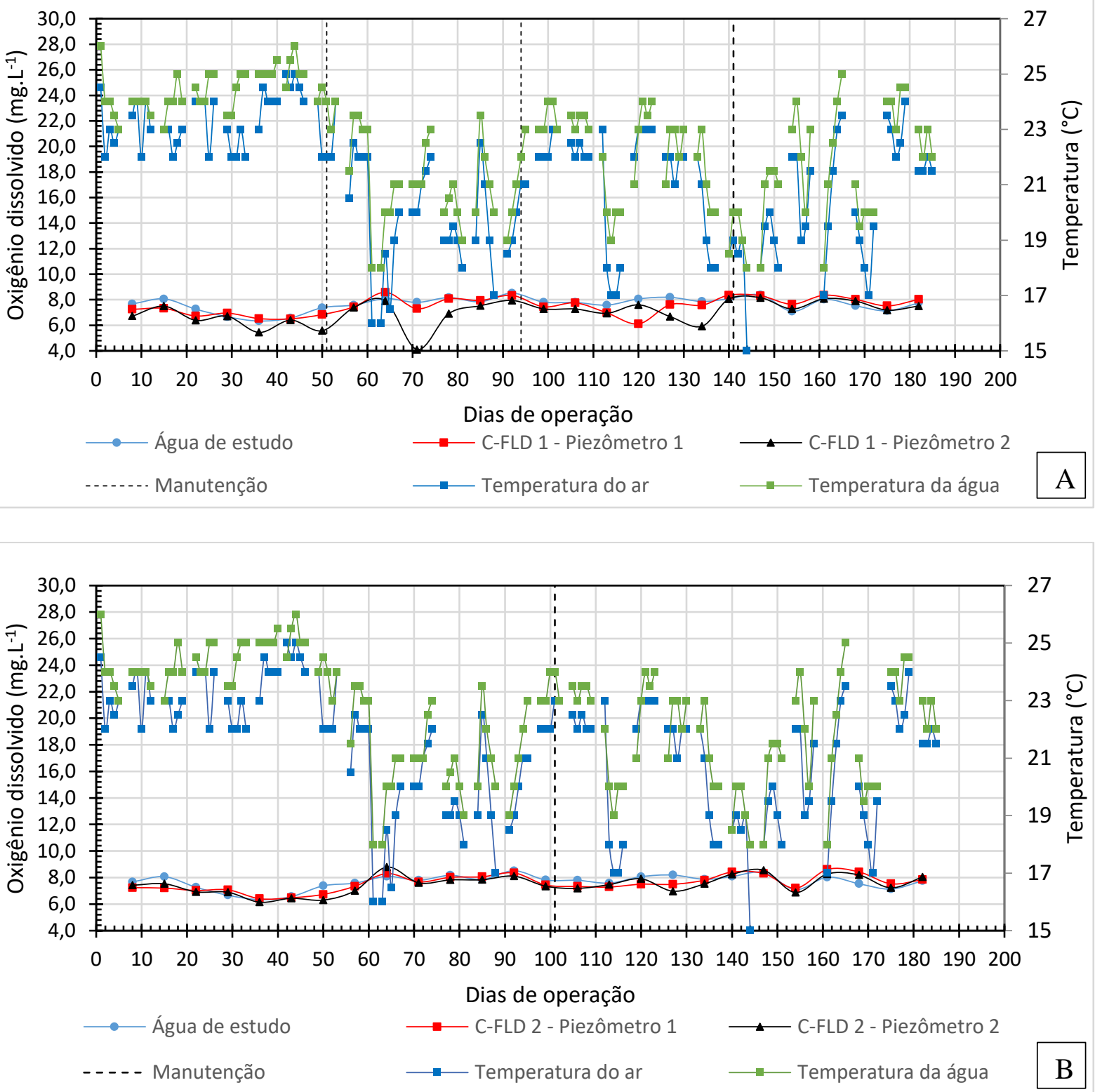

Fonte: Autor

Legenda: A - Filtro lento domiciliar de acrílico; B - Filtro lento domiciliar Defofo.

No filtro C-FLD 1, a diminuição do O.D. entre os valores medidos nos piezômetros $1 \mathrm{e}$ 2 foi maior do que os resultados do C-FLD 2, em um dos pontos do C-FLD 1 constata-se um consumo de O.D. de $3 \mathrm{mg} . \mathrm{L}^{-1}$, esse fato também pode ser explicado devido ao consumo de O.D. pela camada biológica que se forma no início da camada filtrante. Segundo Mutsvangwa e Matope (2017), a concentração de oxigênio dissolvido é influenciada por vários fatores incluindo a temperatura da água, presença de matéria orgânica, salinidade e pressão atmosférica. Os pesquisadores verificaram que a redução do oxigênio dissolvido nos filtros, 
sem uma fonte externa de carbono, foi menor, e que a redução é devido à demanda de oxigênio pelas bactérias aeróbias e bactérias nitrificantes da camada superior do filtro.

No filtro C-FLD 2, a medida de O.D. dos dois piezômetros mostraram-se relativamente próximas, a maior parte dos dias o valor de O.D. do piezômetro 2 foi menor do que do piezômetro 1 o que pode ser explicado pelo consumo de O.D. pela camada biológica que se forma no início da camada filtrante.

Figura 51 - Monitoramento da concentração de oxigênio dissolvido e da temperatura nos I-

FLDs
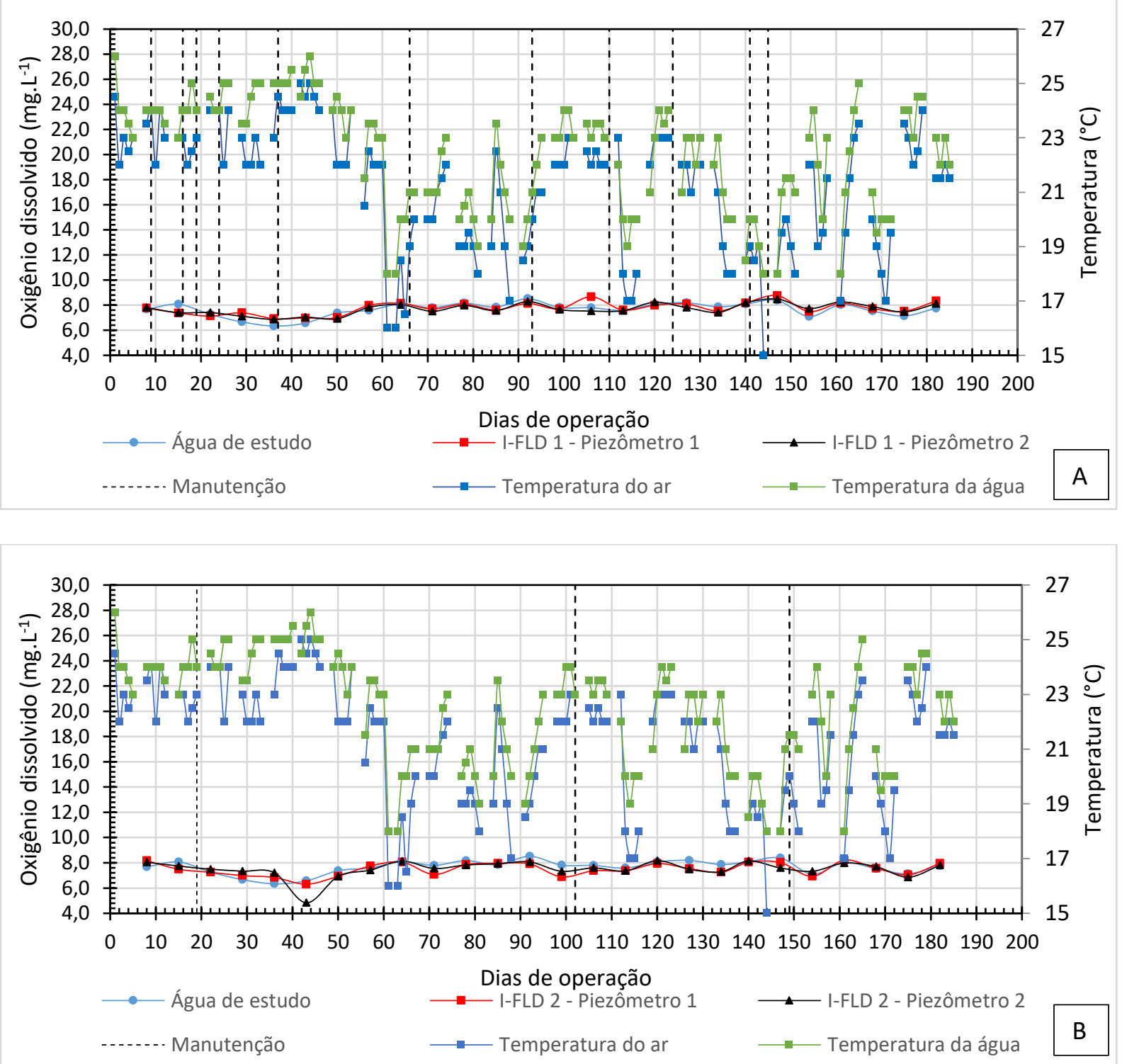

Legenda: A - Filtro lento domiciliar de acrílico; B - Filtro lento domiciliar Defofo.

Fonte: Autor

Os valores de O.D. do I-FLD 1 foram relativamente próximos nos dois piezômetros. Nota-se que no $106^{\circ}$ dia houve uma diferença de aproximadamente $1 \mathrm{mg} . \mathrm{L}^{-1}$ entre os dois 
piezômetros. No I-FLD 2 os resultados de O.D. mostraram-se relativamente próximos, com exceção do $43^{\circ}$ dia em que se verifica uma queda acentuada de O.D. devido ao consumo pela camada biológica. Nos filtros intermitentes os valores de O.D. dos piezômetros 1, apresentaram-se superiores ao da água de estudo em alguns dias, devido ao fato de ocorrer aeração da água quando da alimentação dos filtros.

Os resultados de O.D. do C-FLD 1, C-FLD 2, I-FLD 1 e I-FLD 2 apresentaram diferenças estatisticamente significativas entre si (teste de Kruskal Wallis ao nível de significância de 5\%). A comparação estatística entre o consumo de O.D. nos FLDs é apresentada na Tabela 22. O C-FLD 1 tem diferença significativa em relação ao C-FLD 2, IFLD 1 e I-FLD 2 e o C-FLD 2 apresentou diferença significativa em relação ao I-FLD 2. Essas diferenças de consumo de O. D. mostram que o regime de escoamento dos filtros (contínuo e intermitente) influencia no consumo de O. D..

A comparação estatística entre os valores do O.D. entre os piezômetros de todos os FLDs é apresentada na Tabela 23. Apenas no C-FLD 1 constatou-se diferença significativa entre os piezômetros P1 e P2, nos demais não houve essa diferença entre os piezômetros. E, entre filtros de mesmo diâmetro pode-se constatar diferenças entre o P2 do C-FLD 1 e o P2 do I-FLD1.

Tabela 22 - Comparação estatística do consumo de oxigênio dissolvido entre os filtros ${ }^{1}$

\begin{tabular}{ccccc}
\hline & C-FLD1 & C-FLD2 & I-FLD1 & I-FLD2 \\
\hline C-FLD1 & & $0,003^{*}$ & $0,000^{*}$ & $0,000^{*}$ \\
C-FLD2 & $0,003^{*}$ & & 0,197 & $0,029^{*}$ \\
I-FLD1 & $0,000^{*}$ & 0,197 & & 0,087 \\
I-FLD2 & $0,000^{*}$ & $0,029 *$ & 0,087 & \\
\hline
\end{tabular}

${ }^{1}$ Teste de Mann-Whitney pairwise para consumo de oxigênio dissolvido nos filtros

*Significativo ao nível de $5 \%$ de probabilidade (Pvalor < 0,05)

Fonte: Autor 
Tabela 23 - Comparação estatística para o oxigênio dissolvido nos filtros ${ }^{1}$

\begin{tabular}{llllllllll}
\hline & & \multicolumn{2}{c}{ C-FLD1 } & \multicolumn{2}{c}{ C-FLD2 } & \multicolumn{3}{c}{ I-FLD1 } & \multicolumn{2}{c}{ I-FLD2 } \\
\cline { 2 - 10 } & Piezômetros & P1 & P2 & P1 & P2 & P1 & P2 & P1 & P2 \\
\hline C-FLD1 & P1 & & $0,04^{*}$ & 0,90 & 0,80 & 0,18 & 0,41 & 0,71 & 0,93 \\
& P2 & $0,04^{*}$ & & $0,04^{*}$ & 0,09 & $0,00^{*}$ & $0,00 *$ & 0,08 & $0,03^{*}$ \\
C-FLD2 & P1 & 0,90 & $0,04^{*}$ & & 0,59 & 0,25 & 0,45 & 0,58 & 0,93 \\
& P2 & 0,80 & 0,09 & 0,59 & & 0,13 & 0,28 & 1,00 & 0,74 \\
I-FLD1 & P1 & 0,18 & $0,00^{*}$ & 0,25 & 0,13 & & 0,70 & 0,06 & 0,13 \\
& P2 & 0,41 & $0,00 *$ & 0,45 & 0,28 & 0,70 & & 0,17 & 0,31 \\
I-FLD2 & P1 & 0,71 & 0,08 & 0,58 & 1,00 & 0,06 & 0,17 & & 0,60 \\
& P2 & 0,93 & 0,03 & 0,93 & 0,74 & 0,13 & 0,31 & 0,60 & \\
\hline
\end{tabular}

${ }^{1}$ Teste de Mann-Whitney pairwise para oxigênio dissolvido nos filtros

*Significativo ao nível de $5 \%$ de probabilidade (Pvalor $<0,05$ )

Fonte: Autor

Nos experimentos de Maciel (2018), era esperado uma diminuição do O.D. na região da camada biológica (schmutzdecke) conforme o avanço das carreiras de filtração e em decorrência do amadurecimento dos filtros, entretanto esse comportamento não foi uma regra para os FLDs contínuos e intermitentes.

Estudos realizados por Young-Rojanschi, Madramootoo (2014b) analisaram o perfil de oxigênio dissolvido no filtro e concluíram que períodos de pausa mais longos ( 48 h e 72 h) levam a uma redução do oxigênio dissolvido efluente do filtro e ao longo da profundidade do filtro.

\subsection{Cor aparente e turbidez}

Nas Figuras 52 e 53 apresentam-se os resultados de cor aparente e de turbidez para os filtros contínuos, respectivamente. Os gráficos mostram os resultados da água de estudo, dos filtros contínuo C-FLD 1 e C-FLD 2, os dias em que foram realizadas as limpezas ou manutenção dos filtros e os limites máximos de cor aparente e de turbidez exigidos pela Portaria GM/MS no 888/2021 que são de 15 uC e 5 UNT.

A operação teve início no dia 19 de março, período chuvoso, o que explica os picos de cor e de turbidez. O valor médio de cor aparente da água de alimentação foi de 16,25 $\pm 23,37$ uC. O C-FLD 1 teve uma média de 4,21 $\pm 5,77$ uC e 74,08 \% de eficiência de remoção e o CFLD 2 teve um valor médio de 4,39 \pm 4,55 uC e 72,98\% de remoção. Os valores de máximo e de mínimo da cor aparente da água de alimentação foram de 191,5 e 0,51 uC. Os resultados de 
cor do C-FLD 1 e do C-FLD 2 apresentaram 96,99\% e 96,24\% dos valores menores ou iguais aos limites exigidos pela Portaria GM/MS nº 888/2021.

Figura 52 - Monitoramento da cor aparente da água de estudo e dos C-FLDs

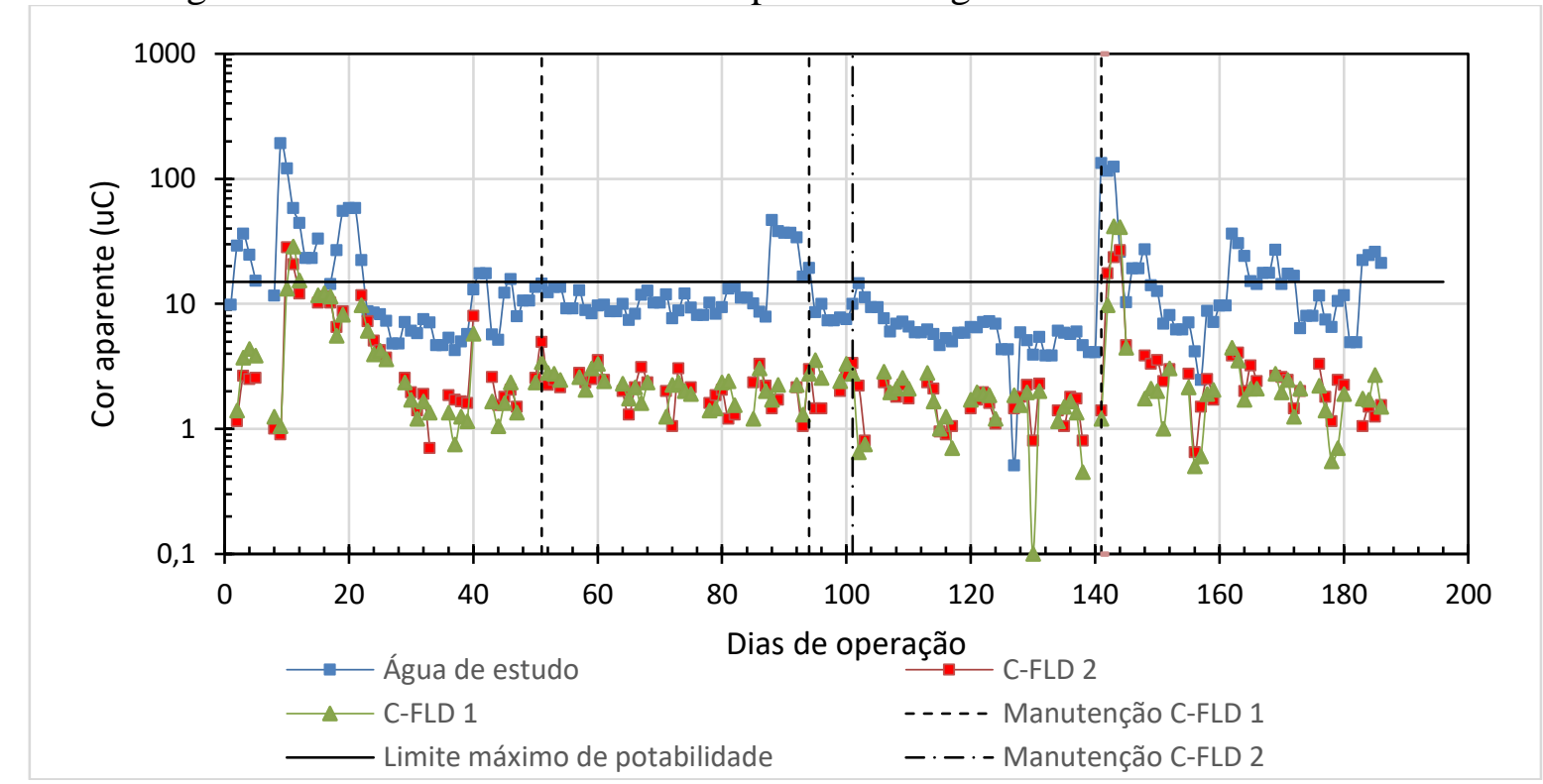

Fonte: Autor

Figura 53 - Monitoramento da turbidez da água de estudo e dos C-FLDs

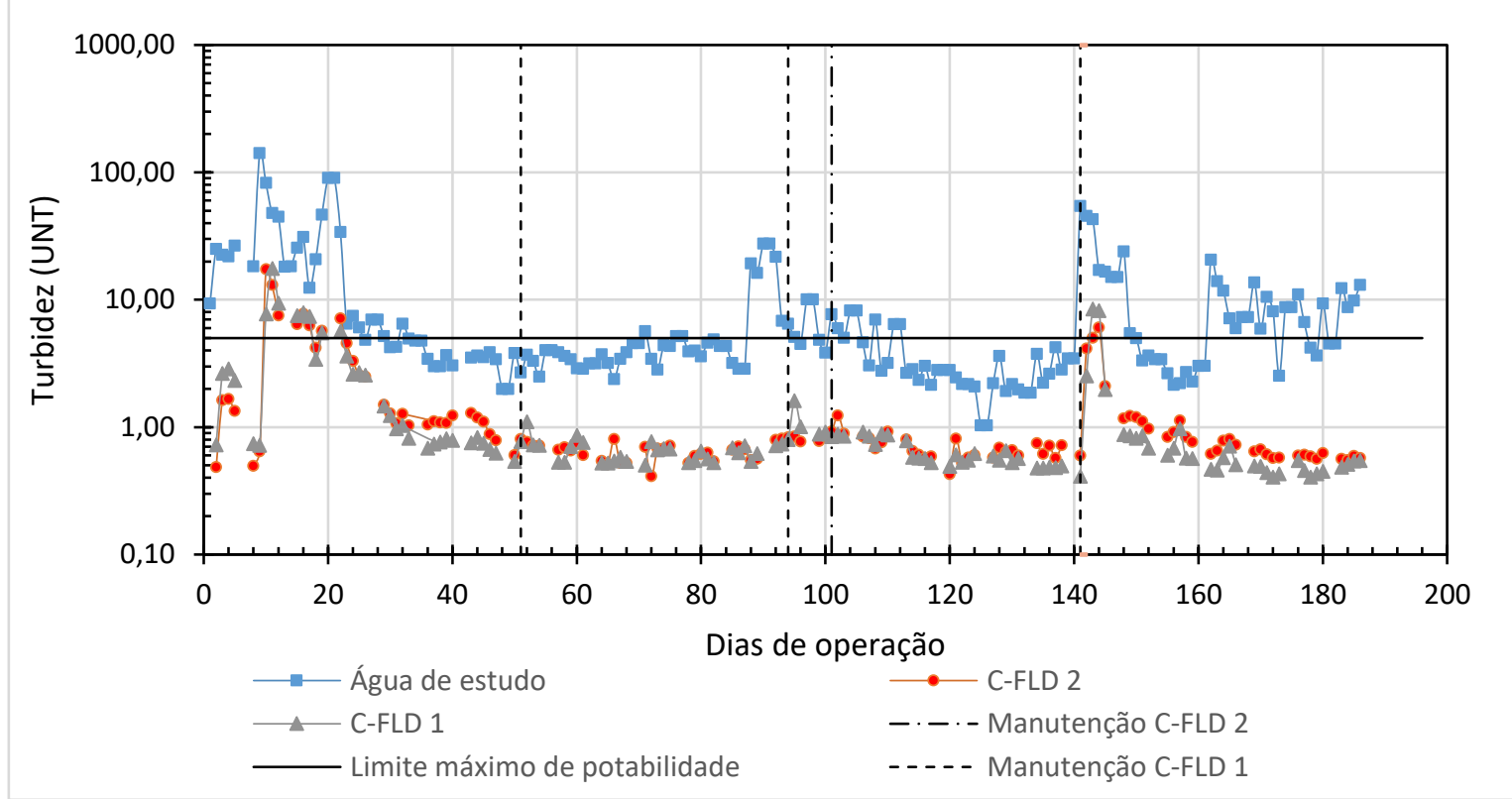

Fonte: Autor

A turbidez da água de alimentação variou de 1,03 até 140,50 UNT. A turbidez média da água de alimentação foi de 10,28 \pm 16,99 UNT. O C-FLD 1 teve um valor médio de 1,41 2 2,29 UNT com uma eficiência de remoção de 86,24\% e o C-FLD 2 teve uma média de 1,47 $\pm 2,27$ 
UNT e 85,71\% de remoção. Os resultados de turbidez do C-FLD 1 e do C-FLD 2 apresentaram $92,48 \%$ e $92,48 \%$ dos valores menores ou iguais aos limites exigidos pela Portaria GM/MS n ${ }^{\circ}$ $888 / 2021$.

Os resultados de cor aparente e de turbidez atenderam o limite máximo exigido no padrão de potabilidade na maioria dos dias de operação. Apenas no início tiveram alguns resultados acima desse limite, conforme mencionado anteriormente.

Nas Figuras 54 e 55 apresentam-se os resultados de cor aparente e de turbidez dos filtros intermitentes I-FLD 1 e I-FLD 2.

Figura 54 - Monitoramento da cor aparente da água de estudo e dos I-FLDs
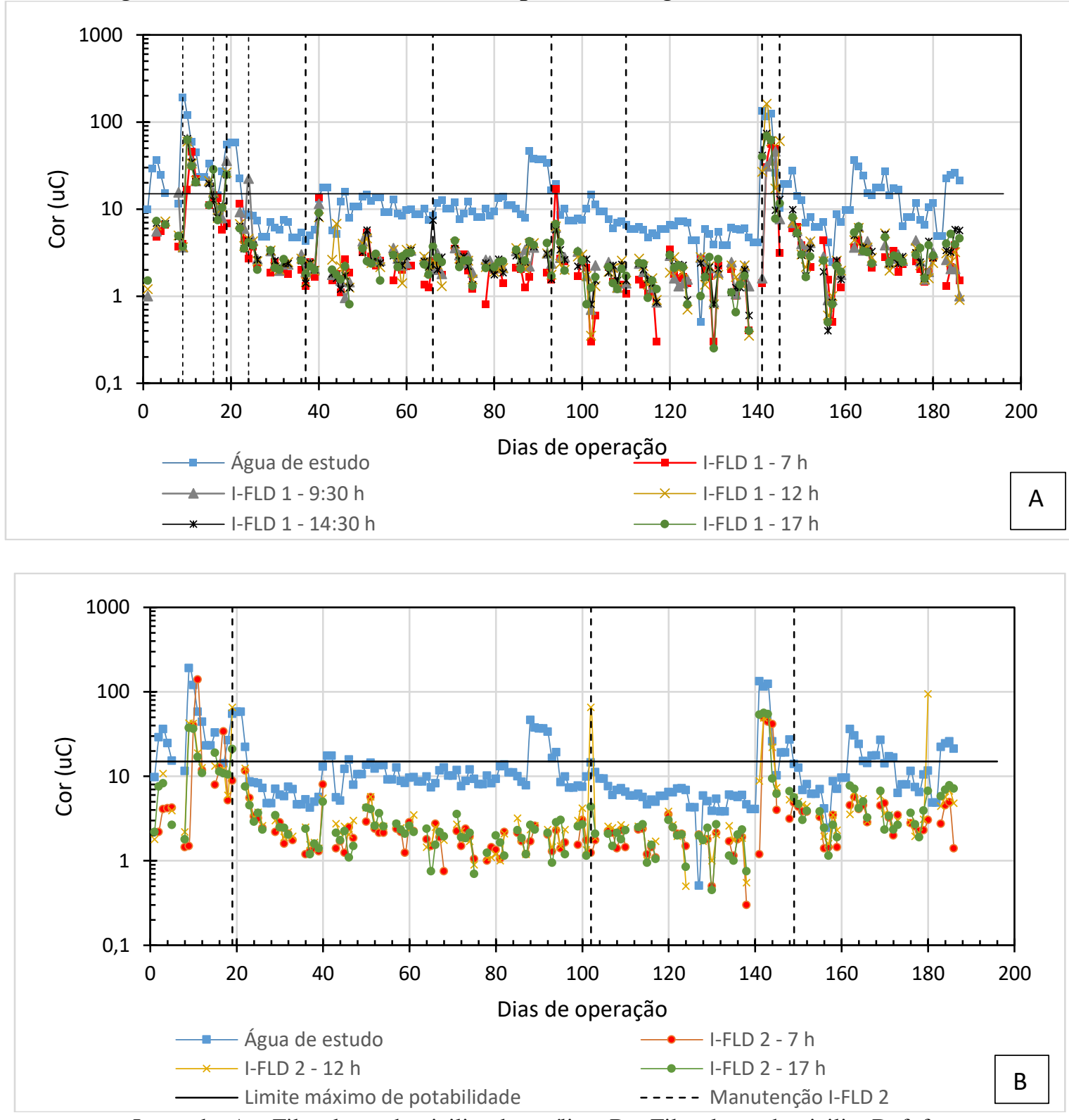

Legenda: A - Filtro lento domiciliar de acrílico; B - Filtro lento domiciliar Defofo.

Fonte: Autor 
Os resultados de cor do I-FLD 1 nos horários das 7, 9:30, 12, 14:30 e 17 h apresentaram $94,70 \%, 91,54 \%, 92,42 \%, 93,85 \%$ e $93,85 \%$ dos valores menores ou iguais aos limites exigidos pela Portaria GM/MS nº 888/2021, respectivamente.

Os resultados de cor do I-FLD 2 nos horários das 7, 12 e 17 h apresentaram 95,49\%, 93,18\% e 93,89\% dos valores menores ou iguais aos limites exigidos pela Portaria GM/MS n ${ }^{\circ}$ $888 / 2021$, respectivamente.

Figura 55 - Monitoramento da turbidez da água de estudo e dos I-FLDs
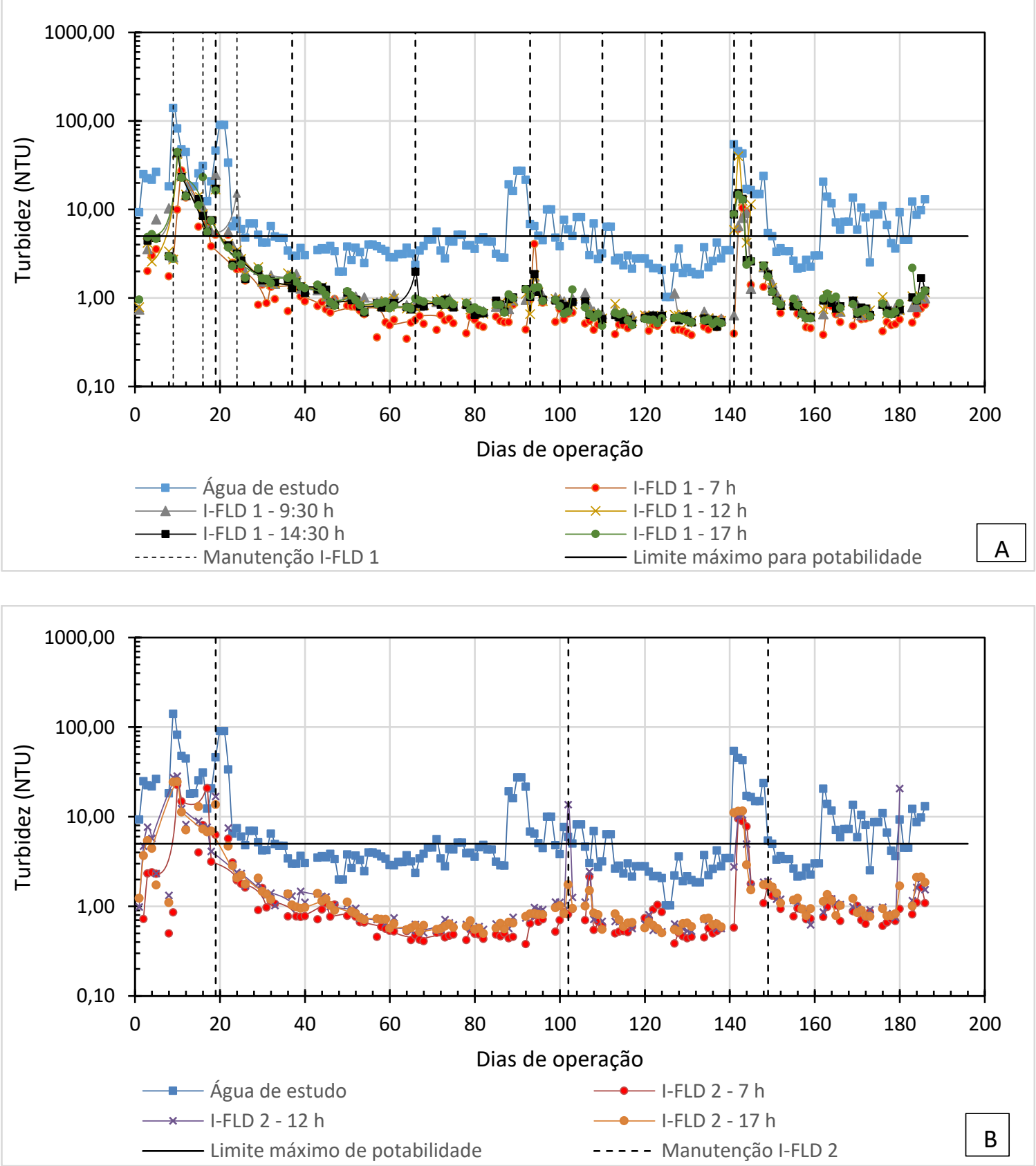

Legenda: A - Filtro lento domiciliar de acrílico; B - Filtro lento domiciliar Defofo.

Fonte: Autor 
A análise dos gráficos mostra que o filtro I-FLD 1 ficou mais sobrecarregado do que IFLD 2, pois precisou ser limpo mais vezes durante o mesmo período de operação. Isso pode ser explicado pelo fato da área superficial do I-FLD 1 ser menor e consequentemente acumular impurezas nos poros de forma mais rápida que no I-FLD 2.

Os resultados de turbidez do I-FLD 1 nos horários das 7, 9:30, 12, 14:30 e $17 \mathrm{~h}$ apresentaram $91,67 \%, 88,64 \%, 90,98 \%, 91,54 \%$ e $90,91 \%$ dos valores menores ou iguais aos limites exigidos pela Portaria GM/MS nº 888/2021, respectivamente.

Os resultados de turbidez do I-FLD 2 nos horários das 7, 12 e 17 h apresentaram 92,48\%, $88,81 \%$ e $90,23 \%$ dos valores menores ou iguais aos limites exigidos pela Portaria GM/MS n ${ }^{\circ}$ 888/2021, respectivamente.

As alimentações realizadas nos diferentes horários para os filtros I-FLD 1 e I-FLD 2 apresentaram regularidade na eficiência do tratamento ao longo dos dias de operação, com exceção de quando era realizada manutenção prévia no filtro, antes do horário de alimentação. Nesses casos os resultados de cor aparente e de turbidez eram significativamente maiores.

Os resultados de cor e de turbidez da AE (água de estudo) e dos FLDs apresentaram diferenças estatisticamente significativas entre si (teste de Kruskal Wallis ao nível de significância de 5\%). A comparação estatística de cor e de turbidez entre AE e os FLDs são apresentadas nas Tabelas 24 e 25, respectivamente. Os resultados da comparação estatística de cor mostram que apenas a água de estudo apresentou diferença significativa em relação a água tratada pelos filtros, não houve diferenças significativas em relação ao parâmetro de cor na comparação entre os filtros. Já na comparação de turbidez, a água de estudo tem diferença significativa em relação a água tratada pelos filtros e há uma diferença significativa entre o CFLD 1 e o C-FLD 2 e entre o I-FLD 1 e o C-FLD 2, mostrando que o diâmetro e o tipo de operação influenciam no desempenho dos filtros para esse parâmetro.

\begin{tabular}{|c|c|c|c|c|c|}
\hline & $\mathrm{AE}$ & C-FLD1 & C-FLD2 & I-FLD1 & I-FLD2 \\
\hline $\mathrm{AE}$ & & $0,00 *$ & $0,00 *$ & $0,00 *$ & $0,00^{*}$ \\
\hline C-FLD1 & $0,00 *$ & & 0,46 & 0,16 & 0,11 \\
\hline C-FLD2 & $0,00^{*}$ & 0,46 & & 0,46 & 0,40 \\
\hline I-FLD1 & $0,00^{*}$ & 0,16 & 0,46 & & 0,89 \\
\hline I-FLD2 & $0,00^{*}$ & 0,11 & 0,40 & 0,89 & \\
\hline
\end{tabular}

${ }^{1}$ Teste de Mann-Whitney pairwise para cor aparente nos filtros

*Significativo ao nível de 5\% de probabilidade $(\mathrm{P}<0,05)$

Fonte: Autor 
Tabela 25 - Comparação estatística de turbidez entre AE e os filtros ${ }^{1}$

\begin{tabular}{cccccc}
\hline & $\mathrm{AE}$ & C-FLD1 & C-FLD2 & I-FLD1 & I-FLD2 \\
\hline AE & & $0,00^{*}$ & $0,00^{*}$ & $0,00^{*}$ & $0,00^{*}$ \\
C-FLD1 & $0,00^{*}$ & & $0,01^{*}$ & 0,47 & 0,31 \\
C-FLD2 & $0,00^{*}$ & $0,01^{*}$ & & $0,00^{*}$ & 0,30 \\
I-FLD1 & $0,00^{*}$ & 0,47 & $0,00^{*}$ & & 0,15 \\
I-FLD2 & $0,00^{*}$ & 0,31 & 0,30 & 0,15 & \\
\hline
\end{tabular}

${ }^{1}$ Teste de Mann-Whitney pairwise para turbidez nos filtros

*Significativo ao nível de $5 \%$ de probabilidade $(\mathrm{P}<0,05)$

Fonte: Autor

No estudo de Terin e Sabogal-Paz (2019) a água a ser tratada tinha o valor médio da cor aparente de 8,2 uH, os filtros contínuos apresentaram uma redução de 97,73\% e os filtros intermitentes uma redução de $94,73 \%$ para o período de pausa de 4 horas e de $97,17 \%$ para o período de pausa de 12 horas. Apesar da eficiência dos C-FLDs e dos I-FLDs serem menores do que os resultados obtidos por Terin e Sabogal-Paz (2019), o valor da cor aparente da água de estudo era o dobro do valor $(16 \mathrm{uH})$ e a eficiência variou de $60 \%$ até $74 \%$ nos filtros, o que mostra que mesmo com valores elevados de turbidez, os filtros apresentam uma eficiência significativa na remoção de cor aparente.

Kennedy et. al. (2012), estudaram filtros do modelo Hydraid com diâmetro da base de $26 \mathrm{~cm}$ e do topo de $47 \mathrm{~cm}$, uma lâmina d'água estacionária de $5 \mathrm{~cm}$, precedida de uma placa difusora e uma altura máxima do nível de água de $21 \mathrm{~cm}$, após a lâmina d’água estacionária havia uma camada de areia com $42 \mathrm{~cm}$ de profundidade seguida de uma camada de separação de cascalho de $5 \mathrm{~cm}$, uma camada suporte de cascalho de $5 \mathrm{~cm}$ e um tubo de saída lateral. A turbidez da água de alimentação variou de 2,2 a 14,6 UNT, com média de 8,2 UNT, a porcentagem de remoção de turbidez melhorou quando se comparou o início (83\%, 81\% e 79\%) com o $16^{\circ}$ dia de operação $(93 \%, 92 \%$ e $90 \%)$.

Jenkings et al. (2009) analisaram filtros com operação intermitente com capacidade para tratar 20 litros, com tubo de saída lateral, no fundo usou $5 \mathrm{~cm}$ de rocha na camada suporte, seguido de $5 \mathrm{~cm}$ de pedregulho, $50 \mathrm{~cm}$ de areia da camada filtrante e $5 \mathrm{~cm}$ de lâmina de água estacionária. Acima da água, existia uma placa difusora à 2,5 cm de altura e o nível de água máximo podia atingir $25 \mathrm{~cm}$ de altura acima dessa placa. Os pesquisadores trabalharam com uma água de alimentação com turbidez que variou de 5 à 59 UNT e obtiveram remoção de $91 \%$ 
e $87 \%$ para filtros operando com tempos de residência longo (16 horas) e curto (5 horas), respectivamente.

Young-Rojanschi e Madramootoo (2014a) realizaram o experimento em escala laboratorial seguindo o modelo da CAWST Versão 10. Os pesquisadores compararam filtros operados de forma intermitente e contínua e obtiveram uma eficiência de remoção de turbidez de $87 \%$ e $96 \%$ respectivamente.

No estudo de Terin e Sabogal-Paz (2019), a água a ser tratada tinha o valor médio da turbidez de 2,4 UNT, os filtros contínuos apresentaram uma redução de 84,39\% e os filtros intermitentes uma redução de $81,41 \%$ para o período de pausa de 4 horas e de $83,78 \%$ para o período de pausa de 12 horas.

No estudo, a eficiência de remoção de turbidez sempre foi acima de $85 \%$ para os CFDLs e acima de $88 \%$ para os I-FLDs para a água de alimentação com turbidez média de 10,28 UNT, valores que corroboram com os obtidos pelos pesquisadores (JENKINGS et al., 2009; KENNEDY et. al., 2012; YOUNG-ROJANSCHI E MADRAMOOTOO, 2014b; TERIN e SABOGAL-PAZ, 2019).

\subsection{Condutividade e absorbância}

A condutividade elétrica (CE) medida das águas tratadas apresentou resultados próximos e superiores aos valores medidos da água de estudo. O valor médio da condutividade

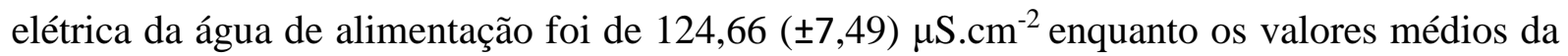
água filtrada foram de $124,47( \pm 6,87) \mu \mathrm{S} . \mathrm{cm}^{-2}$ no C-FLD $1,125,19( \pm 6,77) \mu \mathrm{S} . c m^{-2}$ no C-FLD $2,126,01( \pm 7,36) \mu \mathrm{S} . \mathrm{cm}^{-2}$ no I-FLD 1, e 125,38 $( \pm 7,79) \mu \mathrm{S} . \mathrm{cm}^{-2}$ no I-FLD 2. Como os resultados da água de alimentação e dos filtros foram próximos e superiores percebe-se que não houve remoção significativa de sólidos dissolvidos.

Nas Figuras 56 e 57 apresentam-se os resultados de condutividade elétrica para os filtros contínuos e intermitentes, respectivamente. Observou-se um comportamento ascendente dos resultados durante a carreira de filtração, ou seja, entre os dias de manutenção e, esse mesmo comportamento foi observado nos gráficos da perda de carga, esse padrão observado em ambos os gráficos pode indicar a ocorrência de lixiviação entre as carreiras de filtração, uma vez que os resultados da condutividade elétrica da água tratada foram próximos e superiores ao da água de estudo.

Sabogal-Paz et al. (2020) estudaram os FLDs utilizando uma água preparada, diluindo uma solução de bisfenol (BPA - Alfa Aesar®, 97\%) em água deionizada para simular água da 
chuva contaminada, o valor médio de condutividade da água era de $3,24 \mu \mathrm{S} . \mathrm{m}^{-1}$, a água tratada nos filtros contínuos apresentaram valor médio de $36,2 \mu \mathrm{S} . \mathrm{m}^{-1} \mathrm{e}$ nos filtros intermitentes o valor médio de 30,0 $\mu \mathrm{S} \cdot \mathrm{m}^{-1}$. A condutividade depende da concentração de íons (por exemplo: fosfato, cloreto, sulfato, nitrato, silício, alumínio, cálcio, ferro, magnésio e sódio) e esses íons aumentaram consideravelmente após à filtração (Sabogal-Paz et al., 2020), fenômeno que pode ser atribuído à lixiviação do meio filtrante (Young-Rojanschi e Madramootoo, 2014a e 2014b).

No estudo de Young-Rojanschi e Madramootoo (2014a) a água influente era preparada com água de lago com suplementação de E. coli, tinha condutividade elétrica de $117 \mu \mathrm{S} . \mathrm{m}^{-1} \mathrm{e}$ obtiveram, para períodos de pausa diferentes, os seguintes valores de condutividade elétrica de $155 \mu \mathrm{S} . \mathrm{m}^{-1}$ (período de pausa de 1 dia), $157 \mu \mathrm{S} . \mathrm{m}^{-1}$ (período de pausa de 2 dia) e $163 \mu \mathrm{S} . \mathrm{m}^{-1}$ (período de pausa de 3 dia).

Os resultados da condutividade elétrica da água tratada foram próximos e superiores ao da água de alimentação, com exceção do C-FLD 1, o período de pausa máximo dos filtros intermitentes foi de 62 horas ou 2,3 dias. Os valores obtidos não tiveram um aumento significativo quanto os observados por Young-Rojanschi e Madramootoo (2014a) e SabogalPaz et al. (2020), esse pequeno aumento pode estar associado às características e aos íons presente na água estudo, que foi preparada com água de rio e água de poço, e apresentou um valor médio de condutividade elétrica superior aos valores da água influente dos estudos supracitados.

Figura 56 - Monitoramento da condutividade da água de estudo e dos C-FLDs

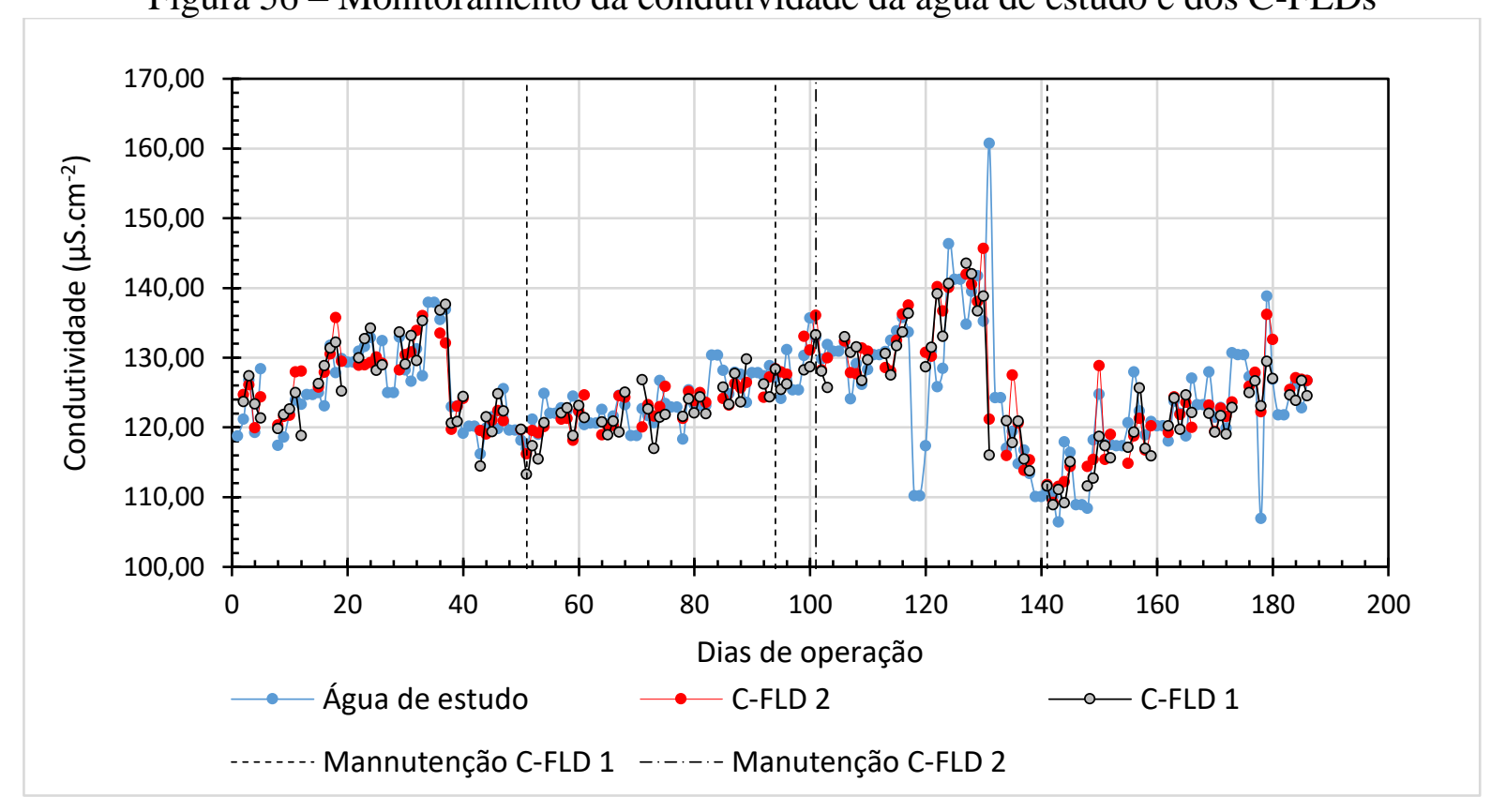

Fonte: Autor 
Figura 57 - Monitoramento da condutividade da água de estudo e dos I-FLDs

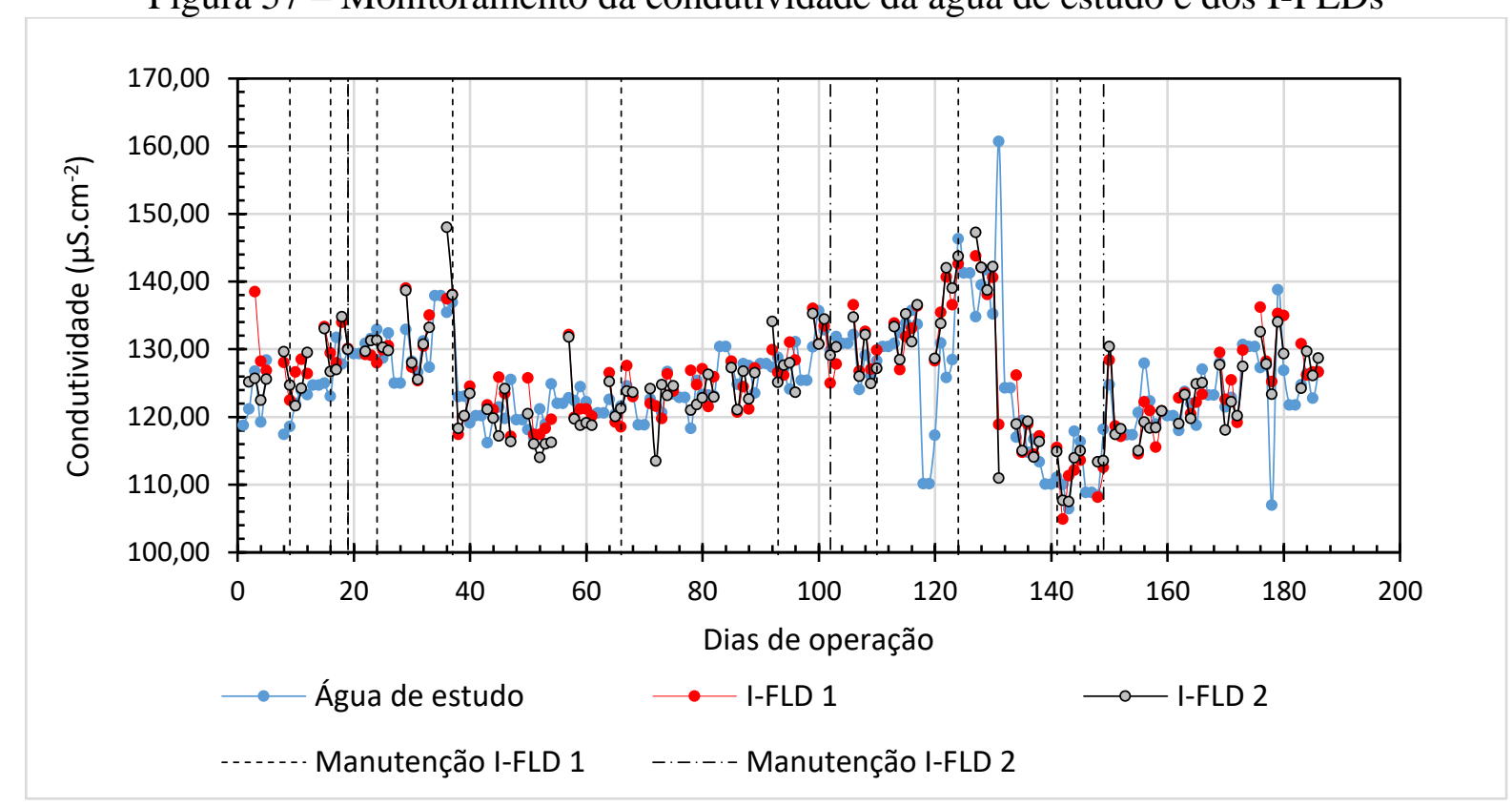

Fonte: Autor

A absorbância em $254 \mathrm{~nm}$ pode ser utilizada em substituição à determinação do COT (Carbono Orgânico Total) e precursores de trihalometanos, uma vez que a luz UV no comprimento de onda de 254 nm é absorvida por substâncias húmicas (EDZWALD, BECKER e WATTIER, 1985; EDZWALD e TOBIASON, 2011).

Na Figura 58 apresentam-se os resultados da absorbância no $\lambda 254 \mathrm{~nm}$ para a água de estudo e para as águas filtradas nos C-FLD 1 e 2 e nos I-FLD 1 e 2. Nos dias de pico, como nos dias $88^{\circ}, 116^{\circ}, 144^{\circ}$ e $165^{\circ}$, observou-se uma redução significativa dos valores de absorbância quando comparados com os valores da água de estudo e foi possível visualizar que os filtros contínuos foram mais eficientes do que os filtros intermitentes. O pico de absorbância observado no dia 144 é reflexo da qualidade da AE que teve turbidez de 42,75 UNT e cor aparente de $124 \mathrm{uC}$. 
Figura 58 - Monitoramento da absorbância $(\lambda 254 \mathrm{~nm})$ da água de estudo, dos C-FLDs e dos IFLDs

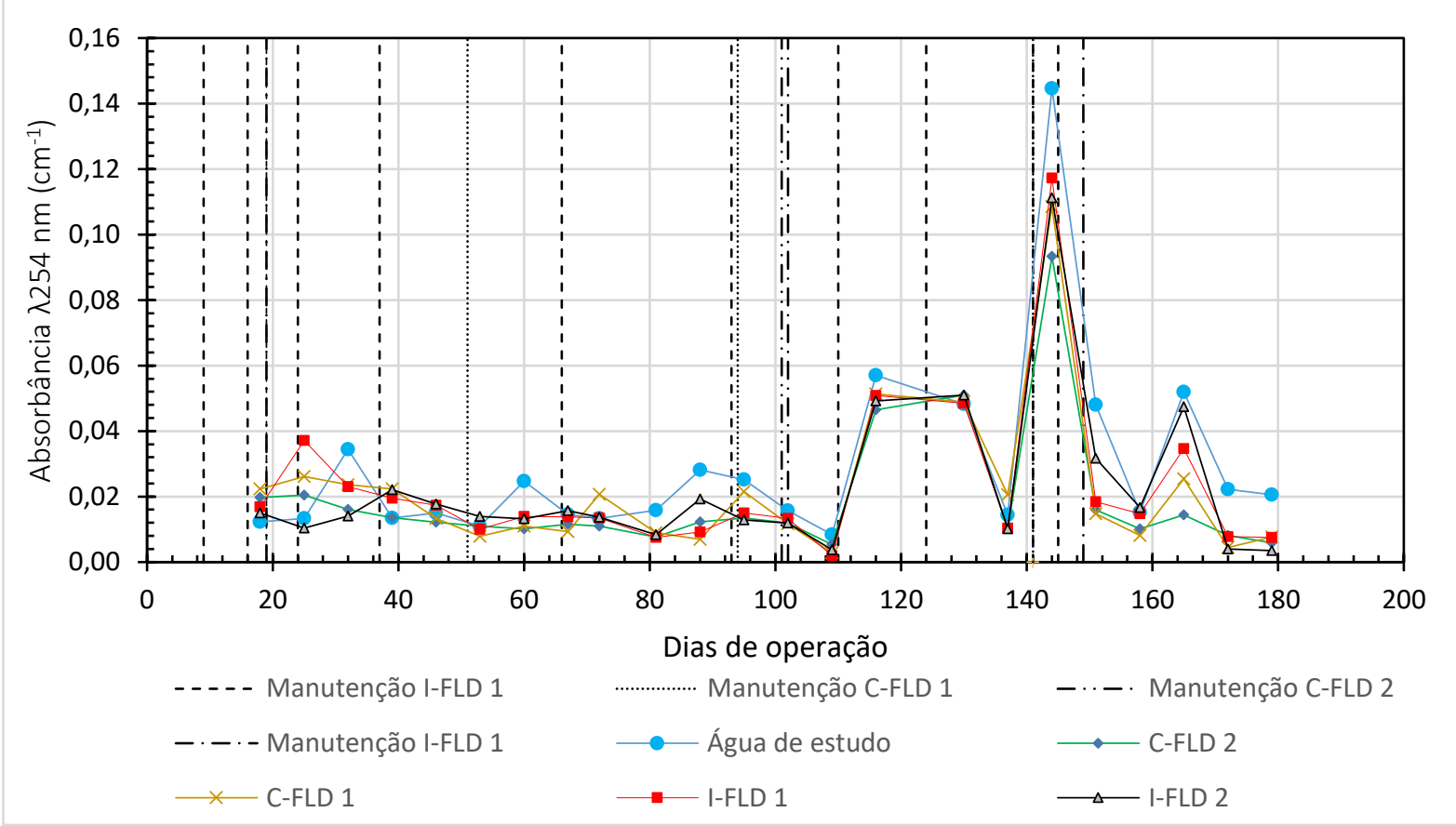

Fonte: Autor

O valor médio da absorbância para a água de alimentação foi de $0,029 \pm 0,029 \mathrm{~cm}^{-1}$, os valores médios e a eficiência de remoção da absorbância para os C-FLD 1; C-FLD 2; I-FLD 1 e I-FLD 2 foram de $0,022 \pm 0,023 \mathrm{~cm}^{-1}$ e $25,3 \%, 0,019 \pm 0,020 \mathrm{~cm}^{-1}$ e $35,3 \%, 0,023 \pm 0,024$ $\mathrm{cm}^{-1}$ e $21,7 \%$ e $0,022 \pm 0,024 \mathrm{~cm}^{-1}$ e $22,6 \%$, respectivamente. Os valores de absorbância dos filtros que ficaram acima dos valores de absorbância da água de estudo podem estar relacionados com as manutenções que foram realizadas nos respectivos filtros, o que gerou uma redução na qualidade dos parâmetros. Ressalta-se que a absorbância está relacionada com a presença de matéria orgânica dissolvida na água e que a medição foi realizada uma vez por semana.

Os resultados de condutividade elétrica $(\mathrm{p}=0,39)$ da AE e dos FLDs não apresentaram diferenças estatisticamente significativas entre si (teste de Kruskal Wallis ao nível de significância de 5\%), ou seja, a condutividade elétrica da água de estudo (antes do tratamento) e após o tratamento nos FLDs não têm diferenças significativos, então tanto o tratamento quanto a configuração do filtro e o tipo de alimentação não influenciaram nesse parâmetro.

Os resultados de absorbância da AE e dos FLDs apresentaram diferenças estatisticamente significativas entre si (teste de Kruskal Wallis ao nível de significância de 5\%). A comparação estatística de absorbância entre AE e os FLDs está apresentada na Tabela 26 e 
mostra que apenas a água de estudo apresentou diferença significativa em relação a água tratada pelos filtros e não houve diferenças significativas em relação ao parâmetro de absorbância entre os filtros.

\begin{tabular}{|c|c|c|c|c|c|}
\hline & $\mathrm{AE}$ & C-FLD1 & C-FLD2 & I-FLD1 & I-FLD2 \\
\hline $\mathrm{AE}$ & & $0,00^{*}$ & $0,00 *$ & $0,00^{*}$ & $0,00 *$ \\
\hline C-FLD1 & $0,00 *$ & & 0,08 & 0,47 & 0,47 \\
\hline C-FLD2 & $0,00 *$ & 0,08 & & 0,36 & 0,34 \\
\hline I-FLD1 & $0,00^{*}$ & 0,47 & 0,36 & & 0,99 \\
\hline I-FLD2 & $0,00 *$ & 0,47 & 0,34 & 0,99 & \\
\hline
\end{tabular}

No estudo de Maciel (2018) foram utilizados dois tipos de água influente, a primeira água influente (água subterrânea + caulinita) tinha absorbância de $0,005 \mathrm{~cm}^{-1} \mathrm{e}$ a segunda água influente (Córrego Monjolinho) tinha absorbância de $0,089 \mathrm{~cm}^{-1}$. Os filtros que trataram o primeiro tipo de água influente tiveram como resultados: $0,008 \mathrm{~cm}^{-1} \mathrm{e} 0,007 \mathrm{~cm}^{-1}$ para os filtros intermitentes, um aumento de $58 \%$ e $75 \%$, respectivamente e de $0,007 \mathrm{~cm}^{-1}$ para os filtros contínuos, um aumento de $46 \%$. Os filtros que tratam o segundo tipo de água influente tiveram como resultados: $0,041 \mathrm{~cm}^{-1}$ e $0,035 \mathrm{~cm}^{-1}$ para os filtros intermitentes, uma remoção de $48 \%$ e $57 \%$, respectivamente e de $0,029 \mathrm{~cm}^{-1}$ e de $0,027 \mathrm{~cm}^{-1}$ para os filtros contínuos, uma remoção de $64 \%$ e de $67 \%$, respectivamente.

Lynn et al. (2013) estudaram filtros intermitentes utilizando água influente oriunda de lago enriquecida com esgoto, a água influente tinha absorbância $\left(U^{254}\right)$ de $0,15 \mathrm{~cm}^{-1} \mathrm{e}$ obtiveram água tratada com absorbância de $0,10 \mathrm{~cm}^{-1}$, representando uma remoção absorbância de $36 \%$.

A água influente utilizada no estudo tinha absorbância de $0,029 \mathrm{~cm}^{-1}$, valor que ficou entre as duas águas influentes estudadas por Maciel (2018) e menor que a água influente utilizada por Lynn et al. (2013). As águas tratadas nos C-FLDs apresentaram uma redução absorbância de $25 \%$ e $35 \%$, o que mostra uma eficiência consideravelmente maior do que a obtida no tratamento da primeira água influente e uma menor eficiência quando comparada com o tratamento da segunda água influente de Maciel (2018). As águas produzidas pelos I-FLDs 
apresentaram redução de absorbância $21 \%$ e $22 \%$, valores menores do que os obtidos por Lynn et al. (2013).

\subsubsection{4. $\mathrm{pH}$, nitrato e nitrito}

Os resultados do $\mathrm{pH}$, tanto da água de estudo quanto das águas filtradas, atendem o padrão de potabilidade brasileiro, que estabelece valores de $\mathrm{pH}$ entre 6,0 e 9,5. O valor médio do pH da água de alimentação foi de 7,05 ( $\pm 0,23)$, e dos filtros C-FLD 1, C-FLD 2, I-FLD 1 e I-FLD 2 foram de 7,51 \pm 0,25 (aumento de 6,5\%); 7,46 \pm 0,28 (aumento de 5,8\%); 7,52 $\pm 0,26$ (aumento de 6,6\%); e 7,48 \pm 0,24 (aumento de 6,1\%), respectivamente. Os resultados de $\mathrm{pH}$ das águas filtradas apresentaram pequeno aumento quando comparados com os da água de alimentação.

Os valores de pH para os filtros contínuo e intermitentes são apresentados nas Figuras 59 e 60 , respectivamente.

Figura 59 - Monitoramento do pH da água de estudo e dos C-FLDs

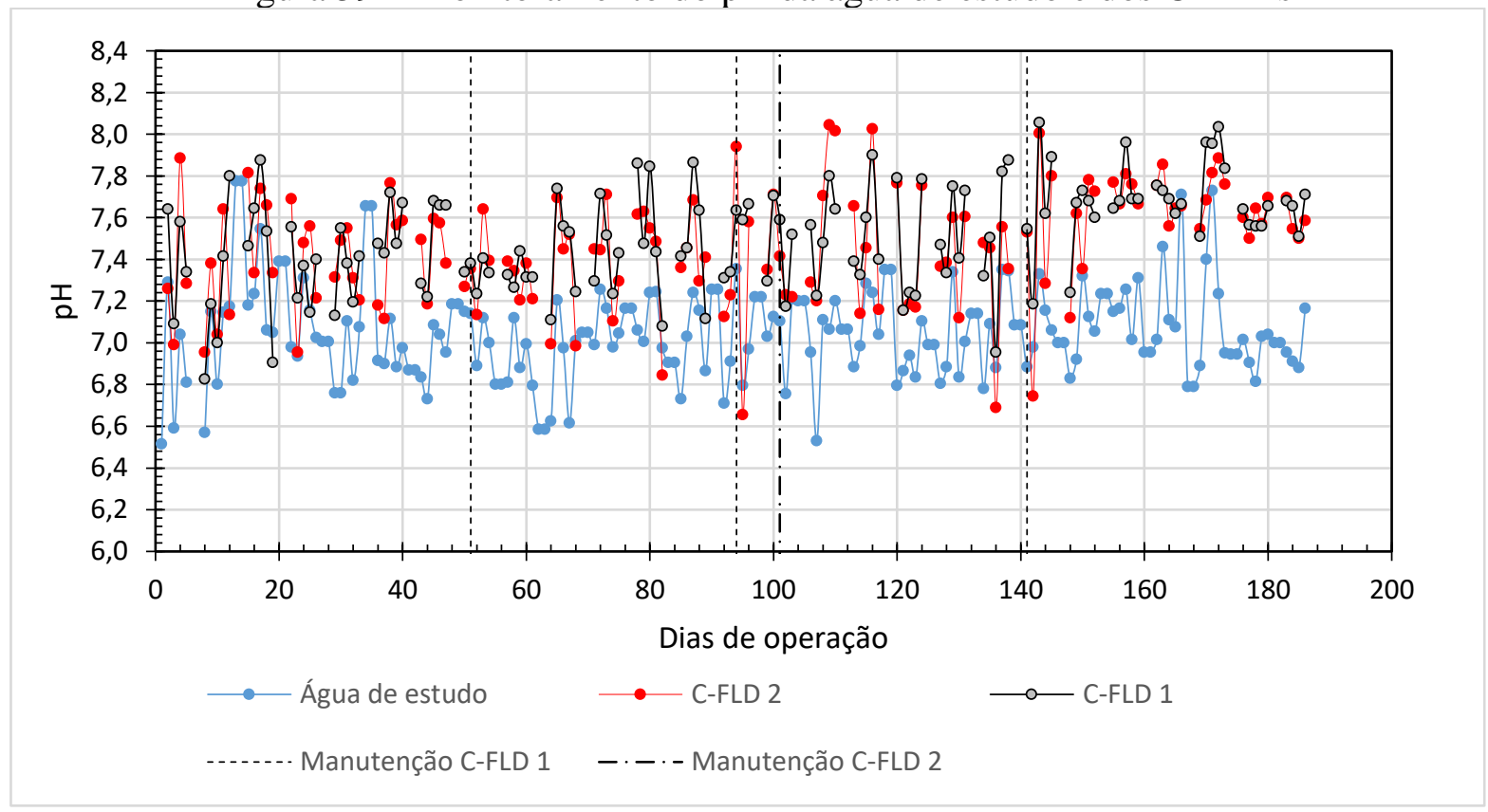

Fonte: Autor 
Figura 60 - Monitoramento do pH da água de estudo e dos I-FLDs

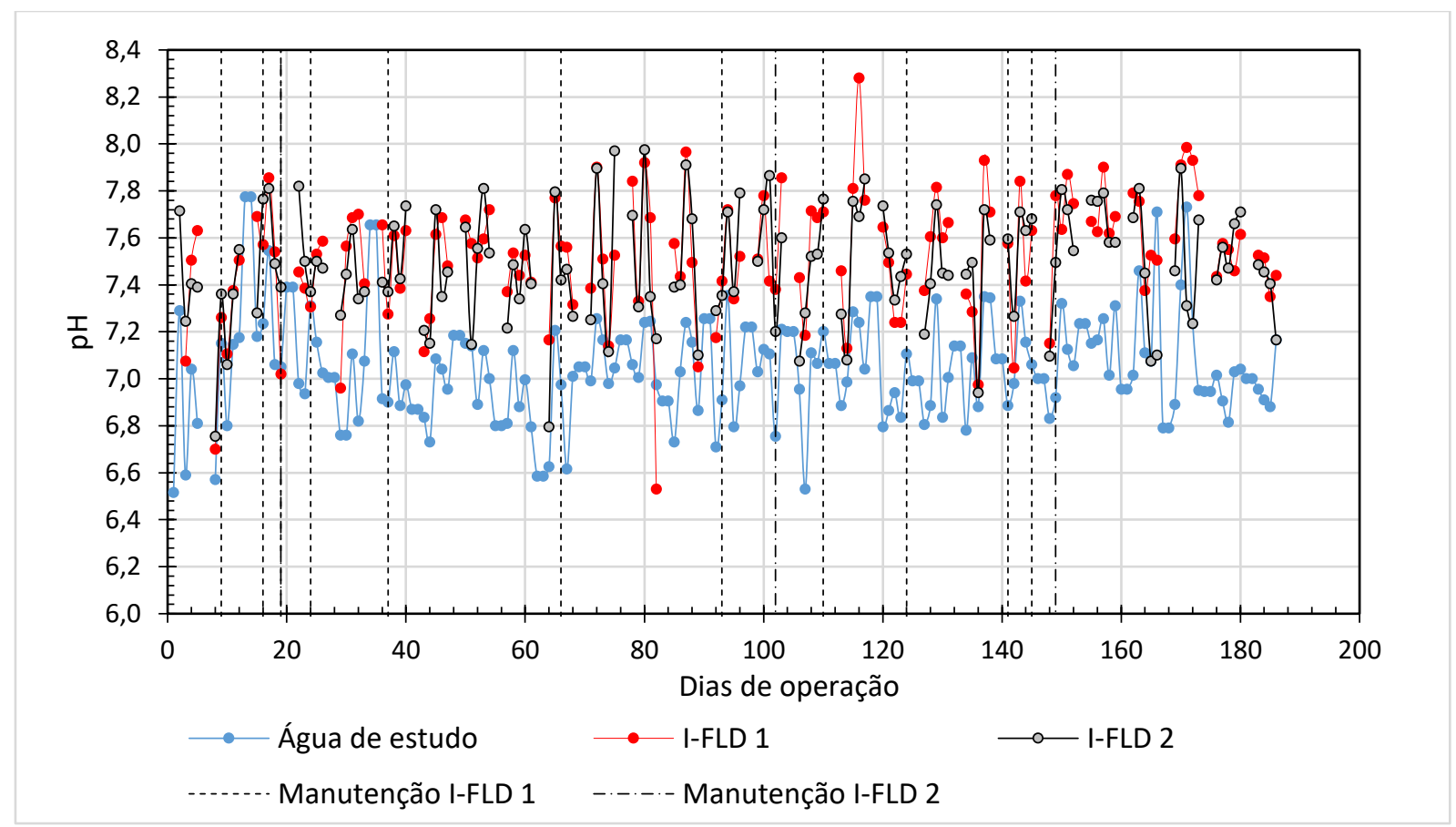

Fonte: Autor

Os resultados de $\mathrm{pH}$ da $\mathrm{AE}$ e dos FLDs apresentaram diferenças estatisticamente significativas entre si (teste de Kruskal Wallis ao nível de significância de 5\%). A comparação estatística de pH entre AE e os FLDs está apresentada na Tabela 27 e mostra que apenas a água de estudo apresentou diferença significativa em relação a água tratada pelos filtros, logo não houve diferenças significativas em relação ao parâmetro de $\mathrm{pH}$ entre os filtros.

Tabela 27 - Comparação estatística de $\mathrm{pH}$ entre AE e os filtros ${ }^{1}$

\begin{tabular}{cccccc}
\hline & AE & C-FLD1 & C-FLD2 & I-FLD1 & I-FLD2 \\
\hline AE & & $0,00^{*}$ & $0,00^{*}$ & $0,00^{*}$ & $0,00^{*}$ \\
C-FLD1 & $0,00^{*}$ & & 0,18 & 0,66 & 0,47 \\
C-FLD2 & $0,00^{*}$ & 0,18 & & 0,09 & 0,56 \\
I-FLD1 & $0,00^{*}$ & 0,66 & 0,09 & & 0,18 \\
I-FLD2 & $0,00^{*}$ & 0,47 & 0,56 & 0,18 & \\
\hline
\end{tabular}

${ }^{1}$ Teste de Mann-Whitney pairwise para $\mathrm{pH}$ nos filtros

*Significativo ao nível de $5 \%$ de probabilidade $(\mathrm{P}<0,05)$

Fonte: Autor 
Young-Rojanschi e Madramootoo (2014a) notaram um aumento da condutividade e do $\mathrm{pH}$ da água filtrada, sendo mais intenso quando o período de pausa era maior (em contato com o meio filtrante) e atribuíram essa alteração à lixiviação do meio filtrante. $\mathrm{O}$ aumento de $\mathrm{pH}$ pode ocorrer durante o processo de desnitrificação porque a redução de nitrato para nitrogênio gasoso pode resultar na produção de bicarbonato $\left(\mathrm{HCO}_{3}\right)$ (METCALF e EDDY, 2016). Nos filtros de Sabogal-Paz et al. (2020) também foram constatados aumento do pH (2-4\%) na água filtrada.

Mutsvangwa e Matope (2017) não constataram mudanças significativas no pH da água afluente e efluente. No geral, houve uma pequena diminuição do $\mathrm{pH}$ de 8,6 para 6,8. Kennedy et. al. (2012) tiveram uma redução do pH ao longo do experimento, a água afluente tinha pH médio de 8,32 e o pH efluente dos filtros foram de 7,83, 7,82 e 7,85.

Ocorreu um aumento do $\mathrm{pH}$ nas águas filtrada de 5,8 a $6,6 \%$ o que pode estar relacionado ao fenômeno da lixiviação do meio filtrante e/ou da desnitrificação (METCALF e EDDY, 2016), e corroboram com os relatos dos pesquisadores Young-Rojanschi e Madramootoo (2014a) e Sabogal-Paz et al. (2020).

A faixa de detecção do nitrito foi de 0,002 a $0,3 \mathrm{mg} \cdot \mathrm{L}^{-1}$ e do nitrato foi de 0,1 a $10 \mathrm{mg} . \mathrm{L}^{-}$ 1, segundo os métodos de redução de Cádmio. Nas Figuras 61 e 62 apresentam-se os resultados de nitrato e nitrito dos filtros contínuos e intermitentes e a indicação do limite de detecção mínimo do nitrito de $0,002 \mathrm{mg} . \mathrm{L}^{-1}$.

Figura 61 - Monitoramento de nitrato da água de estudo, dos C-FLDs e dos I-FLDs

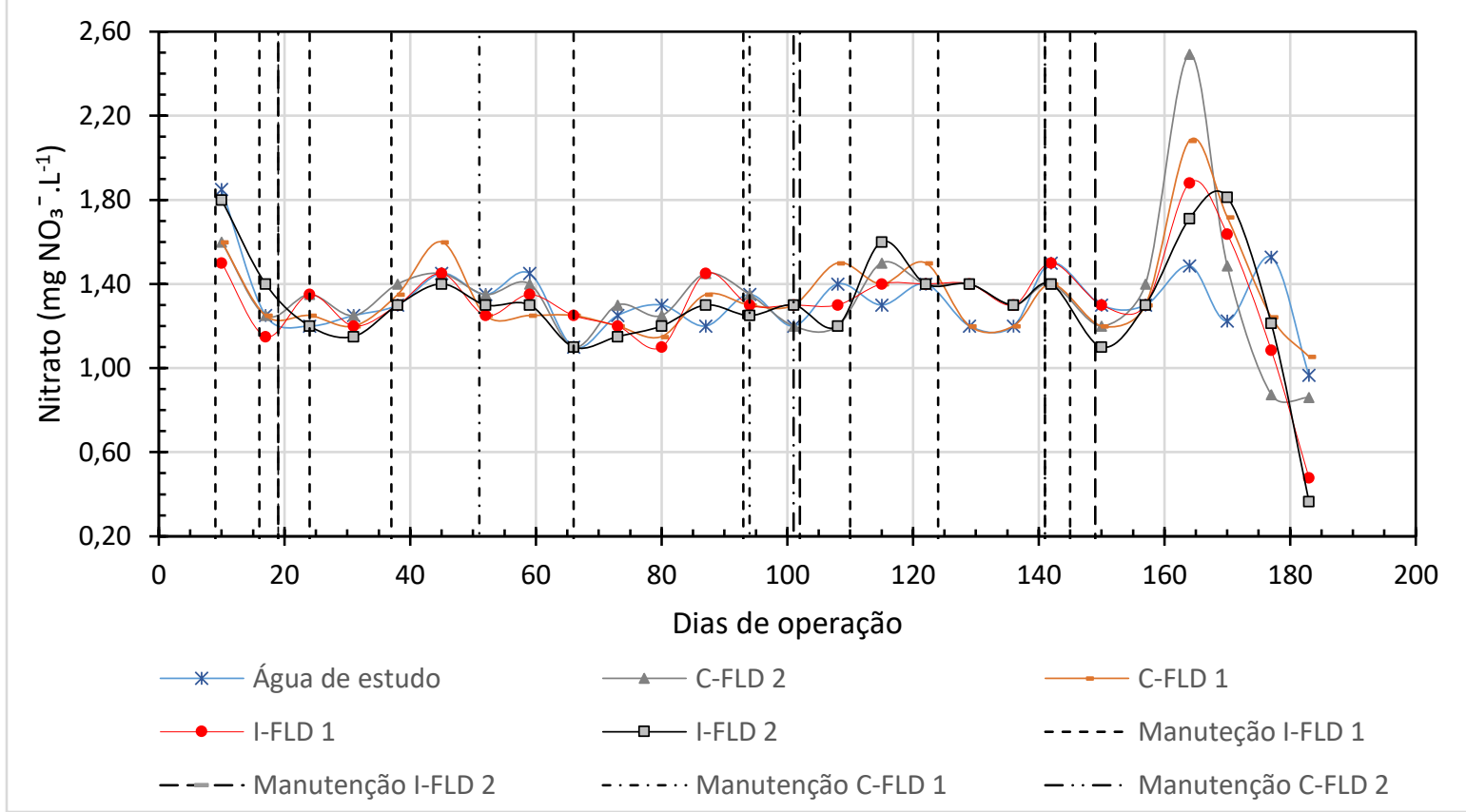

Fonte: Autor 
Figura 62 - Monitoramento de nitrito da água de estudo, dos C-FLDs e dos I-FLDs

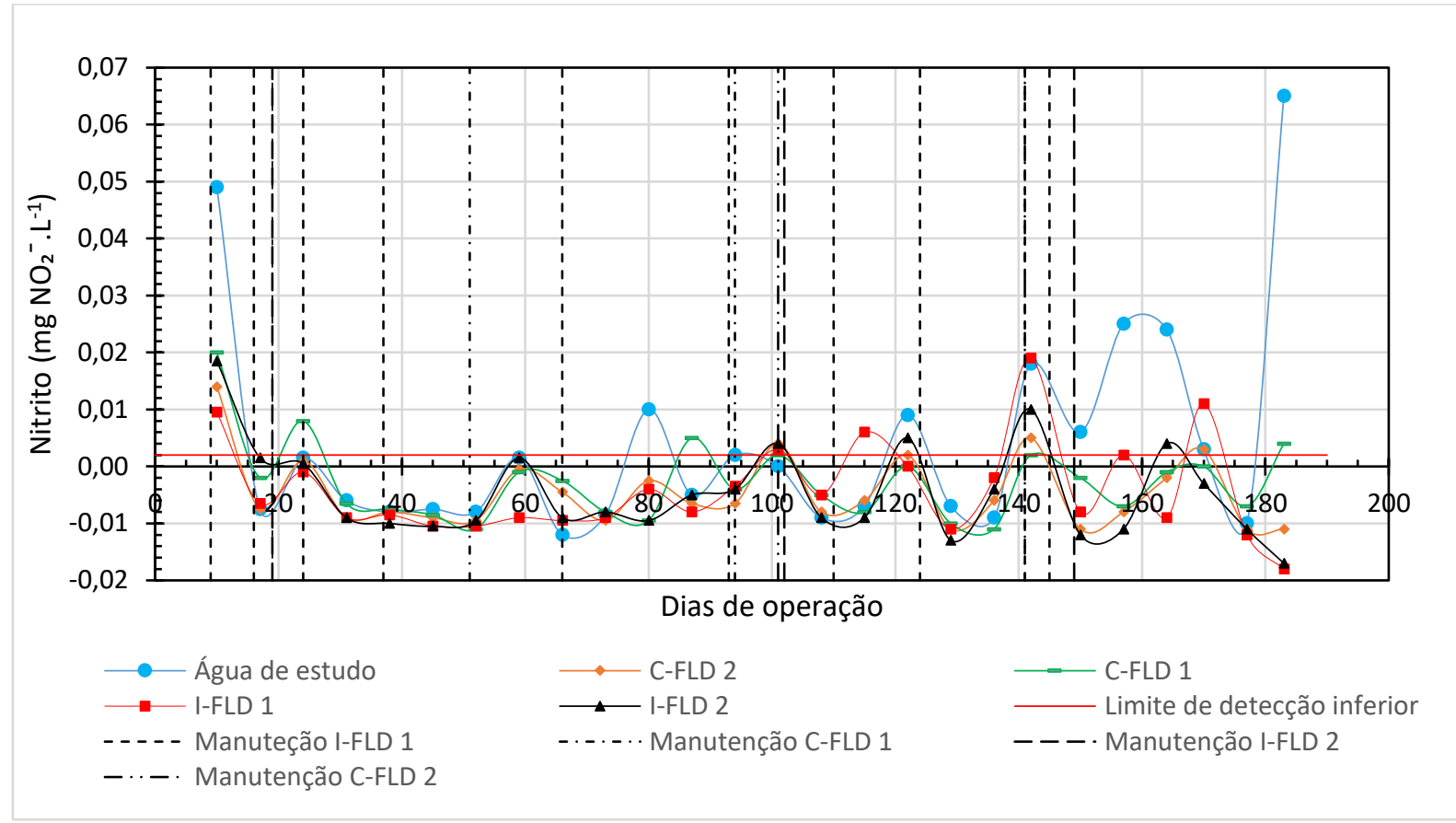

Fonte: Autor

Os resultados de nitrato $(\mathrm{p}=0,92)$ e nitrito $(\mathrm{p}=0,15)$ da $\mathrm{AE}$ e dos FLDs não apresentaram diferenças estatisticamente significativas entre si (teste de Kruskal Wallis ao nível de significância de 5\%), desta forma, a diferença antes e depois do tratamento e entre a configuração e a operação dos filtros não influenciam esses parâmetros.

O valor médio de nitrato para a água de alimentação foi de $1,3 \pm 0,168 \mathrm{mg}$. $\mathrm{L}^{-1}$. Para os filtros C-FLD 1, C-FLD 2, I-FLD 1 e I-FLD 2 foram de 1,3 \pm 0,215 mg.L ${ }^{-1}, 1,4 \pm$ 0,288 mg.L1, $1,3 \pm 0,238 \mathrm{mg} \cdot \mathrm{L}^{-1}, 1,3 \pm 0,273 \mathrm{mg} \cdot \mathrm{L}^{-1}$, respectivamente, ou seja, foram semelhantes e atenderam o limite estabelecido para potabilidade de $10 \mathrm{mg} . \mathrm{L}^{-1}$.

A maioria dos resultados de nitrito apresentaram-se abaixo do limite de detecção, que é de $0,002 \mathrm{mg} . \mathrm{L}^{-1}$, tanto da água de estudo quanto das águas filtradas. O pico observado no início da operação pode estar relacionado com o período de chuva em que se iniciou o trabalho. Todos os resultados atendem o limite de potabilidade de $1 \mathrm{mg} . \mathrm{L}^{-1}$. Maciel (2018) também obteve a concentração de nitrito abaixo da curva de detecção do espectrofotômetro para as águas afluentes e filtradas.

O resultado foi diferente do observado por Young-Rojanschi e Madramootoo (2014b), no qual houve diminuição da concentração de nitrogênio total, aumento de nitrato e de nitrito. Os filtros de Young-Rojanschi e Madramootoo (2014b) eram abastecidos com volume 
corresponde apenas ao volume de vazios da camada filtrante, o que impedia a renovação total da água após uma nova alimentação, fazendo com que a concentração de oxigênio dissolvido atingisse a anaerobiose, processo que favorece a desnitrificação (reduz nitrato a nitrito e reduz nitrito a nitrogênio gasoso).

No estudo de Murphy et al. (2010) foi levantado a hipótese de que a nitrificação ocorre dentro da camada biológica (schmutzdecke) durante a filtração e que a desnitrificação ocorre ao longo do meio filtrante durante o tempo de residência. Esses fenômenos tiveram como base, o consumo de O.D. da água afluente pela camada biológica deixando a coluna de filtração praticamente anaeróbica e o fundo do filtro reter porções de água remanescente de filtrações anteriores.

Segundo Young-Rojanschi e Madramootoo (2014a), após o amadurecimento, a nitrificação pareceu ocorrer em todos os filtros, com a diminuição de $\mathrm{NH}_{4}{ }^{-}$e sem diferença significativa entre os filtros operados com tempo de residência diferentes e a desnitrificação também ocorreu nos filtros, com uma diminuição do nitrogênio total e um aumento de nitrato em todos os filtros.

A desnitrificação teve um desempenho maior nos filtros que operaram com tempo de residência mais longos, com valores de nitrato significativamente maiores nos filtros operados com três dias de tempo de residência. A diferença nos níveis de nitrito também foi significativamente maior nos filtros de três dias em comparação com o de um dia de tempo de residência. Isso se justifica, pois bactérias desnitrificantes preferem ambientes pobres em oxigênio e ricos em carbono, o que era mais provável de ocorrer nos filtros operados com dois e três dias de tempo de residência (YOUNG-ROJANSCHI, MADRAMOOTOO, 2014a).

Os resultados obtidos para nitrato e nitrito mostram que o volume de água utilizado na alimentação dos FLDs era suficiente para renovar a água no interior do filtro (ou seja, ocupou o volume de vazios de todas as camadas, somado aos volumes dos tubos e conexões) e que a frequência de alimentações ao longo do dia para os I-FLDs favoreceu a concentração de O.D. ao longo de todo o filtro para que não ocorresse o processo de desnitrificação, o que corrobora com as observações de Murphy et al. (2010), Young-Rojanschi e Madramootoo (2014a) e Maciel (2018).

\subsubsection{Parâmetros microbiológicos}

A estabilidade de redução de patógenos está relacionada com o avanço da carreira de filtração dos FLDs e com a formação completa da camada biológica no período de 30 dias 
(ELLIOT et al., 2008; CAWST, 2012; KENNEDY et al., 2013). O real mecanismo de remoção de microrganismos pela camada biológica é uma combinação de fixação que ocorre no leito filtrante e de predação que ocorre pela atividade biológica (SCHIJVEN et al., 2013).

Nas Figuras 63 e 64 apresentam-se os resultados de Escherichia coli e a remoção em $\log _{10}$ para os quatro filtros.

Figura 63 - Contagem de Escherichia coli na água de estudo e na água efluente dos filtros lentos domiciliares

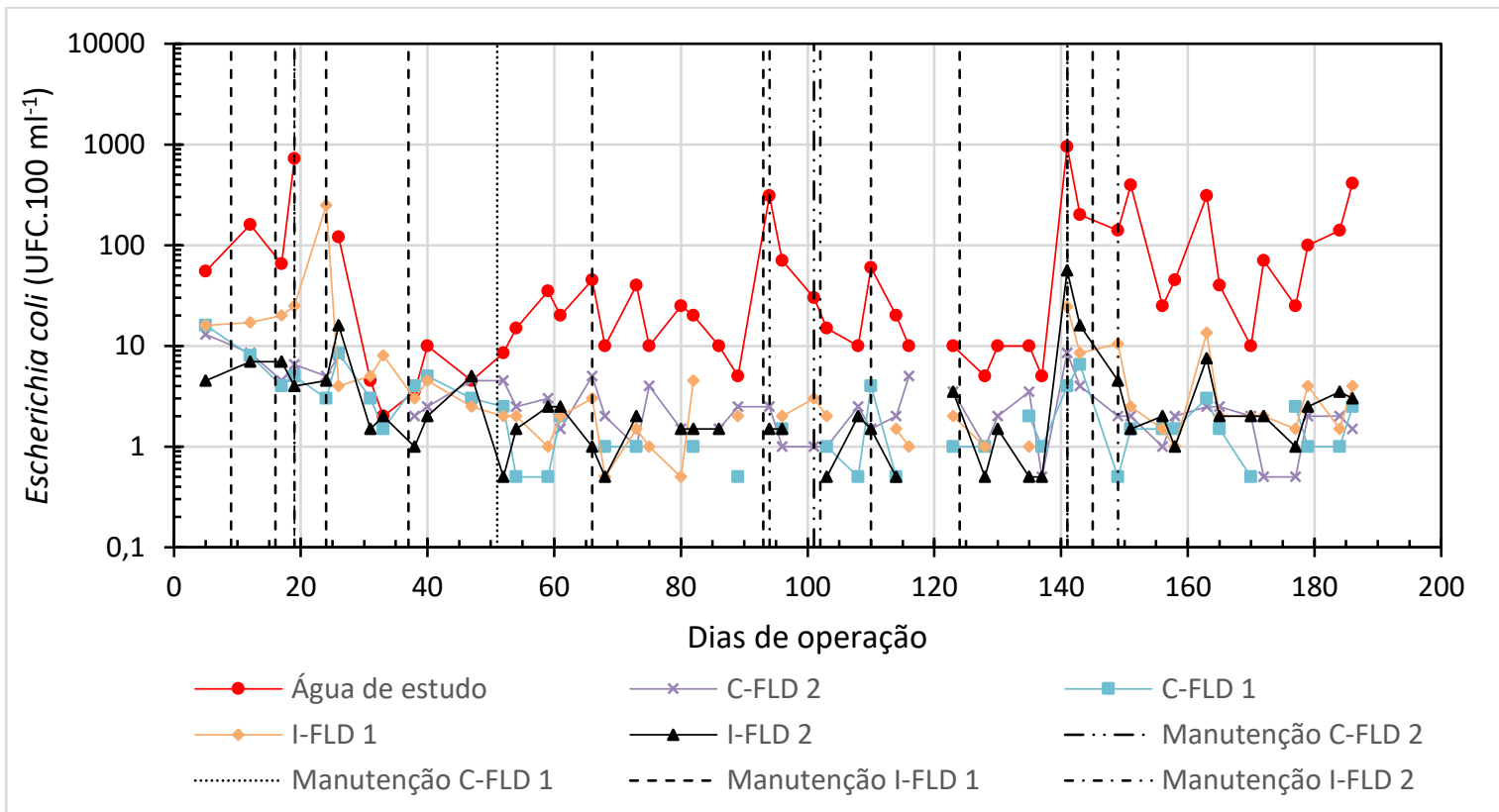

Fonte: Autor

Figura 64 - Redução de Escherichia coli em $\log _{10}$ entre a entrada da água de estudo e a água efluente nos filtros lentos domiciliares

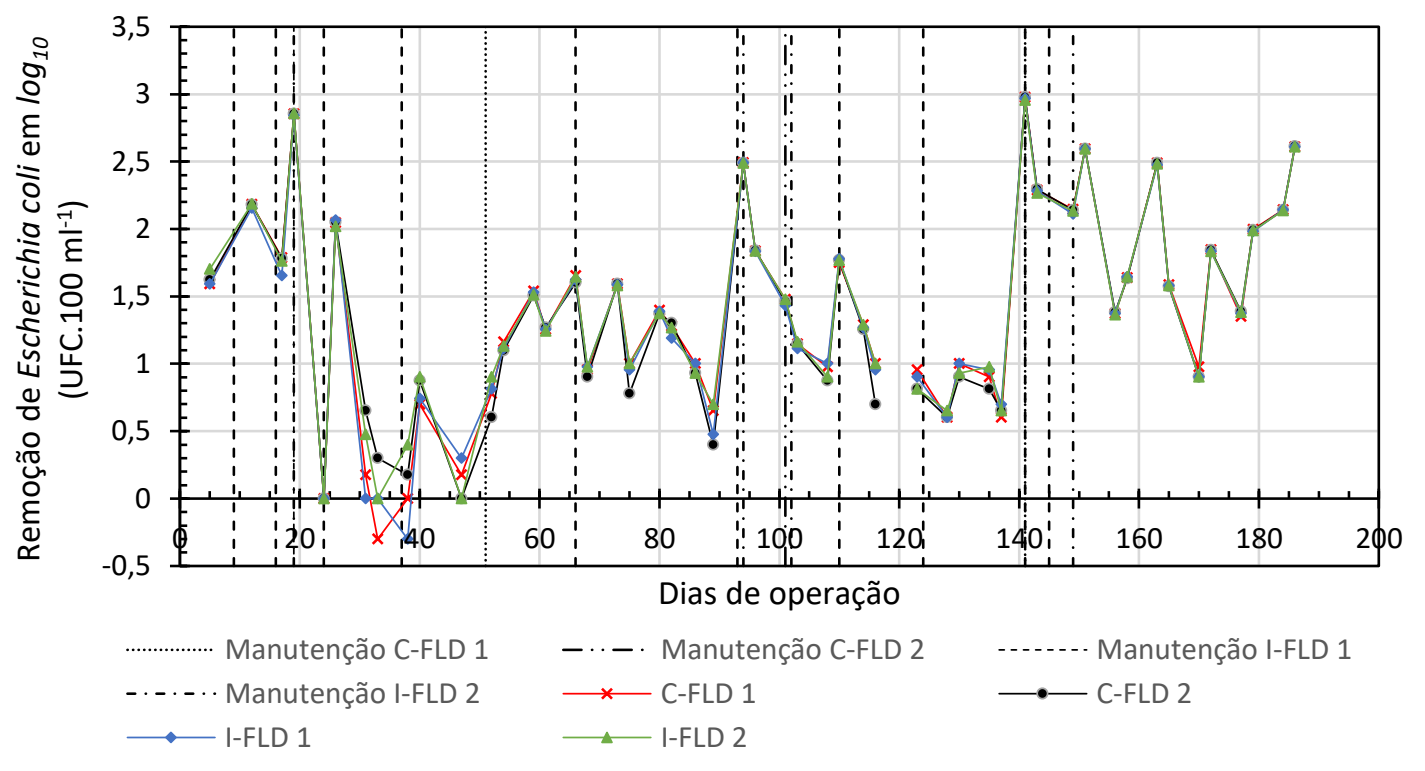

Fonte: Autor 
A eficiência de remoção média de Escherichia coli em log para os filtros C-FLD 1; CFLD 2; I-FLD 1 e I-FLD 2 foram de 1,45 \pm 0,72; 1,44 $\pm 0,70 ; 1,46 \pm 0,70$ e 1,50 \pm 0,65 log, respectivamente. Os filtros contínuos e intermitentes apresentaram resultados de remoção próximos, mesmo após períodos de limpeza.

As reduções nos quatro filtros apresentaram-se de acordo com o encontrado por outros autores na literatura. Elliott et al. (2008) obtiveram reduções E. coli que variaram de 0,3 a 4 $\log _{10}$. Young-Rojanschi, Madramootoo (2014b) obtiveram reduções de E. coli de 1,8 $\pm 0,8 ; 1,9$ $\pm 0,8$ e 1,8 $\pm 0,9 \log _{10}$ para filtros tempo de residência de um, dois e três dias, respectivamente. Young-Rojanschi, Madramootoo (2014a) compararam filtros operados em escoamento contínuo e intermitente e a operação contínua apresentou resultados de remoção de $E$. coli significativamente melhores: $3,71 \log _{10}$ versus $1,67 \log _{10}$.

Os resultados de Escherichia coli da AE e dos FLDs apresentaram diferenças estatisticamente significativas entre si (teste de Kruskal Wallis ao nível de significância de 5\%). A comparação estatística de E. coli entre AE e os FLDs está apresentada na Tabela 28.

Os resultados da comparação estatística de E. coli mostram que a água de estudo tem diferença significativa em relação a água tratada pelos filtros e há uma diferença significativa entre o C-FLD 1 e o C-FLD 2 e entre o C-FLD 1 e o I-FLD 1, mostrando que o diâmetro e o tipo de operação influenciam no desempenho dos filtros para esse parâmetro.

Tabela 28 - Comparação estatística de Escherichia coli entre AE e os filtros ${ }^{1}$

\begin{tabular}{|c|c|c|c|c|c|}
\hline & $\mathrm{AE}$ & C-FLD1 & C-FLD2 & I-FLD1 & I-FLD2 \\
\hline $\mathrm{AE}$ & & $0,00 *$ & $0,00 *$ & $0,00 *$ & $0,00^{*}$ \\
\hline C-FLD1 & $0,00^{*}$ & & $0,02 *$ & $0,03 *$ & 0,16 \\
\hline C-FLD2 & $0,00 *$ & $0,02 *$ & & 0,94 & 0,25 \\
\hline I-FLD1 & $0,00 *$ & $0,03 *$ & 0,94 & & 0,30 \\
\hline I-FLD2 & $0,00 *$ & 0,16 & 0,25 & 0,30 & \\
\hline
\end{tabular}

Schijven et al. (2013) desenvolveram um modelo para prever a remoção de vírus e bactérias patogênico. No estudo foram testados várias temperaturas, vazões, tamanho de grãos e idade da camada biológica em plantas piloto. A remoção de E. coli foi de 0,94 e 4,5 $\log _{10}$, considerando primeiro apenas a filtração, e depois, adicionalmente, os processos da camada 
biológica. O modelo considerou dois termos, um para filtragem de coloides e outro para contribuição da camada biológica na remoção de microrganismos. Este último é um termo dependente da temperatura para a atividade biológica. O modelo mostrou que a remoção de microrganismos é mais sensível às mudanças de temperatura e idade da camada biológica. A remoção é mais eficiente em temperaturas mais elevadas e com maior idade da camada biológica. Em um estudo de campo avaliando a sustentabilidade e eficácia de 55 filtros instalados de 1999 à 2010 no Haiti, Sisson et al. (2013) constataram que 29 filtros ainda estavam em uso e que a eficiência de remoção de $E$. coli foi de $1,1 \log _{10}$.

Maciel e Sabogal-Paz (2018) obtiveram uma redução de E. coli de 2,29 \pm 0,74 e 2,14 \pm $0,73 \log _{10}$ para os filtros contínuos e de $1,40 \pm 0,61$ e $1,26 \pm 0,45 \log _{10}$ para os filtros intermitentes. Andreoli e Sabogal-Paz (2020) obtiveram uma redução de E. coli de $3 \log _{10}$ para os filtros contínuos e $2 \log _{10}$ para os filtros intermitentes.

No presente estudo, a remoção média de E. coli para os quatro filtros foi de $1,46 \log _{10} \mathrm{e}$ não houve diferença significativa entre os filtros operados de forma contínua ou intermitente.

Nas Figuras 65 e 66 apresentam-se os resultados obtidos de coliformes totais e a sua remoção em $\log _{10}$ para os filtros contínuos e intermitentes.

Figura 65 - Contagem de coliforme totais na água de estudo e na água efluente dos filtros lentos domiciliares

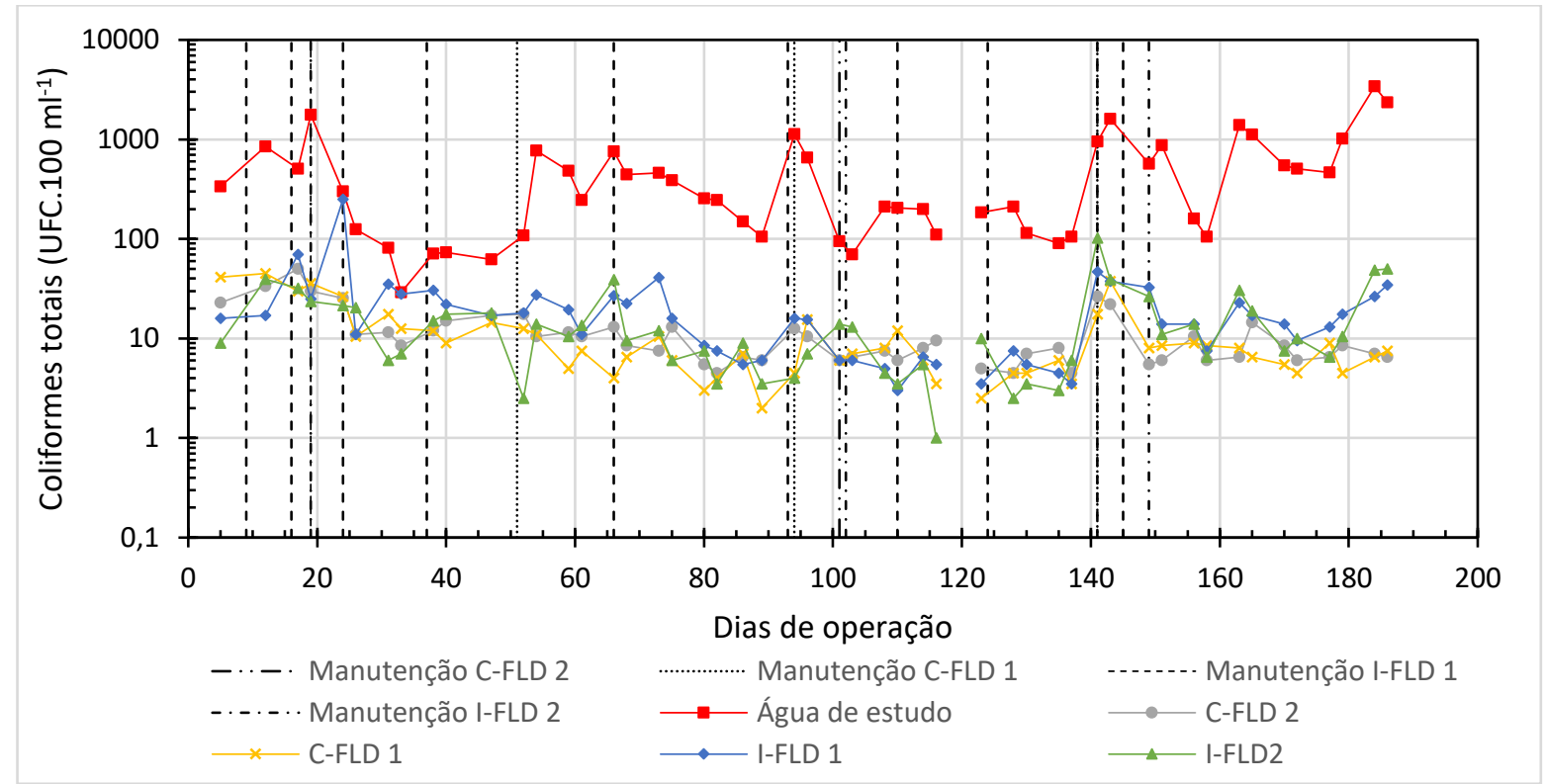

Fonte: Autor 
Figura 66 - Redução de coliformes totais em $\log _{10}$ entre a entrada da água de estudo e a água efluente nos filtros lentos domiciliares

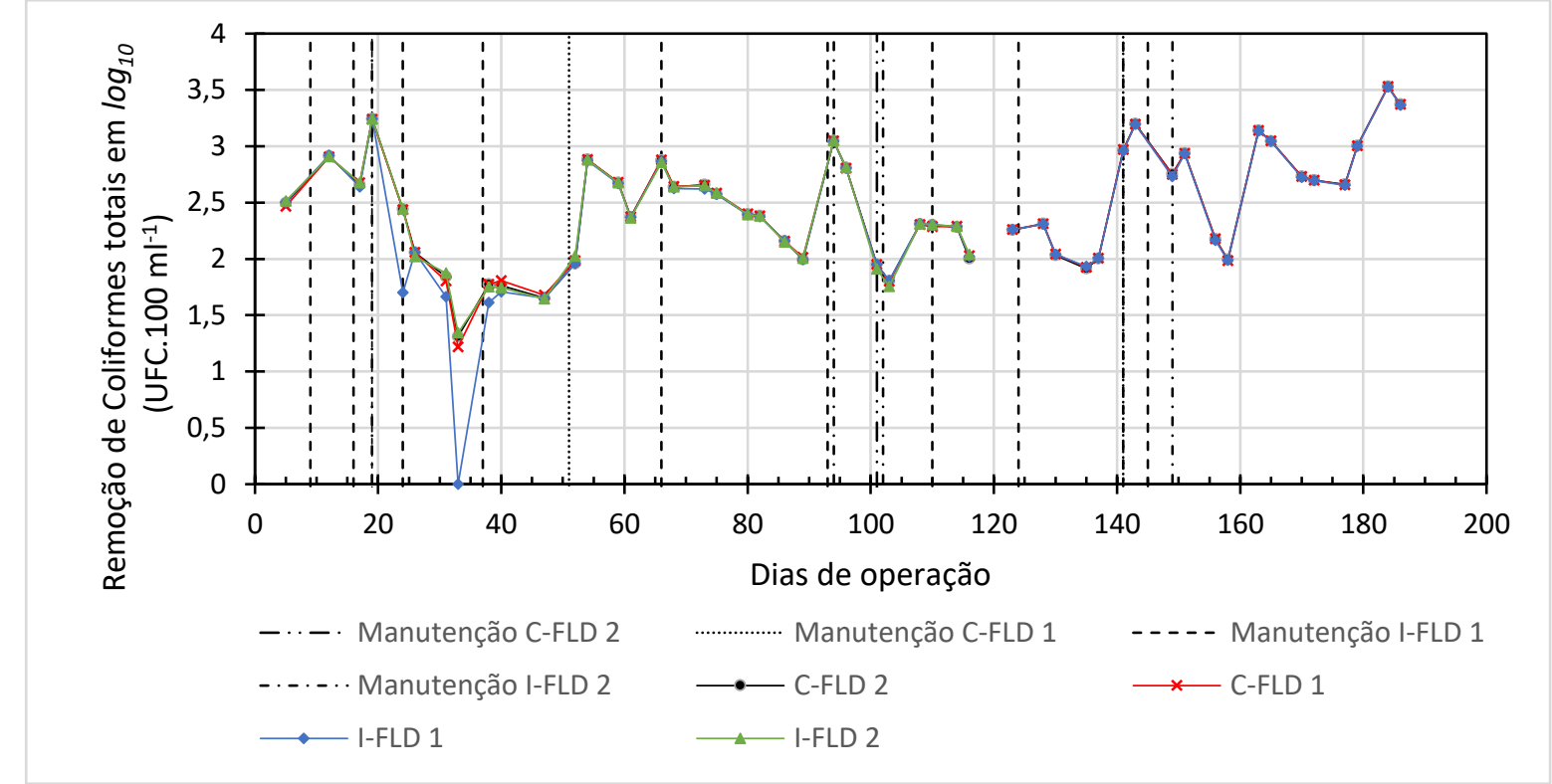

Fonte: Autor

A eficiência de remoção média de coliformes totais em $\log _{10}$ para os filtros C-FLD 1 e 2 e I-FLD 1 e 2 foram de 2,46 $\pm 0,50 ; 2,46 \pm 0,50 ; 2,41 \pm 0,60$ e 2,46 0,50 $\log _{10}$, respectivamente. No presente estudo, a remoção média dos quatro filtros foi de $2,45 \log _{10}$, sendo que as amostras dos quatro filtros foram coletadas após tempo de residência de 14 horas. Não houve diferença significativa nos filtros operados de forma contínua e intermitente.

Os resultados de coliformes totais da AE e dos FLDs apresentaram diferenças estatisticamente significativas entre si (teste de Kruskal Wallis ao nível de significância de 5\%). A comparação estatística de coliformes totais entre AE e os FLDs está apresentada na Tabela 29.

Os resultados da comparação estatística de coliformes totais mostram que a água de estudo tem diferença significativa em relação a água tratada pelos filtros e há uma diferença significativa entre o C-FLD 1 e o I-FLD 1 e entre o I-FLD 1 e o C-FLD 2, mostrando que o tipo de operação e o diâmetro influenciam no desempenho dos filtros para esse parâmetro. 
Tabela 29 - Comparação estatística de coliformes totais entre AE e os filtros ${ }^{1}$

\begin{tabular}{cccccc}
\hline & AE & C-FLD1 & C-FLD2 & I-FLD1 & I-FLD2 \\
\hline AE & & $0,00^{*}$ & $0,00^{*}$ & $0,00^{*}$ & $0,00^{*}$ \\
C-FLD1 & $0,00^{*}$ & & 0,19 & $0,00^{*}$ & 0,14 \\
C-FLD2 & $0,00^{*}$ & 0,19 & & $0,01^{*}$ & 0,56 \\
I-FLD1 & $0,00^{*}$ & $0,00^{*}$ & $0,01^{*}$ & & 0,09 \\
I-FLD2 & $0,00^{*}$ & 0,14 & 0,56 & 0,09 & \\
\hline
\end{tabular}

${ }^{1}$ Teste de Mann-Whitney pairwise para coliforme totais nos filtros

*Significativo ao nível de $5 \%$ de probabilidade $(\mathrm{P}<0,05)$

Fonte: Autor

No estudo de Lynn et al. (2013) os resultados de reduções médias para E. coli foi de 1,70 log e para coliformes totais foi de 1,20 log. Estudos realizados por Nair e Ahammed (2014) observaram uma redução de coliformes totais de 2 log após o período de maturação. Baig et al. (2011) investigaram a remoção de E. coli e coliformes totais utilizando biomassa de casca de pinus, colocada no meio da camada filtrante, os filtros apresentaram uma redução média de 93 $\pm 2 \%$ e de $95 \pm 3 \%$ para $E$. coli e coliformes totais, respectivamente.

Jenkings et al. (2009) analisaram a influência do tamanho do grão de areia, o tempo de residência e a taxa de filtração e concluíram que esses fatores têm efeitos significativos no desempenho de remoção microbiológica nos filtros. Na melhor configuração, utilizando areia fina, $10 \mathrm{~cm}$ de lâmina de água acima da camada de areia e tempo de residência de $16 \mathrm{~h}$, obtevese uma remoção de coliformes fecais de 1,83 log, e na pior configuração, com areia grossa, lâmina d'água de $30 \mathrm{~cm}$ e 5 h de tempo de residência obteve-se uma remoção de 1,08 log.

Os resultados obtidos para redução de E. coli foi de 1,4 $\log$ e de coliformes totais foi de 2,4 log, valores próximos ou superiores aos resultados obtidos por outros pesquisadores como Jenkings et al. (2009); Lynn et al. (2013); Nair e Ahammed (2014), Maciel e Sabogal-Paz (2018); Andreoli e Sabogal-Paz (2020).

Desde o início da operação os filtros apresentaram reduções no número de colônias, porém sempre tiveram colônias presentes, o que não atende ao estabelecido no padrão de potabilidade que exige a ausência de Escherichia coli e de coliformes totais em $100 \mathrm{ml}$ de amostra. Portanto, recomenda-se o pós-tratamento da água filtrada que pode ser realizada com a fervura, a utilização da radiação solar ou a cloração, que são métodos simples de desinfecção. 


\subsubsection{Síntese dos parâmetros analisados}

Os resultados do monitoramento dos parâmetros de qualidade da água são apresentados da na Tabela 30. A tabela contém as informações dos valores médios e desvio padrão e da eficiência de remoção.

A análise dos parâmetros de monitoramento da qualidade da água nos FLDs mostra que os filtros operados em escoamento contínuo são mais eficientes na remoção de cor e turbidez quando comparados com os filtros de operação intermitente. A análise estatística mostra que houve diferenças significativas entre a $\mathrm{AE}$ e as águas tratadas pelos FLDs para os parâmetros de cor aparente, turbidez, absorbância, coliformes totais e E. coli, comprovando a redução dos parâmetros em todos os FLDs independente da geometria ou tipo de operação (contínua ou intermitente). O C-FLD 1 apresentou os melhores resultados.

A aplicação da dinâmica de fluidos computacional nos filtros permitiu avaliar se a variação da geometria e do tipo de alimentação pode ter influenciado na hidrodinâmica e se essas alterações podem estar relacionadas com redução dos parâmetros monitorados em cada FLD. 
Tabela 30 - Desempenho dos filtros contínuos em relação aos parâmetros físico-químicos

\begin{tabular}{|c|c|c|c|c|c|c|c|c|c|c|c|}
\hline \multirow[t]{2}{*}{ Parâmetro } & \multirow{2}{*}{$\begin{array}{l}\text { Água de } \\
\text { estudo }\end{array}$} & \multirow{2}{*}{$\frac{\text { C-FLD } 1}{7 \mathrm{~h}}$} & \multirow{2}{*}{$\frac{\text { C-FLD } 2}{7 \mathrm{~h}}$} & \multicolumn{5}{|c|}{ I-FLD 1} & \multicolumn{3}{|c|}{ I-FLD 2} \\
\hline & & & & $7 \mathrm{~h}$ & $9: 30 \mathrm{~h}$ & $12: 00 \mathrm{~h}$ & $14: 30 \mathrm{~h}$ & $17: 00 \mathrm{~h}$ & $7 \mathrm{~h}$ & $12: 00 \mathrm{~h}$ & 17:00 h \\
\hline $\mathrm{pH}$ & $7,05 \pm 0,23$ & $7,51 \pm 0,25$ & $7,46 \pm 0,28$ & $\begin{array}{c}7,52 \\
\pm 0,26\end{array}$ & NR & NR & NR & NR & $\begin{array}{c}7,48 \pm \\
0,24\end{array}$ & NR & NR \\
\hline $\begin{array}{l}\text { Cor aparente } \\
{[\mathrm{uC}]}\end{array}$ & $16,25 \pm 23,37$ & $\begin{array}{c}4,21 \pm 5,77 \\
74,08 \%\end{array}$ & $\begin{array}{c}4,39 \pm 4,55 \\
72,98 \%\end{array}$ & $\begin{array}{c}4,41 \\
\pm 8,11 \\
72,85 \% \\
\end{array}$ & $\begin{array}{c}5,27 \pm \\
9,04 \\
67,56 \% \\
\end{array}$ & $\begin{array}{c}6,38 \pm \\
16,71 \\
60,73 \% \\
\end{array}$ & $\begin{array}{c}5,57 \pm \\
10,93 \\
65,71 \%\end{array}$ & $\begin{array}{c}5,45 \pm \\
10,62 \\
66,48 \% \\
\end{array}$ & $\begin{array}{c}5,26 \pm \\
14,16 \\
67,63 \% \\
\end{array}$ & $\begin{array}{c}6,48 \pm \\
13,39 \\
60,15 \% \\
\end{array}$ & $\begin{array}{c}5,27 \pm \\
9,27 \\
67,58 \% \\
\end{array}$ \\
\hline $\begin{array}{l}\text { Nitrato [mg.L- } \\
\left.{ }^{-}\right]\end{array}$ & $1,3 \pm 0,168$ & $1,3 \pm 0,215$ & $1,4 \pm 0,288$ & $\begin{array}{c}1,3 \\
+0,238 \\
\end{array}$ & NR & NR & NR & NR & $\begin{array}{c}1,3 \pm \\
0,273 \\
\end{array}$ & NR & NR \\
\hline Nitrito $\left[\mathrm{mg} . \mathrm{L}^{-1}\right]$ & $\begin{array}{c}0,004 \pm \\
0,0188\end{array}$ & $<$ L.D. & <L.D. & $<$ L.D. & NR & NR & NR & NR & $<$ L.D. & NR & NR \\
\hline $\begin{array}{l}\text { Coliformes } \\
\text { totais (UFC } 100 \\
\mathrm{ml}^{-1} \text { ) }\end{array}$ & $\begin{array}{l}541,1 \pm \\
640,93\end{array}$ & $\begin{array}{c}11,17 \pm \\
10,11 \\
97,94 \% \\
\end{array}$ & $\begin{array}{c}11,75 \pm \\
8,68 \\
97,83 \% \\
\end{array}$ & $\begin{array}{c}22,54 \pm \\
35,03 \\
95,83 \% \\
\end{array}$ & NR & NR & NR & NR & $\begin{array}{c}15,98 \pm \\
17,21 \\
97,05 \%\end{array}$ & NR & NR \\
\hline $\begin{array}{l}\text { Escherichia. } \\
\text { coli (UFC } 100 \\
\mathrm{ml}^{-1} \text { ) }\end{array}$ & $\begin{array}{c}96,36 \pm \\
181,46\end{array}$ & $\begin{array}{c}2,2 \pm 2,81 \\
97,72 \%\end{array}$ & $\begin{array}{c}2,87 \pm 2,49 \\
97,02 \%\end{array}$ & $\begin{array}{c}9,35 \pm \\
34,91 \\
90,30 \% \\
\end{array}$ & NR & NR & NR & NR & $\begin{array}{c}3,76 \pm \\
8,14 \\
96,10 \% \\
\end{array}$ & NR & NR \\
\hline
\end{tabular}

Média \pm Desvio padrão; Eficiência de remoção (\%); NR: não realizado; L.D. (Limite de Detecção); O.D.: oxigênio dissolvido medido na água de estudo e no piezômetro 2 dos FLDs.

Fonte: Autor 


\subsubsection{Análises bivariadas}

Nas Tabelas 31, 32 e 33 apresentam-se os resultados dos coeficientes de correlação de Spearman para o primeiro, o segundo e o terceiro conjunto de dados, respetivamente.

Os resultados obtidos para todos os FLDs foram semelhantes para o primeiro conjunto de dados analisado estatisticamente, desta forma a correlação da perda de carga unitária com a turbidez apresentou a maior correlação inversa, indicando que quanto maior a perda de carga unitária (carreira de filtração mais desenvolvida) menor era a turbidez, conforme esperado, uma vez que a maturidade do filtro melhora a eficiência do tratamento e consequentemente reduz a turbidez. Nos FLDs a correlação da turbidez com a cor foi a maior correlação direta, o que mostra que quanto maior a turbidez maior a cor aparente, uma correlação esperada devido à presença de sólidos suspensos e dissolvidos; e a correlação da temperatura da água com a turbidez foi a segunda maior correlação direta, indicando que quanto maior a temperatura da água maior a turbidez, essa correlação ocorreu devido ao tipo de clima sub tropical, com verões quentes e chuvosos e invernos secos, desta forma, o aumento da temperatura estava associado à precipitação e consequentemente ao aumento da turbidez.

No segundo conjunto de dados analisado, todos os FLDs apresentaram a maior correlação direta entre o O.D. P1 e O.D. P2, o que era um fator esperado. A correlação da temperatura da água com o O.D. P1 foi a maior correlação inversa observada no C-FLD1 no IFLD2 e a correlação da temperatura da água com o O.D. P2 foi a maior correlação inversa observada no C-FLD2 e I-FLD1.

No terceiro conjunto de dados analisado, todos os FLDs apresentaram a correlação direta entre a turbidez e coliformes totais e entre coliformes totais e E. coli dentro das três maiores correlações observadas. Os I-FLDs apresentaram a maior correlação direta entre a turbidez e a $E$. coli, indicando que o aumento de turbidez (sólidos presentes na água tratada) está associado ao aumento de E. coli, uma vez que os microorganismos podem estar adsorvidos na superfície dos sólidos. 
Tabela 31 - Teste de correlação de Spearman para o primeiro conjunto de dados

\begin{tabular}{|c|c|c|c|c|c|c|c|}
\hline & & Cor aparente & Turbidez & $\mathrm{pH}$ & Condutividade & Temperatura água & Perda de carga unitária \\
\hline \multirow{6}{*}{ C-FLD1 } & Cor aparente & 1,00 & 0,49 & $-0,04$ & $-0,06$ & 0,06 & $-0,41$ \\
\hline & Turbidez & 0,49 & 1,00 & $-0,19$ & 0,14 & $\mathbf{0 , 3 8}$ & $-0,64$ \\
\hline & $\mathrm{pH}$ & $-0,04$ & $-0,19$ & 1,00 & $-0,19$ & $-0,21$ & 0,25 \\
\hline & Condutividade & $-0,06$ & 0,14 & $-0,19$ & 1,00 & 0,31 & 0,03 \\
\hline & Temperatura água & 0,06 & $\mathbf{0 , 3 8}$ & $-0,21$ & 0,31 & 1,00 & $-0,18$ \\
\hline & Perda de carga unitária & $-0,41$ & $-0,64$ & 0,25 & 0,03 & $-0,18$ & 1,00 \\
\hline \multirow{6}{*}{ C-FLD2 } & Cor aparente & 1,00 & $\mathbf{0 , 5 4}$ & 0,10 & $-0,15$ & 0,12 & 0,21 \\
\hline & Turbidez & $\mathbf{0 , 5 4}$ & 1,00 & $-0,02$ & $-0,01$ & $\mathbf{0 , 3 9}$ & $-0,37$ \\
\hline & $\mathrm{pH}$ & 0,10 & $-0,02$ & 1,00 & $-0,11$ & $-0,09$ & 0,07 \\
\hline & Condutividade & $-0,15$ & $-0,01$ & $-0,11$ & 1,00 & 0,29 & 0,13 \\
\hline & Temperatura água & 0,12 & $\mathbf{0 , 3 9}$ & $-0,09$ & 0,29 & 1,00 & 0,19 \\
\hline & Perda de carga unitária & 0,21 & $-\mathbf{0 , 3 7}$ & 0,07 & 0,13 & 0,19 & 1,00 \\
\hline \multirow{6}{*}{ I-FLD1 } & Cor aparente & 1,00 & 0,64 & $-0,05$ & $-0,13$ & 0,10 & $-0,12$ \\
\hline & Turbidez & 0,64 & 1,00 & $-0,07$ & $-0,10$ & $\mathbf{0 , 3 6}$ & $-0,25$ \\
\hline & $\mathrm{pH}$ & $-0,05$ & $-0,07$ & 1,00 & $-0,14$ & $-0,19$ & 0,18 \\
\hline & Condutividade & $-0,13$ & $-0,10$ & $-0,14$ & 1,00 & 0,27 & $-0,06$ \\
\hline & Temperatura água & 0,10 & $\mathbf{0 , 3 6}$ & $-0,19$ & $\mathbf{0 , 2 7}$ & 1,00 & $-0,37$ \\
\hline & Perda de carga unitária & $-0,12$ & $-0,25$ & 0,18 & $-0,06$ & $-0,37$ & 1,00 \\
\hline \multirow{6}{*}{ I-FLD2 } & Cor aparente & 1,00 & $\mathbf{0 , 5 9}$ & $-0,02$ & $-0,07$ & 0,05 & $-0,10$ \\
\hline & Turbidez & $\mathbf{0 , 5 9}$ & 1,00 & 0,07 & 0,00 & $\mathbf{0 , 4 0}$ & $-0,29$ \\
\hline & $\mathrm{pH}$ & $-0,02$ & 0,07 & 1,00 & $-0,13$ & $-0,07$ & 0,09 \\
\hline & Condutividade & $-0,07$ & 0,00 & $-0,13$ & 1,00 & 0,24 & $-0,04$ \\
\hline & Temperatura água & 0,05 & $\mathbf{0 , 4 0}$ & $-0,07$ & 0,24 & 1,00 & $-0,38$ \\
\hline & Perda de carga unitária & $-0,10$ & $-0,29$ & 0,09 & $-0,04$ & $-0,38$ & 1,00 \\
\hline
\end{tabular}

Obs.: Em negrito são as três maiores correlações.

Fonte: Autor 
Tabela 32 - Teste de correlação de Spearman para o segundo conjunto de dados

\begin{tabular}{llccc}
\hline & & Temperatura água & O.D. P1 & O.D. P2 \\
\hline \multirow{2}{*}{ C-FLD1 } & Temperatura água & 1,00 & $\mathbf{- 0 , 6 6}$ & $-0,57$ \\
& O.D. P1 & $\mathbf{- 0 , 6 6}$ & 1,00 & $\mathbf{0 , 6 9}$ \\
& O.D. P2 & $-0,57$ & $\mathbf{0 , 6 9}$ & 1,00 \\
\hline \multirow{2}{*}{ C-FLD2 } & Temperatura água & 1,00 & $-0,82$ & $\mathbf{- 0 , 8 4}$ \\
& O.D. P1 & $-0,82$ & 1,00 & $\mathbf{0 , 9 1}$ \\
& O.D. P2 & $\mathbf{- 0 , 8 4}$ & $\mathbf{0 , 9 1}$ & 1,00 \\
\hline \multirow{2}{*}{ I-FLD1 } & Temperatura água & 1,00 & $-0,55$ & $\mathbf{- 0 , 7 1}$ \\
& O.D. P1 & $-0,55$ & 1,00 & $\mathbf{0 , 8 6}$ \\
& O.D. P2 & $\mathbf{- 0 , 7 1}$ & $\mathbf{0 , 8 6}$ & 1,00 \\
\hline \multirow{3}{*}{ I-FLD2 } & Temperatura água & 1,00 & $\mathbf{- 0 , 6 5}$ & $-0,62$ \\
& O.D. P1 & $\mathbf{- 0 , 6 5}$ & 1,00 & $\mathbf{0 , 8 8}$ \\
& O.D. P2 & $-0,62$ & $\mathbf{0 , 8 8}$ & 1,00 \\
\hline
\end{tabular}

Obs.: O.D. P1 é o oxigênio dissolvido do piezômetro 1; O.D. P2 é o oxigênio dissolvido do piezômetro 2; em negrito são as duas maiores correlações.

Fonte: Autor

Tabela 33 - Teste de correlação de Spearman para o terceiro conjunto de dados

\begin{tabular}{|c|c|c|c|c|c|}
\hline & & Turbidez & $\begin{array}{c}\text { Perda de carga } \\
\text { unitária }\end{array}$ & $\begin{array}{l}\text { Coliformes } \\
\text { totais }\end{array}$ & E. coli \\
\hline \multirow{4}{*}{ C-FLD1 } & Turbidez & 1,00 & $-0,73$ & 0,73 & 0,52 \\
\hline & $\begin{array}{l}\text { Perda de carga } \\
\text { unitária }\end{array}$ & $-0,73$ & 1,00 & $-0,47$ & $-0,24$ \\
\hline & Coliformes totais & 0,73 & $-0,47$ & 1,00 & $\mathbf{0 , 7 8}$ \\
\hline & E. coli & 0,52 & $-0,24$ & $\mathbf{0 , 7 8}$ & 1,00 \\
\hline \multirow{4}{*}{ C-FLD2 } & Turbidez & 1,00 & $-0,42$ & 0,58 & 0,39 \\
\hline & $\begin{array}{l}\text { Perda de carga } \\
\text { unitária }\end{array}$ & $-0,42$ & 1,00 & 0,37 & 0,10 \\
\hline & Coliformes totais & $\mathbf{0 , 5 8}$ & 0,37 & 1,00 & 0,66 \\
\hline & E. coli & 0,39 & 0,10 & 0,66 & 1,00 \\
\hline \multirow{4}{*}{ I-FLD1 } & Turbidez & 1,00 & $-0,31$ & $\mathbf{0 , 5 9}$ & 0,71 \\
\hline & $\begin{array}{l}\text { Perda de carga } \\
\text { unitária }\end{array}$ & $-0,31$ & 1,00 & $-0,20$ & $-0,12$ \\
\hline & Coliformes totais & $\mathbf{0 , 5 9}$ & $-0,20$ & 1,00 & 0,64 \\
\hline & E. coli & 0,71 & $-0,12$ & 0,64 & 1,00 \\
\hline \multirow{4}{*}{ I-FLD2 } & Turbidez & 1,00 & $-0,33$ & 0,64 & $\mathbf{0 , 7 0}$ \\
\hline & $\begin{array}{l}\text { Perda de carga } \\
\text { unitária }\end{array}$ & $-0,33$ & 1,00 & $-0,20$ & $-0,23$ \\
\hline & Coliformes totais & 0,64 & $-0,20$ & 1,00 & 0,69 \\
\hline & E. coli & $\mathbf{0 , 7 0}$ & $-0,23$ & 0,69 & 1,00 \\
\hline
\end{tabular}

Obs.: Em negrito são as três maiores correlações.

Fonte: Autor 


\subsection{Validação das simulações numéricas em análises hidráulicas para FLDs}

O mínimo volume do elemento finito foi calculado para o Co de 0,9 para cada um dos FLDs, conforme relatado na Tabela 34.

Tabela 34 - Parâmetros para os ensaios de DTR computacional

\begin{tabular}{lcc}
\hline Filtros & Co & $\begin{array}{c}\text { Mínimo volume do } \\
\text { elemento finito }\left(\mathrm{m}^{3}\right)\end{array}$ \\
\hline C-FLD 1 & 0,9 & $1,318212 \times 10^{-10}$ \\
\hline C-FLD 2 & 0,9 & $3,672438 \times 10^{-10}$ \\
\hline I-FLD 1 & 0,9 & $1,318212 \times 10^{-10}$ \\
\hline I-FLD 2 & 0,9 & $3,672438 \times 10^{-10}$ \\
\hline
\end{tabular}

Fonte: Autor

Nas simulações em regime permanente foram obtidas as velocidades de saída, localizada no centro do tubo de saída, ou seja, no centroide da extremidade final do tubo de saída. Foi analisado o comportamento dessa velocidade em função dos volumes de controle conforme apresentado na Figura 67. Verifica-se que o valor mínimo necessário para que não ocorressem variações maiores que 5\% de velocidade para o C-FLD1 foi de 233.264 elementos e para o C-FLD2 foi de 268.474 elementos.

Figura 67-Velocidade em função do número de elementos da malha numérica obtida no teste de independência de malha do C-FLD1 e do C-FLD2.

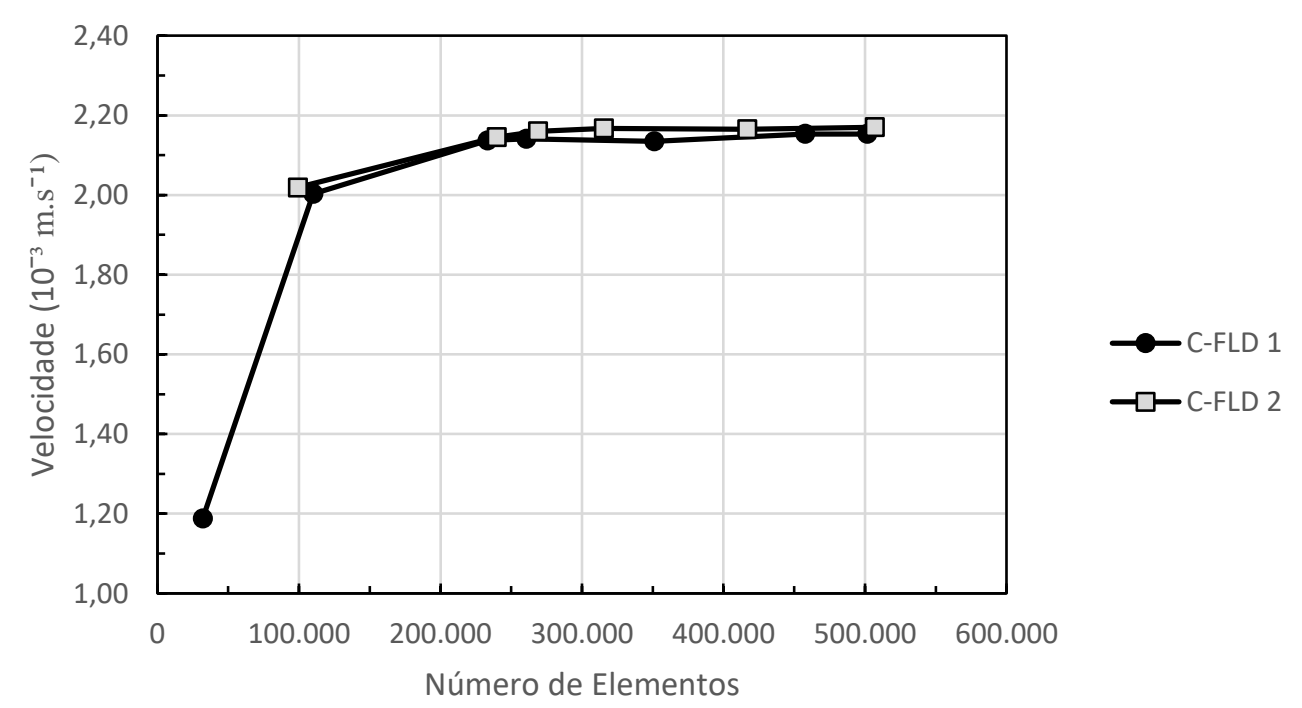

Fonte: Autor 
Nas Tabelas 35 e 36 apresentam-se, sequencialmente para o C-FLD 1 e C-FLD 2, as características das malhas geradas como volumes de controle, número de nós, velocidade e variação percentual. Os resultados de cada malha obtida para o C-FLD 1 e C-FLD 2 são mostrados nas Figuras 68 e 69, respectivamente.

Tabela 35 - Características das malhas do C-FLD 1.

\begin{tabular}{lllll}
\hline Malha & $\begin{array}{l}\text { Volumes } \\
\text { controle }\end{array}$ & Número de nós & Velocidade (m/s) & $\begin{array}{l}\text { Variação } \\
\text { percentual* }\end{array}$ \\
\hline 1 & 31.959 & 8.276 & $1,19 \mathrm{E}-03$ & $-44,60 \%$ \\
\hline 2 & 110.131 & 30.418 & $2,00 \mathrm{E}-03$ & $-6,59 \%$ \\
\hline 3 & 233.264 & 44.466 & $2,14 \mathrm{E}-03$ & $-0,35 \%$ \\
\hline 4 & 260.545 & 49.901 & $2,14 \mathrm{E}-03$ & $-0,16 \%$ \\
\hline 5 & 351.029 & 65.068 & $2,14 \mathrm{E}-03$ & $-0,44 \%$ \\
\hline 6 & 457.624 & 83.283 & $2,15 \mathrm{E}-03$ & $0,40 \%$ \\
\hline 7 & 501.498 & 90.791 & $2,16 \mathrm{E}-03$ & $0,54 \%$ \\
\hline
\end{tabular}

* variação percentual em relação à média dos cinco últimos valores.

Fonte: Autor

Tabela 36 - Características das malhas do C-FLD 2.

\begin{tabular}{lllll}
\hline Malha & $\begin{array}{c}\text { Volumes } \\
\text { controle }\end{array}$ & Número de nós & Velocidade $(\mathrm{m} / \mathrm{s})$ & $\begin{array}{l}\text { Variação } \\
\text { percentual* }\end{array}$ \\
\hline 1 & 99.098 & 18.656 & 0,002019 & $-6,77 \%$ \\
\hline 2 & 268.474 & 50.652 & 0,00216 & $-0,25 \%$ \\
\hline 3 & 315.349 & 59.694 & 0,002167 & $0,07 \%$ \\
\hline 4 & 416.785 & 76.675 & 0,002165 & $-0,02 \%$ \\
\hline 5 & 506.886 & 92.148 & 0,00217 & $0,21 \%$ \\
\hline
\end{tabular}

* variação percentual em relação à média dos quatro últimos valores.

Fonte: Autor 
Figura 68 - Malhas do FLD de acrílico contínuo (C-FLD 1)

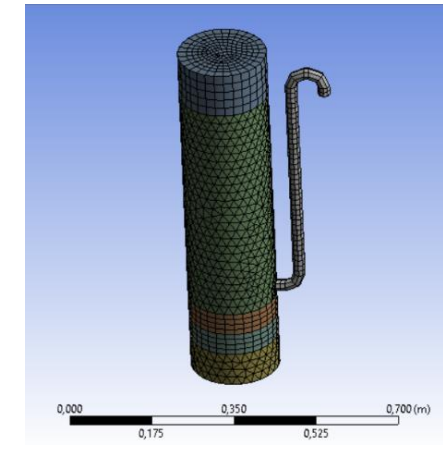

31.959 Volumes de controle

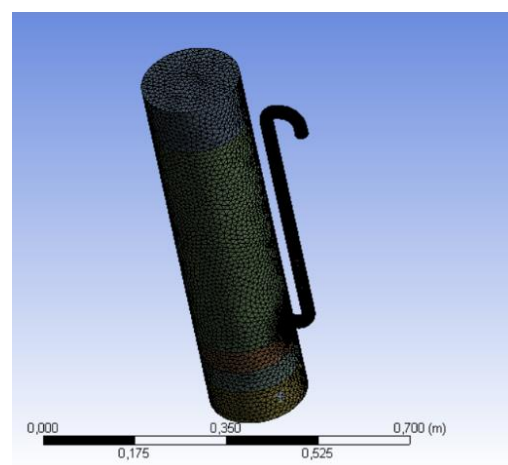

260.545 Volumes de controle

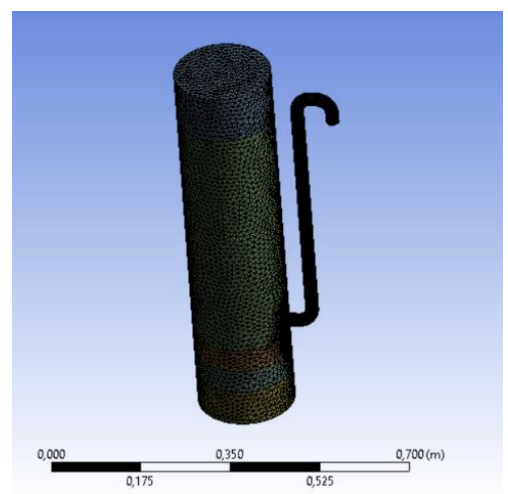

501.498 Volumes de controle

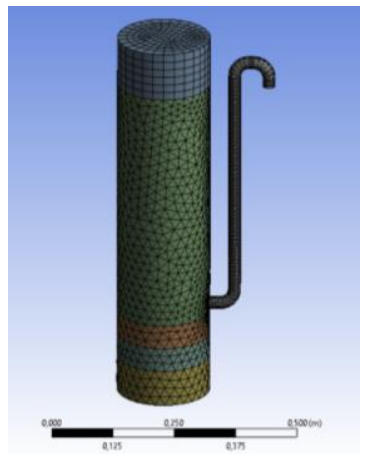

110.131 Volumes de controle

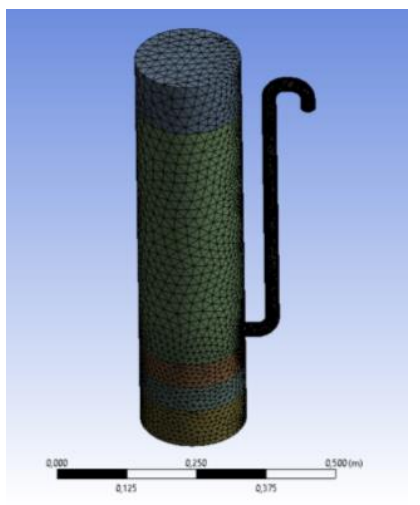

351.029 Volumes de controle

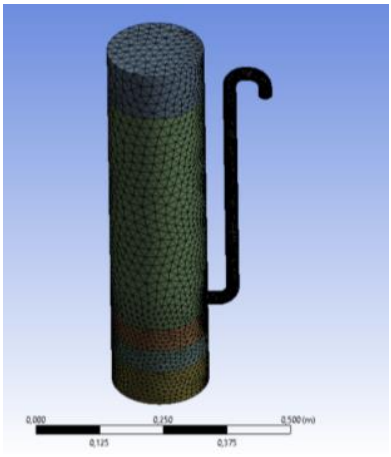

233.264 Volumes de controle

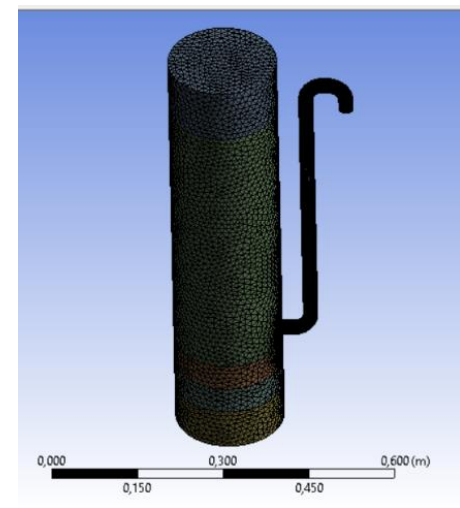

457.624 Volumes de controle

Fonte: Autor 
Figura 69 - Malhas do FLD de Defofo MPVC contínuo (C-FLD 2)

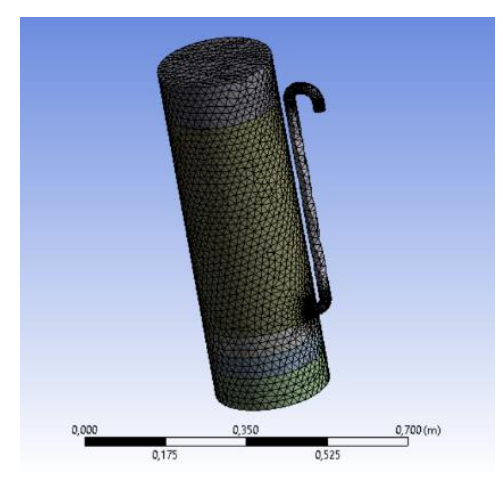

99.098 Volumes de controle

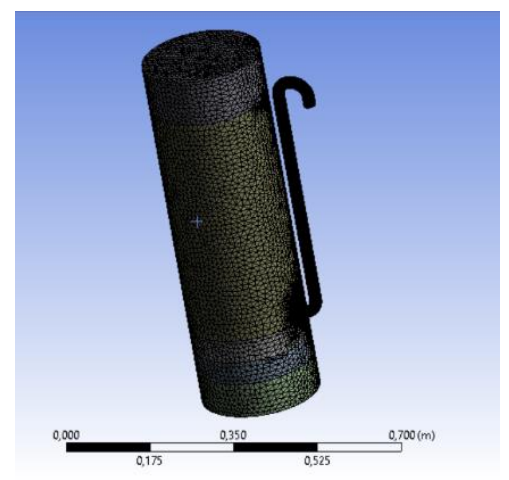

351.349 Volumes de controle

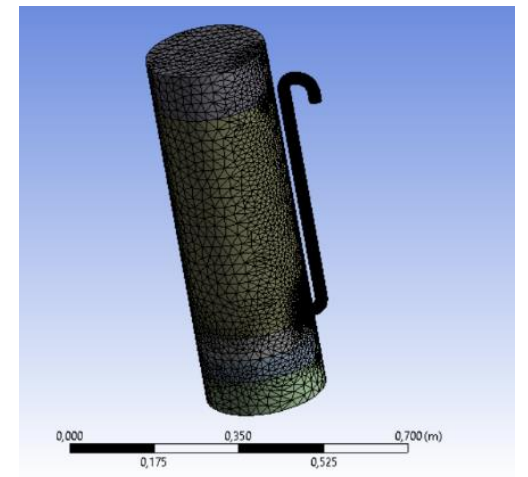

268.474 Volumes de controle

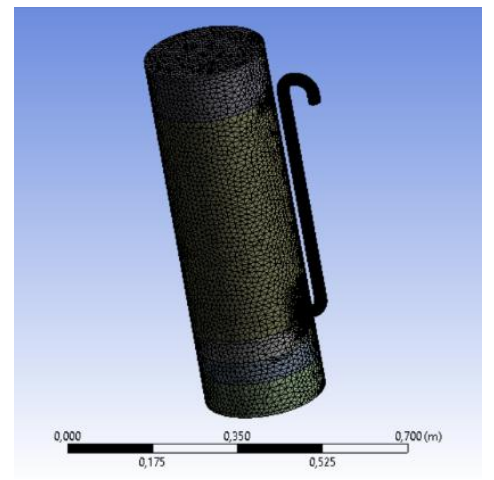

416.785 Volumes de controle

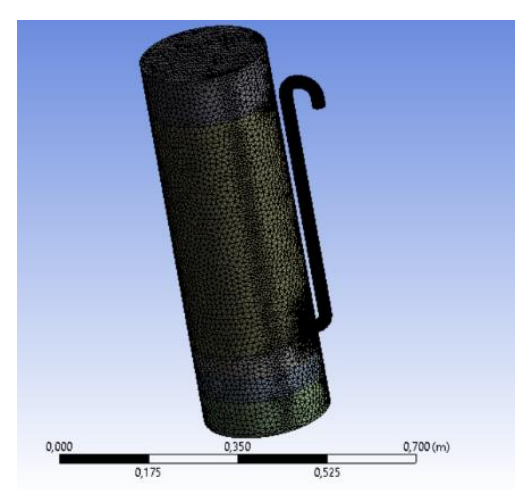

506.886 Volumes de controle

Fonte: Autor

Na Figura 70 é apresentado a malha utilizada na simulação do C-FLD 1 com 233.264 elementos e na Figura 71 é mostrada a malha utilizada para representar o C-FLD 2 com de 268.474 elementos.

Considerando a orientação de cima para baixo, nas Figuras 70 e 71, a primeira camada superior é constituída de uma lâmina d’água estacionária, a segunda camada filtrante é composta de areia fina e as outras três camadas suporte são compostas por areia grossa, pedregulho miúdo e pedregulho graúdo, respectivamente, por fim há o tubo de saída que coleta 
água no interior do filtro, especificamente no centro da camada de pedregulho graúdo, conforme a geometria do modelo físico construído em laboratório.

Figura 70 - Malha obtida para o C-FLD1.

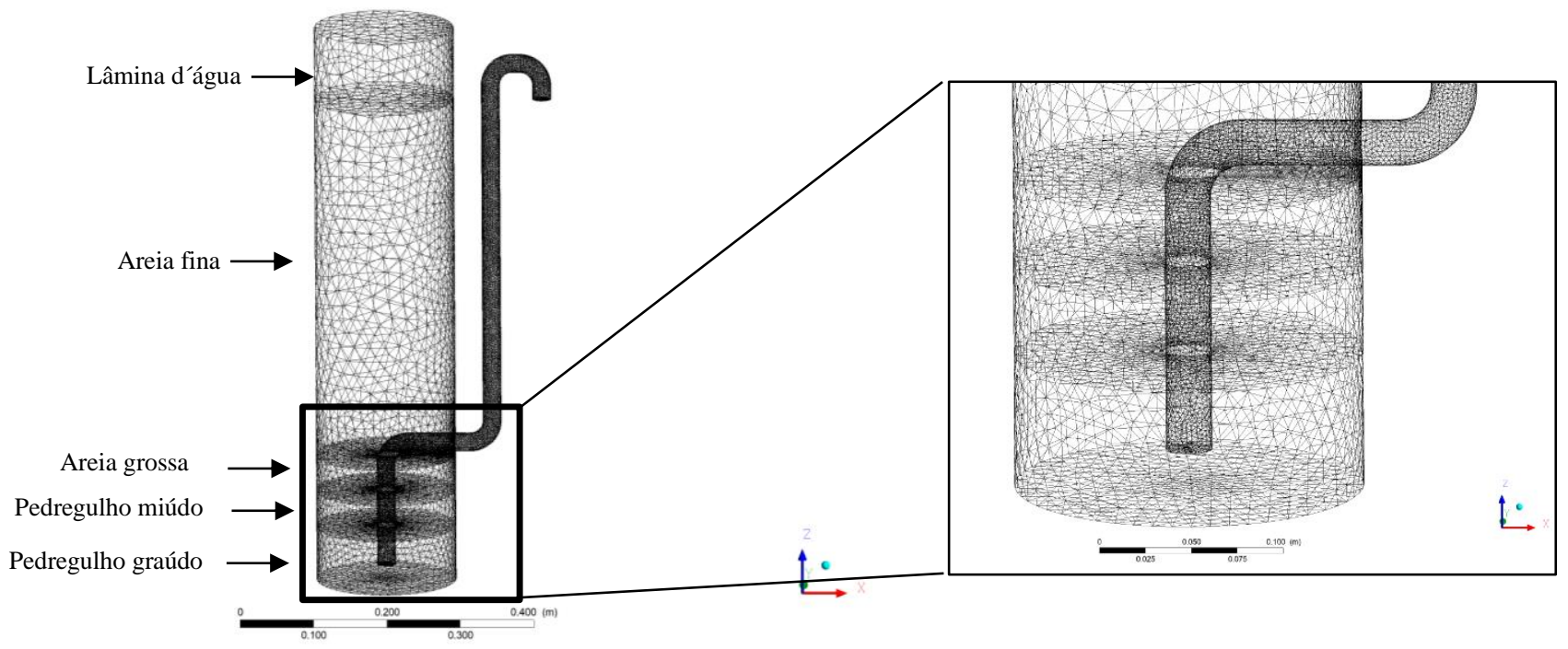

Fonte: Autor

Figura 71 - Malha obtida para o C-FLD2.

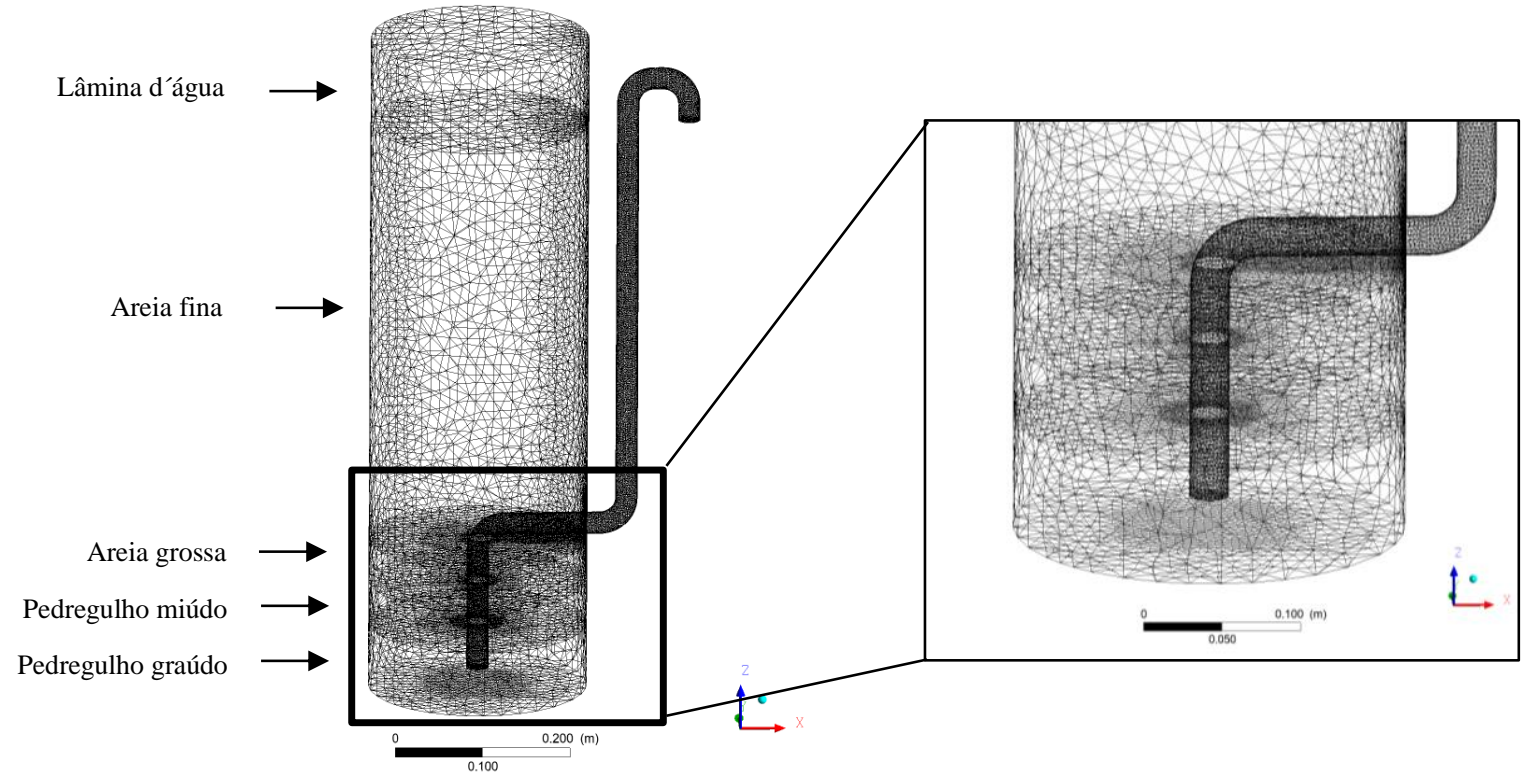

Fonte: Autor

Os perfis de velocidade no plano XZ no centro dos FLDs foram visualmente semelhantes, conforme observados na Figura 72, a escala de velocidade foi previamente definida e o tubo de saída foi retirado da visualização para melhor análise da variação da 
velocidade no interior dos filtros. Verificou-se que na camada de água a velocidade era maior do que quando atingia as camadas filtrante e drenantes, e depois aumentava na camada de pedregulho grosso antes atingir a tomada de água.

Figura 72 - Perfis de velocidade no plano XZ dos FLDs.
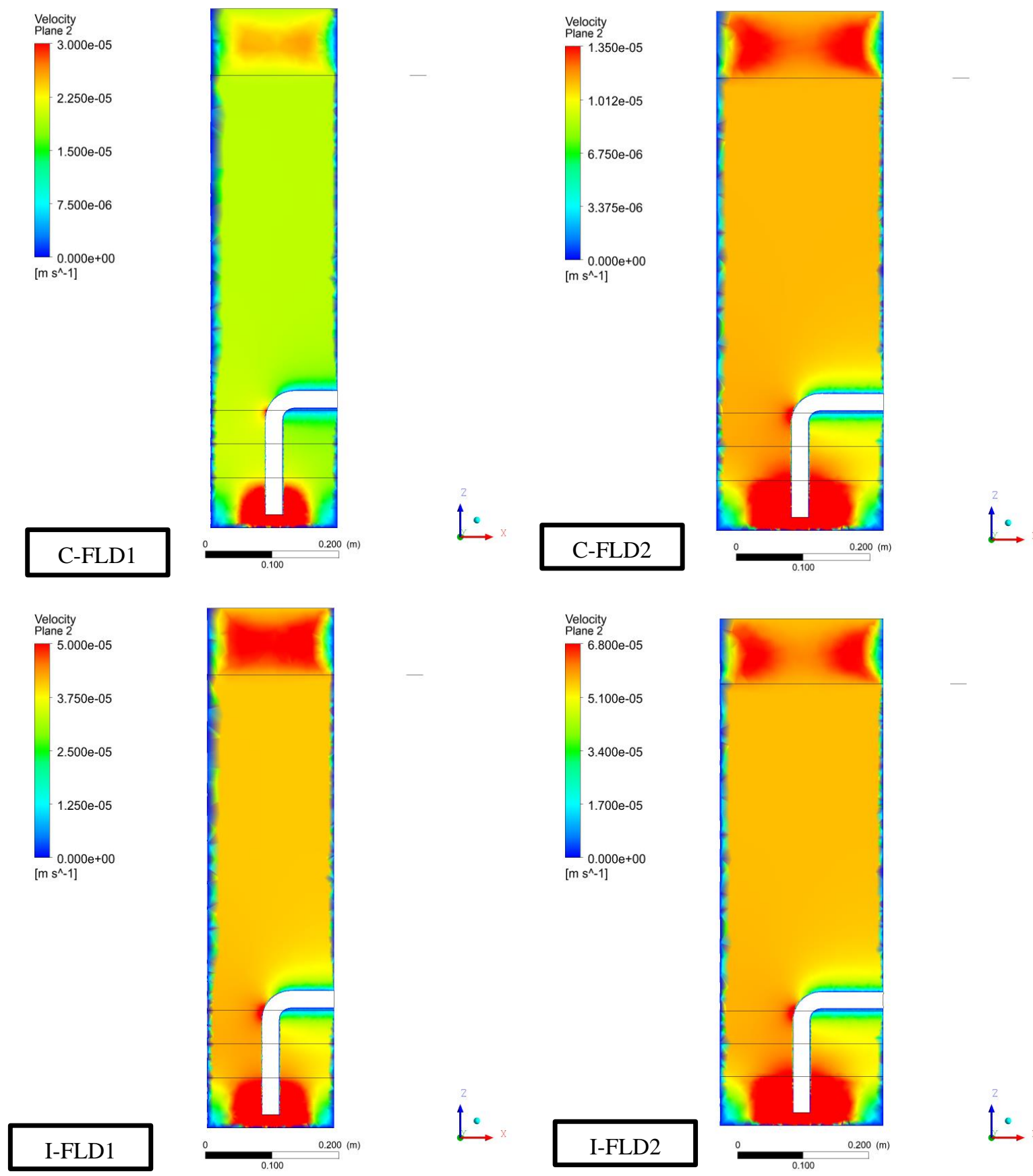

Fonte: Autor 
Nas simulações, as velocidades foram amostradas no centróide do filtro, localizada na camada de areia fina, e foram compatíveis as velocidades dos experimentos reais (Tabela 37), o que indica a representatividade dos modelos matemáticos em relação aos FLDs construídos em escala real.

Tabela 37 - Velocidade dos FLDs modelos físicos (experimental) e simulados

\begin{tabular}{lllc}
\hline \multirow{2}{*}{ FLD } & \multicolumn{2}{c}{ Velocidade $\left(\mathrm{m}^{-1}{ }^{-1}\right)$} & Diferença \\
\cline { 2 - 3 } & Experimental & Simulação & $(\%)$ \\
\hline C- FLD 1 & $1,959 \times 10^{-5}$ & $1,956 \times 10^{-5}$ & $-0,15$ \\
C- FLD 2 & $1,132 \times 10^{-5}$ & $1,129 \times 10^{-5}$ & $-0,27$ \\
I- FLD 1 & $4,10 \times 10^{-5}$ & $4,092 \times 10^{-5}$ & $-2,44$ \\
I- FLD 2 & $5,66 \times 10^{-5}$ & $5,648 \times 10^{-5}$ & $-2,83$ \\
\hline
\end{tabular}

Fonte: Autor

Os perfis de velocidade obtidos para os FLD's, conforme Figura 73, mostram que nos pontos iniciais na lâmina de água a velocidade é maior e depois tem uma redução quando começa a percorrer a camada filtrante, a velocidade se mantém constante até atingir as últimas camadas, quando tem um aumento próximo da região de tomada de água/coleta de água tratada e o último ponto mostra a velocidade próxima à parede no fundo do filtro. $\mathrm{O}$ aumento de velocidade nas proximidades da tomada de água corrobora com as observações de Berbert et al. (2016).

Figura 73 - Perfis de velocidade dos FLDs.

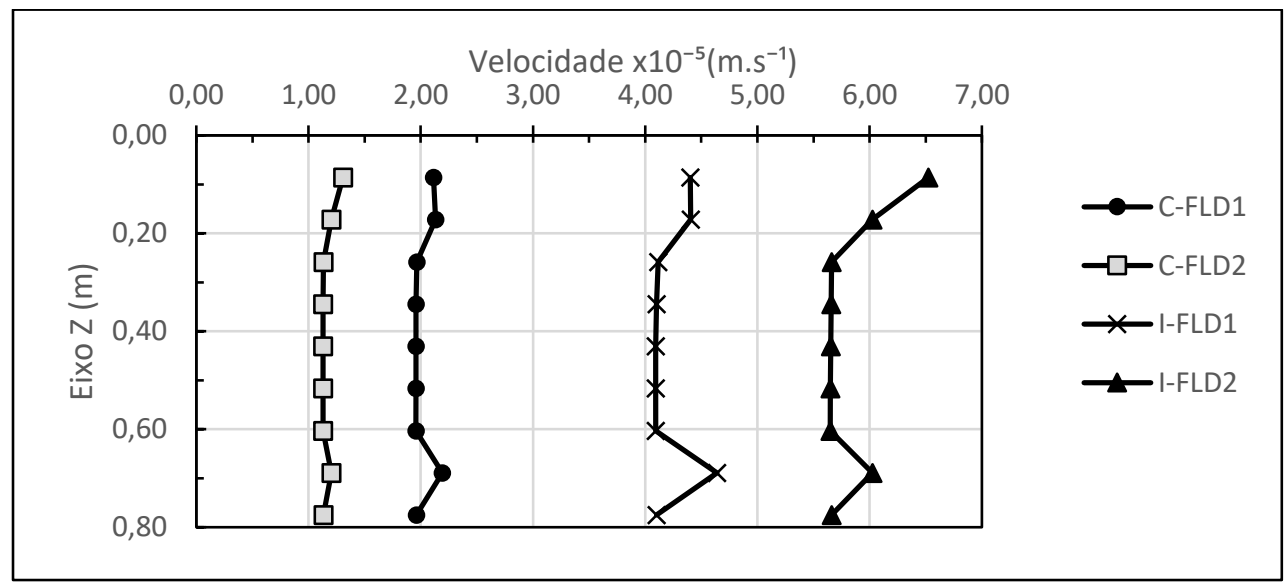

Fonte: Autor 
Ressalta-se que esses resultados foram determinados com base nos parâmetros físicos de porosidade, permeabilidade e espessura das camadas, ou seja, não consideram a influência do amadurecimento da camada biológica e da colmatação dos filtros, que podem alterar significativamente a velocidade e a perda de carga durante a operação, que teve duração de 186 dias nos filtros construídos em escala real.

Os campos de velocidade podem ser caracterizados pelas linhas de corrente em três dimensões obtidas para os FLDs. O escoamento em estado estacionário nos FLDs mostrou os caminhos que as partículas seguiram pelo reator. Na camada filtrante e nas camadas suporte de areia grossa e pedregulho miúdo a velocidade foi uniforme. Na camada de pedregulho graúdo, foram constatados caminhos preferenciais e uma pequena zona de estagnação na parte inferior, próximas às paredes do filtro, como consequência da localização da tomada de água do tubo de saída, conforme apresentados nas Figuras 74 e 75 para os C-FLDs e I-FLDs.

Figura 74 - Linhas de corrente dos C-FLDs e os detalhes observados.

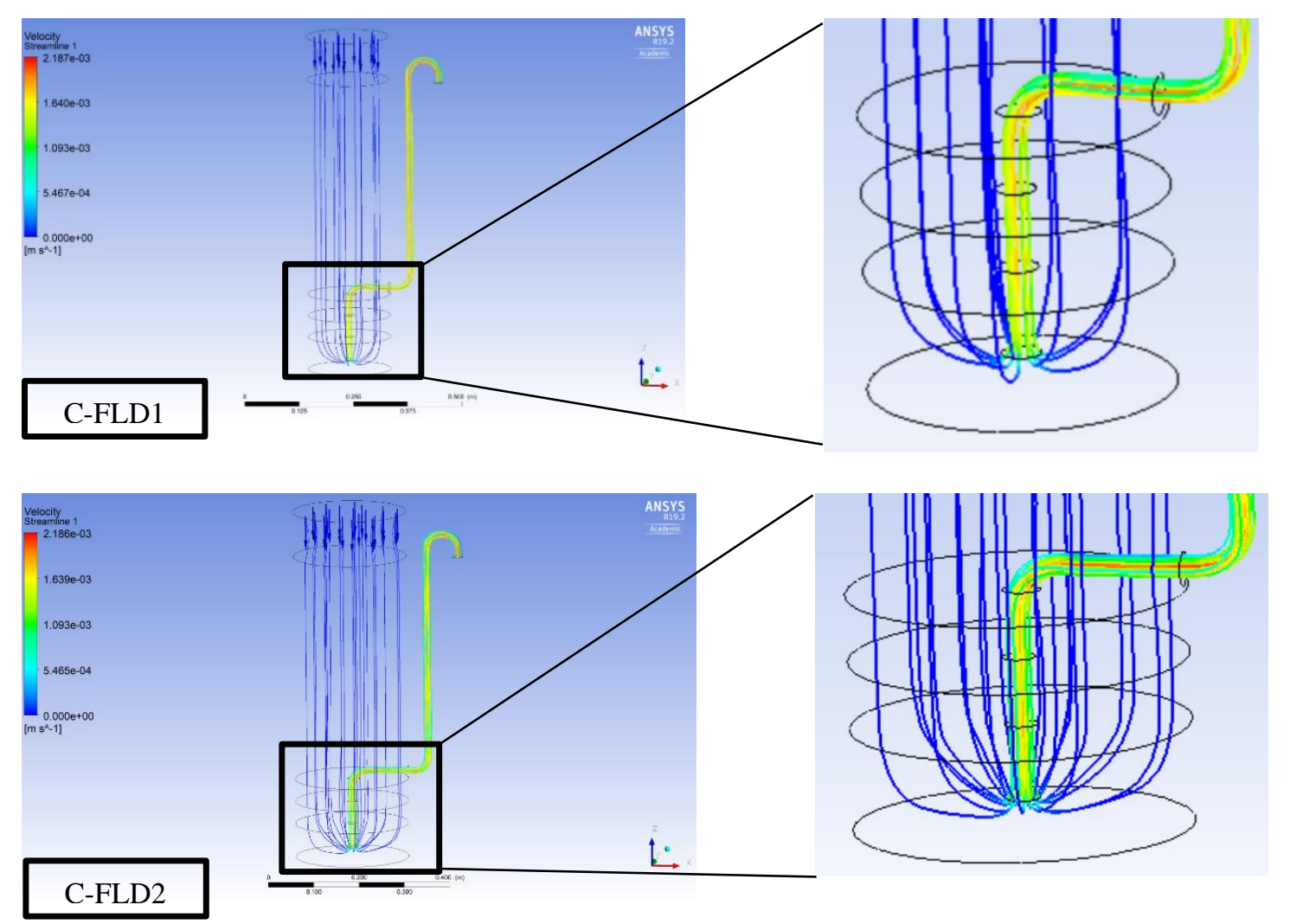

Fonte: Autor 
Figura 75 - Linhas de corrente dos I-FLDs e os detalhes observados.

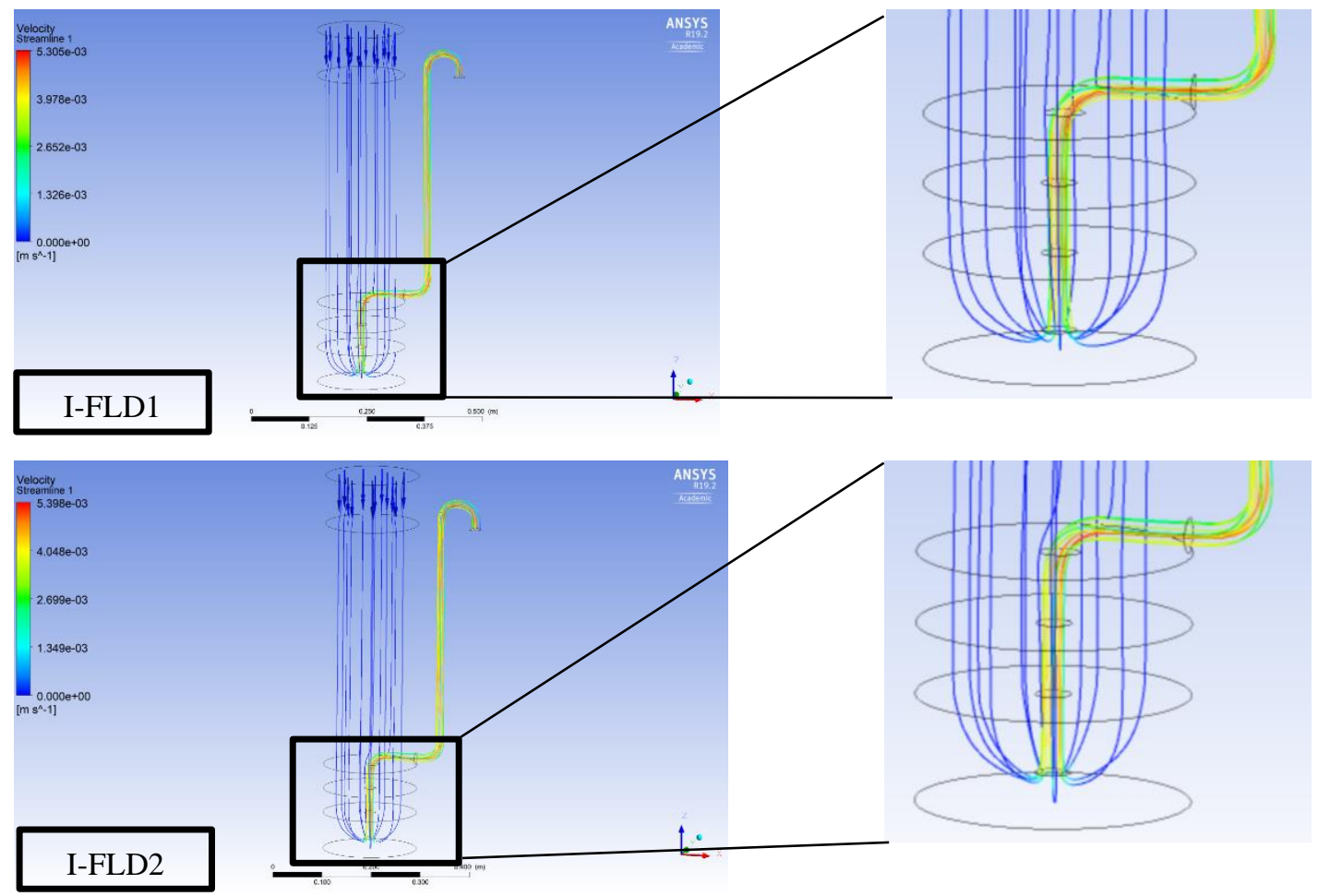

Fonte: Autor

De acordo com os resultados, as linhas de corrente apresentaram simetria em relação ao eixo central, a existência de zona morta próximo da base do FLD na camada de pedregulho graúdo e a inexistência de curto-circuito. Comportamento semelhante foi descrito por Berbert et al. (2016) que constatou a simetria e a zona morta em FLD, sem obter o volume da zona morta, com a mesma configuração de saída utilizada no presente estudo.

\subsubsection{Comparação entre a DTR experimental e a simulada com a DFC}

A verificação e a validação dos modelos utilizados na simulação dos quatro filtros foram realizadas com base na distribuição do tempo de residência experimental e computacional. Resultados de simulações CFD são validadas com ensaios de DTR experimentais (BRANNOCK, WANG e LESLIE, 2010; FURMAN e STEGOWSKI, 2011; GHARIBIAN, HAZRATI e ROSTAMIZADEH, 2020; KLUSENER et al., 2007; QI et al., 2013; TALVY et al., 2011; ZHANG, PAN e REMPEL, 2007).

Na Figura 76 apresentam-se os gráficos referentes aos resultados dos três ensaios experimentais e da simulação computacional para os C-FLDs. As curvas DTRs experimentais e simuladas apresentaram comportamentos semelhantes. 
Nos ensaios experimentais das DTRs, a sonda de condutividade foi posicionada na saída da torneira e no interior de um frasco, esse frasco viabilizava a leitura das amostras, uma vez que a água tratada que saída através da torneira era coletada e armazenada temporariamente nesse frasco e renovada a cada recebimento de uma nova amostra de água tratada. Esse frasco possivelmente influenciou o sinal obtido experimentalmente, o que mostra a diferença observada nos resultados das DTRs experimentais e simuladas, assim como foi constatado por Talvy et al. (2011) que optou em modificar o RTD simulado para ajustar ao RTD experimental. Ressalta-se que os RTDs foram simulados utilizando a velocidade média e valores constantes da condição de contorno como a porosidade e a permeabilidade, sendo que na construção do experimento real as camadas podem ter sofrido compactações naturais e antrópicas e apresentarem valores diferentes dos obtidos em laboratório, o que pode justificar a demora no tempo de resposta ao estímulo dos C-FLDs simulados comparados com os experimentais.

Figura 76 - Curvas DTR experimentais e computacional dos C-FLDs.
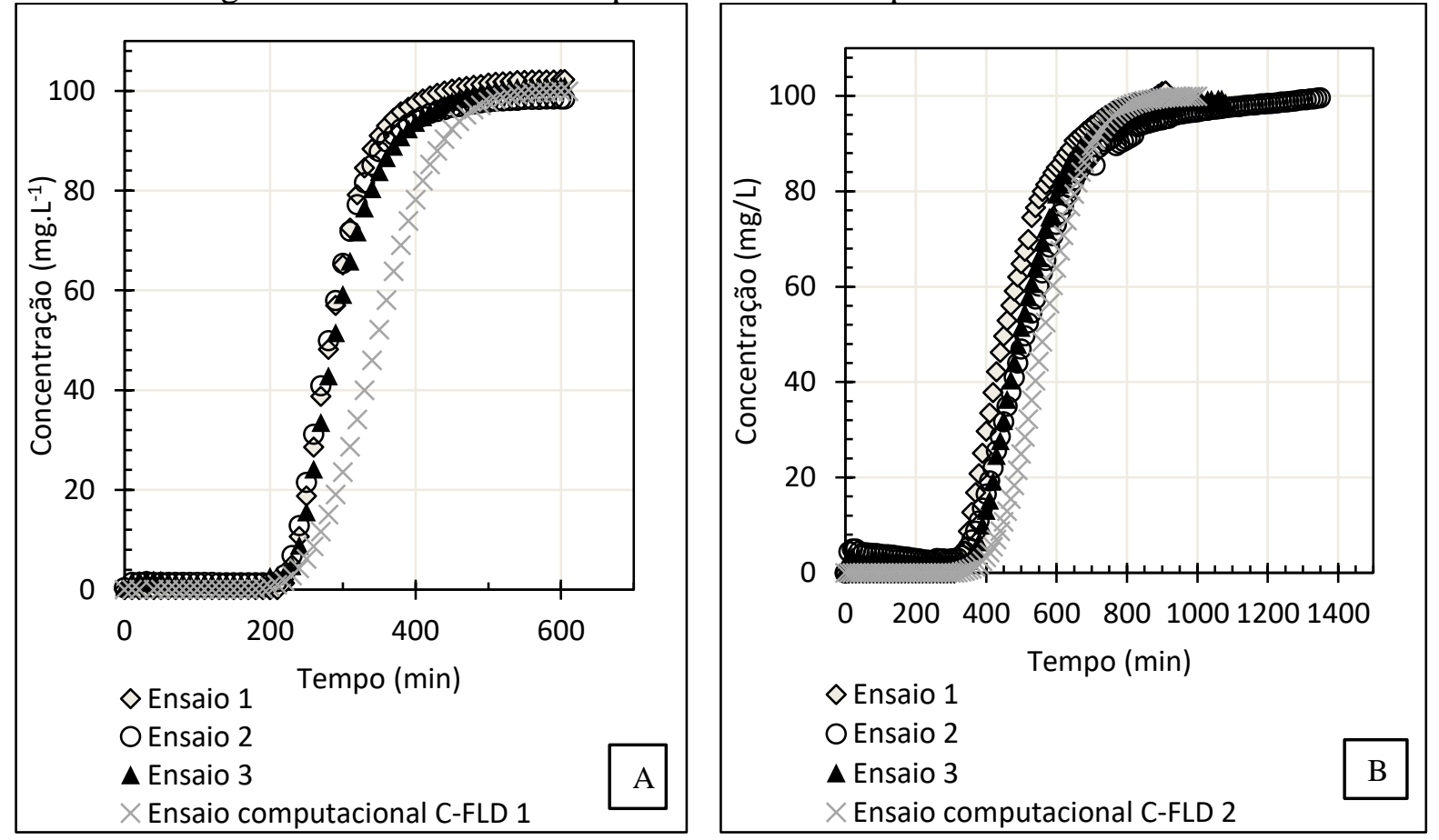

Notas: A - C-FLD 1 e B - C-FLD 2.

Fonte: Autor

Nas Figuras 77 e 78 são mostradas quadro a quadro o avanço do escalar passivo ao longo do tempo de simulação considerando um plano 2D traçado no centro do filtro para o C-FLD 1 e o C-FLD 2, respectivamente. Os quadros foram obtidos nos tempos de 600s, 4.200s, 12.800s, 
16.800 s, 20.400s e 28.200s para o C-FLD 1 e nos tempos de 600s, 11.400s, 25.800s, 20.400s, 40.200s e 44.400s para o C-FLD 2.

A partir dos resultados dos C-FLDs, observou-se um comportamento semelhante do traçador, conforme esperado. O traçador foi injetado na camada de água, percorreu o interior do filtro de acordo com o escoamento e com as linhas de corrente e, ao final, o traçador preencheu todos os poros das camadas, representado pela cor vermelha em todo o filtro. O que diferenciou os ensaios foi justamente o tempo de detenção hidráulico (TDH) requerido para cada filtro, que considera os parâmetros físicos como as espessuras das camadas, as porosidades e o diâmetro dos filtros. O C-FLD 1 demorou 28.200 s para atingir a concentração máxima de 100 mg. $\mathrm{L}^{-1}$ na saída do tubo e o C-FLD 2 precisou de 44.400s, variação está que ocorreu devido as diferentes taxas de filtração aplicadas em cada filtro. 
Figura 77 - Escalar passivo no tempo para um plano XZ no C-FLD 1.

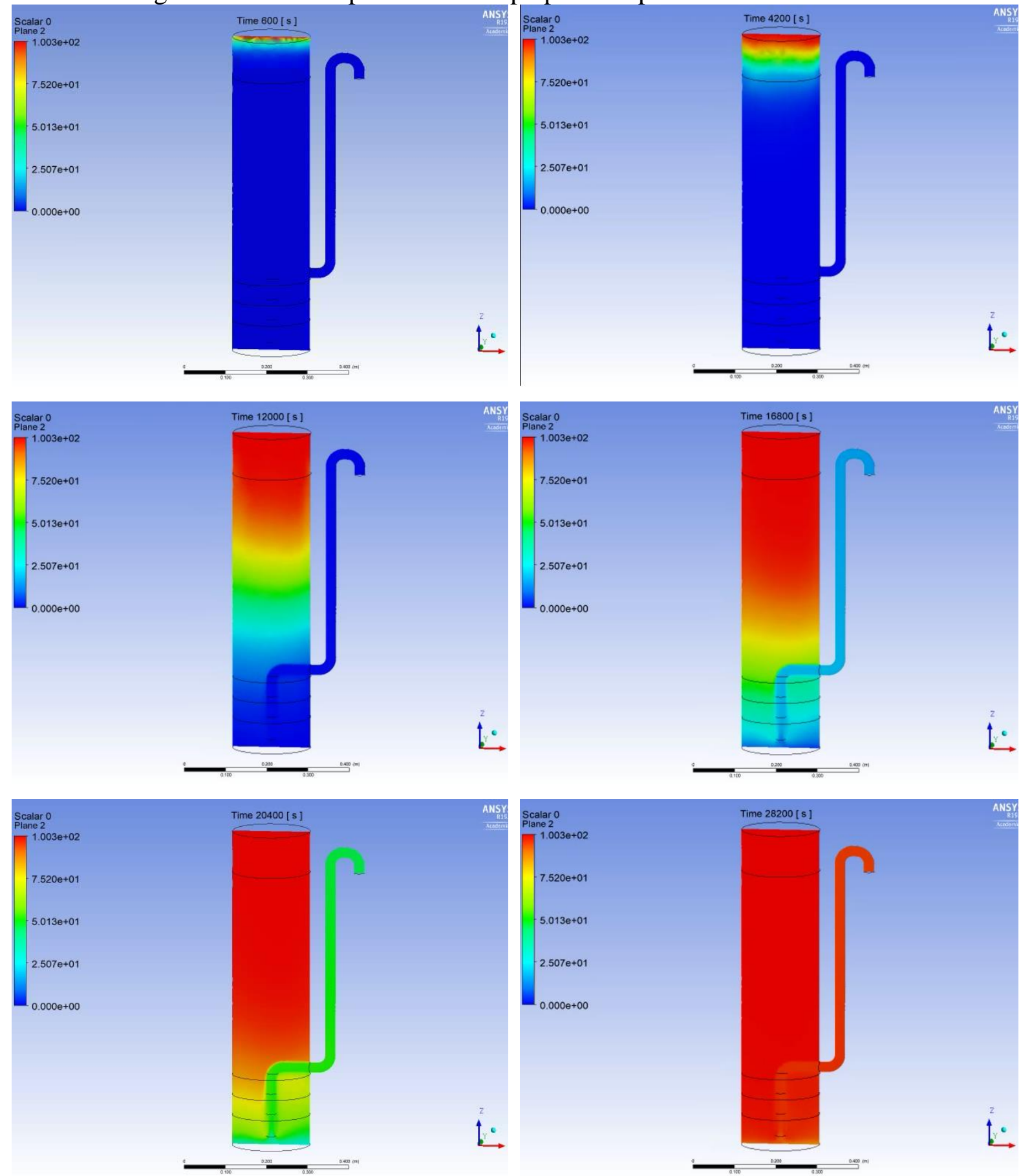

Fonte: Autor 
Figura 78 - Escalar passivo no tempo para um plano XZ no C-FLD 2.

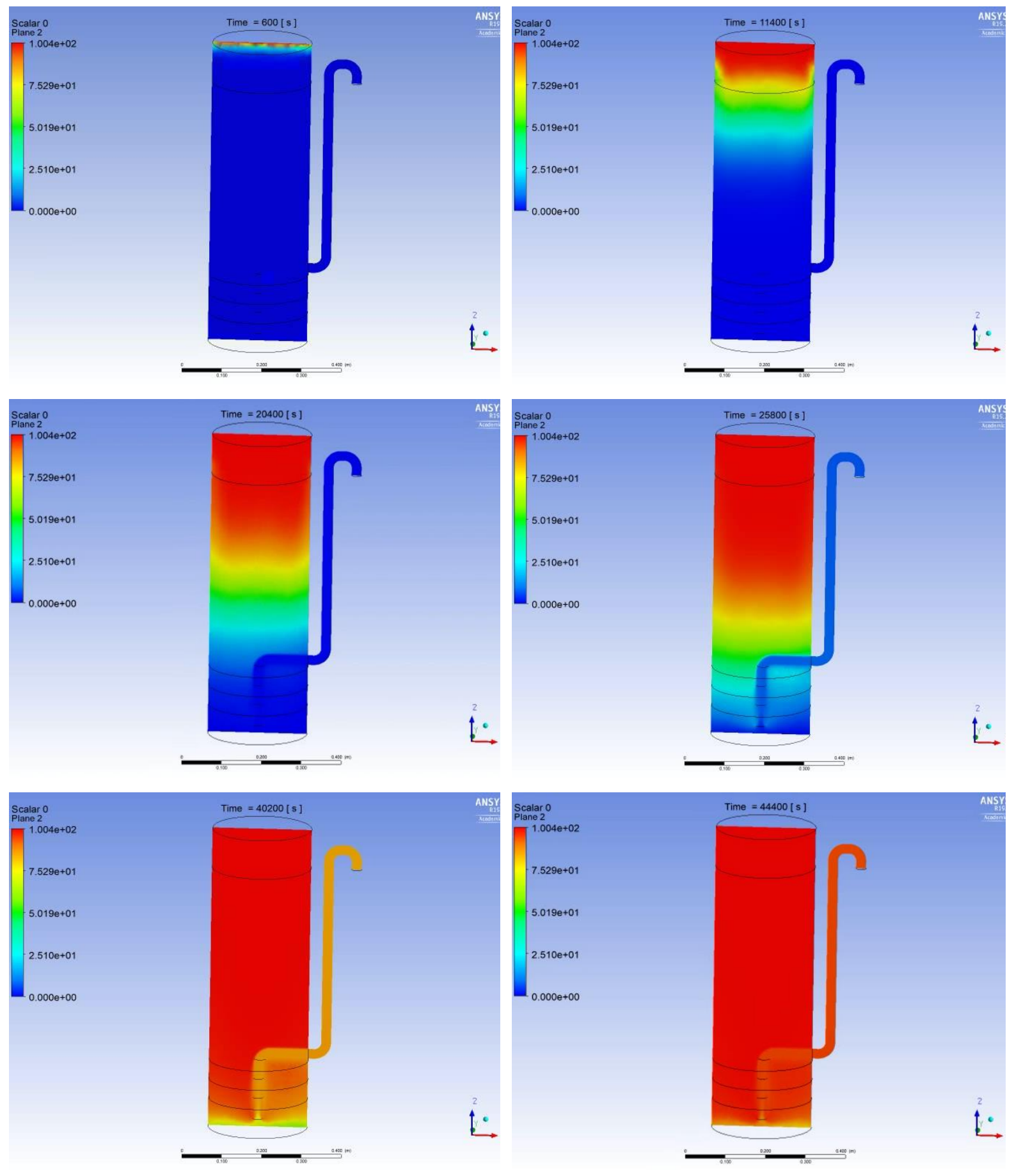

Fonte: Autor

As DTRs computacionais dos I-FLD 1 e I-FLD 2 são apresentadas nas Figuras 79A e 79B, respectivamente, e mostram que as simulações apresentam uma distribuição normal ou Gaussiana perfeita.

O tempo para atingir as concentrações máximas e a mínimas foram menores nos ensaios experimentais quando comparados com o simulado. Essas diferenças podem indicar que o 
traçador percorreu caminhos preferenciais (as linhas de corrente próximas ao centro) atingindo a saída do filtro em um tempo menor que o simulado e/ou também podem estar relacionados ao mesmo conjunto de fatores observados nos C-FLDs simulados e discutido anteriormente, que foram: à utilização do frasco para leitura das amostras por meio da sonda condutividade, a utilização da velocidade média e o uso de valores constantes da porosidade e da permeabilidade para cada camada. Todos esses fatores podem justificar o atraso no tempo de resposta ao estímulo dos I-FLDs simulados comparados com os experimentais.

Figura 79 - Curvas DTR experimentais e computacional dos I-FLDs.

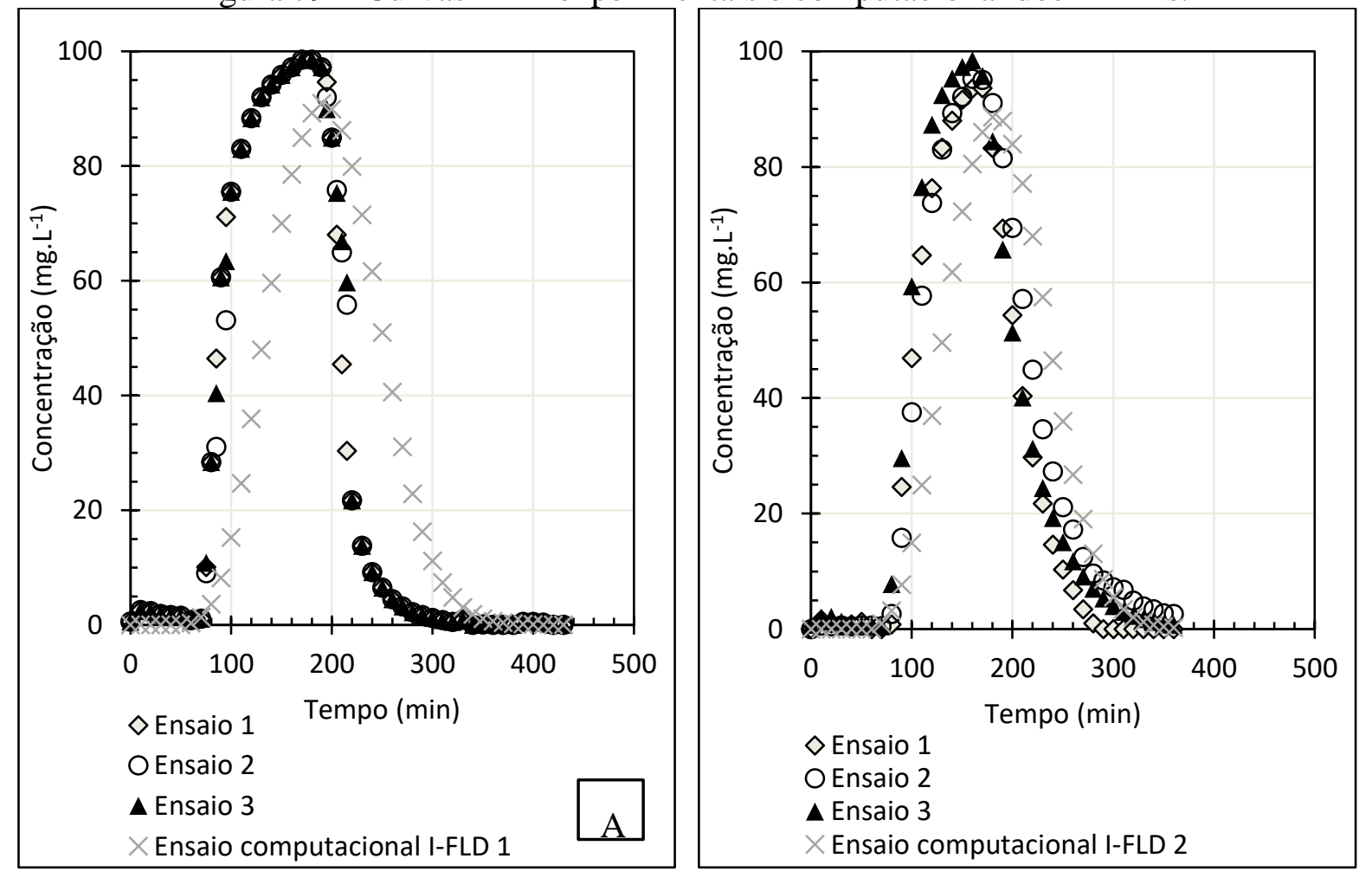

Notas: A - I-FLD 1 e B - I-FLD 2.

Fonte: Autor

Nas Figuras 80 e 81 são apresentadas imagens mostrando o avanço do escalar passivo ao longo do tempo de simulação em um plano 2D traçado no centro do filtro para o I-FLD 1 e I-FLD 2, respectivamente. Os quadros foram obtidos nos tempos de 600s, 4.200s, 9.000s, $10.800 \mathrm{~s}, 14.400 \mathrm{~s}$ e $21.000 \mathrm{~s}$ para o I-FLD 1 e nos tempos de $600 \mathrm{~s}, 4.200 \mathrm{~s}, 8.400 \mathrm{~s}, 11.400 \mathrm{~s}$, 13.800s e 18.600s para o I-FLD 2. Observa-se que o traçador é injetado na camada de água e que percorre o interior do filtro de acordo com o escoamento e com as linhas de corrente, atinge um valor máximo na saída e depois atinge um valor mínimo de $0 \mathrm{mg} . \mathrm{L}^{-1}$, ou seja, houve um 
degrau positivo e um degrau negativo, diferente do comportamento apresentando nas Figuras 77 e 78 em que houve apenas um degrau positivo.

Figura 80 - Escalar passivo no tempo para um plano XZ no I-FLD 1.
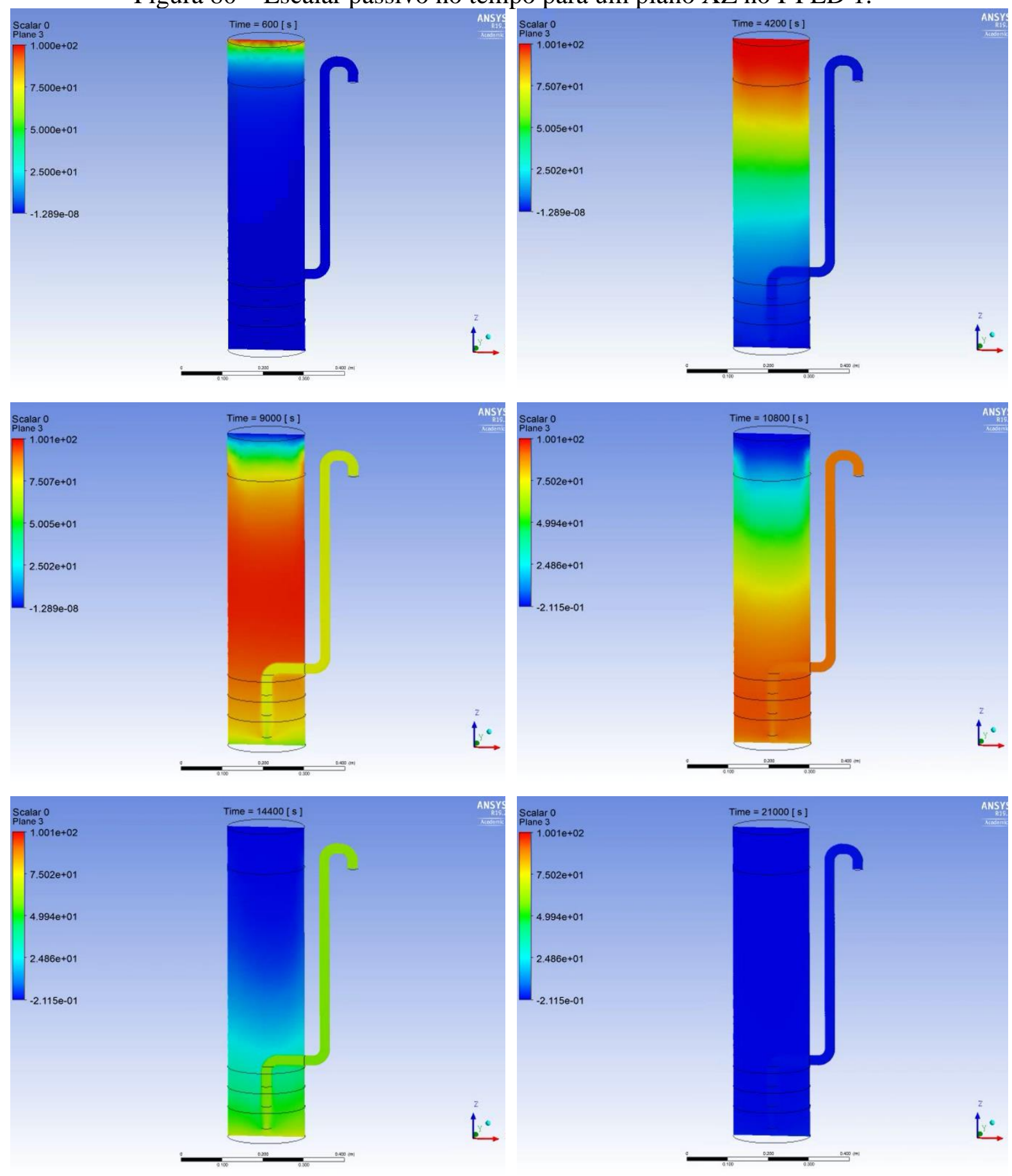

Fonte: Autor 
Figura 81 - Escalar passivo no tempo para um plano XZ no I-FLD 2.

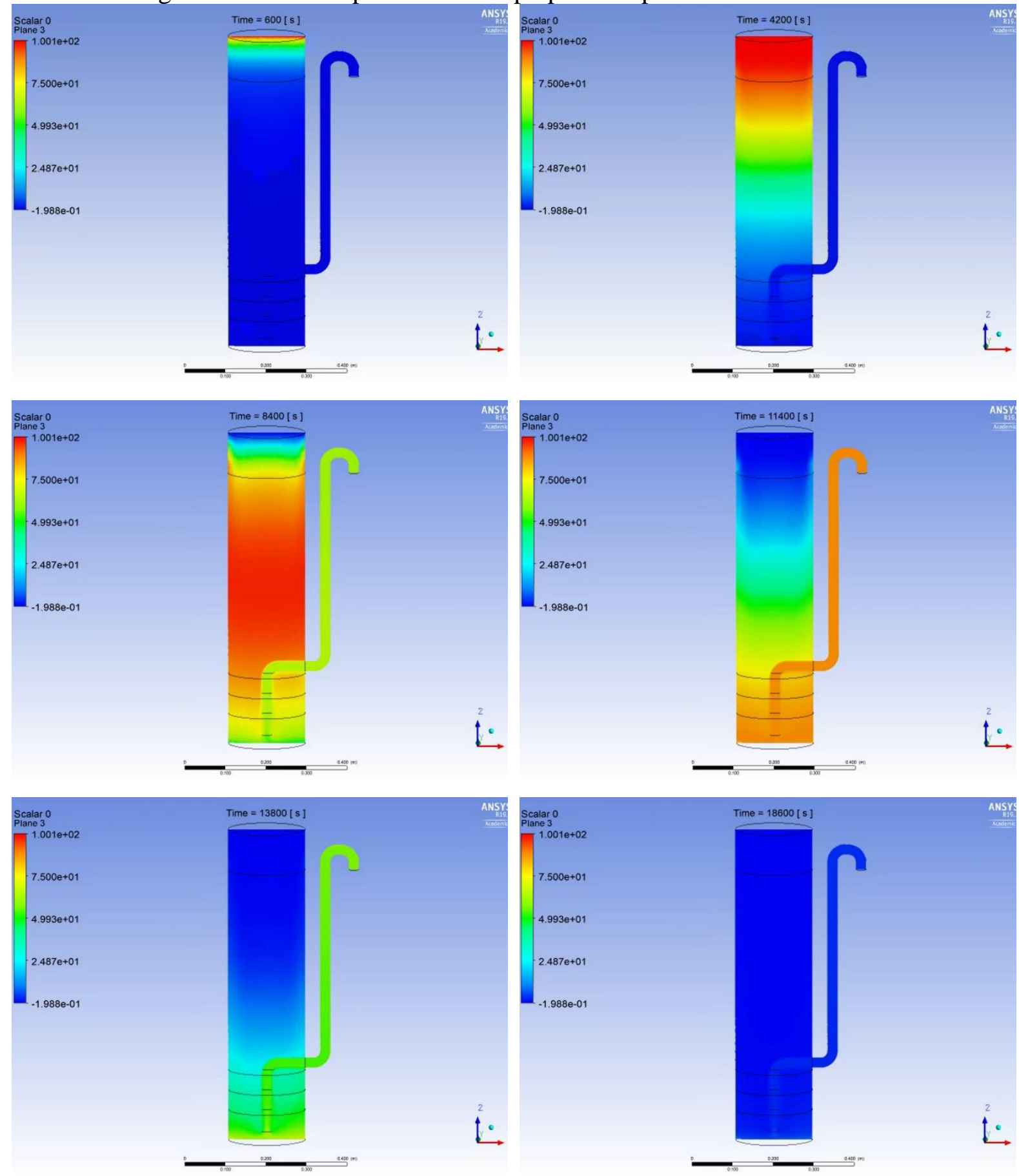

Fonte: Autor

\subsection{Estudo das anomalias no escoamento obtido com DFC}

Nos FLDs simulados, foram definidas às localizações da zona morta e seus volumes para o C-FLD 1, C-FLD 2, I-FLD 1 e I-FLD 2, que foram de 1,68 x $10^{-4} \mathrm{~m}^{3} ; 3,98 \times 10^{-4} \mathrm{~m}^{3}$; $1,82 \times 10^{-4} \mathrm{~m}^{3} \mathrm{e} 3,47 \times 10^{-4} \mathrm{~m}^{3}$, respectivamente. Os resultados percentuais do volume das zonas mortas em relação ao somatório dos volumes das camadas filtrante e drenantes foram de: C- 
FLD1 2,19\%, C-FLD2 2,99\%, I-FLD1 2,37\% e I-FLD2 2,60\%. Constatou-se que os valores foram baixos, inferiores à 3\%, e isso indica que não é necessário realizar mudanças nas geometrias. Verificou-se também que para um mesmo tipo de regime de escoamento, seja em escoamento contínuo ou intermitente, o aumento do diâmetro implicou no aumento do volume da zona morta. Os resultados dos volumes da zona morta no C-FLD 1, C-FLD 2, I-FLD 1 e IFLD 2, são apresentados nas Figuras de 82, 83, 84 e 85, respectivamente.

Figura 82-Zona morta no C-FLD1 (A - Linhas de corrente e plano de contorno da velocidade; B - Volume da zona morta).

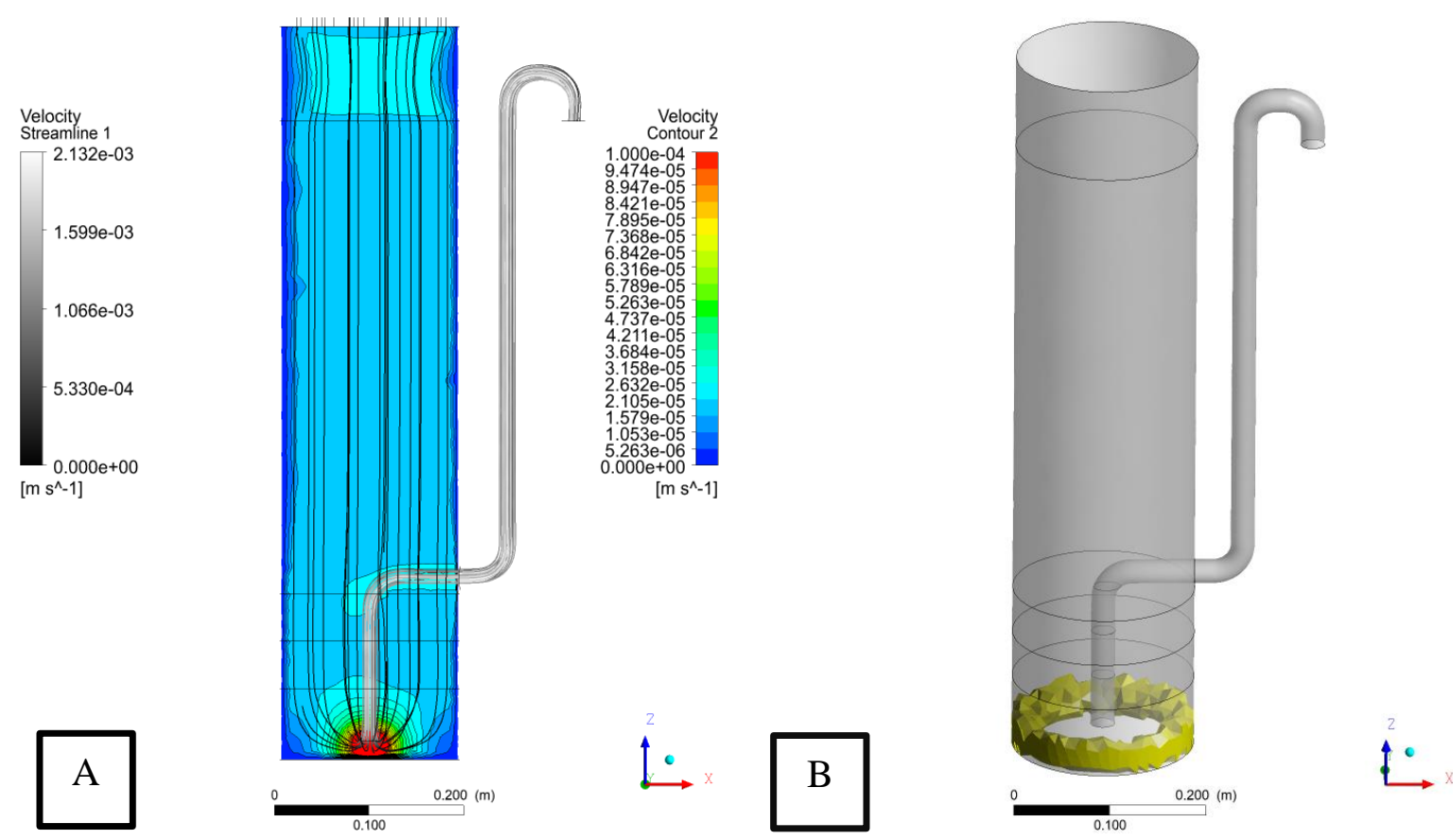

Obs.: Na Figura B o volume morto é representado pela cor amarela.

Fonte: Autor 
Figura 83-Zona morta no C-FLD2 (A - Linhas de corrente e plano de contorno da velocidade; B - Volume da zona morta).
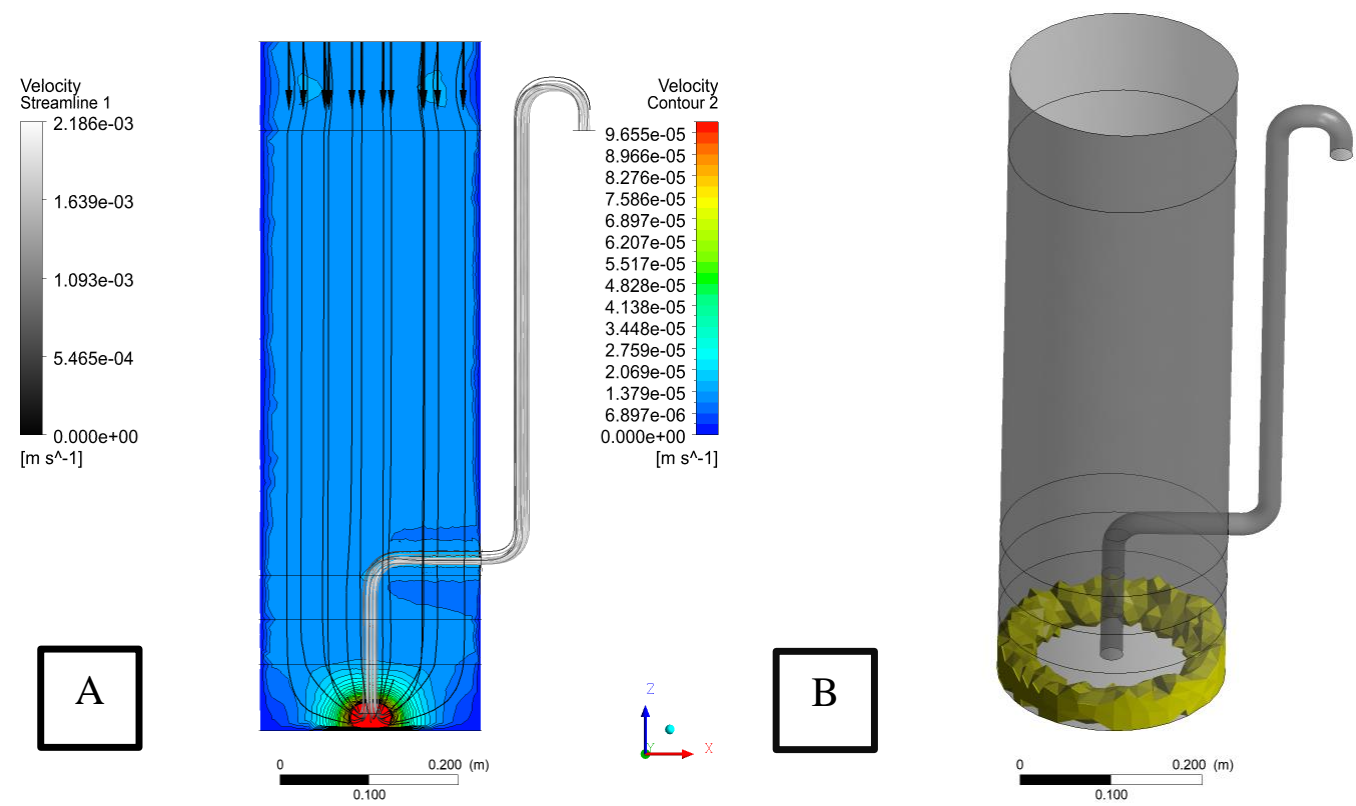

Obs.: Na Figura B o volume morto é representado pela cor amarela.

Fonte: Autor

Figura 84 - Zona morta no I-FLD1 (A - Linhas de corrente e plano de contorno da velocidade; B - Volume da zona morta).
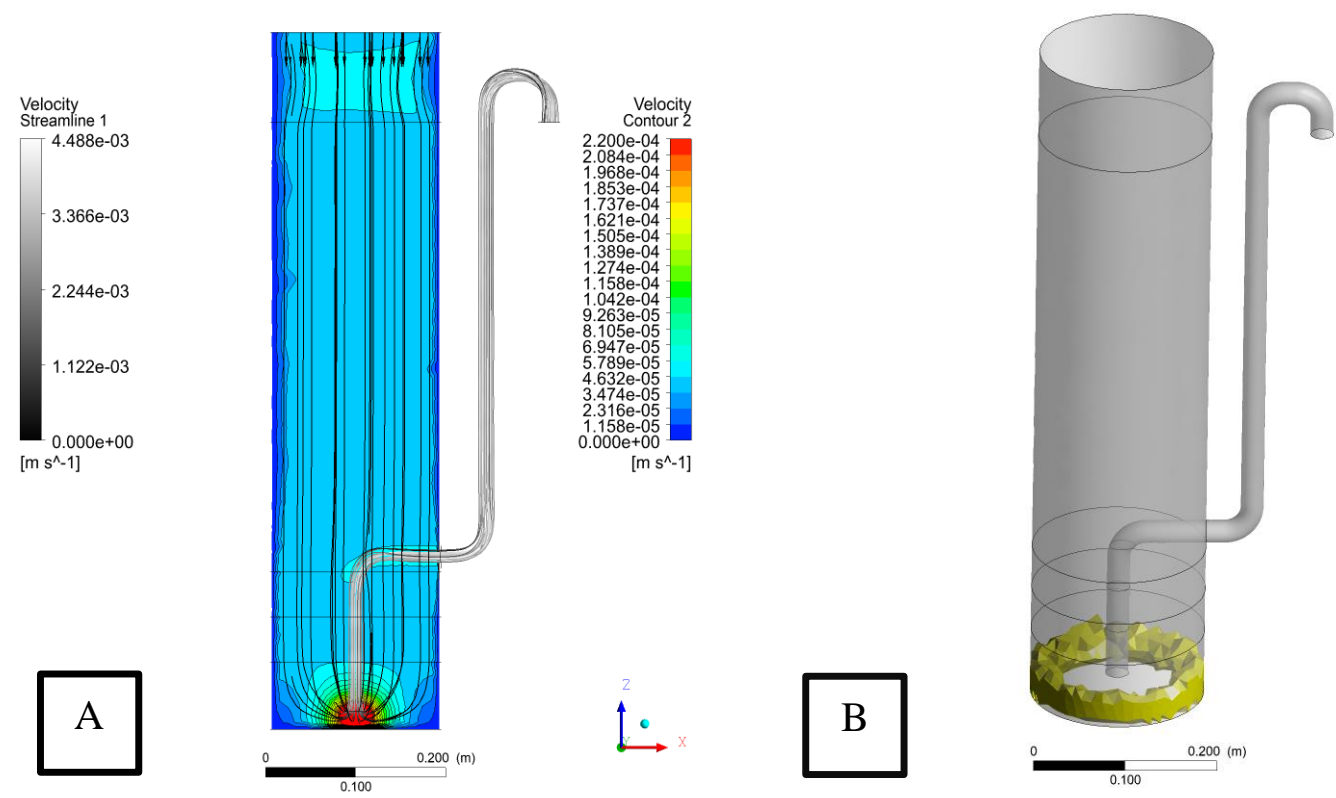

Obs.: Na Figura B o volume morto é representado pela cor amarela.

Fonte: Autor 
Figura 85 - Zona morta no I-FLD2 (A - Linhas de corrente e plano de contorno da velocidade; B - Volume da zona morta).

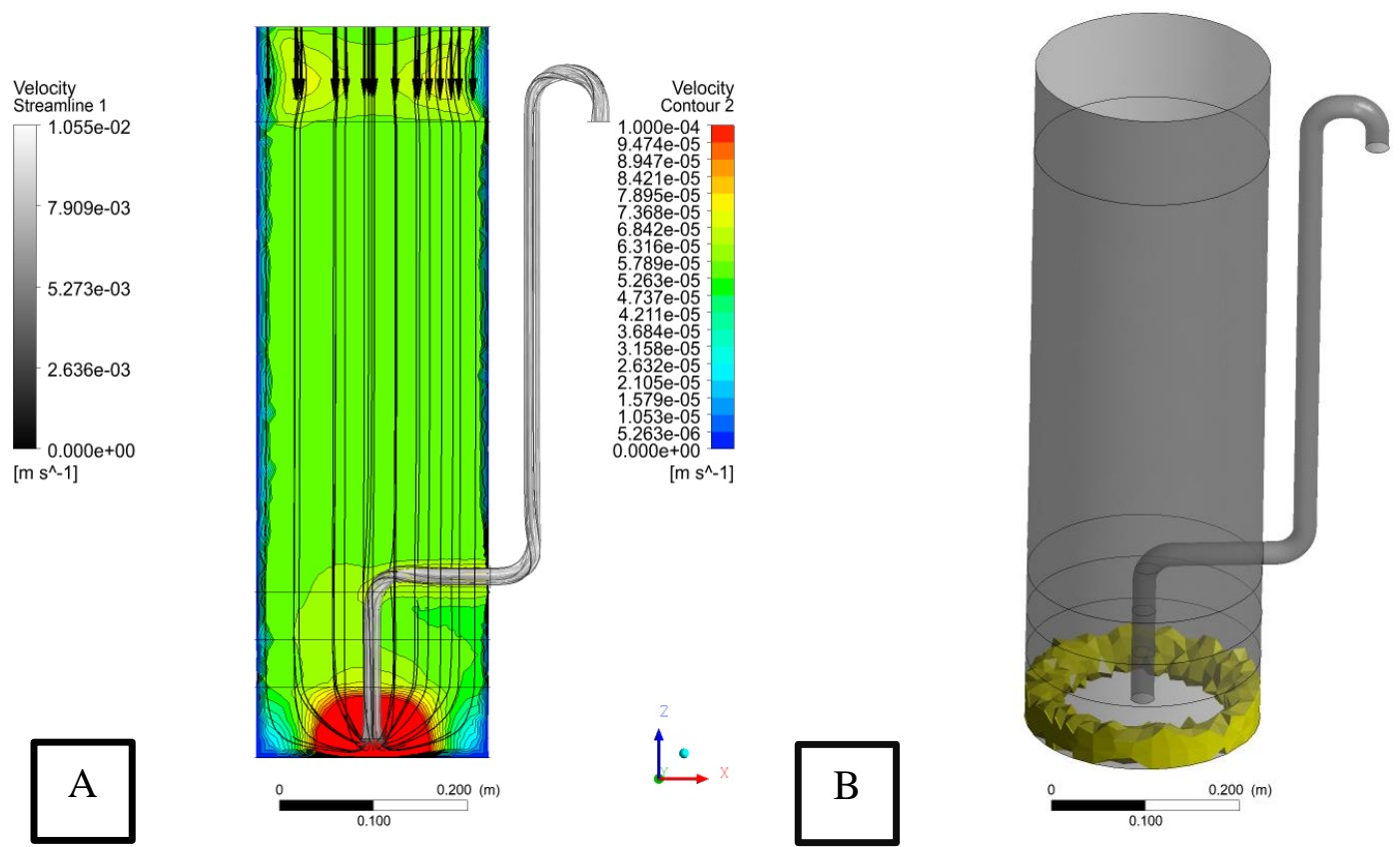

Obs.: Na Figura B o volume morto é representado pela cor amarela.

Fonte: Autor

\subsection{Análise estatística}

Os desvios padrões máximo, mínimo e médio obtidos entre os resultados da simulação e os ensaios experimentais foram de $\pm 18,4, \pm 0,56$ e \pm 4,68 para o C-FLD 1 e de $\pm 14,6, \pm 0,35$ e \pm 4,65 para o C-FLD 2. Verificou-se que o desvio padrão foi maior no intervalo de tempo de 250 min até 400 min para o C-FLD 1 e maior no intervalo de tempo de $400 \mathrm{~min}$ até $600 \mathrm{~min}$ para o C-FLD 2, conforme apresentado na Figura 86. Essa variação pode estar relacionada com as linhas de corrente próximas ao centro do filtro que tem um percurso menor quando comparada com as linhas de corrente próximas às paredes do filtro, isso reduz o caminho a ser percorrido e consequentemente faz com que a concentração seja atingida em um tempo menor. 
Figura 86 - Desvio padrão da curva computacional dos C-FLDs.
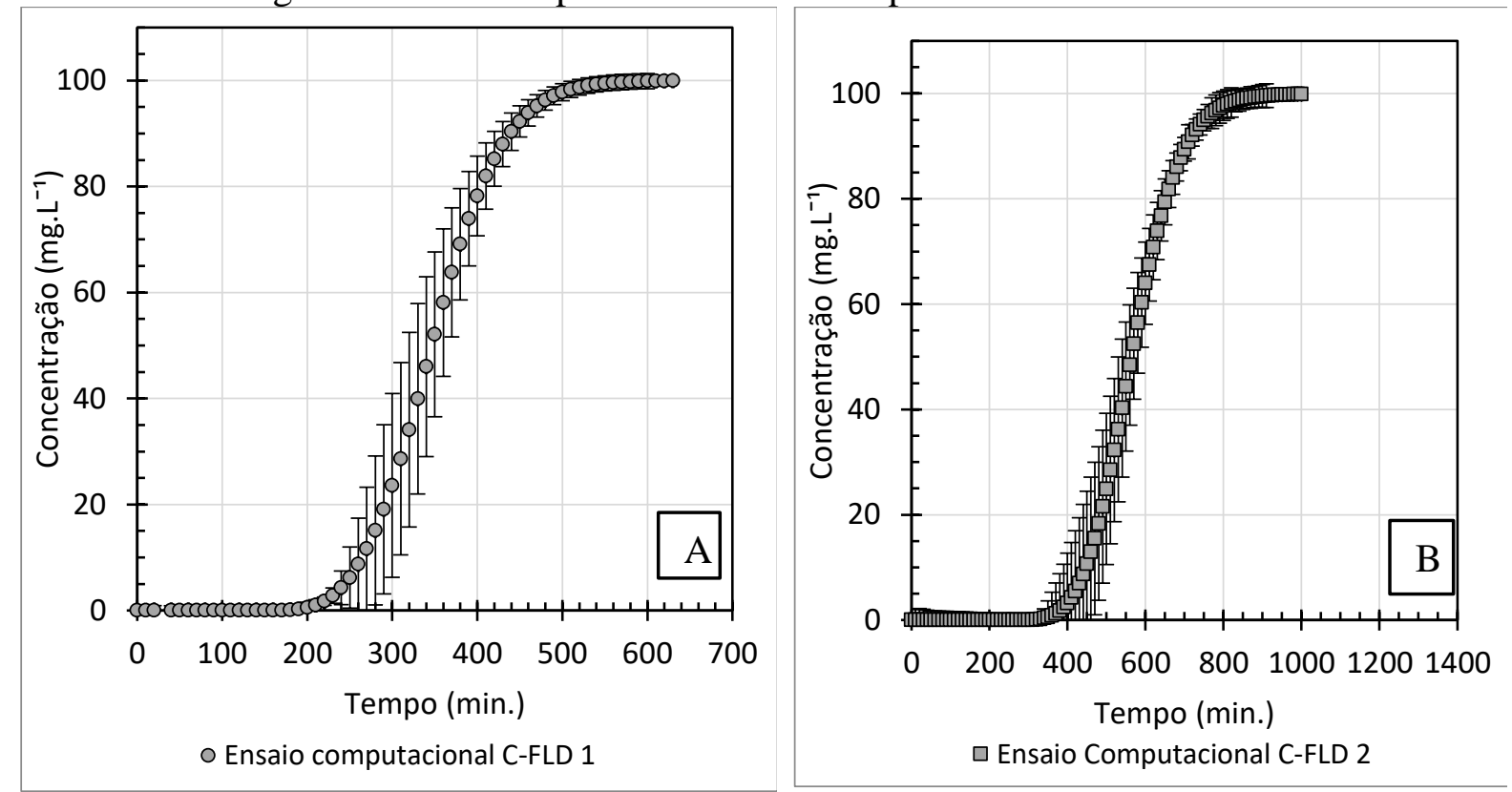

Notas: A - C-FLD 1 e B - C-FLD 2.

Fonte: Autor

Os desvios padrão máximo, mínimo e médio entre os resultados da simulação e os ensaios experimentais foram de $\pm 24,1, \pm 0,30$ e \pm 7,24 para o I-FLD 1 e de $\pm 19,1, \pm 0,30$ e \pm 6,56 para o I-FLD 2, conforme disposto na Figura 87. Nos I-FLDs verificou-se que o desvio padrão foi maior nos períodos ascendentes e descendentes, ou seja, nos intervalos de tempo de $80 \mathrm{~min}$ até $160 \mathrm{~min}$ e de $220 \mathrm{~min}$ até $280 \mathrm{~min}$ para o I-FLD 1, e nos períodos de 90 min até 160 min e de 190 min até 260 min. Essas variações podem estar relacionadas com as linhas de corrente próximas ao centro do filtro que tem atingem a saída em um tempo menor. 
Figura 87 - Desvio padrão da curva computacional dos I-FLDs.
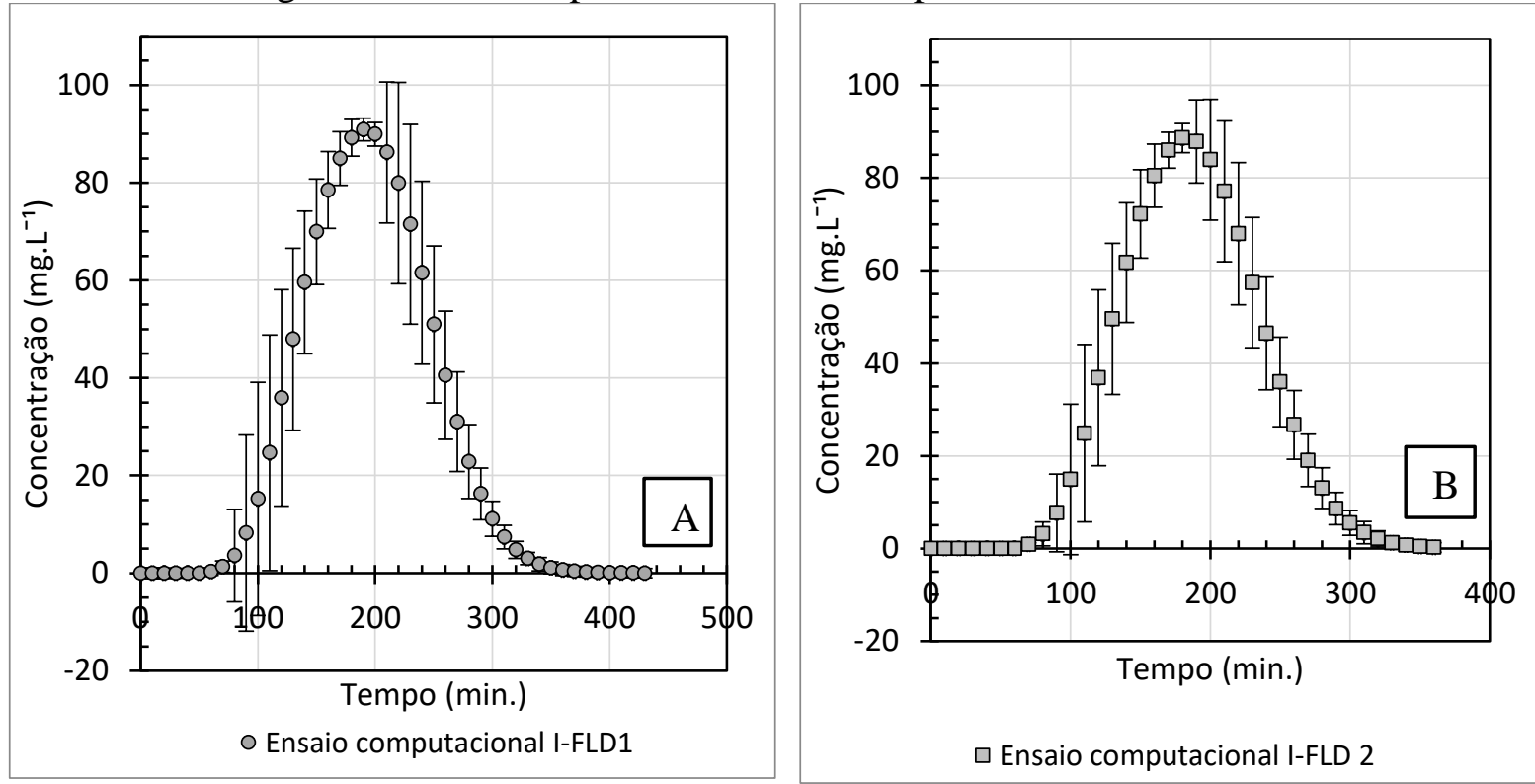

Notas: A - I-FLD 1 e B - I-FLD 2.

Fonte: Autor

O teste não paramétrico de Kruskal Wallis (nível de significância de 5\%), mostrou que os resultados dos três ensaios experimentais das DTRs e o ensaio computacional da DTR não apresentaram diferenças estatisticamente significativas entre si para cada um dos filtros, o CFLD 1, C-FLD 2, I-FLD 1 e I-FLD2 tiveram o valor de $\mathrm{p}$ de 0,27;0,25; 0,01 e 0,38. Desta forma o resultado da DTR obtido com CFD é semelhante aos resultados da DTRs obtidas experimentalmente nos modelos físicos em escala plena.

\subsection{Análise da influência da hidrodinâmica na eficiência do filtro}

Os resultados da simulação numérica mostram que os caminhos percorridos pelas linhas de corrente dos FLDs foram semelhantes, ou seja, a geometria e o tipo de operação (contínua ou intermitente) não alteraram o escoamento de água de forma significativa.

Nos filtros intermitentes foi constatado que houve maior variação de velocidade nos pontos iniciais na lâmina de água até o início da camada filtrante e o reflexo dessa alteração de velocidade foi observada na eficiência dos filtros, uma vez que os filtros operados em escoamento contínuo foram mais eficientes na remoção de cor e turbidez do que filtros operados em escoamento intermitente. $\mathrm{O}$ filtro que apresentou o menor volume de zona morta foi o CFLD 1 com 2,19\% e foi o que apresentou os melhores resultados de eficiência em relação aos parâmetros monitorados. 


\section{CONCLUSÕES}

A hipótese 1, de que taxas de filtração baixas, para filtros operados em um mesmo regime de escoamento, resultam em melhores eficiências de tratamento se confirmou para os filtros em escoamento contínuo. Os resultados de eficiência da remoção de cor aparente, turbidez, E. coli e coliformes foram maiores.

Dentre os filtros em escoamento intermitente, o filtro com baixa taxa de filtração apresentou maior eficiência de remoção apenas para os parâmetros de cor e turbidez.

A hipótese 2, sobre a minimização de fenômenos hidráulicos adversos, observados pelo perfil de velocidade, e o aumento da eficiência do tratamento nos filtros, foi confirmada. Os filtros contínuos mostraram que sofrem menos variações de velocidade nas camadas iniciais do filtro e esse comportamento refletiu em melhores eficiências no tratamento de água.

Os resultados estatísticos mostraram que não houve diferenças significativas na comparação dos dados das DTRs experimentais e simuladas. O comportamento das linhas de corrente dos C-FLDs e dos I-FLDs foram semelhantes e mostraram que não sofrem influência devido à geometria, à taxa de filtração ou ao tipo de alimentação contínua ou intermitente. Nos C-FLDs e nos I-FLDs verificou-se que o escoamento era do tipo pistonado, sem curto circuito, com a presença de zona morta próximo da base e quanto menor o diâmetro menor a zona morta. Não foi verificado a necessidade de se alterar o design dos FLDs.

Os filtros operados em escoamento contínuo apresentaram menor variação de velocidade nas camadas iniciais do filtro o que reduz as interferências no tratamento de água, conforme foi observado no melhor desempenho apresentado pelos filtros contínuos. O filtro contínuo de menor diâmetro (C-FLD 1) foi o que apresentou melhores resultados em termos de eficiência de tratamento e da hidrodinâmica. 



\section{RECOMENDAÇÕES}

Com base nos resultados obtidos para os filtros operados em escoamento contínuo e intermitente e na viabilidade da operação diária dos filtros pelos usuários observou-se que:

- Os FLDs em escoamento intermitente são mais viáveis que os FLDs em escoamento contínuo, uma vez que não necessita do controle de vazão diário, nem de energia elétrica para o bombeamento e os FLDs em escoamento intermitente apresentaram eficiência de remoção dos parâmetros semelhantes aos dos filtros em escoamento contínuo;

- A geometria dos FLDs com diâmetro de 250 mm (I-FLD 2) teve como vantagem a necessidade de somente três alimentações se comparada ao protótipo I- FLD 1, com diâmetro menor, para obter a mesma produção diária de 48 L, assim, pode ser mais vantajosa do ponto de vista operacional.

A partir do desenvolvimento dessa pesquisa e dos resultados obtidos foram levantadas sugestões para futuros trabalhos nessa área:

- Os quatro filtros experimentais em escala plena foram modelados com as suas configurações e características específicas, isso permitiu compreender as linhas de corrente que percorrem as camadas. Caso haja novas configurações e/ou materiais com características diferentes recomenda-se fazer uma nova simulação para verificar possíveis alterações e/ou melhoras na eficiência do escoamento do filtro antes de se construir um protótipo;

- O desenho da geometria pode ser tão detalhado quanto o pesquisador julgar necessário, isso pode ser importante para analisar a influência no escoamento;

- A dinâmica dos fluidos computacional foi uma ferramenta essencial para compreender e visualizar o escoamento nos filtros operados, os modelos foram validados com êxito. Dessa forma, seria possível inserir modelos cinético, nesses já criados, para analisar a remoção de parâmetros específicos, como por exemplo, nitrito, nitrato, $\mathrm{N}$-amoniacal, coliformes fecais, E. coli e oxigênio dissolvido. 


\section{REFERÊNCIAS}

ANDREOLI, F. C.; SABOGAL-PAZ, L. P. Household slow sand filter to treat groundwater with microbiological risks in rural communities. Water research. v. 186, 116352, 2020. https://doi.org/10.1016/j.watres.2020.116352.

ANSYS. Ansys Fluent Theory Guide. Versão 15.0. Ansys Inc., Canonsburg, Estados Unidos da América, 2013.

AMERICAN PUBLIC HEALTH ASSOCIATION, AMERICAN WATER WORKS ASSOCIATION, WATER ENVIRONMENT FEDERATION (APHA, AWWA, WEF). Standard methods for the examination of water and wastewater. $23^{\circ} \mathrm{Ed}$. American Public Health Association, Estados Unidos da América, Washington, 2017.

ASSOCIAÇÃO BRASILEIRA DE NORMAS TÉCNICAS. ABNT NBR 6458. Grãos de pedregulho retidos na peneira de abertura 4,8 $\mathrm{mm}$ - Determinação da massa específica, da massa específica aparente e da absorção de água. Rio de Janeiro, 2016.

ASSOCIAÇÃO BRASILEIRA DE NORMAS TÉCNICAS. ABNT NBR 6502. Rochas e solos. Rio de Janeiro, 1995.

ASSOCIAÇÃO BRASILEIRA DE NORMAS TÉCNICAS. ABNT NBR 11799. Material filtrante - Areia, antracito e pedregulho —Especificação. Rio de Janeiro, 2016.

ASSOCIAÇÃO BRASILEIRA DE NORMAS TÉCNICAS. ABNT NBR 13292. Solo Determinação do coeficiente de permeabilidade de solos granulares à carga constante. Rio de Janeiro, 1995.

ASSOCIAÇÃO BRASILEIRA DE NORMAS TÉCNICAS. NORMA MERCOSUL. ABNT NM 45. Agregados - Determinação da massa unitária e do volume de vazios. Rio de Janeiro, 2006.

ASSOCIAÇÃO BRASILEIRA DE NORMAS TÉCNICAS. NORMA MERCOSUL. ABNT

NM 248. Agregados - Determinação da composição granulométrica. Rio de Janeiro, 2001. 
BAIG, S. A.; MAHMOOD, Q.; NAWAB, B.; SHAFQAT, M. N.; PERVEZ, A. Improvement of drinking water quality by using plant biomass through household biosand filter - A decentralized approach. Ecological Engineering, v. 37, n.11, 1842-1848 p., November, 2011.

BAKER, M.N. The Quest for Pure Water. 1948. p. 99-112. Nova York, Estados Unidos da América. The American Water Works Association. Disponível em: < https://babel.hathitrust.org/cgi/pt?id=mdp.39015007372272\&view=1up\&seq=11>. Acesso em: 06. jun. 2019.

BERBERT, A. C.; ALMEIDA, R. A de; REZENDE, R. V. de P.; LAUTENSCHLAGER, S. R. The Use of Computation Fluids Dynamics to Select Outlet System Configuration in Biosand Filters. Conference: 13th IWA Specialized Conference on Small Water and Wastewater Systems \& 5th IWA Specialized Conference on Resources-Oriented Sanitation At: Athens, September, 2016.

BOTARI, A.; DI BERNARDO, L. Hydrodynamic analysis of particle collection efficiency: comparing downflow and upflow filtration. Acta Scientiarum. Technology, v. 34, n. 2, p. 167175. 2012. doi:10.4025/actascitechnol.v34i2.10803.

BRADLEY, I.; STRAUB, A.; MARACCINI, P.; MARKAZI, S.; NGUYEN, T.H., 2011. Iron oxide amended biosand filters for virus removal. Water Research 45, 4501-4510. doi:10.1016/j.watres.2011.05.045.

BRANNOCK, M.; WANG, Y.; LESLIE, G. Mixing characterisation of full-scale membrane bioreactors: CFD modelling with experimental validation. Water Research, v. 44 (10), 31813191 p., 2010. https://doi.org/10.1016/j.watres.2010.02.029

BRASIL, Lei Federal no 11.445/07, de 5 de janeiro de 2007, Estabelece diretrizes nacionais para o saneamento básico; altera as Leis $\mathrm{n}^{\text {os }}$ 6.766, de 19 de dezembro de 1979, 8.036, de 11 de maio de 1990, 8.666, de 21 de junho de 1993, 8.987, de 13 de fevereiro de 1995; revoga a Lei no6.528, de 11 de maio de 1978; e dá outras providências. 
BRASIL, Lei Federal $\mathbf{n}^{\mathbf{0}} \mathbf{1 4 . 0 2 6 / 2 0}$, de 15 de julho de 2020, Atualiza o marco legal do saneamento básico e altera a Lei $n^{\circ}$ 9.984, de 17 de julho de 2000, para atribuir à Agência Nacional de Águas e Saneamento Básico (ANA) competência para editar normas de referência sobre o serviço de saneamento, a Lei $\mathrm{n}^{\circ} 10.768$, de 19 de novembro de 2003, para alterar o nome e as atribuições do cargo de Especialista em Recursos Hídricos, a Lei n ${ }^{\circ}$ 11.107, de 6 de abril de 2005, para vedar a prestação por contrato de programa dos serviços públicos de que trata o art. 175 da Constituição Federal, a Lei no 11.445, de 5 de janeiro de 2007, para aprimorar as condições estruturais do saneamento básico no País, a Lei n 12.305 , de 2 de agosto de 2010, para tratar dos prazos para a disposição final ambientalmente adequada dos rejeitos, a Lei ${ }^{\circ}$ 13.089, de 12 de janeiro de 2015 (Estatuto da Metrópole), para estender seu âmbito de aplicação às microrregiões, e a Lei $\mathrm{n}^{\circ} 13.529$, de 4 de dezembro de 2017, para autorizar a União a participar de fundo com a finalidade exclusiva de financiar serviços técnicos especializados.

BRASIL, Ministério da Saúde. Gabinete do Ministro. Portaria GM/MS nº 888, de 4 de maio de 2021. Altera o Anexo XX da Portaria de Consolidação GM/MS n 5 , de 28 de setembro de 2017, para dispor sobre os procedimentos de controle e de vigilância da qualidade da água para consumo humano e seu padrão de potabilidade.

CALIXTO, K. G.; SABOGAZ-PAZ, L. P.; POZZI, E.; CAMPOS, L. C. Ripening of household slow sand filter by adding fish food. Journal of Water, Sanitation and Hyfiene for Development. v. 10.1, 76 - 85, 2020. doi: 10.2166/washdev.2020.143.

CAMPOS, L. C.; SMITH, S. R.; GRAHAM, N. J. D. Deterministic based model of slow sand filtration. I: model development. Journal of Environmental Engineering v. 132(8), 872-886 p., 2006a. https://doi.org/10.1061/(ASCE)0733-9372(2006)132:8(872)

CAMPOS, L. C.; SMITH, S. R.; GRAHAM, N. J. D. Deterministic based model of slow sand filtration. II: model application. Journal of Environmental Engineering v. 132(8), 887-894 p., 2006b. https://doi.org/10.1061/(ASCE)0733-9372(2006)132:8(887)

CAWST, CENTRE FOR AFFORDABLE WATER AND SANITATION, Biosand Filter Construction Manual, Calgary, Canada, 2012. Disponível em: <www.cawst.org> Acesso em: 01out. 2016. 
CAWST, CENTRE FOR AFFORDABLE WATER AND SANITATION, Biosand filter manual: Design, construction, installation, operation and maintenance, Calgary, Canada, 2009. Disponível em: <www.cawst.org> Acesso em: 01out. 2016.

DARCY, H. Recherches expérimentales relatives au mouvement de I'eau dans les tuyaux. Paris: Mallet-Bachelier, 1857. 268 p.

EDZWALD, J. K.; BECKER, W. C.; WATTIER, K. L. Surrogate parameters for monitoring organic-matter and the precursors. Journal American Water Works Association, v. 77, n. 4, p. 122-132, 1985.

EDZWALD, J. K.; TOBIASON, J. E. Chemical Principles, Source Water Composition, and Watershed Protection. In: EDZWALD, J. K. (Ed.). Water Quality \& Treatment. Denver, Colorado: Mc Graw Hill, 2011.

ElliOTT, M. A.; STAUBER, C. E.; KOKSAL, F.; DIGIANO, F. A.; SOBSEY, M. D. Reductions of E.coli, echovirus type 12 and bacteriophages in na intermittently operated household-scale slow sand filter. Water Research, v. 42, p. 2662-2670, 2008. https://doi.org/10.1016/j.watres.2008.01.016

FAVA, N. de M. N.; TERIN, U. C.; FREITAS, B. L. S.; SABOGAZ-PAZ, L. P.; FERNANDEZ-IBAÑEZ, P.; BYRNE, J. A. Household slow sand filters in continuous and intermittent flows and their efficiency in microorganism's removal from river water. Environmental Technology. 2020. https://doi.org/10.1080/09593330.2020.1841834.

FOGLER, H. S. Elementos de engenharia das reações químicas, 4 ed. LTC Editora, Rio de Janeiro, 2009.

FORCHHEIMER, P. Wasserbewegung durch Boden. Zeitschrift des Vereins Deutscher Ingenieure, v. 45, n. 49, p. 1736-1741, 1901a.

FORCHHEIMER, P. Wasserbewegung durch Boden. Zeitschrift des Vereins Deutscher Ingenieure, v. 45, n. 50, p. 1781-1788, $1901 \mathrm{~b}$. 
FORTUNA, A. O. Técnicas computacionais para dinâmica dos fluidos: Conceitos básicos e aplicações. São Paulo: Editora da Universidade de São Paulo, 2000.

FREITAS, B. L. S.; SABOGAZ-PAZ, L. P. Pretreatment using Opuntia cochenillifera followed by household slow sand filters: technological alternatives for supplying isolated communities. Environmental Technology. 2019. https://doi.org/10.1080/09593330.2019.1582700.

FURMAN, L.; STEGOWSKI, Z. CFD models of jet mixing and their validation by tracer experiments. Chemical Engineering and Processing: Process Intensification 50(3), 300304, 2011. https://doi.org/10.1016/j.cep.2011.01.007.

GALVIS G.; LATORRE J.; VISSCHER J. T. Multi-stage filtration: na innovative water treatment technology. The Hague: IRC International Water and Sanitation Center. 1998.

GHARIBIAN, S.; HAZRATI, H.; ROSTAMIZADEH, M. 2020. Continuous electrooxidation of Methylene Blue infilter press electrochemical flowcell: CFD simulation and RTD validation. Chemical Engineering \& Processing: Process Intensification. 150 (2020) 107880. https://doi.org/10.1016/j.cep.2020.107880

GONÇALVES, N. D. F. Método dos Volumes Finitos em Malhas Não-Estruturadas. 2007. 71p. Dissertação (Mestrado em Engenharia Matemática) - Faculdade de Ciências da Universidade do Porto. Porto. 2007.

GRESCH, M.; BRUGGER, R.; MEYER, A.; GUJER, W., 2009. Compartmental models for continuous flow reactors derived from CFD simulations. Environmental Science \& Tecnhnology. Tec. 43, 2381-2387. https://doi.org/10.1021/es801651j

HASSAN, A. A.; LI, Z.; SAHLE-DEMESSIE, E.; SORIAL, G. A. Computacional fluid dynamics simulation of transport and retention nanoparticle in satured sand filters. Journal of Hazardous Materials. 244-245. 251-258, 2013. 
HOWARD, G.; BARTRAM, J. Domestic Water Quantity, Service Level and Health. World Health Organization. Genebra, Suíça. 2003.

INSTITUTO BRASILEIRO DE GEOGRAFIA E ESTATÍSTICA - IBGE. Pesquisa nacional de saneamento básico 2017: abastecimento de água e esgotamento sanitário. 2020. Coordenação de População e Indicadores Sociais. Rio de Janeiro, Brasil. Disponível em: < https://biblioteca.ibge.gov.br/visualizacao/livros/liv101734.pdf >. Acesso em: 22 dez. 2020.

INSTITUTO TRATA BRASIL. O que é saneamento? 2013. Disponível em: < http://www.tratabrasil.org.br/o-que-e-saneamento >. Acesso em: 23 jun. 2018.

JENKINGS, M. W.; TIWARI, S. K.; DARBY, J. Bacterial, viral and turbidity removal by intermittent slow sand filtration for household use in developing countries: Experimental investigation and modeling. Water Research. v. 45. 6227-6239 p., 2011.

JENKINGS, M. W.; TIWARI, S. K.; DARBY, J.; NYAKASH, D.; SAENYI, W.; LANGENBACH, K. The BioSand Filter for Improved Drinkin Water Quality in High Risk Communities in the Njoro Watershed, Kenya. Global Livestock Collaborative Research Support Program. University of California. 2009.

KENNEDY, T. J.; HERNANDEZ, E. A.; MORSE, A. N.; ANDERSON, T. A. Hydraulic Loading Rate Effect on Removal Rates in a BioSand Filter: A Pilot Study of Three Conditions. $\begin{array}{llllllll}\text { Water, Air, \& Soil Pollution. } & \text { v. 223, } & \text { n. } & 7, & 4527-4537 & \text { p., } & 2012 .\end{array}$ https://link.springer.com/article/10.1007/s11270-012-1215-4

KIKKAWA, I. Modification of a Biosand Filter in the Northern Region of Ghana. Master of Engineering in Civil and Enviromental Engineering at the Massachusetts Institute of Techonlogy. 2008.

KLUSENER, P. A. A.; JONKERS, G.; DURING, F.; HOLLANDER, E. D.; SCHELLEKENS, C. J.; PLOEMEN, I. H. J.; OTHMAN, A.; BOS, A. N. R.. Horizontal cross-flow bubble column reactors: CFD and validation by plant scale tracer experiments. Chemical Engineering Science v. 62(18-20), 5495-5502 p., 2007. https://doi.org/10.1016/j.ces.2007.03.044 
LANGERGRABER, G.; GIRALDI, D.; MENA, J.; MEYER, D.; PEÑA, M.; TOSCANO, A.; BROVELLI, A.; KORKUSUZ, E. A. Recent developments in numerical modelling of subsurface flow constructed wetlands. Science of The Total Environment v. 407 (13), 3931-3943 p., 2009. https://doi.org/10.1016/j.scitotenv.2008.07.057

LANGENBACH, K.; KUSCHK, P.; HORN, H.; KÄSTNER, M. Modeling of slow sand filtration for disinfection of secondary clarifier effluent. Water research. v. 44, 159-166 p., 2010.

LEMOS, E. M. Implementação de um método de volumes finitos de ordem superior com tratamento multibloco aplicado à simulação de escoamento de fluidos viscoelásticos. Tese apresentada à Universidade Federal do Rio de Janeiro, Rio de Janeiro, RJ, 2011.

LEVENSPIEL, O. Chemical Reaction Engineering. 3 rd ed. Department of Chemical Engineering, Oregon State University, 1999.

LEVENSPIEL, O. Engenharia das Reações Químicas. 3 ed. São Paulo. Ed. Edgard Blucher LTDA. 2000.

LIBÂNIO, M. Fundamentos de Qualidade e Tratamento de Água. 3 ed. v. 1. 444 p. Campinas. Editora Átomo, 2010.

LYNN, T. J.; WANJUGI, P.; HARWOOD, V. J.; ERGAS, S. J. Dynamic performance of biosand filters. Journal - American Water Works Associations. E587-E595, 2013. https://doi.org/10.5942/jawwa.2013.105.0116.

MACIEL, P. M. F. Filtração lenta domiciliar como alternativa de tratamento de água em comunidades isoladas: eficiências com e sem controle de nível da água e aceleração do amadurecimento. Tese apresentada à Universidade de São Paulo, São Carlos, SP, 2018.

MACIEL, P. M. F.; SABOGAL-PAZ, L. P. Household slow sand filters with and without water level control: continuous and intermitente flow efficiencies. Environmental Technology, 1479-487X, 2018. https://doi.org/10.1080/09593330.2018.1515988 
MEDEIROS, R. C.; FAVA, N. de M. N.; FREITAS, B. L. S.; SABOGAL-PAZ, L. P.; HOFFMANN, M. T.; DAVIS, J.; FERNANDEZ-IBAÑEZ, P.; BYRNE, J. A. Drinking water treatment by multistage filtration on a household scale: Efficiency and challenges. Water research. v. 178, 115816, 2020. https://doi.org/10.1016/j.watres.2020.115816

METCALF, L.; EDDY, H. P. Tratamento de efluentes e recuperação de recursos. Tradução de Ivanildo Hespanhol, José Carlos Mierzwa. 5 ed. Porto Alegre: AMGH, 2016.

MURPHY, H. M.; MCBEAN, E. A.; FARAHBAKHSH, K. Nitrification, denitrification and ammonification in point-of-use biosand filters in rural Cambodia. Journal of Water and Health, v. 8, n. 4, p. 803-817, 2010.

MUTSVANGWA, C.; MATOPE E. Use of an external organic carbon source in the removal of nitrates in bio-sand filters (BSFs). Drinking Water Engineerging and Science. v. 10, 119127 p., 2017.

NAIR, A. T.; AHAMMED M, M. Biosand Filtration: A sustainable Option for Household Treatment of Drinking Water. International Symposium on Integrated Water Resources Managemente. At: Kozhikode, Kerala, IndiaAthens, February, 2014.

OLIVEIRA, D. M.; MOREIRA, R. M. Simulação numérica da hidrodinâmica e da qualidade da água aplicada à bacia do rio guapi-macaçu. 2010. VI congresso nacional de engenharia mecânica VI national congress of mechanical engineering, agosto de 2010 Campina Grande - Paraíba - Brasil.

QI, W. K.; GUO, Y. L.; XUE, M.; LI, Y. Y. Hydraulic analysis of an upflow sand filter: Tracer experiments, mathematical model and CFD computation. Chemical Engineering Science. v. 104, 460-472 p., 2013. https://doi.org/10.1016/j.ces.2013.09.035

ROBINSON, R. A.; STOKE, R. H. Electrolyte solutions. Butterworths Publications. Londres, 1965.

SABOGAL-PAZ, L. P.; CAMPOS, L. C.; BOGUSH A.; CANALES, M. Household slow sand filters in intermittent and continuous flows to treat water containing low mineral ion 
concentrations and Bisphenol A. Science of the Total Environment. v. 702, 135078, 2020. https://doi.org/10.1016/j.scitotenv.2020.135078

SÁNCHEZ, F.; REY, H.; VIEDMA, A.; NICOLÁS-PÉREZ, F.; KAISER, A. S.; MARTÍNEZ, M. CFD simulation of fluid dynamic and biokinetic processes within activated sludge reactors under intermittent aeration regime. Water Research. v. 139, 47-57 p., 2018. https://doi.org/10.1016/j.watres.2018.03.067

SANTOS, U. C.; GARCIA, D. B. Modelos de processos difusivos e solução aproximada usando volumes finitos. Ciência e Natura, v. 37, n. 3, Set-Dez., 920-933 p., 2015.

SCHIJVEN, F. J.; BERG, H. H. J. L. V. D.; COLIN, M.; DULLEMONT, Y.; HIJNEN, W. A. M.; MAGIC-KNEZEV, A.; OORTHUIZEN, W. A.; WUBBELS, G. A mathematical model for removal of human pathogenic viruses and bacteria by slow sand filtration under variable operational conditions. Water research. v. 47, 2592-2602 p., 2013.

SISSON, A. J.; WAMPLER, P. J.; REDISKE, R. R.; MOLLA, A. R. An assessment of longterm biosand filter use and sustainability in the Artibonite Valley near Deschapelles, Haiti. Jornal of water sanitation and hygiene for development, v. 3, n. 1, p. 51-60, 2013.

SIVAGURU, K.; BEGUM, K. M. M. S.; ANANTHARAMAN, N. Hydrodynamic studies on three-phase fluidized bed using CFD analysis. Chemical Engineering Journal. v. 155, 207 214 p., 2009.

SOBSEY, M. D.; STAUBER, C.E.; CASANOVA, L. M.; BROWN, J. M. ELLIOT, M. A. Point of Use Household Drinking Water Filtration: A Practical, Effective Solution for Providing Sustained Access to Safe Drinking Water in the Developing World. Environmental Science \& Technology. ,v. 42, n.12, 4261-4267 p., 2008.

STAUBER, C. E.; ELLIOTT M. A.; KOKSAL F.; ORTIZ, G. M.; DIGIANO, F. A.; SOBSEY, M. D. Characterisation of the biosand filter for E. coli reductions from household drinking water under controlled laboratory and field use conditions. Water Science and Technology, v. 54, n. 3, p. 1-7, 2006. 
STROPKY, D.; POUGATCH, K.; NOWAK, P.; SALCUDEAN, M.; PAGORIA, P.; GARTSHORE, I.; YUAN, J. RTD (residence time distribution) predictions in large mechanically aerated lagoons. Water Science \& Technology. v. 55, n. 11, 29-36 p., 2007. https://doi.org/10.2166/wst.2007.346

TALVY, S.; DEBASTE, F.; MARTINELLI, L.; CHAUVEHEID, E.; HAUT, B. Development of a tool, using CFD, for the assessment of the disinfection process by ozonation in industrial scale drinking water treatment plants. Chemical Engineering Science. v. 66, 3185-3194 p., 2011. https://doi.org/10.1016/j.ces.2011.02.039

TCHOBANOGLOUS, G., BURTON, F.L., STENSEL, H.D. Wastewater Engineering: Treatment and Reuse. McGraw-Hill Higher Education, New York. 2003.

TERIN, U. C.; SABOGAL-PAZ, L. P. Microcystis aeruginosa and microcystin-LR removal by household slow sand filters operating in continuous and intermittent flows. Water Research. v. 150, 29-39 p., 2019. https://doi.org/10.1016/j.watres.2018.11.055

UNITED NATIONS ENVIRONMENT PROGRAMME - UNEP. A Snapshot of the World's Water Quality: Towards a global assessment. Unites Nations Environment Programme, Nairóbi, Quénia, 2016.

WORLD HEALTH ORGANIZATION - WHO. Guidelines for Drinking-water Quality. 4 ed. WHO, 2011.

WORLD HEALTH ORGANIZATION - WHO. Results of round 1 of the WHO International Scheme to Evaluate Household Water Treatment Technologies. World Health Organization. Genebra, Suíça, 2016.

WORLD HEALTH ORGANIZATION - WHO. Results of round II of the WHO International Scheme to Evaluate Household Water Treatment Technologies. World Health Organization. Genebra, Suíça, 2019. 
WORLD HEALTH ORGANIZATION - WHO. SLOW SAND FILTRATION. World Health Organization. 122 p. Genebra, Suíça, 1974. Disponível em: <https://apps.who.int/iris/handle/10665/38974>. Acesso em: 06 de jun. 2019.

WORLD HEALTH ORGANIZATION - WHO. Water for Life: Making it Happen, Geneva:WHO and UNICEF, 38 p., 2005. Disponível em: <http://www.who.int/water_sanitation_health/waterforlife.pdf>. Acesso em: 23 jun. 2018.

YANG, Y.; YANG, J.; ZUO, J.; LI, Y., HE, S., YANG, X., ZANG, K. Study on two operating conditions of a full-scale oxidationditch for optimization of energy consumption and effluentquality by using CFD model. Water Research. v. 45, 3439-3452 p., 2011. https://doi.org/10.1016/j.watres.2011.04.007

YOUNG-ROJANSCHI, C.; MADRAMOOTOO, C. Comparing the performance of biosand filters operated with multiday residence periods. Journal of Water Supply: Research and Technology-Aqua. 64, 157. 2014a. https://doi.org/10.2166/aqua.2014.027.

YOUNG-ROJANSCHI, C; MADRAMOOTOO, C. Intermittent Versus Continuous Operation of Biosand Filters. Water Research v. 45. 1-10 p., 2014b.

ZHANG, L.; PAN, Q.; REMPEL, G. L. Residence time distribution in a multistage agitated contactor with Newtonian fluids: CFD prediction and experimental validation. Industrial and Engineering Chemistry Research. $46 \quad$ (11), 3538-3546. 2007. https://doi.org/10.1021/ie060567+. 